\title{
SYNTHESE UND UNTERSUCHUNG
}

\section{VON NUKLEOBASEN-FUNKTIONALISIERTEN PEPTIDEN}

\author{
Dissertation \\ zur Erlangung des Doktorgrades \\ der Mathematisch-Naturwissenschaftlichen Fakultäten \\ der Georg-August-Universität zu Göttingen
}

vorgelegt von

Nadine Jede

aus Neumünster

Göttingen 2006 
D7

Referent:

Prof. Dr. U. Diederichsen

Korreferent:

Prof. Dr. A. de Meijere

Tag der mündlichen Prüfung: $\quad$ 03.05.2006 
Die vorliegende Arbeit wurde in der Zeit von April 2003 bis Februar 2006 am Institut für Organische und Biomolekulare Chemie der Georg-August-Universität zu Göttingen unter Leitung von Prof. Dr. U. Diederichsen angefertigt.

Mein besonderer Dank gilt meinem Doktorvater, Herrn Prof. Dr. U. Diederichsen, für die interessante Themenstellung, die fortlaufende Unterstützung, begleitet von einer stetigen Diskussionsbereitschaft und die gewährte wissenschaftliche Freiheit. 
Ich danke allen Mitarbeitern der Serviceabteilungen, der Massen-Abteilung mit H. Frauendorf und der NMR-Abteilung unter R. Machinek.

Allen Mitarbeitern des Arbeitskreises möchte ich für ihre Kollegialität, Hilfsbereitschaft und Freundlichkeit danken.

Insbesondere danke ich herzlich meinen Laborkollegen Ružica Ranevski und dem „Nichtschwimmer“ Marian Pitulescu für das ausgesprochen angenehme Arbeitsklima - Marian, danke für die zahlreichen Tipps \& Tricks und ansteckende Heiterkeit.

Brigitte Worbs sowie meinen Praktikanten Germund Glatz und Susanne Hesse danke ich für ihre wertvolle Mitarbeit.

Angelina Weiß gilt mein Dank für das Anfertigen der Massenspektren.

Andrea Küsel danke ich für motivierende Gespräche, Zuversicht und Hilfe beim Modelling.

Für etliches Korrekturlesen möchte ich mich bei Nicola Diezemann, Angelina Weiß, Andrea Küsel, Katja Bensmann und Stephan Heermann ganz besonders bedanken.

Danke an Andrea, Angelina, Nicola und Olli für die netten mittäglichen Stunden.

Ganz dickes Dankeschön an Nicola - für Dein unermüdliches Engagement und Hilfe in jeglicher Lebenslage \& für Spaß und Freude in der Zimmermannstrasse \& für Deine Freundschaft.

Ali, Philipp, Hansfrieder und Dirk - Euch danke ich für die schöne und lustige Zeit neben der Chemie.

Vielen lieben Dank an Babse - für die letzten 22 Jahre und Deine Einzigartigkeit.

Für immerwährende, liebevolle Unterstützung bedanke ich mich bei meiner Mutter.

Zu guter Letzt Danke Stephan - für Liebe, Verständnis, Geduld \& den Eifer mich jeden Tag aufs Neue zu motivieren und zu unterstützen...und natürlich dafür, dass es Dich gibt. 
INHALTSVERZEICHNIS

1 EinLeitung Und ZielsetZUng

2 Allgemeiner Teil $\quad 5$

2.1 Peptidnukleinsäuren (PNAS)

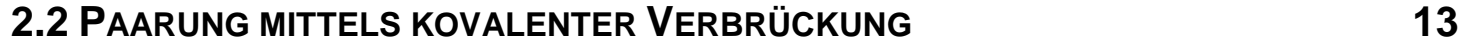

$2.3 \alpha$-PEPTID-HeLICES $\quad 18$

2.3.1 AlLGEMEINES ZU $\alpha$-HELICES 18

2.3.2 HELICAL WHEEL (HELIXRAD) 22

2.3.3 ASSOZIATION DER $\alpha$-HELICES BÜNDEL (COILED COIL-MOTIV) 23

2.3.4 HELIX-VORHERSAGE

2.3.5 LEUCIN-ZIPPER-MOTIV 27

2.3.6 EINBAU VON NUKLEOAMINOSÄUREN IN $\alpha$-HELICES 28

$\begin{array}{ll}\text { 2.4 TRYPSIN-INHIBITOR MCOTI-II } & \mathbf{3 0}\end{array}$

3 Kovalente Verbrückung zWeier Alanyl-PNA Stränge 33

3.1 Synthese der Boc-Alanyl/Homoalanyl NuKLeoaminosÄUREN 41

$\begin{array}{ll}\text { 3.2 DeR STILBEN-LinKeR } & 44\end{array}$

3.3 SYNTHESE VON PNA-DOPPELSTRÄNGEN MIT VERBRÜCKENDEM HEGAS-LINKER $\quad 46$

$\begin{array}{ll}\text { 3.4 SPEKTROSKOPISCHE UNTERSUCHUNGEN } & 49\end{array}$

4 Helikale $\alpha$-Peptide mit Nukleobasen als Erkennungs- einheit in DeR SEITENKETTE

4.1 Synthese $\alpha$-helikaler Peptide nach Boc-Festphasen-Strategie 56

4.2 Synthese $\boldsymbol{\alpha}$-helikaler Peptide nach Fmoc-Festphasen-Strategie $\mathbf{5 8}$ 4.2.1 SYNTHESE DER FMOC-HOMOALANYL-NUKLEOAMINOSÄUREN 59

4.3 Synthese $\alpha$-Helikaler Peptide mittels Boc-Thioester Ligation 61

4.4 ERGEBNISSE DER SPEKTROSKOPISCHEN UNTERSUCHUNGEN 64

5 INKORPORATION VON NUKLEOAMINOSÄUREN IN DAS LINEARE MIKROPEPTID-GERÜST MCOTI-29

5.1 SYNTHESE DER FMOC-ALANYL-NUKLEOAMINOSÄUREN UND DEREN EINBAU IN $\begin{array}{ll}\text { DAS LINEARE MIKROPEPTID } & \mathbf{7 0}\end{array}$

5.2 ERgebNISSE UND DISKUSSION DER BIOLOGISCHEN AKTIVITÄT 71 
6 Zusammenfassung Und Ausblick $\quad 73$

$\begin{array}{lll}7 & \text { SUMMARY AND OUTLOOK } & 77\end{array}$

8 EXPERIMENTELLER TEIL $\quad 80$

$\begin{array}{lr}\text { 8.1 Allgemeine ArbeitsteChNIKeN } & 80\end{array}$

8.2 Allgemeine Arbeitsvorschriften (AAV) 84

$\begin{array}{ll}\text { 8.3 SYNTHETISIERTE VERBINDUNGEN } & 89\end{array}$

8.4 SYNTHESE DER NUKLEOAMINOSÄUREN 93

8.5 SYNTHESE DES STILBEN-LINKERS 113

8.6 Synthese der Gemischten PePtidnUKLEINSÄURen 118

8.7 SyntheSe deR Gemischten PEPTIDNUKLEINSÄUREN MIT LiNKER 127

9 ANHANG 130

10 AbkÜRZUngsverZEICHNIS 132

11 LITERATURVERZEICHNIS 136 


\section{$1 \quad$ Einleitung und Zielsetzung}

Die molekulare Struktur der DNA erkannte 1920 zunächst P. A. Levene, der die grundlegende Zusammensetzung aus heterozyklischen Nukleobasen, Zucker und Phosphorsäure nachwies. ${ }^{[1,2]} \mathrm{J}$. Watson und F. Crick entschlüsselten 1953 die räumliche Struktur der DNA und erhielten 1962 dafür den Nobelpreis. ${ }^{[3,4]}$

Die Konformation der DNA, die Doppelhelix, wird ausgebildet, indem Wasserstoffbrückenbindungen zwischen den Nukleobasen zweier, antiparallel angeordneter Stränge gebildet werden. ${ }^{[5]} \mathrm{Da}$ die Speicherung und Weitergabe genetischer Information im Allgemeinen von der sequenziellen Abfolge der Nukleobasen gesteuert wird, ist es wesentlich, deren Erkennung untereinander zu untersuchen. ${ }^{[6]}$ Aufgrund der Wasserstoff-Donor- und Akzeptorfolge sowie der Größe und Orientierung der Basenpaare können in der B-DNA nur die Nukleobasen Adenin und Thymin sowie Guanin und Cytosin miteinander paaren (Abb. 1.1). ${ }^{[7]}$ Bereits kleinste Modifikationen können die Eigenschaften der B-DNA stark beeinflussen. ${ }^{[6,8,9]}$

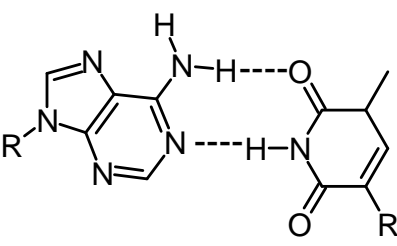

Adenin
Thymin

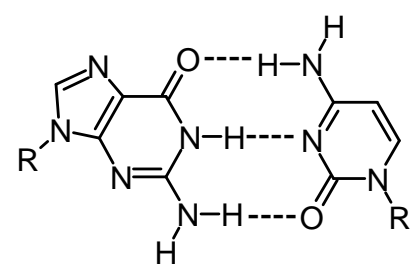

Guanin

Cytosin

Abb. 1.1: Wechselseitige Erkennung der kanonischen Nukleobasen durch Wasserstoffbrücken in der DNA; R = Desoxyribose

Neben der Nukleobasenpaarung ist es ebenso wichtig, Untersuchungen der Rückgratkonstitution und der gesamten Sekundärstruktur der DNA durchzuführen. Das modifizierte Design der DNA ist für das Verständnis und für die Aufklärung biochemischer Wechselwirkungen sowie für die Diagnostik und Pharmakologie von entscheidender Bedeutung und somit eine große Herausforderung. ${ }^{[10,11]}$ Daher ist es notwendig, Modellsysteme zu entwerfen, an denen die Grundprinzipien der Prozesse untersucht werden können.

Als DNA-Mimetikum wurden Peptidnukleinsäuren (PNAs), wie die Alanyl-PNA, entworfen. ${ }^{[12]}$ Sie besteht aus alternierend konfigurierten Alanyl-NukleoaminosäureMonomerbausteinen. Die Nukleobasen sind dabei kovalent über die $\beta$-Position mit 
der Aminosäure Alanin verknüpft (Abb. 1.2).$^{[12]}$ Die Alanyl-PNA unterliegt im Unterschied zur DNA keinen topologischen Zwängen durch die Helikalisierung, da sie in einer linearen $\beta$-Faltblattstruktur mit einem Basenabstand von 3.6 $\AA$ in der Lage ist, Doppelstränge auszubilden.

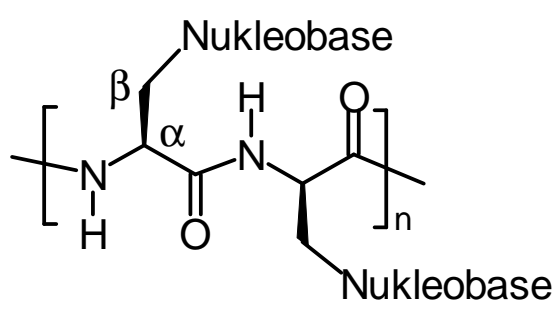

Abb. 1.2: Alanyl-PNA, die statt des Zucker-Phosphat-Rückgrates der DNA ein Peptidrückgrat aufweist, das an den Seitenketten mit Nukleobasen substituiert ist. Nukleobase = Adenin, Cytosin, Guanin, Thymin

Vorteilhaft an dem Modellsystem der Alanyl-PNA ist, dass die einzelnen stabilisierenden Effekte, wie van-der-Waals und hydrophobe Wechselwirkungen bzw. Wasserstoffbrückenbindungen wegen der vorliegenden linearen DoppelstrangStruktur getrennt voneinander betrachtet werden können, was in natürlichen Systemen nahezu unmöglich ist. ${ }^{[13,14,15]}$ Ausgehend von Alanyl-PNAs können auch seitenkettenhomologe PNAs untersucht werden. Alanyl-PNAs mit zusätzlicher Methyleneinheit in der Seitenkette werden als Homoalanyl-PNAs ${ }^{[16,17]}$ bezeichnet, mit zwei zusätzlichen Methlyeneinheiten als Norvalyl-PNAs. ${ }^{[14 a, 18]}$

$\alpha$-Helikale Peptide werden in vielen natürlichen Proteinen in der Strukturform des coiled coil gefunden (Abb. 1.3). Das coiled coil-Motiv ist eine der häufigsten und wichtigsten Protein-Interaktionsdomänen und wird hinsichtlich des Verständnisses der Sequenz/Struktur-Beziehung in Proteinen untersucht. ${ }^{[19,20]}$ Wesentlich hierbei sind Wechselwirkungen zwischen den Seitenketten der Aminosäuren und die des $\alpha$ helikalen Peptidgerüstes. ${ }^{[21]}$ Insbesondere sind eingebaute Erkennungseinheiten essentiell für diverse chemische und biologische Prozesse in lebenden Systemen. Natürliche Proteine verwenden für die komplementäre Erkennung Wasserstoffbrückenbindungen, hydrophobe sowie elektrostatische Wechselwirkungen. ${ }^{[22]}$ 


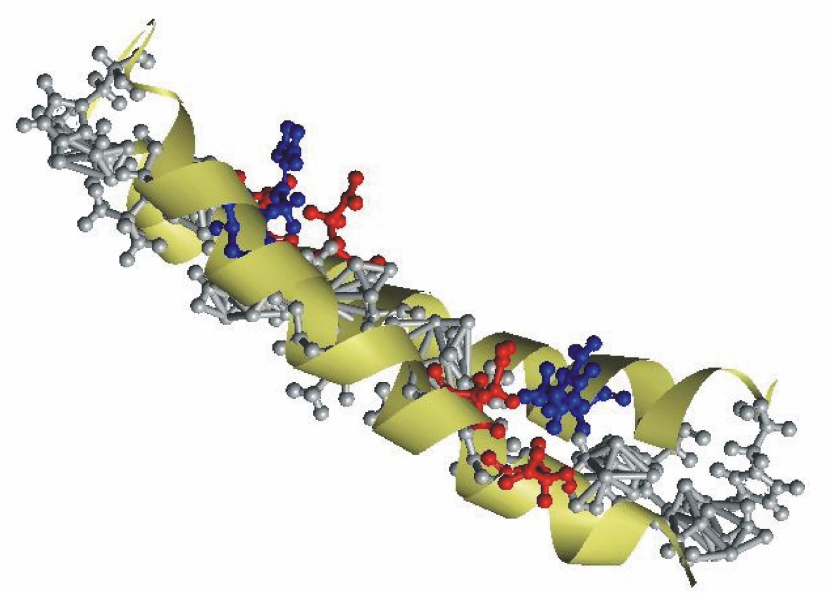

Abb. 1.3: NMR-Struktur des antiparallelen coiled coils aus dem Protein ProP (Osmosensor aus E. coli); die antiparallele Struktur wird stabilisiert durch die Wechselwirkungen der Aminosäure (blau) des einen Stranges mit den Aminosäuren (rot) des anderen; grau = hydrophobe Reste ${ }^{[23,24]}$

Zwei grundlegenden Zielen sollen in dieser Arbeit nachgegangen werden: zum einen der intramolekularen Paarung zweier Alanyl PNA-Stränge und zum anderen der Entwicklung von Methoden zur Inkorporation von Nukleoaminosäuren in bestimmte peptidische Strukturen. Es sollen Alanyl- und Homoalanyl-Nukleoaminosäuren jeweils Fmoc- und Boc-geschützt synthetisiert und in drei Bereichen eingesetzt werden.

Der erste Bereich befasst sich mit Synthesen von alternierend aufgebauten Peptidnukleinsäuren, die kovalent über einen Linker verbunden werden. Diese kovalente Verbrückung imitiert die Watson-Crick Basenpaarung und kann zusätzlich das planare rigide Doppelstrang-Gerüst der PNA stabilisieren. Für das Ziel, eine rein kovalente Verknüpfung aufzubauen, wird als Linker ein Ethylenglycol-Derivat verwendet. Des Weiteren soll als rigide Einheit ein Stilben-Linker synthetisiert werden. Untersuchungen der Doppelstrangstabilität erfolgen mittels temperaturabhängiger UVSpektroskopie.

Im zweiten Teil dieser Arbeit sollen Homoalanyl-Nukleoaminosäure-Monomere in ein $\alpha$-helikales Peptid mit proteinogenen Aminosäuren eingebaut und die Wechselwirkungen hinsichtlich der Nukleobasenpaarung untersucht werden. Zwei der mit Nukleobasen inkorporierten $\alpha$-Peptide werden über die Basenpaarung der Homoalanyl-Nukleoaminosäuren verknüpft. Um die Selbstpaarung der $\alpha$-Helices zu gewährleisten, sollen die Homoalanyl-Bausteine über heptade repeats ${ }^{[25,26]}$ so 
eingebaut werden, dass die Nukleoaminosäuren im hydrophoben Kern lokalisiert sind und Wasserstoffbrückenbindungen ausbilden. Um Stabilisierung aufgrund anderer Aminosäuren zu verhindern, werden in dieser Arbeit lediglich die natürlichen Aminosäuren Alanin und Lysin verwendet. Eine Glutaminsäure soll als helixbildende Komponente eingebaut werden, die eine Stabilisierung über eine Salzbrücke mit Lysin hervorbringt. Die Peptidsynthese erfolgt nach Boc- sowie nach Fmoc-Strategie. Da für eine Ausbildung stabiler Helices eine Mindestlänge von 15-20 Aminosäuren notwendig ist, sollen 15 und 21 mere hergestellt werden. ${ }^{[27]}$ Die Paarungseigenschaften werden UV-spektroskopisch mit Testpeptiden verglichen, die ausschließlich natürliche Aminosäuren enthalten.

Der dritte Teil dieser Arbeit soll sich mit dem Einbau der synthetisierten Fmocgeschützten Alanyl-Nukleoaminosäure als Arginin-Mimetikum in das lineare Mikropeptid MCoTI-29 beschäftigen, um Veränderungen biologischer Aktivitäten zu zeigen. 


\section{$2 \quad$ Allgemeiner Teil}

\subsection{Peptidnukleinsäuren (PNAs)}

Peptidnukleinsäuren (peptide nucleic acids) sind DNA-Analoga, die 1991 erstmals von P. E. Nielsen beschrieben wurden. ${ }^{[28,29]}$ Das Rückgrat einer PNA besteht im Gegensatz zum Desoxyribose-Phosphodiester-Rückgrat der DNA aus einer Aminoethylglycin-Polyamidstruktur (Abb. 2.1).<smiles>[B]C1CC(OP(=O)(O)OC2CC(C)CC2C)C(CC)O1</smiles>

DNA<smiles>[B]CC(=O)N(CC(=O)O)CC(C)(C)CN</smiles>

Aminoethylglycin-PNA<smiles>[B]CC(NC(=O)C1CCCC1C)C(=O)NC1C[B]CC1</smiles>

Alanyl-PNA

Abb. 2.1: Schematische Darstellung von DNA, Aminoethylglycin- und Alanyl-PNA, $B=$ Nukleobase

Das tertiäre Amid ist über einen Essigsäure-Linker mit den kanonischen Nukleobasen Adenin, Cytosin, Guanin und Thymin verknüpft (Abb. 2.2). Eine weitere PNA, die Alanyl-PNA, wird erhalten, wenn das Rückgrat der Aminoethylglycin-Einheit verkürzt wird. Alanyl-PNA-Oligomere bestehen aus einem regulären Peptidstrang, dessen Seitenketten an den $\beta$-Positionen mit Nukleobasen substituiert sind (Abb. 2.1, rechts)..$^{[13,14,15,30]}$
A (Adenin)
C (Cytosin)
G (Guanin)
T (Thymin)<smiles>Nc1ncnc2[nH]cnc12</smiles><smiles>Nc1cc[nH]c(=O)n1</smiles><smiles>Nc1nc2[nH]cnc2c(=O)[nH]1</smiles><smiles>Cc1c[nH]c(=O)[nH]c1=O</smiles>

Abb. 2.2: Kanonische Nukleobasen der DNA

Die Ausbildung eines linearen Alanyl-PNA-Doppelstranges wird durch Dipol-DipolWechselwirkungen, Solvenseffekte, Wasserstoffbrückenbindungen und Stapelungswechselwirkungen der Nukleobasen stabilisiert. ${ }^{[11]}$ 
Wesentliche Unterschiede zwischen DNA- und PNA-Molekülen sind zum einen die starke Enzymstabilität der PNA, so dass ein Abbau durch Nukleasen sowie Proteasen kaum erfolgt, was die Anwendung in der Analytik ermöglicht. ${ }^{[32]}$ Zum anderen weist PNA ein flexibles, ungeladenes Peptid-Rückgrat auf, welches die Aminoethylglycin-PNA befähigt, nahezu unabhängig von der Salzkonzentration, an eine komplementäre Sequenz der DNA-Doppelhelix unter Verdrängung eines DNAStranges zu hybridisieren. Diese PNA/DNA-Komplexe weisen eine wesentlich höhere Stabilität als die DNA/DNA-Komplexe auf. Die Alanyl-PNA bindet dagegen nicht an DNA oder RNA. Mögliche Gründe hierfür sind, dass am $\mathrm{C}_{\alpha}$-Atom der Nukleoaminosäuren ein Chiralitätszentren vorliegt und die konformationelle Flexibilität durch die zwei Amidbindungen pro Repetitionseinheit gehindert ist.

Konfiguartion der Alanyl-PNA:

Im linearen Alanyl-PNA-Strang weisen die Nukleobasen entweder in die gleiche oder in die entgegengesetzte Richtung, je nachdem in welcher Konfiguration die PNA vorliegt. Bei alternierender Konfiguration der Nukleoaminosäure-Einheiten in linearer $\beta$ Faltblatt Konformation zeigen alle Basen in die gleiche Richtung (Abb. 2.3). ${ }^{[13,14,15,30,33]}$
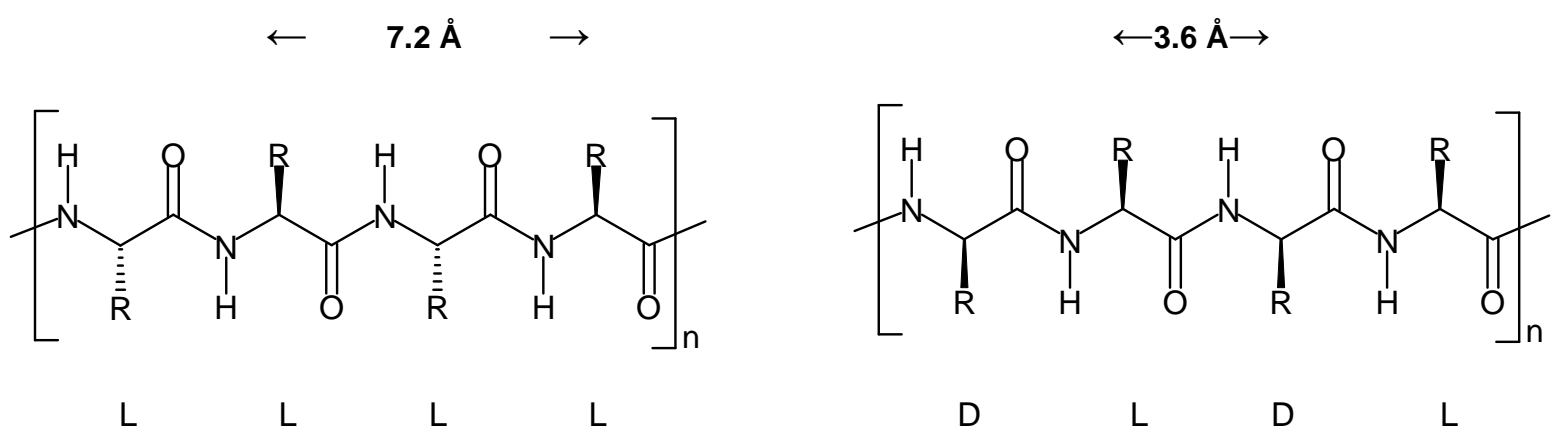

Abb. 2.3: Gleiche (L,L,L,L) und alternierende Konfiguration (D,L,D,L) des Alanyl-Peptidstranges, $\mathrm{R}=\mathrm{CH}_{2}$-Nukleobase

Bei gleicher Konfiguration zeigen benachbarte Nukleobasen eines PNA-Stranges in die entgegengesetzte Richtung. ${ }^{[13 a]}$ Der Abstand benachbarter Basen beträgt hier $7.2 \AA$, wohingegen der Basenabstand bei alternierender Konfiguration bei $3.6 \AA$ liegt, was in etwa dem Abstand der Nukleobasen in der B-DNA mit $3.4 \AA$ entspricht (Abb. 2.3). ${ }^{[2]}$ 
Abb. 2.4 zeigt ein PNA-Alanyl-Doppelstrang Modell mit Guanin-Cytosin paarenden Hexameren.

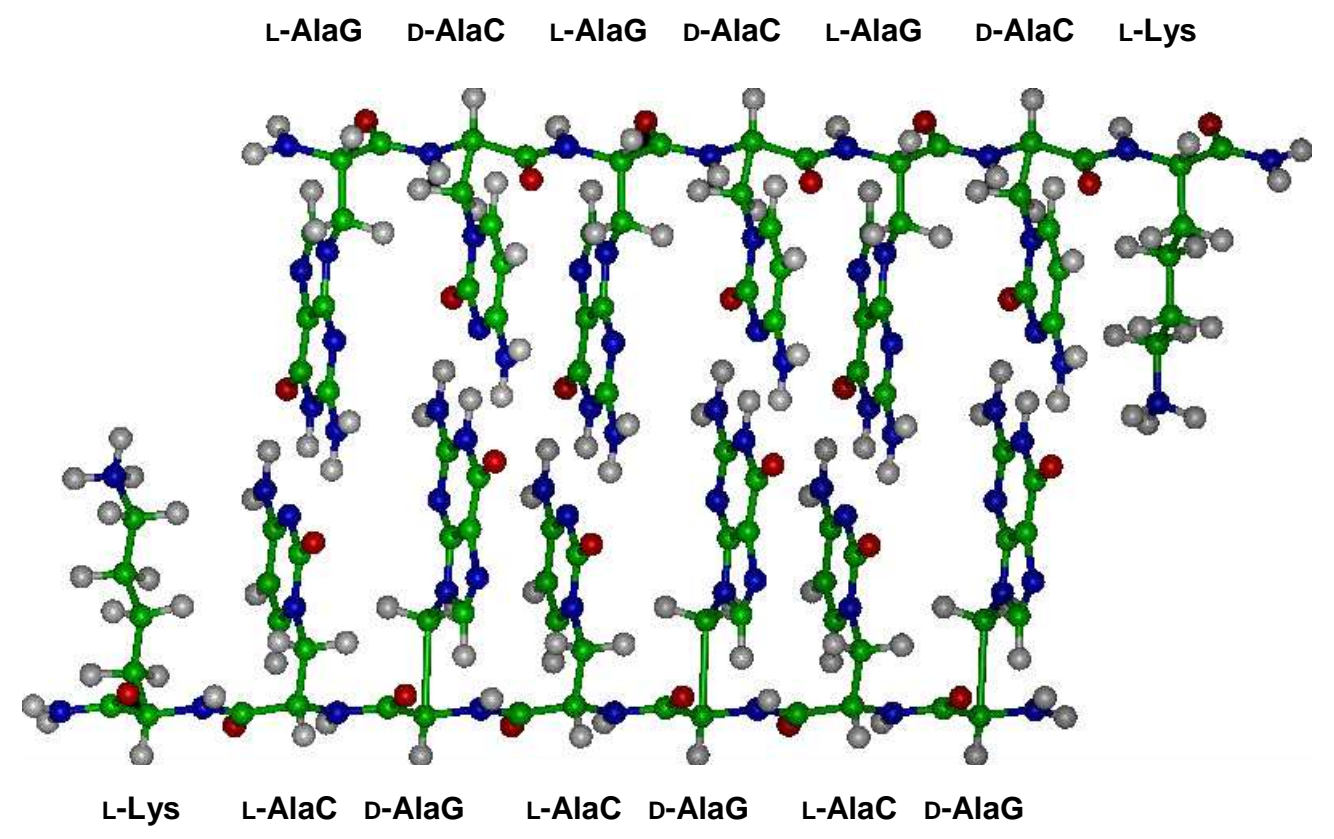

Abb. 2.4: Modell eines linearen, alternierend konfigurierten Alanyl-PNA-Doppelstranges mit paarenden G-C Hexameren; AlaG $=\beta-(9-G u a n i n y l) a l a n i n ; A l a C=\beta-(1-C y t o s i n y l) a l a n i n$

Konformation der Alanyl-PNA:

Bei der Ausbildung von PNA-Doppelsträngen steht die Basenpaar-Ebene idealisiert betrachtet orthogonal auf dem Peptidrückgrat. In Abb. 2.5 ist die Vorzugskonformation der Alanyl-Nukleoaminosäure in der Newman-Projektion dargestellt. Die antiperiplanare Konformation ist hier bezüglich des $\mathrm{H}_{\alpha}$-Atoms energetisch am günstigsten. Die gauche Konformation ist aufgrund sterischer Wechselwirkungen weniger begünstigt, da das Puringerüst so ausgerichtet ist, dass es zur 1,5-Repulsion zwischen der Nukleobase und der Methyleneinheit kommt. Wenn das H-8 Atom des PurinRinges allerdings in die Richtung des Rückgrates orientiert ist, kommt es zu keiner Spannung durch 1,5-Repulsion. Analoges gilt für die Ausrichtung des H-6 Atoms der Pyrimidinbasen zum Rückgrat. ${ }^{[14 a, 34]}$ 


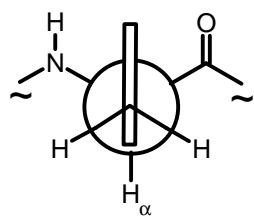

antiperiplanar

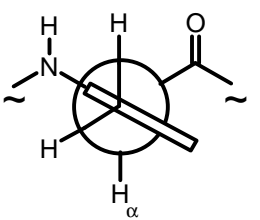

gauche

Vorzugskonformation

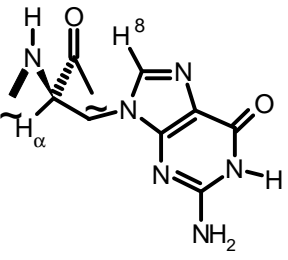

keine 1,5-Repulsion

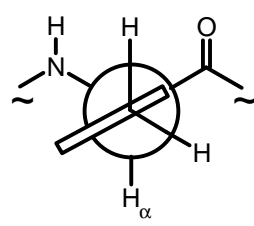

gauche

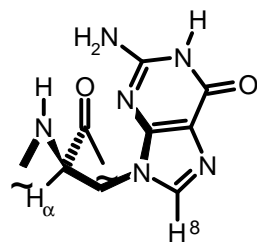

1,5-Repulsion

Abb. 2.5: Antiperiplanare und gauche Konformationen der Alanyl-Nukleoaminosäureeinheit,

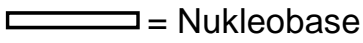

Homologe der Alanyl-PNA:

Homoalanyl-Peptidnukleinsäuren (Homoalanyl-PNAs) werden durch Einbau einer Methyleneinheit in die Seitenkette der Alanyl-PNA erhalten. ${ }^{[16,17]}$ Verlängerung um zwei Methyleneinheiten ergibt die seitenkettenhomologe Norvalyl-Peptidnukleinsäure (Norvalyl-PNA). ${ }^{[18]}$ Untersuchungen der Paarungseigenschaften von Alanyl-PNA und seinen Homologen können grundlegende Kenntnisse über Paarungsaffinitäten der Nukleobasen und deren Stapelungseigenschaften in Abhängigkeit der Orientierung der Nachbarbase geben (Abb. 2.6). ${ }^{[16,17,18]}$<smiles>[B]C[C@H](NC(=O)[C@H](C[B])NC(C)C)C(N)=O</smiles>

Alanyl-PNA<smiles>[B]CC[C@H](NC(=O)[C@H](CC[B])NC(C)C)C(N)=O</smiles>

Homoalanyl-PNA<smiles>[B]CCC[C@H](NC(=O)[C@H](CCC[B])NC(C)C)C(N)=O</smiles>

Norvalyl-PNA

Abb. 2.6: Seitenkettenhomologe der Alanyl-PNA; B = Nukleobase

Paarungsmodi:

Die helikale Rückgrattopologie der DNA ermöglicht ausschließlich eine Paarung im Watson-Crick Modus. ${ }^{[16,17]}$ Lineare Alanyl-PNAs können dagegen auch andere 
Paarungsmodi verwirklichen, so dass die Basenpaarkomplementarität nicht eindeutig ist. Somit können neben Purin-Pyrimidin Basenpaarungen auch Purin-Purin wie Pyrimidin-Pyrimidin Basenpaarungen ausgebildet werden. Pyrimidin-Pyrimidin Paarungen werden allerdings kaum beobachtet, da die Stapelungswechselwirkungen sehr viel weniger ausgeprägt sind als bei den Purin-Purin Paarungen. ${ }^{[16,17]}$

Es sind bis zu vier Paarungsmodi möglich: der Watson-Crick und der Hoogsten Paarungsmodus sowie die durch Spiegelung erhaltenen reverse Watson-Crick und reverse Hoogsteen Paarungsmodi. Ein Wechsel vom Watson-Crick bzw. reverse Watson-Crick Paarungsmodus in den Hoogsteen bzw. reverse Hoogsteen Paarungsmodus erfolgt durch Verschiebung einer Nukleobase in der Basenpaarebene (Abb. 2.7). ${ }^{[35]}$ Dabei kommt es zur Änderung der Lage des Rückgrates und der Ausrichtung der Nukleobasen. Die Paarungsselektivität ist somit abhängig von der Rückgrattopologie und den Donor-Akzeptor-Funktionalitäten der Basen. Die in Abb. 2.7 gezeigte Hoogsteen und reverse Hoogsteen Paarung von Guanin und Cytosin ist nur im sauren protonierten Zustand möglich. Ferner ist zu erkennen, dass die Watson-Crick Paarung als einzige zu drei Wasserstoffbrückenbindungen führt. In anderen Paarungsmodi werden lediglich zwei Wasserstoffbrückenbindungen ausgebildet.

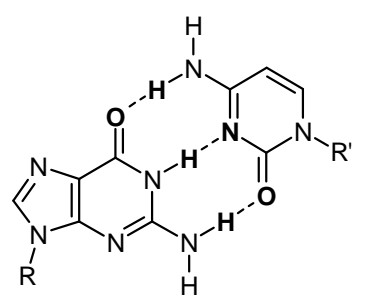

Watson-Crick

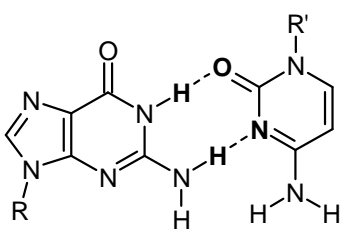

reverse Watson-Crick

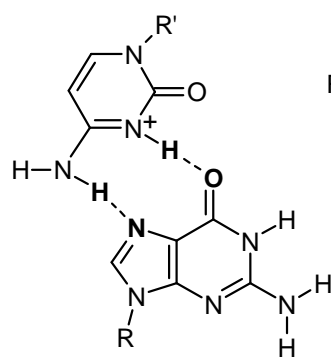

Hoogsteen

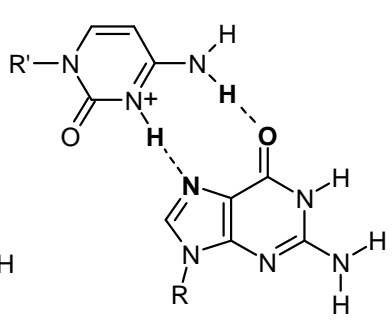

reverse Hoogsteen

Abb. 2.7: Mögliche Paarungsmodi der Guanin-Cytosin-Paarung, $R, R^{\prime}=\mathrm{CH}_{2}$-Peptidstrang

Strangorientierung:

Peptide sowie PNAs werden vom N- zum C-Terminus angegeben, so dass innen eine Strangrichtung zugeschrieben werden kann. Doppelstränge können entweder parallel oder antiparallel orientiert sein. Um parallele Strangorientierung handelt es sich, wenn der N- bzw. der C-Terminus der Stränge in die gleiche Richtung zeigt. Weisen die Termini der Stränge im Paarungskomplex hingegen in entgegensetzte Richtung, spricht man von antiparalleler Strangorientierung (Abb. 2.8). Der Einbau 
von Lysinamid am C-Terminus führt möglicherweise zu einer Begünstigung der antiparallelen Strangorientierung aufgrund der Repulsion positiver Ladungen. ${ }^{[16,17]}$

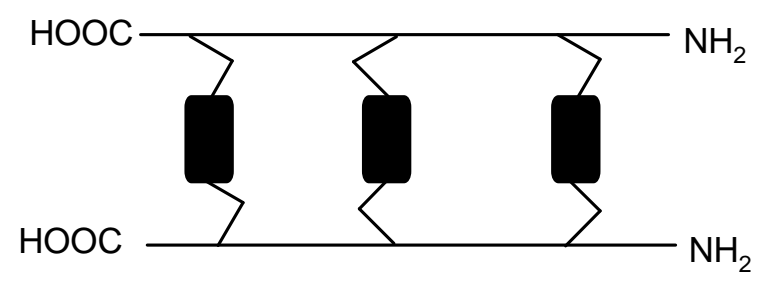

parallel

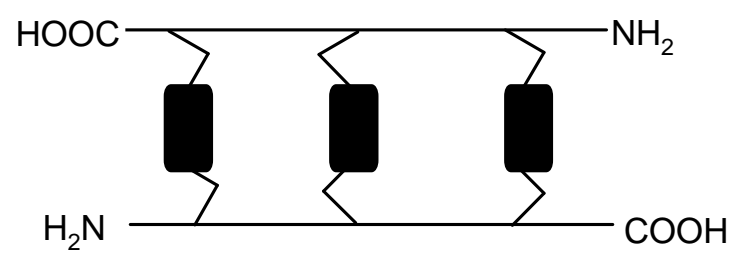

antiparallel

Abb. 2.8: Schematische Darstellung von parallel und antiparallel orientierten Doppelsträngen

Konfiguration:

Ein weiterer Parameter ist die Konfiguration der Peptidnukleinsäuren. Die AlanylPNA-Stränge weisen eine alternierende Konfiguration auf. Die Paarung der Basen erfolgt, indem sich entgegengesetzte oder gleich konfigurierte Nukleoaminosäuren paaren (hetero- bzw. homochirale Paarung) (Abb. 2.9). ${ }^{[16,17]}$

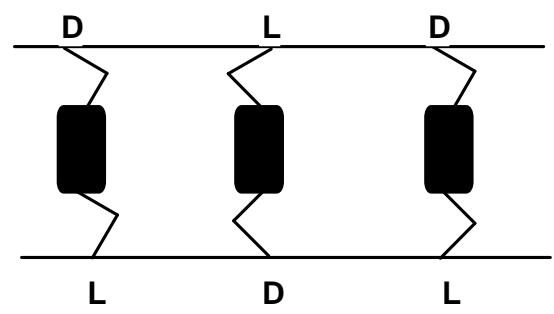

heterochiral

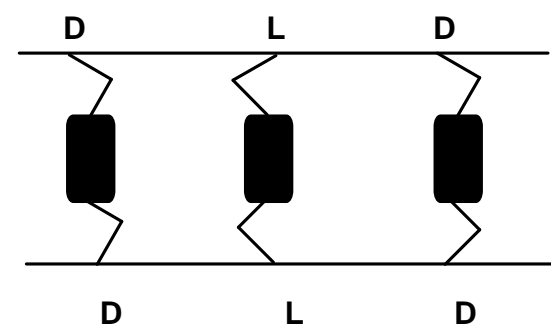

homochiral

Abb. 2.9: Schematische Darstellung von homochiralen und heterochiralen Paarungskomplexen

Das Retro-Inverso-Prinzip ${ }^{[36]}$ beschreibt, dass es bei gleichzeitiger Umkehr von Strangorientierung (parallel $\mathrm{zu}$ antiparallel) und Konfiguration (homo- zu heterochiraler Paarung) zu keiner Änderung der Seitenketten-Topologie im Doppelstrang kommt. Tab. 2.1 zeigt einen Überblick über mögliche Paarungsmodi bei strukturellen Veränderungen. Es erfolgt eine Änderung des Paarungsmodus, wenn ein Gemisch aus alternierender Homoalanyl- und Alanyl-PNA vorliegt. Bei Betrachtung von reiner Alanyl- bzw. reiner Homoalanyl-PNA sind vier Kombinationen möglich (antiparallel/homochiral, antiparallel/heterochiral, parallel/homochiral und parallel/heterochiral), aber nach dem Retro-Inverso-Prinzip paaren jeweils zwei Paarungskomplexe im sel- 
ben Paarungsmodus. Das gleiche gilt bei einem Gemisch von Alanyl- und Homoalanyl-Peptidnukleinosäuren. ${ }^{[16,17]}$

\begin{tabular}{|l|c|c|}
\hline \multicolumn{1}{|c|}{ PNA } & antiparallel & parallel \\
\hline $\begin{array}{l}\text { (AlaB })_{n} \quad \text { bzw. } \\
(\mathrm{HalB})_{n}\end{array}$ & $\begin{array}{c}\text { homochiral: Watson-Crick } \\
\text { Hoogsteen }\end{array}$ & $\begin{array}{c}\text { heterochiral: Watson-Crick } \\
\text { Hoogsteen }\end{array}$ \\
\hline$(\text { AlaB-HalB })_{n}$ & $\begin{array}{c}\text { heterochiral: Watson-Crick } \\
\text { Hoogsteen }\end{array}$ & $\begin{array}{c}\text { homochiral: Watson-Crick } \\
\text { Hoogsteen }\end{array}$ \\
\hline
\end{tabular}

Tab. 2.1: Strukturelle Merkmale für die Paarung der Alanyl(Ala)/Homoalanyl(Hal)-, Alanyl- und Homoalanyl-PNA im Watson-Crick- bzw. Hoogsteen-Modus; B = Nukleobase

\section{Mögliche Paarungskomplexe:}

Als Maß für die Stabilität des gesamten Paarungskomplexes wird die UV-Schmelztemperatur $T_{m}$ angegeben. Es können Selbstpaarungen und Enantiomerenpaarungen erfolgen. Um die Löslichkeit der PNA, die mit zunehmender Länge abnimmt, zu verbessern wird sie z.B. mit Lysin, modifiziert.

\begin{tabular}{|c|c|}
\hline Selbstpaarung & antiparallel \\
\hline heterochiral & 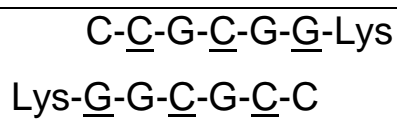 \\
\hline homochiral & 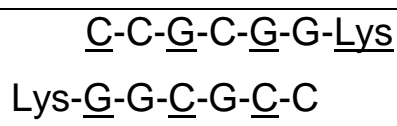 \\
\hline
\end{tabular}

\begin{tabular}{|c|c|}
\hline Enantiomerenpaarung & antiparallel \\
\hline heterochiral & 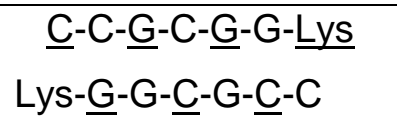 \\
\hline homochiral & $\begin{array}{c}\underline{\mathrm{C}}-\mathrm{C}-\underline{\mathrm{G}}-\mathrm{C}-\underline{\mathrm{G}}-\mathrm{G}-\underline{\mathrm{L} y \mathrm{~S}} \\
\text { Lys-} \underline{\mathrm{G}}-\mathrm{G}-\underline{\mathrm{C}}-\mathrm{G}-\underline{\mathrm{C}}-\mathrm{C}\end{array}$ \\
\hline
\end{tabular}

Tab. 2.2: Möglichkeiten der Selbstpaarung (oben) und der Enantiomerenpaarung (unten) des Oligomers $\mathrm{H}$-(AlaC-AlaC-AlaG-AlaC-AlaG-AlaG)-Lys- $\mathrm{NH}_{2}$ bzw. H-(HalC- $\left.\underline{\mathrm{HalC}}-\mathrm{HalG}-\underline{\mathrm{HalC}}-\mathrm{HalG}-\underline{\mathrm{HalG}}\right)$-Lys$\mathrm{NH}_{2} ; \mathrm{C}=\beta$-(1-Cytosinyl)-alanin (AlaC) bzw. $\beta$-(1-Cytosinyl)-homoalanin (HalC); $\mathrm{G}=\beta$-(9-Guaninyl)alanin (AlaG) bzw. $\beta$-(9-Guaninyl)-homoalanin (HalG); D-konfigurierte Nukleoaminosäuren sind unterstrichen. 
Hexamere besitzen ausreichend viele Nukleobasen zur Ausbildung stabiler Komplexe mit $T_{m}=21-58{ }^{\circ}{ }^{[16]}$ In Tab. 2.2 sind Oligomere zusammengefasst, die aus drei $\beta$-(9-Guaninyl)-alanin (AlaG) und drei komplementären $\beta$-(1-Cytosinyl)-alanin (AlaC) Nukleoaminosäuren mit alternierender Konfiguration bestehen. Neben der Guanin-Cytosin Paarung kann auch eine Guanin-Guanin Paarung zur Stabilisierung verwirklicht werden. Cytosin-Cytosin Paarung hat keinen positiven Effekt auf die Stabilität. 


\subsection{Paarung mittels kovalenter Verbrückung}

Das klassische Watson-Crick Modell der DNA zeigt den komplementären Zusammenhalt der Doppelstränge über eindeutig definierte Wasserstoffbrückenbindungen (Abb. 2.10). ${ }^{[2]}$ Eine kovalente Verknüpfung über ein molekulares Gerüst, das dem

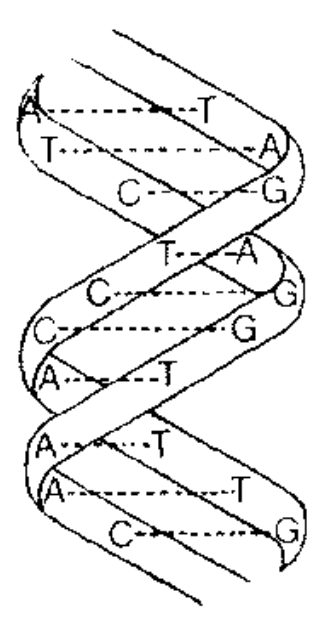
wasserstoffbindenden Basenpaar ähnelt, stellt eine gute Nachahmung der Watson-Crick Basenpaarung dar, die in diverse biologische Systeme inkorporiert werden kann. Unterschiedliche Möglichkeiten der kovalent verknüpften Verbrückung wurden entwickelt, wobei es sich entweder um nukleotide oder um nicht-nukleotide Verknüpfungen handelt.

Abb. 2.10: Doppelstrang-Helix aus komplementären Guanin-Cytosin $(C, G)$ und Adenin-Thymin $(A, T)$ Paarungen über Wasserstoffbrückenbindungen

Mitte der achtziger Jahre stellte N. Leonard das Prinzip der nukleotiden Verbrückung, die die Wasserstoffbrückenbindung der Watson-Crick-Basenpaare kovalent imitieren soll, vor. ${ }^{[37]}$ Das erste aufgestellte Modell ist in Abb. 2.11 (rechts) gezeigt.

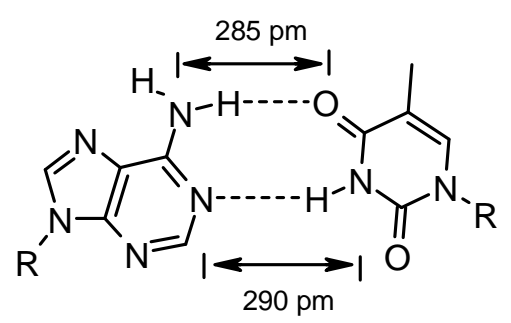

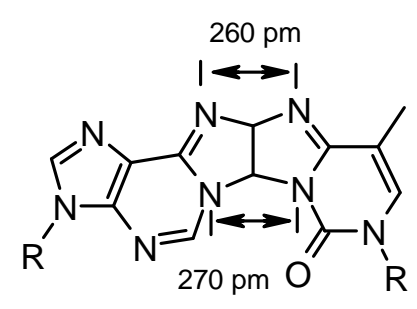

Abb. 2.11: Adenin-Thymin Basenpaarung (links); im Vergleich dazu die Imitation der Wasserstoffbrückenbindung (rechts); R = 2'-Desoxyribose 
In den darauf folgenden Jahren entwickelten zahlreiche Gruppen nicht-nukleotide Brücken, die auf Oligo(ethylenglycol)- ${ }^{[38]}$, Terephtalamid- ${ }^{[39]}$ und Disulfid-Verbindungen ${ }^{[40]}$ beruhen. Diese Brücken fungieren anstelle eines Oligonukleotid-Segmentes als sogenannte „Kappe“. Kurze helikale Konformationen von Doppel- sowie Triplestrang-Oligonukleotiden können so stabilisiert werden (Abb. 2.12).

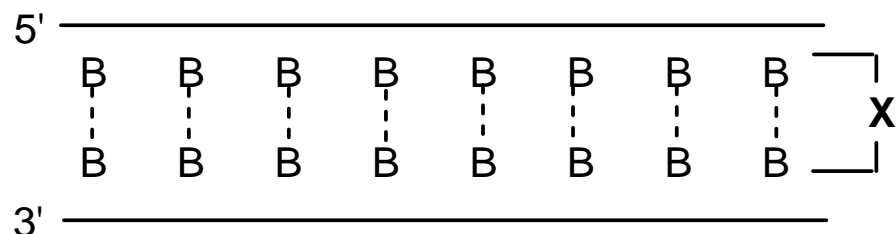

Abb. 2.12: Schema eines Oligonukleotid-Doppelstranges mit überbrücktem Linker (X);

B---B = komplementäres Basenpaar

Oligonukleotide, die auf diese Weise verbrückt sind, können als Ersatz für Polyoligonukleotide in DNA- und RNA-gebundenen Proteinen, in oligonukleotidbasierten Katalysen und in selbstorganisierten Systemen eingesetzt werden. ${ }^{[38,39,40]}$

Ein anderes Modell stellt die Verknüpfung komplementärer Nukleobasen, wie z.B. über eine Methylenbrücke dar (Modell in Abb. 2.13 von Y. Kishi). ${ }^{[41,42]}$ Die so verknüpften Doppelstränge weisen neue chemische Eigenschaften auf.
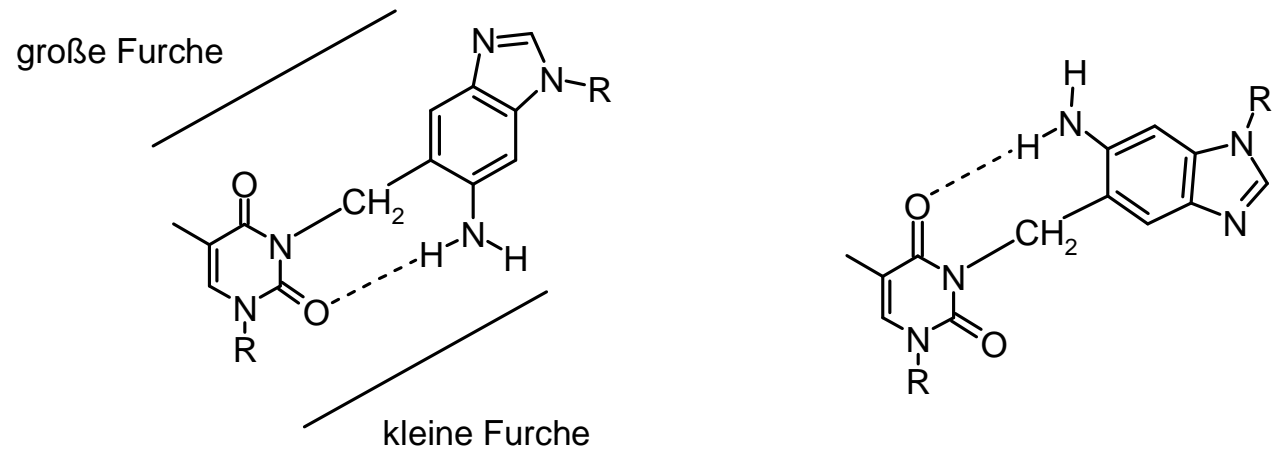

Abb. 2.13: Modell für kovalent-verknüpfte Watson-Crick (links) und reverse Watson-Crick Basenpaarung (rechts), $R=2$ '-Desoxyribose

G. Verdine und A. Ferentz beschäftigten sich mit Disulfidbrücken, wie die in Abb. 2.14 gezeigten Dithiobisethan- und Dithiobispropan-Linker. ${ }^{[0]}$ 

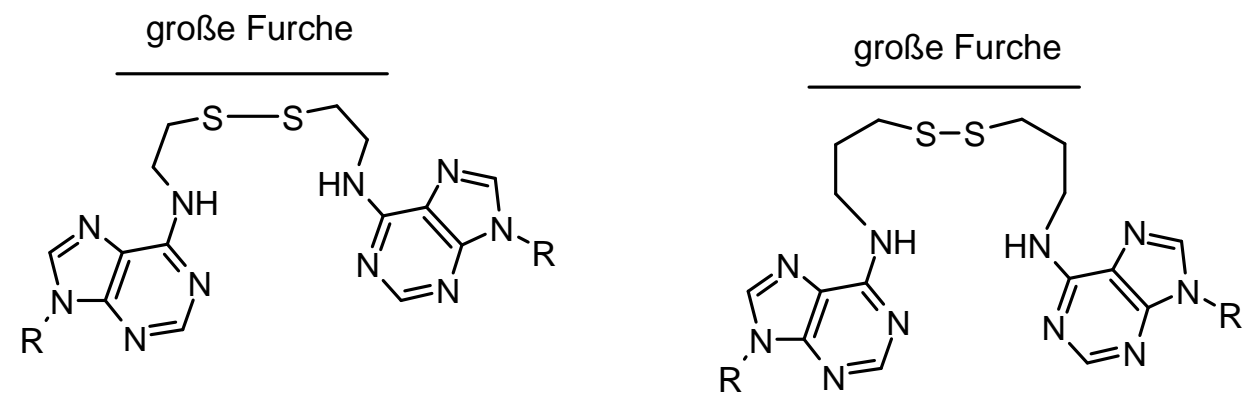

Abb. 2.14: Disulfid-Linker Dithiobisethan und Dithiobispropan; $R=$ Desoxyribose

Es wurden 2-Amino-6-(1-ethylsulfoxy)vinylpurin-Derivate entwickelt, die in einer hochselektiven Alkylierung mit Cytidin zu einer imitierten Watson-Crick Verbrückung führten. Diese Verknüpfung mittels reaktiver Spezies könnte die Inhibierung der Genexpression in der Antisense und Antigene Strategie beeinflussen (Abb. 2.15). ${ }^{[43]}$

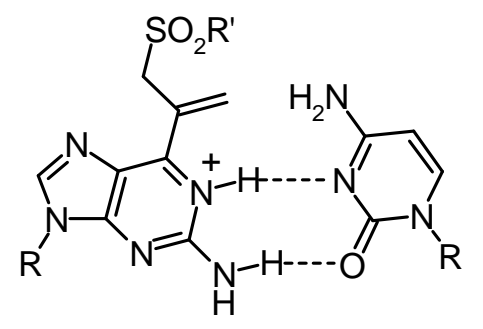

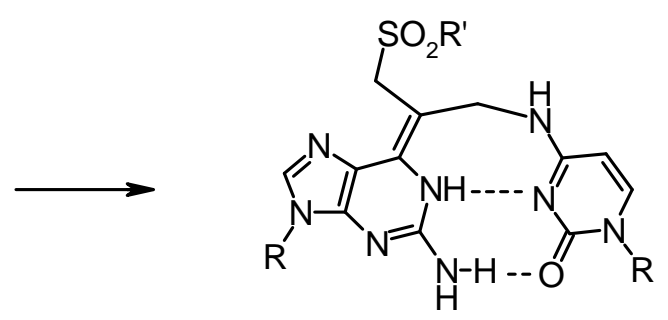

Abb. 2.15: Verknüpfung des 2-Amino-6-(1-ethylsulfoxy)vinylpurin-Derivates mit Cytidin; $R=$ Desoxyribose; R' = Me,H

Andere synthetisierte Verbindungen, die eine solche Alkylierung eingehen sind Halo-

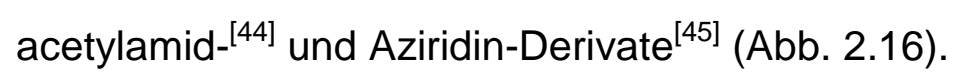<smiles></smiles><smiles>[R]n1cc(C)c(N2CC2)nc1=O</smiles>

Abb. 2.16: 15-(- $\omega$-( $\omega$-Haloacetylamido)-alkyl)-2'-desoxyuridin (links); 5-Methyl-N4,N4-ethanocytosin (rechts); $\mathrm{R}=$ Desoxyribose; $\mathrm{m}=1,3,4 ; \mathrm{n}=1,3 ; \mathrm{X}=\mathrm{Br}, \mathrm{Cl}, \mathrm{I}$

Die Aziridin-Variante ermöglicht die Einbringung der kovalenten Verknüpfung an spezifischen Orten des Oligomers, wobei jedoch eine Cytosin-Cytosin bzw. Cytosin- 
Adenosin Fehlstelle an der Verknüpfungsstelle erforderlich ist. Ebenso ist es nicht möglich, alle vier kanonischen Basen einzubauen. S. J. Benkovic und M. Cowart entwickelten daher einen ethylenverbrückenden Linker, der im Doppelstrang alle vier möglichen Basen enthalten kann. ${ }^{[46]}$ Das N,N-Ethano-2,6-diaminopurin-Derivat reagiert mit der Aminogruppe des Cytidins kovalent zu der ethylenverknüpften Einheit. Mögliche Paarungsmodi sind in Abb. 2.17 gezeigt.<smiles></smiles><smiles></smiles><smiles></smiles><smiles></smiles>

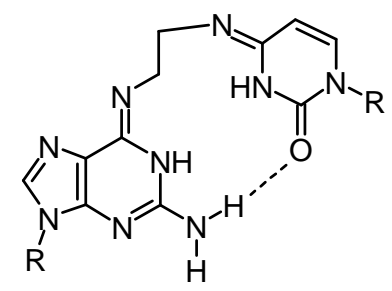

Abb. 2.17: Möglicher Mechanismus zur Bildung kovalenter Verknüpfung der N,N-Ethano-2,6-diaminopurin-Einheit mit der Aminofunktion des Cytosins; R = Desoxyribose

R. L. Letsinger beschäftigte sich mit Haarnadel-Strukturen von Oligonukleotiden und zeigte, dass eine Stilbendicarboxamid-Brücke (Abb. 2.18) ein effektives Strukturelement zur Stabilisierung und Charakterisierung kurzer Oligonukleotid-Doppelsowie Triplestrangbereiche darstellt. ${ }^{[47,48]}$<smiles>O=C(NCCCO)c1ccc(/C=C/c2ccc(C(=O)NCCCO)cc2)cc1</smiles>

Abb. 2.18: Stilbendicarboxamid-Linker mit $R=R^{\prime}=-O P(O)\left(O^{-}\right)$ 
Diese Einheit besitzt einen langen, relativ rigiden Kern, der die Entropie der gesamten Brücke reduzieren soll. Es wurde ein Linker mit Propyleneinheit verwendet, der die Enden der Oligonukleotide an das Amid des Stilbendicarboxamid verknüpft, so dass die gesamte Länge dem Abstand der Rückgratstränge in der DNA-Helix entspricht.

Das Molekül Stilben besteht im Prinzip aus einem Ethenmolekül, das an beiden Enden statt eines Wasserstoffatoms je einen Phenylring trägt. Es existieren vom Stilben beide isomeren Formen (Abb. 2.19). cis- und trans-Stilben sind beide bei Raumtemperatur stabil.<smiles>C(=C/c1ccccc1)\c1ccccc1</smiles><smiles>C(=C\c1ccccc1)\c1ccccc1</smiles>

Abb. 2.19: trans- sowie cis-Stilben

trans-Stilben ist thermodynamisch stabiler als sein Isomer, wie von disubstituierten Doppelbindungen zu erwarten. Derivate des Stilbens werden häufig als Blankophore in Textilien aus Polymerfarbstoffen eingesetzt. ${ }^{[49]}$ 


\section{$2.3 \quad \alpha$-Peptid-Helices}

\subsubsection{Allgemeines zu $\alpha$-Helices}

Die Funktionsweise eines Proteins wird durch dessen Struktur bestimmt, die sich über die Primär-, Sekundär-, Tertiär- sowie Quartärstruktur beschreiben läßt. Die Primärstruktur eines Proteins stellt die Aminosäuresequenz dar und die räumliche Anordnung einer Aminosäuresequenz gibt die Sekundärstruktur wieder. ${ }^{[2]}$ Die Tertiärstruktur beschreibt die gesamte räumliche Struktur der Proteine, d.h. die Faltung der Sekundärstrukturelemente. Von der Quartärstruktur spricht man, wenn Einzelproteine zu einem Gesamtkomplex vereint werden. ${ }^{[2]}$ Die drei häufigsten Sekundärstruktur-Elemente von Polypeptiden bzw. Proteinen sind die $\alpha$-Helix, das $\beta$ Faltblatt und der Turn. ${ }^{[50,51,52,53]}$ Die $\alpha$-Helix wurde 1951 von L. Pauling als erste regelmäßige Proteinstruktur postuliert. ${ }^{[54,55,56,57]} 1958$ wurde sie erstmals mittels Röntgenstrukturanalyse an Myoglobin von J.C. Kendrew nachgewiesen. ${ }^{[58]}$ Das Motiv des $\beta$-Faltblattes und drei verschiedene Arten von $\beta$-Turns wurden von L. Pauling und R. Corey im selben Jahr entdeckt. ${ }^{[56]}$ Nicht zu einem Motiv gehörende Teile der Aminosäureketten eines Proteins nennt man random coil. ${ }^{[2]}$

In einer $\alpha$-Helix erfolgt die Stabilisierung innerhalb eines Polypeptidabschnittes über Wasserstoffbrückenbindungen zwischen der CO-Gruppe der Aminosäure $n$ und der $\mathrm{NH}-$ Gruppe der Aminosäure $n+4$, die vier Aminosäuren entfernt lokalisiert ist. Damit es zur Ausbildung von Wasserstoffbrückenbindungen kommen kann, müssen die CO- und NH-Gruppen dicht beieinander liegen. Diese Voraussetzung wird bei einem aufgewickelten Strang verwirklicht, bei dem die beiden betreffenden Gruppen übereinander zu liegen kommen. Die Seitenketten ragen nach außen, wobei sich die $\beta$ Kohlenstoffatome nicht radial erstrecken, sondern wie Spiralarme (pinwheel) gebogen sind. (Abb. 2.20). ${ }^{[2]}$ 

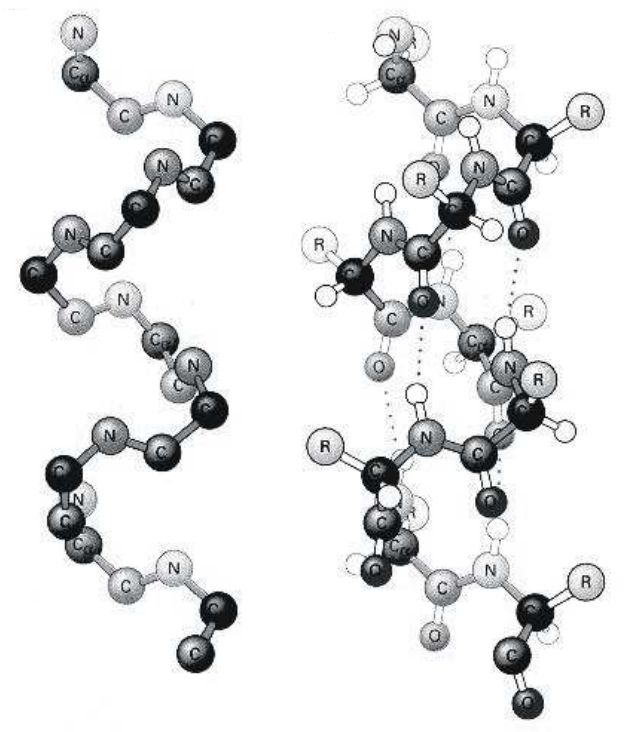

Abb. 2.20: Seitenansicht der $\alpha$-Helix; links: Modell mit markierten $\mathrm{N}(\mathrm{H})-, \mathrm{C}_{\alpha^{-}}$und CO-Atomen; rechts: Modell mit zusätzlichen Wasserstoffbrücken Bindungen und Aminosäureresten ( $R$ )

Jede Aminosäure ist gegenüber der vorigen um $1.5 \AA$ versetzt und um $109.5^{\circ}$ verdreht. ${ }^{[2]}$ Da um die Amidbindung keine Drehung möglich ist, wird die Kette ab der dritten Bindung in eine regelmäßige helikale Struktur gezwungen und durch die erwähnten Wasserstoffbrückenbindungen stabilisiert. Nach vier Aminosäuren ist die erste Windung geschlossen, wobei die erste und vierte Aminosäure sich überlappen. Pro Windung der Helix sind rechnerisch 3.6 Aminosäuren nötig. Somit ist die $\alpha$-Helix eine 3.6 $6_{13}$-Helix. Die sich ausbildenden Wasserstoffbrückenbindungen tragen dazu bei, dass sich ein 13-gliedriger Ring bildet (Abb. 2.21).

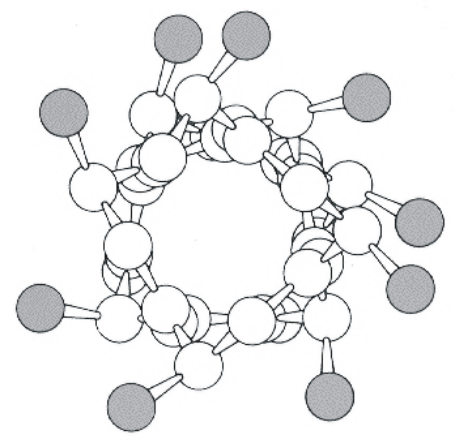

Abb. 2.21: Aufsicht einer 3.6 ${ }_{13}$-Helix: 3.6 Aminosäuren pro Windung führen zu der 13-gliederigen Struktur. 
Da eine volle Umdrehung der Helix 3.6 Aminosäureresten entspricht, beträgt der Abstand zweier Windungen $p$, die so genannte Ganghöhe, $5.4 \AA(3.6 \times 1.5 \AA) .{ }^{[2]}$ Bei einer idealen Helixstruktur müssten die $\mathrm{C}_{\alpha}$-Atome theoretisch nach 5 Windungen ( 5 × 3.6 = 18 Aminosäuren) wieder zur Deckung kommen, was bei vielen natürlichen Proteinen nicht exakt der Fall ist. Die Distanz zwischen den übereinander liegenden Aminosäuren sollte $27 \AA(18 \times 1.5 \AA ̊)$ betragen. Die durch die Helix gebildete sogenannte Röhre besitzt einen Durchmesser von etwa $5 \AA$ und wird von den Atomen des Peptid-Rückgrates gefüllt, was in den van-der-Waals-Darstellungen deutlich wird. ${ }^{\text {[59] }}$ Neben der $\alpha$-Helix kommen in der Natur noch andere Arten von Helices vor, wie die $3_{10}$-Helix und die $\pi$-Helix (Abb. 2.22). ${ }^{[2]} 3_{10}$-Helices treten selten auf, sind kurz und häufig am Beginn oder Ende einer regulären 3.6 ${ }_{13}$-Helix lokalisiert. Der Anstieg pro Aminosäure beträgt hier $2.0 \AA$ ( $\alpha$-Helix: $1.5 \AA$ ) und pro Umdrehung sind drei Aminosäuren nötig ( $\alpha$-Helix: 3.6). Die $3_{10}$-Helix ist insgesamt weniger stabil als die $\alpha$-Helix, da die CO-NH-Dipole nicht ideal entlang der Helix-Achse verlaufen, sondern mit einer Abweichung von $30^{\circ}{ }^{[2]} \pi$-Helices $\left(4.4{ }_{16}\right.$-Helices) werden noch seltener ausgebildet, meist als Schleife am Ende einer $\alpha$-Helix. Pro Windung liegen 4.4 Aminosäuren vor, wobei der Anstieg pro Aminosäure 1.1 Å beträgt. ${ }^{[2]}$ Hinsichtlich des Vorkommens von $\alpha$-Helices in Proteinen gibt es große Unterschiede: In Myoglobin und Hämoglobin z.B. ist die $\alpha$-Helix das häufigste Strukturelement, im Verdauungsenzym Chymotrypsin fehlt sie z.B. aber fast gänzlich. ${ }^{[60,61,62]}$ 


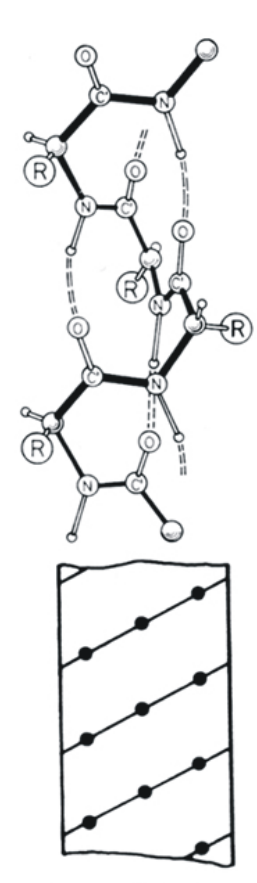

$3_{10}$-Helix
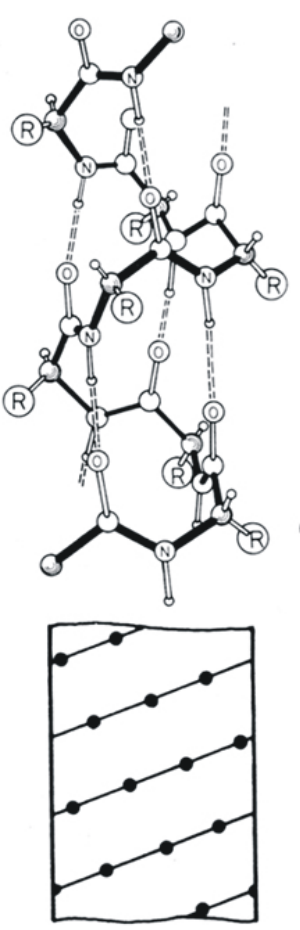

$\alpha$-Helix
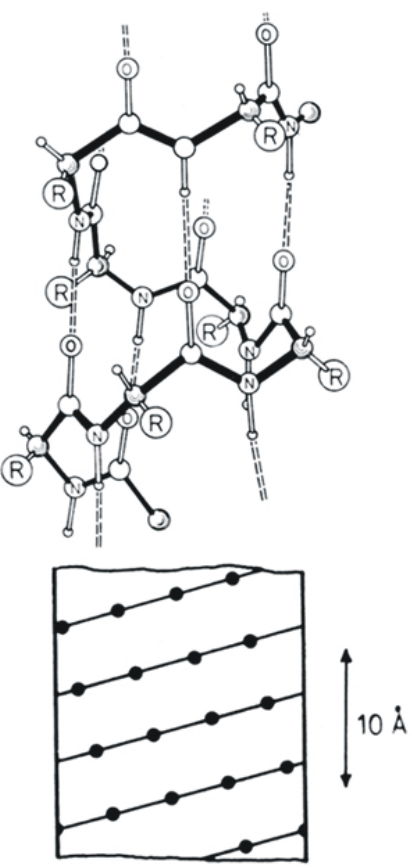

$\pi-$ Helix

Abb. 2.22: oben: Helices der Polypeptidkette mit intramolekularen Wasserstoffbrückenbindungen: $3_{10}$-Helix (links), $\alpha$-Helix (3.6 $6_{13}$-Helix) (mitte), $\pi$-Helix $\left(4.4_{16}\right.$-Helix) (rechts); unten: Punkt-Zylinder Modell, wobei die $\mathrm{C}_{\alpha}$-Positionen markiert sind

In Abb. 2.23 ist eine Peptideinheit der Helix so dargestellt, dass sich alle Gruppen coplanar in der $\mathrm{CO}_{-} \mathrm{C}_{\alpha}-\mathrm{NH}$-Ebene befinden. In dieser Konformation bilden die Atome $\mathrm{CO}, \mathrm{C}_{\alpha}$ und $\mathrm{NH}$ einen Tetraederwinkel von $109.5^{{ }^{[63,64]}}$ Der Torsionswinkel $\varphi$ beschreibt die Drehung um die $\mathrm{NH}-\mathrm{C}_{\alpha^{-}}$-Achse. Wenn sich die $\mathrm{NH}$-Bindung trans zur $\mathrm{C}_{\alpha^{-}}$ CO-Bindung befindet, wird $\varphi$ gleich $0^{0}{ }^{\left[{ }^{[3,64]}\right.}$ Der Winkel $\psi$ beschreibt die Drehung um die CO- $\mathrm{C}_{\alpha}$-Achse. Befindet sich die CO-Bindung trans zur $\mathrm{C}_{\alpha}$ - $\mathrm{NH}$-Bindung ist $\psi$ gleich $0^{\circ}$. Zur Charakterisierung einer möglichen Ver drillung der Bindungsebene der Peptidbindung wird der Winkel $\omega$ definiert. $\mathrm{Er}$ ist gleich Null, wenn die $\mathrm{C}_{\alpha}$-COBindung cis zur nächstfolgenden $\mathrm{C}_{\alpha}-\mathrm{NH}$-Bindung steht. ${ }^{[63,64]}$ Typische Werte der Torsionswinkel $\varphi / \psi$ für eine rechtsgängige $\alpha$-Helix liegen bei $-57 \%-47^{\circ}$, die einer $3{ }_{10^{-}}$ Helix bei $-49 \%-26^{\circ}$ und die einer $\pi$-Helix bei $-57 \%-70^{\circ}$. Der Torsionswinkel $\omega$ ist definitionsgemäß konstant, da sich dieser Winkel innerhalb der planaren Peptidbindung befindet. $^{[63,64]}$ 


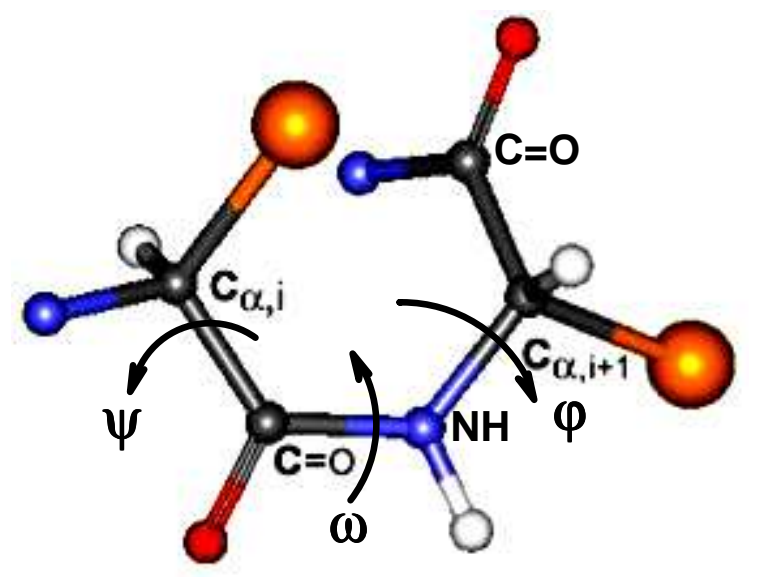

Abb. 2.23: Röntgenkristallstruktur einer trans-ständigen Peptidgruppe mit den Rotationswinkeln $\varphi, \psi$ und $\omega^{[65]}$

Der Schraubensinn der Helix kann nach rechts, d.h. im Uhrzeigersinn, oder nach links weisen. $\alpha$-Helices in natürlichen Peptiden und Proteinen sind grundsätzlich rechtsgängig, da dies sterisch und energetisch günstiger ist. Die einsträngige $\alpha$-Helix ist ein kurzes, stabförmiges Molekül von meist weniger als $4 \mathrm{~nm}$.

Häufig lässt sich eine Helix-Population an der vorliegenden Aminosäure-Sequenz abschätzen; Aminosäuren, wie Alanin, Arginin, Glutaminsäure, Isoleucin, Leucin, Lysin, Methionin, Phenylalanin und Tryptophan treten bevorzugt in Helices auf, während Prolin, Glycin, Threonin und Serin seltener in Helices zu finden sind.

\subsubsection{Helical wheel (Helixrad $)^{[26,66]}$}

Die Darstellung einer Helix in Richtung der Längsachse wird helical wheel (Helixrad) genannt. Das helical wheel stellt eine Projektion der Positionen der $\mathrm{C}_{\alpha}$-Atome auf einer Ebene senkrecht zur Helixachse dar (Abb. 2.24). 

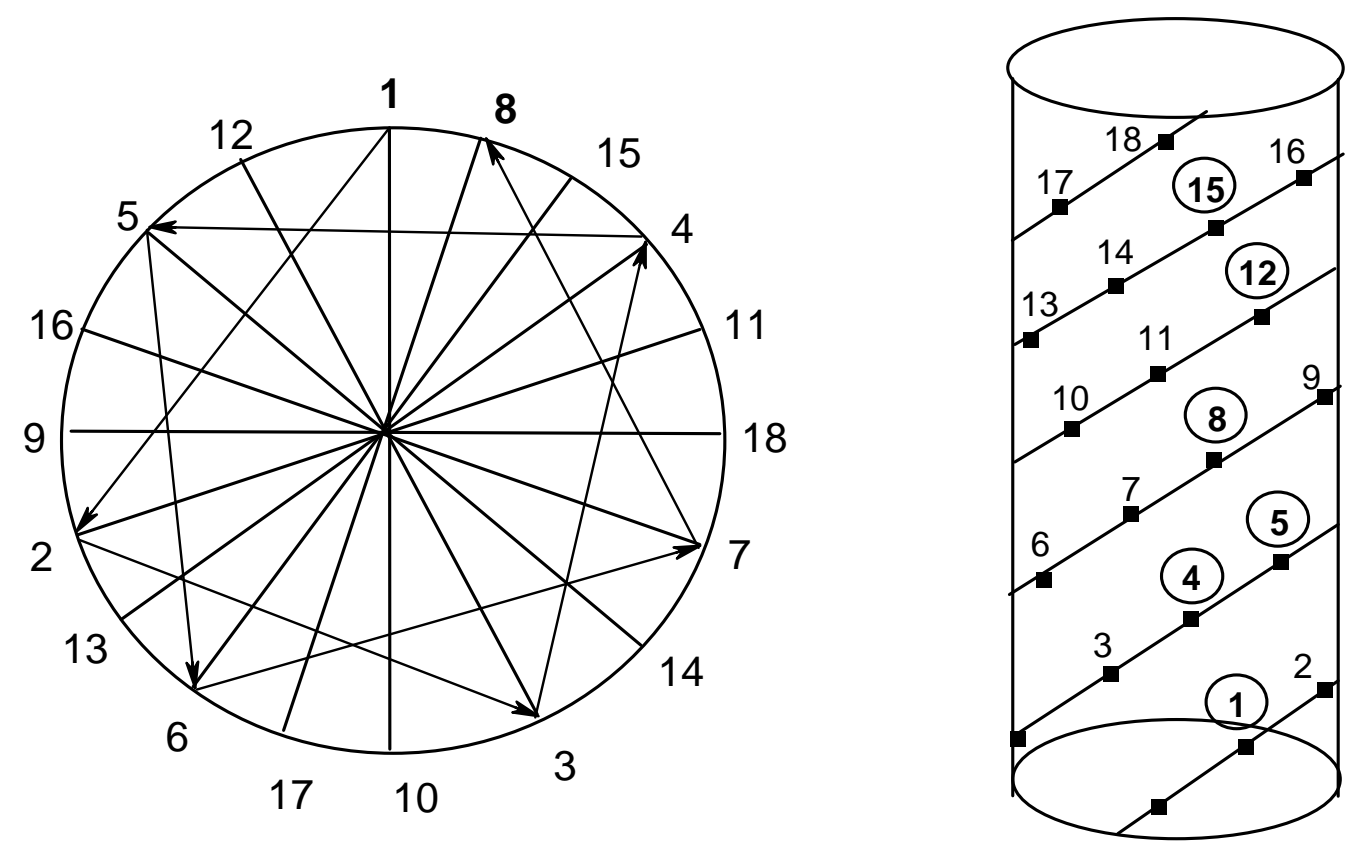

Abb. 2.24: Helical wheel; als Helixrad mit Aminosäureresten 1-18 (links); in der Punkt-Zylinder-Form (rechts)

Mit Hilfe des Helixrades können die Anordnung und die Wechselbeziehungen der Aminosäuren in einer $\alpha$-Helix veranschaulicht werden. Helices, deren eine Seite dem Lösungsmittel zugewandt ist, weisen oft eine charakteristische Verteilung der hydrophilen und hydrophoben Aminosäuren auf; sie sind amphiphatisch. Wie in Abb. 2.24 dargestellt, überdeckt jede Aminosäure einen Sektor von 100. Die wasserstoffverbrückten Reste 1 und 5 sind sich als Teile aufeinander folgender Windungen räumlich nahe. Ähnliches gilt für die Reste 1 und 4. Während erst der Rest der 19. Aminosäure ekliptisch über der Seitenkette der 1. Aminosäure zu liegen kommt, gilt dies angenähert bereits für den zwei Windungen entfernten Rest der 8. Aminosäure. Man spricht hier von einer repetitiven Heptatabfolge (heptade repeat) der Form abcdefga'b'c'd'e'f'g', wobei a dem Rest 1 und a' dem Rest 8 entspricht. Sind a und a' bzw. $d$ und $d$ ' hydrophobe Reste, so entsteht ein linksgewundenes hydrophobes Band um den Zylinder der rechtsgängigen $\alpha$-Helix herum. Hierdurch werden Überstrukturen wie coiled coils ermöglicht.

\subsubsection{Assoziation der $\alpha$-Helices Bündel (coiled coil-Motiv) ${ }^{[67,68]}$}

Kurz nach Entdeckung der Helix konnte F. H. C. Crick zeigen, dass sich $\alpha$-Helices gegenseitig stabilisieren, indem sich mehrere Helices in Bündeln organisieren. ${ }^{[69]}$ 
Lange Helix-Bündel von $100 \mathrm{~nm}$ und mehr sind aus vielen kurzen Einzelhelices aufgebaut, die miteinander verflochten sind und somit lange Seile bilden können, welche zur sogenannten Superspirale (coiled coil) führen (Abb. 2.25).
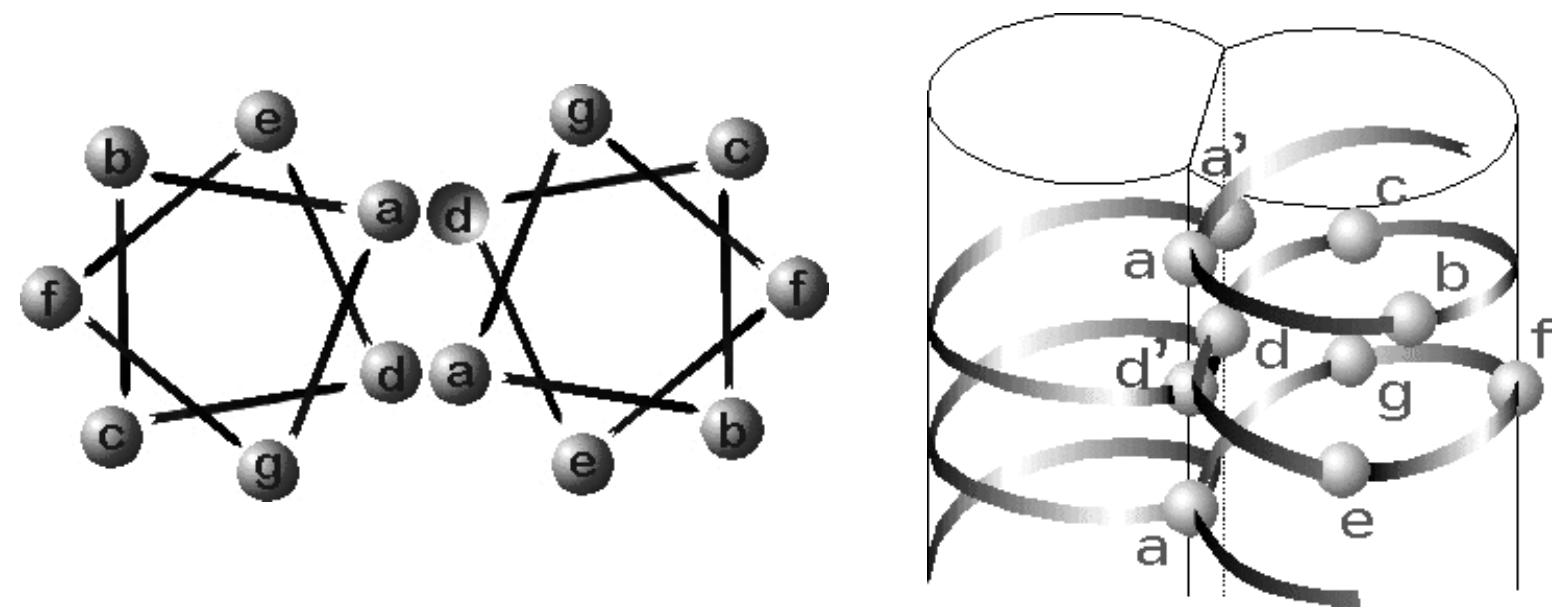

Abb. 2.25: Aminosäurereste in der coiled coil-Struktur an sieben unterschiedlichen Positionen auf der Spirale (heptad repeat); das coiled coil-Protein enthält zwei identische antiparallele Stränge von Aminosäuresequenzen.

Innerhalb jeder Spirale zeigt jede siebte Aminosäure in die gleiche Richtung, da der Basenabstand von $3.6 \AA$ auf $3.5 \AA$ verkürzt ist, wodurch es zur Heptatabfolge abcdefg kommt. Jeder Strang des coiled coil-Motivs wird als heptade repeat gesehen, wobei sich abcdefg an sieben unterschiedlichen Positionen auf der Spirale befinden. Wenn sich zwei Stränge umeinander winden, befinden sich die Aminosäurereste der Position $a$ und $d$ im Inneren und stabilisieren die Struktur mittels hydrophober Kräfte und van-der-Waals Wechselwirkungen der Seitenketten. Dagegen befinden sich die Aminosäurereste $b, c, e, f$ und $g$ auf der Außenseite des Proteins. Position $e$ und $g$ sind meist polar geladen und können die Bildung von Homodimeren über elektrostatische Wechselwirkungen steuern. ${ }^{[70]}$

Coiled coil-Strukturen aus $\alpha$-Helices sind die Grundlage typischer Faserproteine, wie $\alpha$-Keratin, der Grundsubstanz der Haare oder Myosin, einer Komponente der Muskelfasern. Sie sind aber auch, wie z.B. beim Myoglobin, strukturgebundene Komponenten von löslichen, globulären Proteinen. Einzelne Helices können diese Aufgabe im Allgemeinen nicht übernehmen, wohl aber geordnete Aggregate aus zwei, drei, vier oder mehr Individualhelices. ${ }^{[68]}$ 


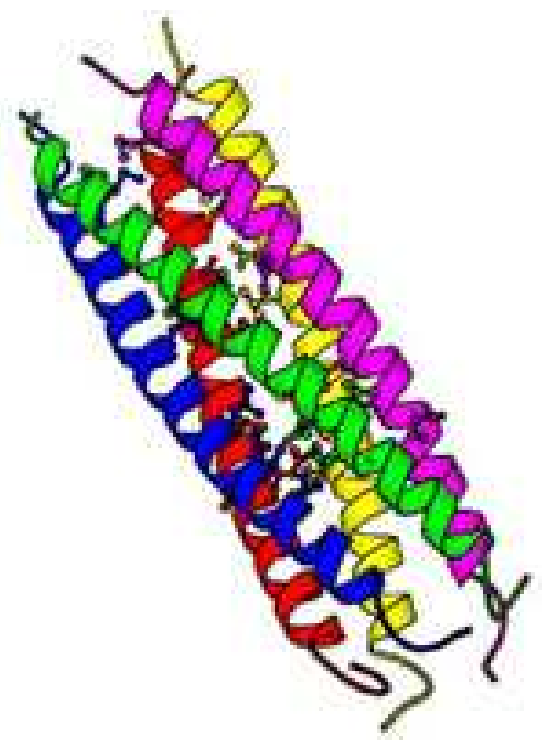

Abb. 2.26 veranschaulicht, wie sich bis zu fünf $\alpha$ Helices aufgrund hydrophober Wechselwirkungen zu einem coiled coil-Motiv zusammenlagern können. Bedingung hierfür ist das Vorliegen amphiphatischer Helices, die zu Wechselwirkungen befähigt sind, da die Helices an einer Seite hydrophil und an der anderen hydrophob sind. Die in Abb. 2.26 gezeigte Geometrie bewirkt dabei, dass das hydrophobe Band nicht parallel zur Helixachse verläuft, sondern die Helix in Form einer gedehnten, linksgängigen Spirale umgibt.

Abb. 2.26: Helix-Bündel aus vier $\alpha$-Helices

\subsubsection{Helix-Vorhersage}

Mit der Veröffentlichung weiterer Röntgenstrukturanalysen wich der helical wheel-Ansatz zunehmend statistischen Verfahren. Ein früher Ansatz dieser Art geht auf P. Y. Chou und G. D. Fasman $(1974,1978)$ zurück. ${ }^{[71,72,73]}$ Die nachfolgende Tabelle gibt die Helixpotentiale von Aminosäuren wieder (Tab. 2.3).

\begin{tabular}{|l|l|l|l|l|l|}
\hline Aminosäure & $\mathbf{P}_{\alpha}$ & $\mathbf{P}_{\alpha i}$ & Aminosäure & $\mathbf{P}_{\alpha}$ & $\mathbf{P}_{\alpha i}$ \\
\hline Glu & 1.53 & 1.45 & lle & 1.00 & 1.22 \\
\hline Ala & 1.45 & 1.59 & Asp & 0.98 & 0.53 \\
\hline Leu & 1.34 & 1.91 & Thr & 0.82 & 0.75 \\
\hline His & 1.24 & 0.87 & Ser & 0.79 & 0.70 \\
\hline Met & 1.20 & 1.25 & Arg & 0.79 & 0.67 \\
\hline Gln & 1.17 & 0.98 & Cys & 0.77 & 0.33 \\
\hline Trp & 1.14 & 1.33 & Asn & 0.73 & 0.53 \\
\hline Val & 1.14 & 1.42 & Tyr & 0.61 & 0.58 \\
\hline Phe & 1.12 & 1.12 & Pro & 0.59 & 0 \\
\hline Lys & 1.07 & 1.13 & Gly & 0.53 & 0.53 \\
\hline
\end{tabular}

Tab. 2.3: Helixpotentiale $\left(P_{\alpha}\right.$ und $\left.P_{\alpha i}\right)$ der Aminosäuren; $P_{\alpha}=$ Wahrscheinlichkeit, mit der ein Rest in der Helix vertreten ist; $P_{\alpha i}=$ Wahrscheinlichkeit, mit der ein Rest im Inneren der Helix vorkommt 
Dabei spricht man von Helixbildnern, wenn das Potential $\left(P_{\alpha}\right)$ deutlich über 1 liegt und von Helixbrechern, wenn es deutlich kleiner ist. Das Potential $P_{\alpha i}$ gibt die Wahrscheinlichkeit der Helixstruktur im Inneren wieder. Bemerkenswert ist, dass Prolin einen realen Wert für $P_{\alpha}$ aufweist, im Zentrum einer Helix jedoch nicht existieren kann $\left(P_{\alpha i}=0\right){ }^{[74]}$

Abb. 2.27 verdeutlicht, dass die Bildung einer $\alpha$-Helix dort beginnt, wo die Reste mehrerer Helixbildner zusammenkommen, darunter insbesondere Leucin, Alanin und Valin. Von diesem Nukleationszentrum ausgehend breitet sich die Struktur aus, bis ein Abbruchsignal erreicht wird. Das zwingende Abbruchsignal am N-Terminus ist hier ein Prolinrest. ${ }^{[68]}$

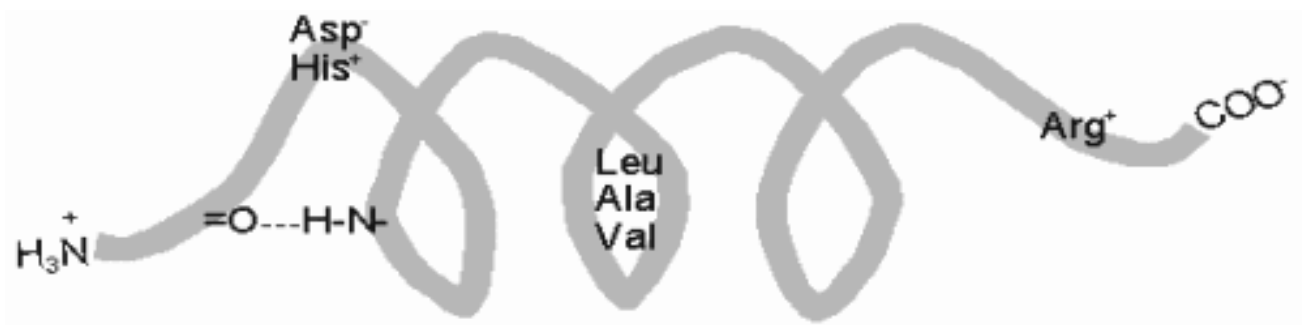

Abb. 2.27: Bildung einer Helix durch Nukleation 


\subsubsection{Leucin-Zipper-Motiv ${ }^{[75,76]}$}

Beim Leucin-Zipper Motiv bilden zwei parallele $\alpha$-Helices Dimere, die die Transkription der DNA regulieren. ${ }^{[76]}$ Die $\alpha$-Helices ordnen sich in einem Winkel von ca. $18^{\circ}$ zueinander an, wobei sie sich umeinander winden. In einer $\alpha$-Helix befindet sich die Seitenkette an jeder 3.5ten und somit auch an jeder siebten Aminosäure auf der gleichen Seite. Sollen sich zwei Helices verzahnen, wird an jeder siebten Stelle der $\alpha$-Helix die hydrophobe Aminosäure Leucin eingebaut. Bei Zusammenlagerung der Helices ordnen sich die hydrophoben Leucine wie die Zähne eines Reißverschlusses an (Abb. 2.28). Es bildet sich ein Leucin-Zipper Motiv aus, das parallel oder antiparallel ausgerichtet sein kann. Der Abstand zwischen jeder siebten Aminosäure beträgt hier ca. $10 \AA$ und man spricht ebenfalls von heptade repeats.

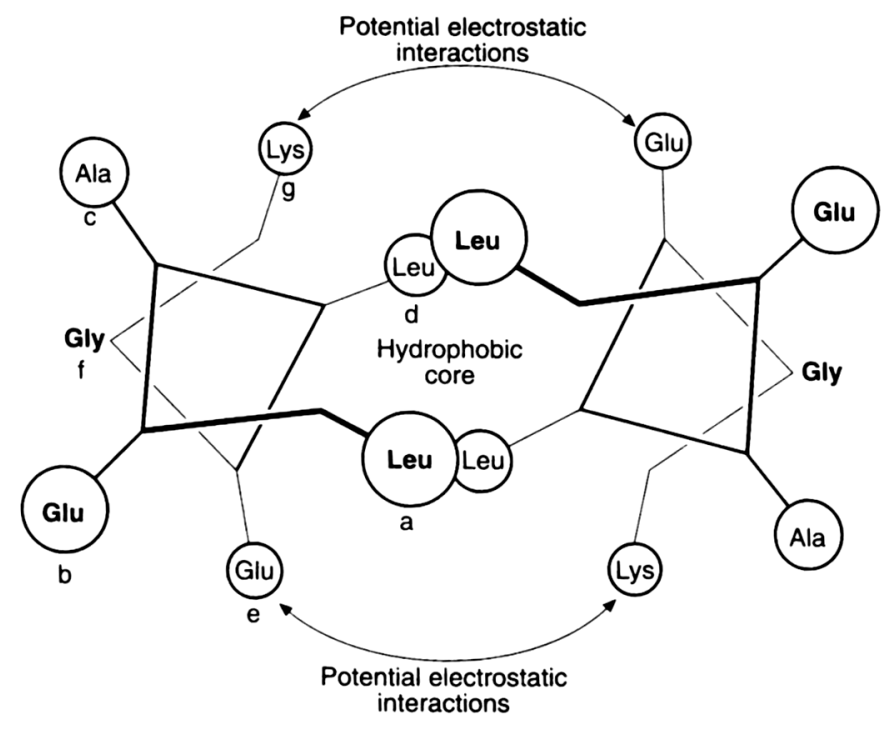

Abb. 2.28: Schematische Darstellung des Leucin-Zipper-Motivs; an Position a und $d$ befindet sich jeweils das hydrophobe Leucin, an $g$ und $e$ die hydrophilen Aminosäuren Lysin und Glutaminsäure 


\subsubsection{Einbau von Nukleoaminosäuren in $\alpha$-Helices ${ }^{[22,77]}$}

Zur komplementären Erkennung sind in natürlichen Proteinen Wasserstoffbrückenbindungen sowie hydrophobe und elektrostatische Wechselwirkungen notwendig. Zusätzliche Stabilisierung der Ausbildung von $\alpha$-Helices kann durch Wasserstoffbrückenbindungen zwischen Nukleobasen erfolgen.

Im Jahr 2000 bauten H. Mihara und Mitarbeiter Homoalanyl-Monomere (Abb. 2.29) in antiparallele zweisträngige $\alpha$-Helices als zusätzliche Erkennungseinheit ein. Es konnte gezeigt werden, dass Peptide mit eingebauten Nukleobasen $\alpha$-Helices ausbilden, die Wechselwirkungen mit spezifischen RNA-Targets eingehen können. ${ }^{[22,77,78]}$

Als Basis-Sequenz wurden $\alpha$-Helices mit jeweils zwei heptad repeat-Einheiten verwendet: $A_{c} L_{d} Q_{e} K_{f} Q_{g} L_{a} A_{b}$ (Abb. 2.29). Leucin wurde in den Positionen $a$ und $d$ als hydrophober Träger eingebaut und Glutamin in den Positionen $e$ und $g$, um die Induzierung von inter- sowie intrahelikalen elektrostatischen Wechselwirkungen zu verringern. Außerdem wurde zur Disulfidbrücken-Bildung die Sequenz-Einheit -GGCam C-Terminus der einen sowie am N-Terminus der anderen Helix eingebaut.

cdef $\mathbf{g} a b c d e f \mathbf{g} a b c d e$
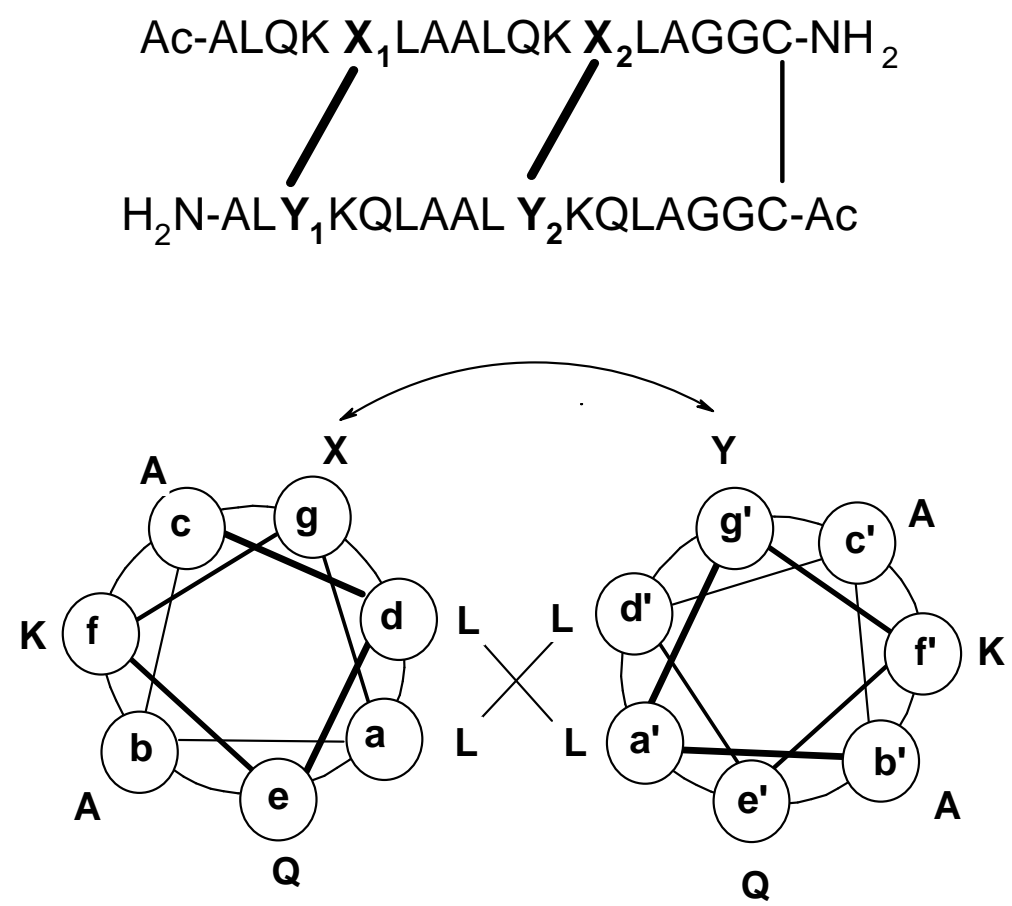

Abb. 2.29: Verwendete Aminosäuresequenzen (oben); helical wheel der synthetisierten Peptide (unten); $X_{1}, X_{2}=Q$, HalT; $Y_{1}, Y_{2}=Q$, Hal $A^{[77]}$ 
In Abb. 2.29 (unten) ist zu erkennen, dass die Positionen $g$ und g' zueinander orientiert sind. In diesen Positionen wurden die Nukleoaminosäuren anstelle von Glutamin eingeführt. Die Gruppe von H. Mihara untersuchte hier unterschiedliche Sequenzvariationen und kommt zu dem Ergebnis, dass eingebaute Homoalanyl-Adenin- und Homoalanyl-Thymin-Monomere einen höheren Helixanteil induzieren und zu höherer Stabilität der Doppelstränge führen als eingebautes Glutamin. Somit tragen zusätzliche Wechselwirkungen wie hydrophobe Basenstapelungen und Wasserstoffbrückenbindungen effizient zur Bildung stabiler $\alpha$-Helices bei. Weitere Untersuchungen zeigen, dass Basenpaare in den Positionen $g$ und $g$ ' effektiver die coiledcoil-Struktur stabilisieren als Basenpaare in den Positionen e und e'. Ebenso wurden Versuche ohne Disulfidverbrückung durchgeführt, die ebenfalls erhöhte Stabilitäten ergeben. 


\subsection{Trypsin-Inhibitor MCoTI-II}

Zyklotide gehören zu der außergewöhnlichen Familie zyklischer Peptide mit dem Motiv des Cystinknotens. ${ }^{[7,80,81]}$ Zyklotide sind kleine Proteine, die ein ungewöhnliches zyklisches Rückgrat aufweisen. Der Momordica Cochinensis Trypsin Inhibitor-II (MCOTI-II) ist ein typischer Vertreter der Proteinfamilie der Inhibitor-Cystinknoten (Abb. 2.30). MCoTI-II wurde erstmals aus Samen des Kürbisgewächses Momordica Cochinensis isoliert und hemmt Trypsin mit einer nanomolaren Dissoziationskonstante. ${ }^{[82,83]}$ Das Peptidrückgrat des Mikroproteins MCoTI-II besteht aus 34 Aminosäureresten und bildet mit sechs Cysteinen das für Zyklotide charakteristische Strukturmotiv des Cystinknotens aus, indem zwei Disulfidbindungen mit ihren Rückgratsegementen einen geschlossenen Ring bilden. Dieser wird von der dritten Disulfidbindung durchdrungen, was $\mathrm{zu}$ einem dreisträngigen $\beta$-Faltblatt führt (Abb. 2.30). ${ }^{[79,80,81]}$
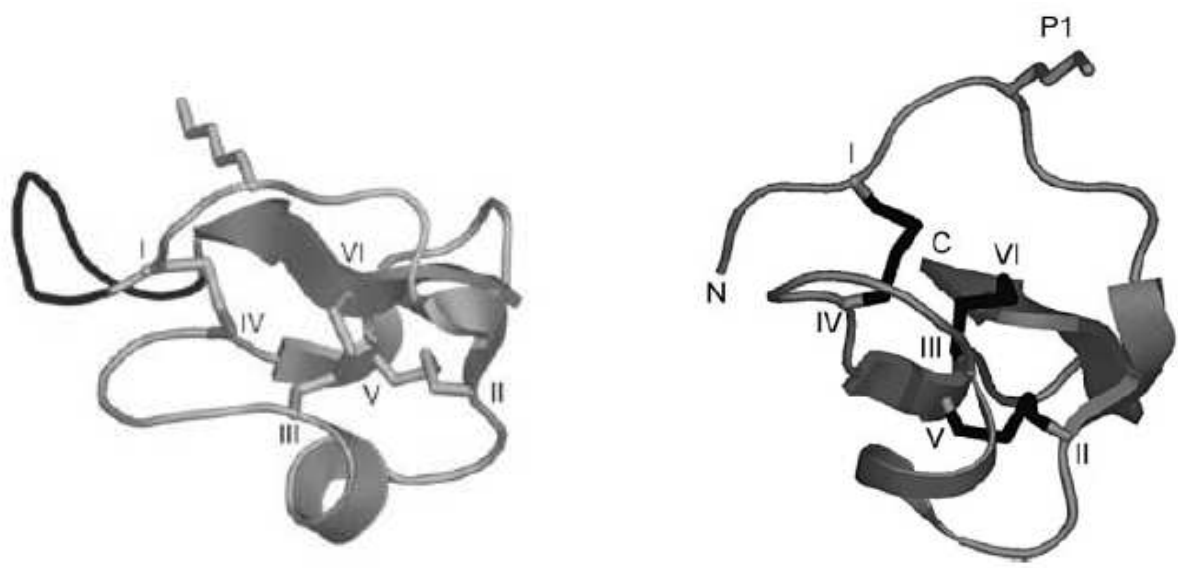

Abb. 2.30: 3D-Model des Zyklopeptids MCoTI-II (links) und des offenkettigen-Analogons MCoTI-29, $\mathrm{I}-\mathrm{VI}=$ Disulfidbrücken ${ }^{[79,80,84]}$

Hierbei ist das erste Cystein mit dem vierten, das zweite mit dem fünften und das dritte mit dem sechsten Cysteinrest der Polypeptidsequenz verknüpft. Aus Abb. 2.30 und Abb. 2.31 ist ersichtlich, dass die zwei intramolekularen Disulfidbrücken CyslCysIV und Cysll-CysV dazu führen, dass sich aus der linearen Sequenz eine Ringstruktur bildet, in der sich die dritte Disulfidbindung Cyslll-CysVI befindet. Die gesamte Struktur enthält sechs Rückgratschleifen (loop1-6) an den Disulfidbindungen und bildet zusätzlich eine $3_{10}$-Helix aus (Abb. 2.30, 2.31). ${ }^{[79,80]}$ 


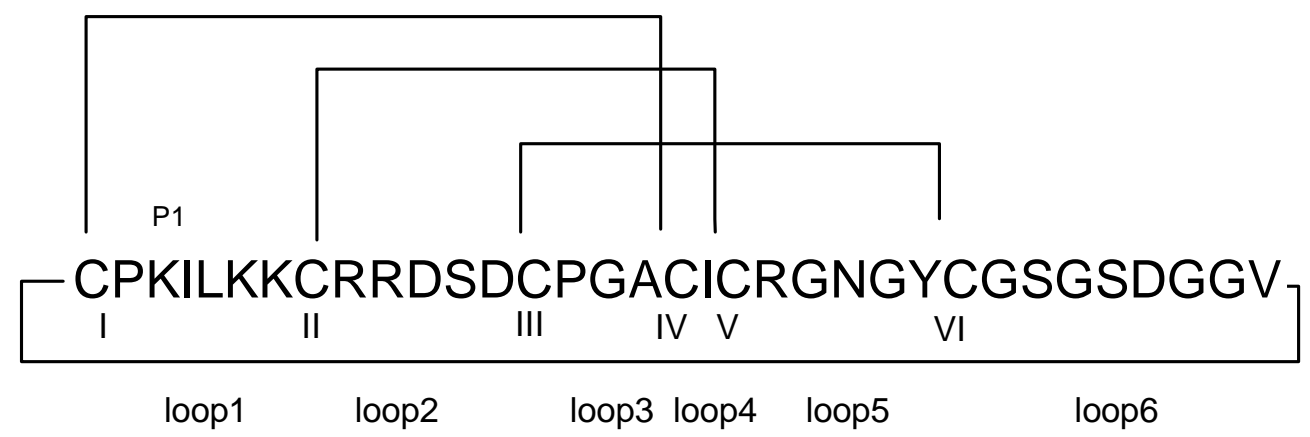

Abb. 2.31: Aminosäuresequenz des Trypsin-Inhibitors MCoTI-II, Disulfidbrücken-Bindungen und Schleifen (loops) des natürlichen Zyklopeptids MCoTI-II

Der Cystinknoten bildet damit ein kompaktes und stabiles Faltungsmotiv und ersetzt den hydrophoben Kern größerer Proteine. Die dadurch resultierende chemische und biologische Stabilität, die geringe Größe und die Zugänglichkeit für Strukturanalysen machen die Cystinknoten-Mikroproteine zu geeigneten Molekülen für die Erforschung biomolekularer Wechselwirkungen. ${ }^{[85]}$

Durch die thermische und proteolytische Stabilität dieses Motivs wird ein großes Spektrum an biologischer Aktivität geboten. ${ }^{[79,86]}$ Es wurden bisher diverse biologische Funktionen der Zyklotide untersucht, wie die uterotonische Aktivität ${ }^{[87]}$, Inhibierung der Neurotensinbindung an Zellmembranen, ${ }^{[8]}$ hämolytische, ${ }^{\left[{ }^{[8,90]}\right.}$ anti$\mathrm{HIV}{ }^{[91]}$ antimikrobielle, ${ }^{[00]}$ insektizide sowie die Trypsin-Inhibitor Aktivität. ${ }^{[33]} \mathrm{Zu}$ sammenfassend ist das Hauptmerkmal des Motivs das zyklische Rückgrat, ein verdrehtes Triple-Strang $\beta$-Faltblatt und der Cystinknoten aus drei Disulfidbindungen.

Das Reaktionszentrum bezüglich der Trypsin-Proteasen befindet sich in der ersten Schleife zwischen Cystein I und IV in der P1-Postion (Abb. 2.30, 2.31). Durch den Arginin-Rest in der P1-Postion wird das aktive Zentrum des Trypsins inhibiert. Die hohe strukturelle Toleranz des Inhibitor-Cystinknoten Motivs gegenüber nicht-Cystein Substitutionen macht MCoTI-II zu einem idealen Rahmenwerk für die Generierung von konformationell eingeschränkten Peptid-Bibliotheken, aus denen Varianten mit neuen Eigenschaften isoliert werden können. Die Cystinknoten gehören zu den kleinsten inhibitorischen Proteinen mit geordneter Struktur.

Da offenkettige MCoTI-II-Analoga dem zyklischen sehr ähnlich sind, wurden diese synthetisiert, um ihre biologische Aktivität zu untersuchen. ${ }^{\left[{ }^{[2]}\right]}$

Die chemische Synthese der macrozyklischen Mikroproteine wurde bislang mittels Festphasen Peptidsynthese (solid phase peptide synthesis, SPPS) nach BocStrategie durchgeführt. ${ }^{[92,93]}$ Der Wechsel von Boc- nach Fmoc-geschützter Synthese 
sollte die Effizienz erhöhen. Ferner konnte dadurch auf die bei Boc-Strategie nötigen sauren Abspaltungsbedingungen verzichtet und auf mildere Reagenzien zurückgegriffen werden. Ein $14 \mathrm{mer}$, welches eine Disulfidbindung aufweist, wurde im Jahr 2001 mittels Fmoc-OAl-Festphasen Strategie synthetisiert. ${ }^{[94]}$

In weiteren Arbeiten wurde die Position Lys10 gegen Arginin und nichtnatürliche Aminosäuren ausgetauscht (Abb. 2.32).

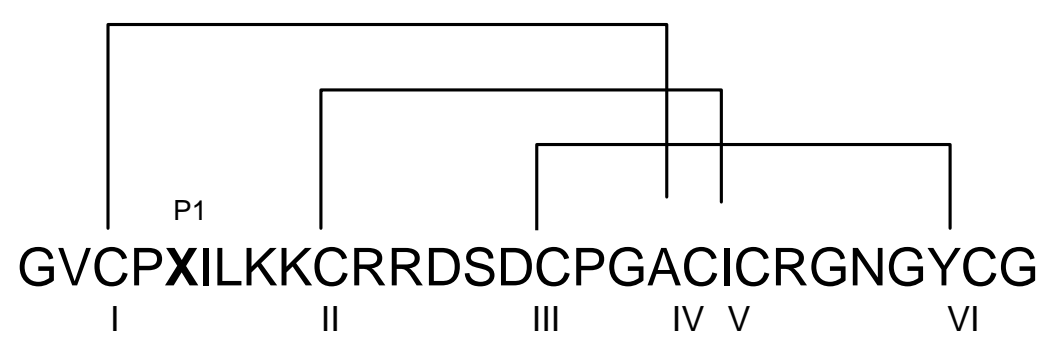

Abb. 2.32: Aminosäuresequenz der offenkettigen Variante MCoTI-29 und Disulfidbindungen; $X=L y s$, $\operatorname{Arg}$

Die Inkorporation nichtnatürlicher Aminosäuren in Proteine wurde durch in vitro Translation beschrieben. ${ }^{[95]}$ Andere Möglichkeiten zur Synthese des Proteins bietet neben dem enzymatischem Aufbau ${ }^{[96]}$ die chemische Totalsynthese. ${ }^{[97]}$ 


\section{Kovalente Verbrückung zweier Alanyl-PNA Stränge}

Die Imitation der Watson-Crick Paarung mittels kovalenter Verbrückung wurde in Kap. 2.2 anhand von DNA-Oligomeren erläutert. In dieser Arbeit sollte die kovalente Verknüpfung zweier komplementär gemischter Alanyl/Homoalanyl-Peptidnukleinsäure-Stränge, die aufgrund ihrer Orientierung eine Watson-Crick Basenpaarung ausbilden, untersucht werden. Der Anspruch an das eingeführte, kovalent gebundene Linker-Molekül bestand darin, durch seine Größe den idealen Abstand vorzugeben, um die Basenpaarung zu stabilisieren (siehe Kap. 2.2). Gleichzeitig sollte die lineare Peptidnukleinsäure-Duplexstruktur erhalten bleiben.

Zum Aufbau des Systems wurden zunächst zwei wesentliche strukturelle Aspekte diskutiert. Zum einen musste der Aufbau der jeweiligen PNA-Stränge in Basenwahl, Sequenzabfolge, Konfiguration und Strangorientierung so gewählt werden, dass der für das Modell stabilste Basenpaarmodus, der Watson-Crick Modus, sicher gestellt war. Zum anderen musste eine adäquate Verknüpfungseinheit für die Oligomere gefunden werden. Für den Peptidstrang wurden als komplementäre Nukleobasen ausschließlich Guanin und Cytosin gewählt, da diese im Watson-Crick Modus über drei Wasserstoffbrückenbindungen in Verbindung stehen und stabilere Komplexe ausbilden als die Adenin-Thymin Paarung mit nur zwei Wasserstoffbrücken. ${ }^{[17]}$ Als Nukleoaminosäuren wurden Alanyl- und Homoalanyl-Nukleoaminosäuren verwendet, um alternierende Alanyl-/Homoalanyl-PNA Oligomere aufzubauen. Da gemischte Nukleoaminosäuren eingesetzt wurden, ist für die Watson-Crick Basenpaarung, nach Erkenntnissen vorheriger Arbeiten ${ }^{[17]}$ (temperaturabhängige UV-Schmelzpunktmessungen; Tab. 3.1), eine antiparallele Strangorientierung sowie eine alternierende Konfiguration der Nukleoaminosäure erforderlich (siehe Kap. 2.1, Tab. 2.1). 


\begin{tabular}{|l|c|c|}
\hline$\underline{G} G \underline{\underline{C}} G \underline{C} C$ & Selbstpaarung & Enantiomerenpaarung \\
\hline Ala-PNA & $40^{\circ} \mathrm{C}$ & $58^{\circ} \mathrm{C}(\mathrm{WC})$ \\
\hline Ala/Hal-PNA & $\mathbf{5 2} \mathbf{C}^{\circ} \mathbf{~ ( W C )}$ & $<51^{\circ} \mathrm{C}$ \\
\hline Hal-PNA & $33^{\circ} \mathrm{C}$ & $37^{\circ} \mathrm{C}$ (WC) \\
\hline
\end{tabular}

Tab. 3.1: Vergleich der Seitenkettenhomologie bei Guanin-Cytosin Paarung; Hal = Homoalanyl; Ala = Alanyl; $W C=$ Watson-Crick; D-konfiguriert $=$ unterstrichen. Je höher die Schmelztemperatur $T_{m}$ ist, desto stärker sind die Basenstapelungen benachbarter Basenpaare innerhalb eines Paarungsmodus.

Ein wesentlicher Unterschied zwischen Alanyl- und Homoalanyl-PNA ist, dass die Basenpaare der Homoalanyl-PNA fast vollständig entstapelt vorliegen. Bei Peptidsträngen aus Homoalanyl-Monomeren werden die Nukleobasen aus der Ebene herausgedreht (Abb. 3.1, 3.2).

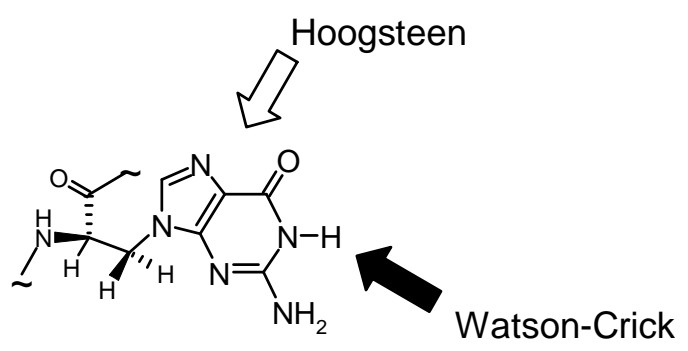

AlaG

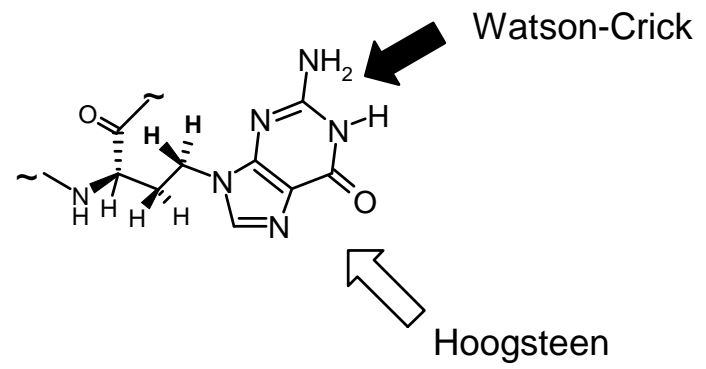

HalG

Abb. 3.1: Vergleich der Vorzugskonformationen der Alanyl(Ala)- und Homoalanyl(Hal)-PNA

Die Ausrichtung des Stranges wird verändert, wenn in einem Alanyl-PNA Strang jede zweite Alanyl-Einheit gegen eine Homoalanyl-Einheit ausgetauscht wird, da die Nukleobase sich umorientiert. Die reine Alanyl-PNA unterscheidet sich somit von der gemischten Alanyl/Homoalanyl-PNA im veränderten Basenstapel. Der Alanyl-PNA Basenstapel weist eine größtmögliche Überlappung und entgegengesetzte Orientierung der Dipole auf, während sich der Basenstapel der alternierenden Alanyl/Homoalanyl-PNA hinsichtlich der Dipole einheitlich orientiert (Abb. 3.2). Letztere Orientierung gleicht der der B-DNA. ${ }^{[17]}$ 


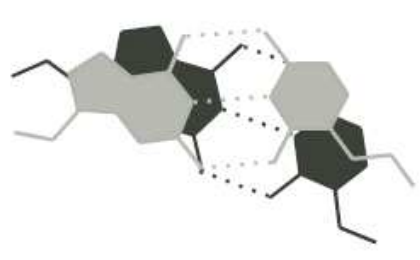

Alanyl-/Homoalanyl-PNA

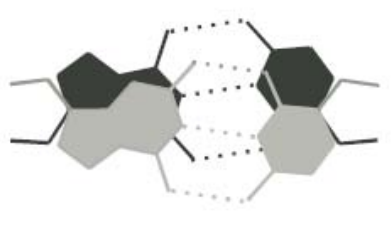

Alanyl-PNA

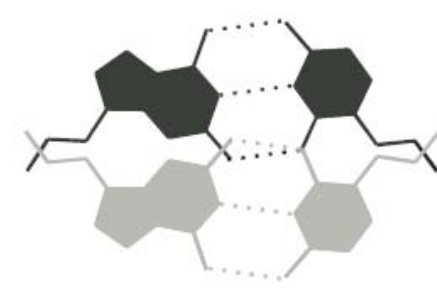

Homoalanyl-PNA

Abb. 3.2: Vergleich der Alanyl/Homoalanyl-PNA mit der Alanyl-PNA und der Homoalanyl-PNA mittels Basenstapel Modellen der Guanin-Cytosin Paarung

Alternierende Alanyl/Homoalanyl-Peptidnukleinsäuren sind geometrisch so orientiert, dass eine parallele Strangorientierung gegenüber der antiparallelen benachteiligt ist. Der Abstand der Nukleobasen ändert sich im Vergleich zu den reinen Peptidnukleinsäuren hierbei nicht. Somit beträgt der ideale Abstand für die Basenstapelung der alternierenden Konfiguration auch $3.6 \AA$ und es können ebenfalls stabile lineare Duplexe gebildet werden.

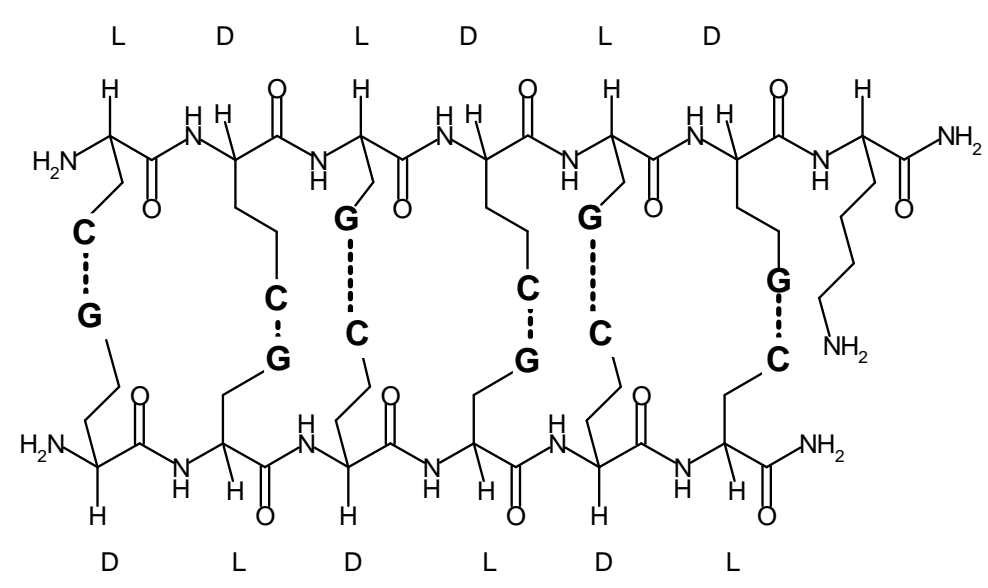

Abb. 3.3: Strukturmodell des verwendeten linearen, antiparallelen, heterochiralen Paarungskomplexes H-AlaC- $\underline{\mathrm{HalC}}-\mathrm{AlaG}-\underline{\mathrm{HalC}}-\mathrm{AlaG}-\underline{\mathrm{HalG}}-(\mathrm{Lys})-\mathrm{NH}_{2}$

Es wurden zunächst PNA-Stränge (Tetramer- wie Hexamer-Oligomere) an fester Phase synthetisiert, die über einen Linker kovalent miteinander verbunden werden sollten (Abb. 3.4, Schritt 3 und 4; Abb. 3.5). Um die Löslichkeit der PNA zu erhöhen wurde am C-Terminus des ersten Peptidstranges Lysin eingebaut. ${ }^{[98]}$

Das Verknüpfungsmolekül soll im Idealfall eine Carbonsäurefunktion aufweisen, die mittels Aktivierungsreagenzien in eine reaktivere Spezies überführt wird, die nukleo- 
phil von der freien Aminofunktion des PNA-Stranges angegriffen und so gebunden werden kann (Abb. 3.4, Schritt 1).

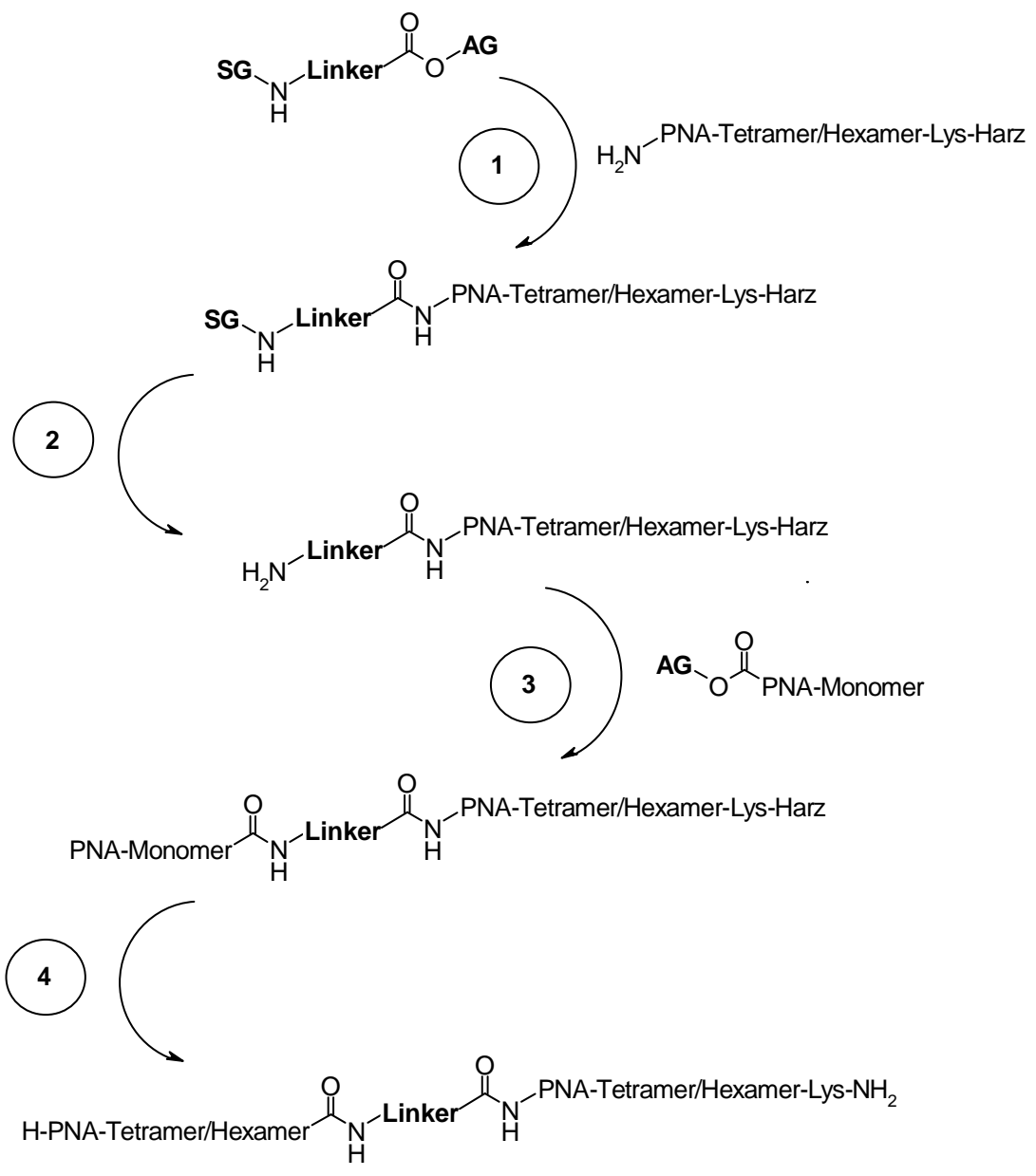

Abb. 3.4: Schematische Darstellung der PNA-Strang-Linker-PNA-Strang Peptidfestphasen Synthese; Harz = MBHA-PS; SG = Schutzgruppe (Fmoc oder Boc); AG = Aktivierungsgruppe (HATU, HOAt); Schritte 1-4 siehe Text

Gleichzeitig muss gesichert sein, dass sich an der anderen Seite des Verbindungsmoleküls eine Aminofunktion befindet, welche allerdings bei Kupplung an den ersten PNA-Strang geschützt vorliegen muss. Als Schutzgruppe erweist sich die tertButoxycarbonyl(Boc)-Gruppe als geeignet, da die Peptid Festphasensynthese des PNA-Stranges nach der Boc-Schutzgruppen Strategie durchgeführt wird. Ebenso möglich wäre auch eine Fluorenylmethyloxycarbonyl(Fmoc)-Schutzgruppe, die unter milderen Bedingungen basisch abgespalten werden kann. Nach Entschützung der Boc- bzw. der Fmoc-Schutzgruppe, sauer mit $5 \% \mathrm{~m}$-Kresol in TFA bzw. basisch mit 20 \%iger Piperidinlösung in DMF oder NMP (Abb. 3.4, Schritt 2), wird eine Nukleo- 
aminosäure an die freie Aminofunktion gekuppelt, die zur letzten Nukleoaminosäure des bereits kovalent gebundenen PNA-Stranges komplementär ist (Abb. 3.4, Schritt 3). Nach weiteren Kupplungsschritten bis zum vollständigen komplementären zweiten Strang kann der Komplex vom Harz abgespalten werden (Abb. 3.4, Schritt 4).

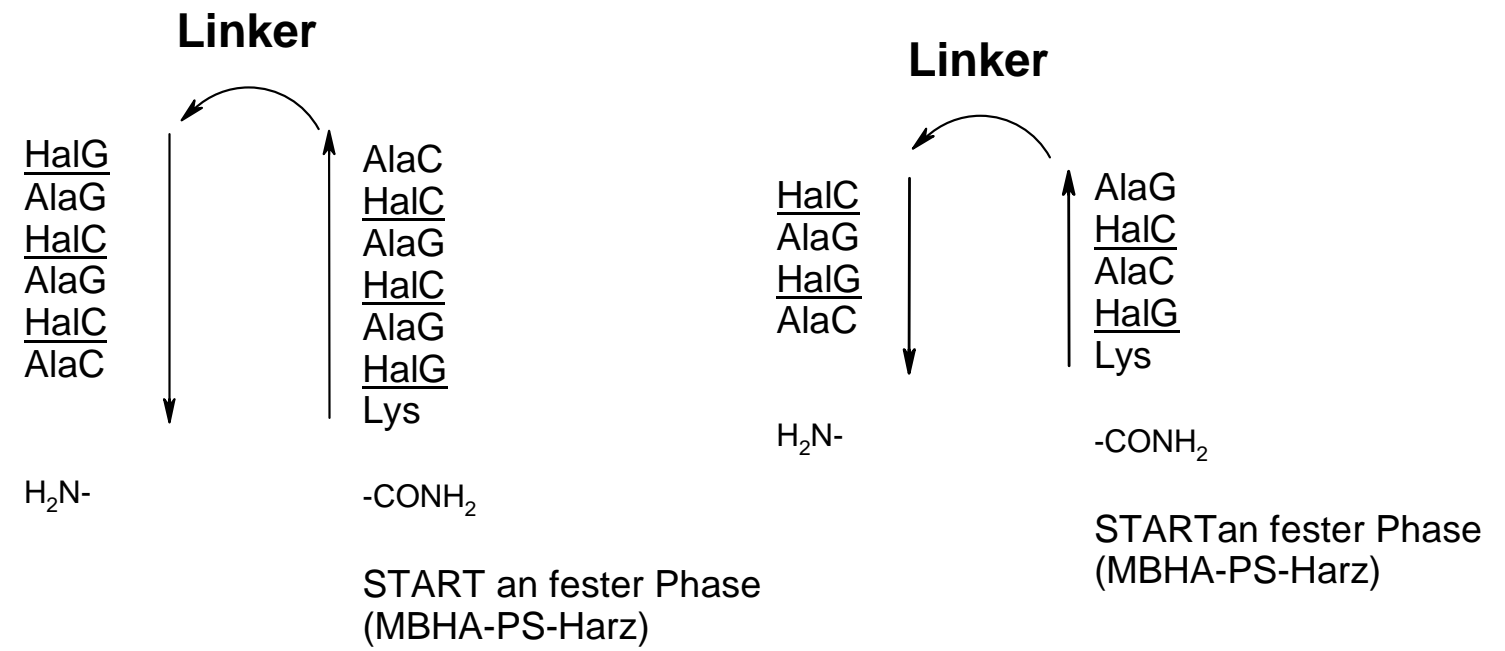

Abb. 3.5: Modell der kovalent verknüpften Peptidnukleinsäure-Stränge; links: als Hexamer-Oligomerstrang H-AlaC- $\underline{\mathrm{HalC}}-\mathrm{AlaG}-\underline{\mathrm{HalC}}-\mathrm{AlaG}-\underline{\mathrm{HalG}}-\mathrm{Linker}-\mathrm{AlaC}-\underline{\mathrm{HalC}}-\mathrm{AlaG}-\underline{\mathrm{HalC}}-\mathrm{AlaG}-\underline{\mathrm{HalG}}-\mathrm{Lys}-\mathrm{NH}_{2}$; rechts: als Tetramer-Oligomerstrang H-AlaC- $\underline{\mathrm{HalG}}-\mathrm{AlaG}-\underline{\mathrm{HalC}}-\mathrm{Linker}-\mathrm{AlaG}-\underline{\mathrm{HalC}}-\mathrm{AlaC}-\underline{\mathrm{HalG}}-\mathrm{Lys}-\mathrm{NH}_{2}$; D-konfigurierte Nukleoaminosäuren sind unterstrichen.

Auf der Suche nach einem geeigneten Linker-Molekül muss bedacht werden, dass es nur eine geringe Flexibilität aufweisen darf, damit die beiden PNA-Stränge räumlich nicht allzu stark voneinander getrennt werden und die Ausbildung der Wasserstoffbrückenbindungen gewährleistet ist. Allerdings darf das Linker-Molekül auch nicht zu kurz sein, da dies das Auseinanderdriften der Basenpaare forcieren würde. Die Verbindung sollte die planare gestapelte Anordnung der Basenpaare so verbrücken und stabilisieren, dass die Anordnung des $\beta$-Faltblattes im Peptidstrang nicht verloren geht.

Um die Nukleobasen und ihre Wasserstoffbrückenbindungen imitieren zu können, muss der Linker eine Länge besitzen, die genau dem Abstand zweier sich gegenüberliegender $\mathrm{C}_{\alpha}$-Atome am Peptidrückgrat entspricht (Abb. 3.6). Die Bindungslänge von $\mathrm{C}_{\beta}$ des AlaG-Monomers bis zum $\mathrm{C}_{y}$ des HalC-Monomers beträgt $10.85 \AA$ (Abb. 3.6). ${ }^{[2]}$ Für die zusätzlichen Methyleneinheiten werden jeweils $1.54 \AA$ be- 
rechnet, was zu einer Gesamtbindungslänge von $15.43 \AA$ führt. In diesem Größenlängen-Bereich sollte sich der einzubauende Linker befinden. ${ }^{[99,100,101]}$

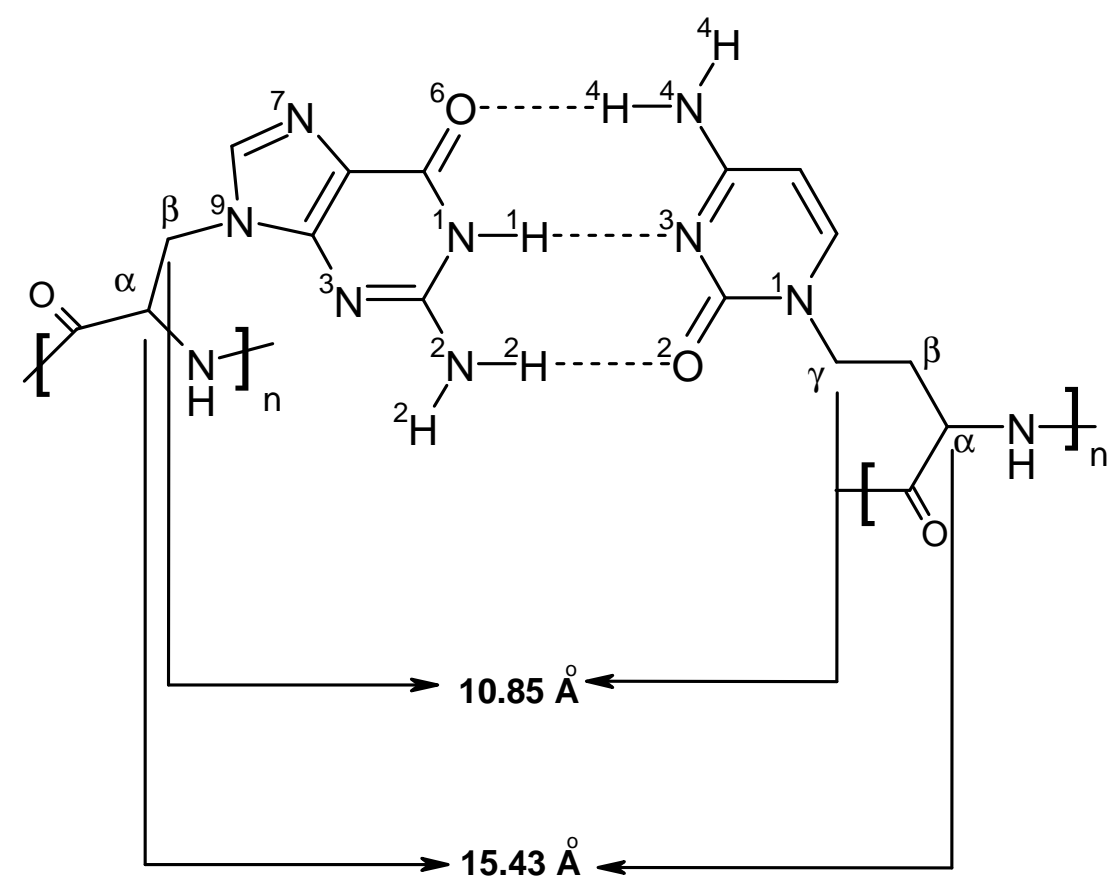

Abb. 3.6: AlaG-HalC Paarung mit Bindungslängen in $\AA$

Um eine kovalente Bindungsverknüpfung zu erreichen, wurde zunächst der aus der Literatur als spacer eingesetzte Fmoc-Hexaethylenglycolaminosäure (Fmoc-Hegas)Linker 1 (Abb. 3.7) als verbrückendes Molekül gewählt und eingebaut. ${ }^{[102,103,]}$

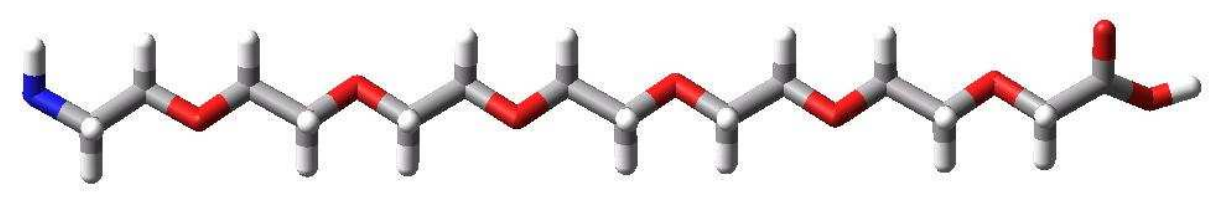

Abb. 3.7: Hegas-Linker 1 ohne Fmoc-Schutzgruppe

Dieser besitzt eine Fmoc-Schutzgruppe und eine Säurefunktion. Die Bindungslänge von $22.0 \AA$ liegt um $6.57 \AA$ höher als erwünscht (Abb. 3.8). Der Glycollinker weist jedoch wegen der Ethylenglycol-Einheiten eine Flexibilität auf, die dazu führt, dass sich die Basenpaare dennoch erkennen können. 


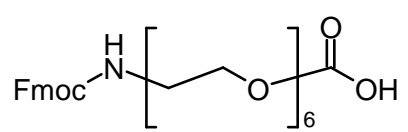

XX

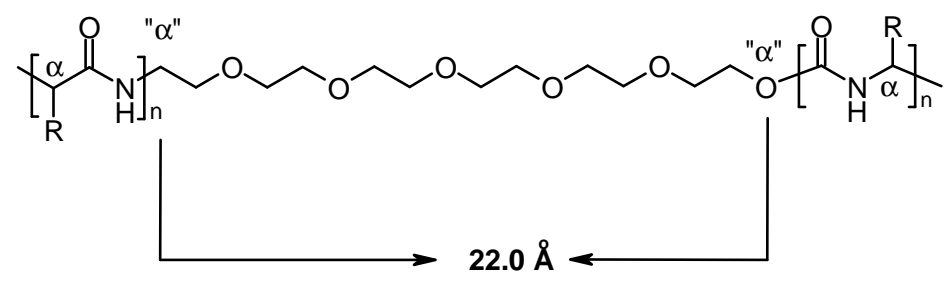

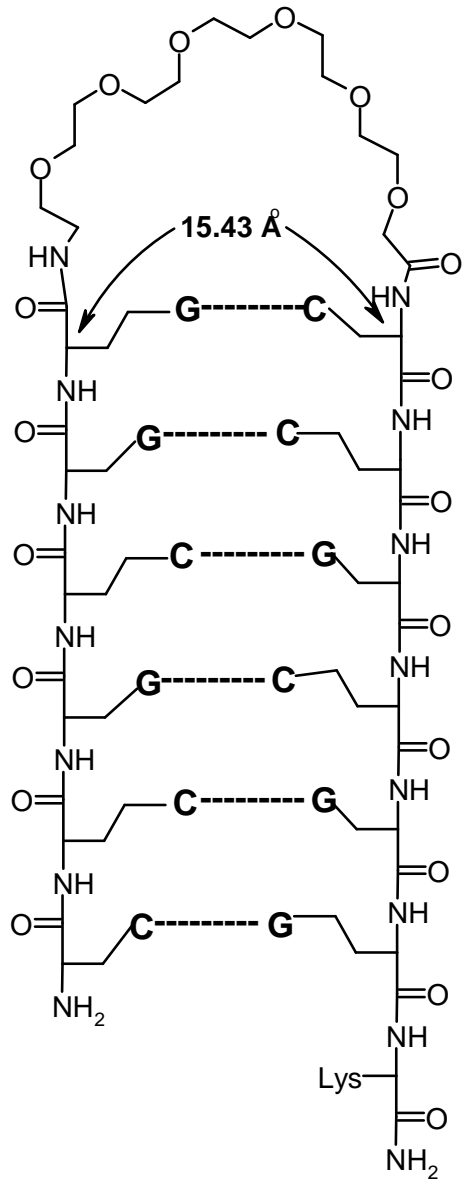

Abb. 3.8: Fmoc-Hegas-Linker (Fluorenylmethyloxycarbonyl-Hexaethylenglycolaminosäure) 1 und Abstand der imitierten Basenpaarung als eingebauter Linker: in gestreckter (links) und gefalteter Form (rechts) ${ }^{[99]}$

Aufgrund der mittels MacroMode ${ }^{\circledR}$ ermittelten Bindungslängen konnte als weiterer Linker ein Stilben-Derivat 2 (Abb. 3.9) modelliert werden, das den Ansprüchen der Bindungslänge weitgehend gerecht wird. Es entspricht in seiner Größe der Wasserstoffbrückenbindung zwischen Purin und Pyrimidin. Die Bindungslänge vom $\mathrm{C}_{\alpha}$ zum $\mathrm{C}_{\alpha}$ beträgt in diesem Derivat zwar $23.31 \AA$, da der Stilben-Linker aber flexibel drehbare Methylen- bzw. Ethyleneinheiten aufweist, kann sich der Linker so eindrehen, dass die Bindungslänge nahezu der der Basenpaarung in Abb. 3.6 gleicht (Abb. 3.10). Das Stilben-Derivat besitzt außerdem im Vergleich zum Glycol-Linker einen langen, rigiden Kern, der die Entropie der gesamten Brücke reduzieren sollte. 


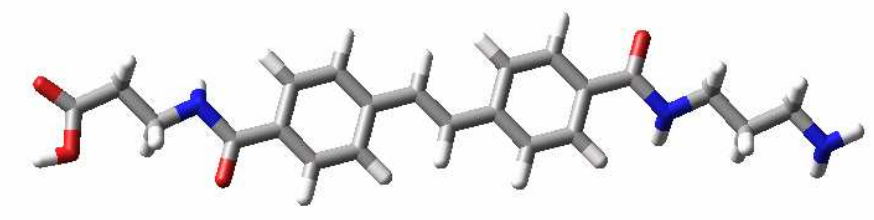

Abb. 3.9: Modell des Stilben-Derivat-Linker trans-Stilben-4-(carbonsäure-methylcarbamoyl)-4'-aminoethylcarbamoyl) 2 ohne Boc-Schutzgruppe<smiles>CC(C)(C)OC(=O)NCCNC(=O)c1ccc(/C=C/c2ccc(C(=O)NCC(=O)O)cc2)cc1</smiles>

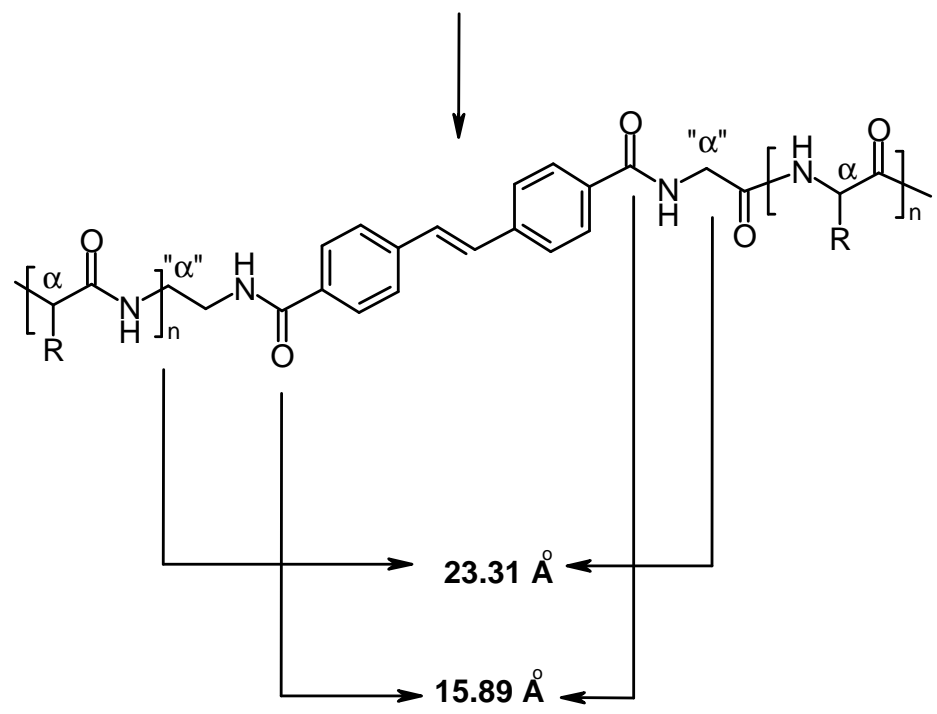

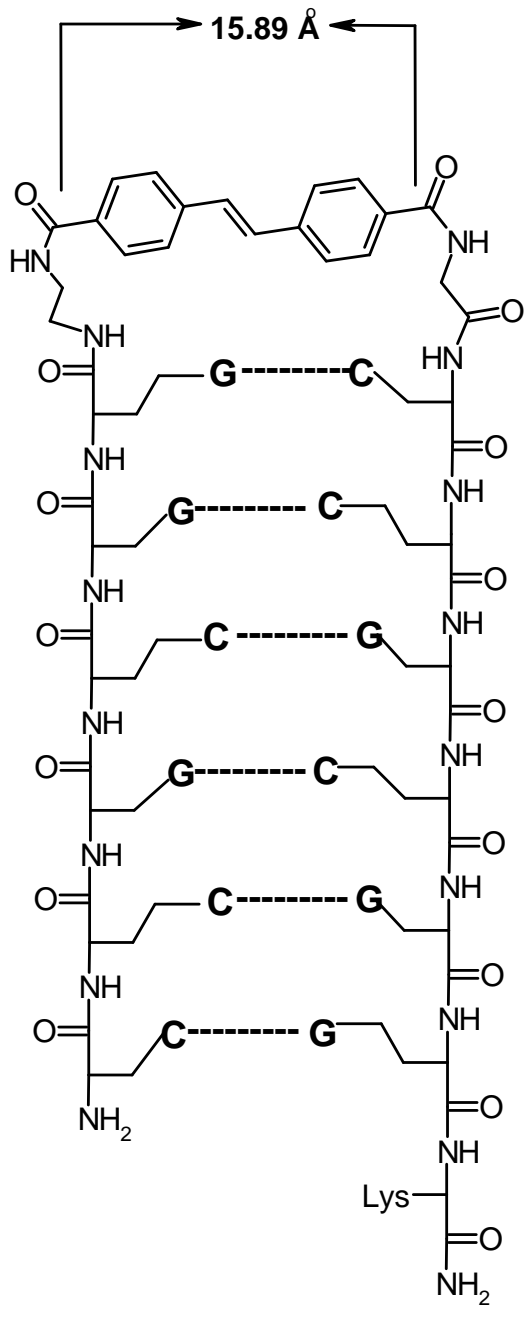

Abb. 3.10: Stilben-Derivat-Linker: $\quad$ trans-Stilben-4-(carbonsäure-methylcarbamoyl)-4'-(tert-butoxycarbonyl)-aminoethylcarbamoyl) 2 und Abstand der imitierten Basenparung als eingebauter Linker ${ }^{[99]}$

Das Stilben-Modell fungierend als Linker wurde bereits in DNA-Doppelstrang Oligomeren eingebaut und untersucht (siehe dazu Kap. 2.2). Stilben (Kap. 2.2, Abb. 2.19) ist ein starres Gerüst und sollte in der trans-Form vorliegen. Der Wechsel in die cisKonfiguration erfolgt erst bei sehr hohen Temperaturen oder mittels photochemischer Bestrahlung. ${ }^{[49]}$ Beide Aromaten sind para-substituiert, was eine vorteilhafte 
Symmetrie ergibt. Als Substituenten wurden Carbamoylgruppen gewählt. An der einen Seite schließt sich an das Amid eine Methylencarbonsäure an, die nach Aktivierung mit bestimmten Kupplungsreagenzien, wie HATU und HOAt (genaueres siehe Kap. 3.3), an das freie Amin der Nukleoaminosäure des PNA-Stranges gebunden werden kann. Am anderen Ende ist eine Aminoethyleneinheit lokalisiert, die Boc-geschützt ist. Diese kann bei der Peptid Festphasensynthese sauer abgespalten werden und im nächsten Schritt mit dem Aktivester einer neuen Nukleoaminosäure reagieren.

\subsection{Synthese der Boc-Alanyl/Homoalanyl Nukleoaminosäuren}

Ausgehend von N-Boc-L-Serin 3 und N-Boc-D-Serin ent-3 beschreibt P. Lohse [104,105] $^{10}$ die Synthese von Alanyl-Nukleoaminosäuren unter Erhalt des Stereozentrums. $N$ Boc-L-Serinlacton 4 bzw. N-Boc-D-Serinlacton ent-4 wurde aus Boc-L-Serin 3 bzw. Boc-D-Serin ent-3 nach J. C. Vederas unter Mitsunobu-Bedingungen ${ }^{[106,107,108]}$ dargestellt. Das Boc-Serinlacton 4 reagiert mittels nukleophiler Ringöffnung durch das Benzyloxycarbonyl-geschützte Cytosin $\left(\mathrm{C}_{z}\right) 5$ und dem Guanin-Vorläufer 2-Amino-6chlorpurin zu Boc-L-AlaG-OH 6 bzw. Boc-D-AlaG-OH ent-6 und Boc-AlaC $-\mathrm{z}-\mathrm{OH} 7$ bzw. seinem Enantiomer ent-7 (Abb. 3.11) ${ }^{[13 a, 17]}$ Die Schutzgruppe Benzyloxycarbonyl an der exozyklischen Aminofunktion des Cytosins ist für die nachfolgende Peptid Festphasensynthese notwendig. Das Guanin benötigt keine Schützung, da die exozyklische Aminogruppe eine äußerst geringe Nukleophilie aufweist. ${ }^{[13 a]}$

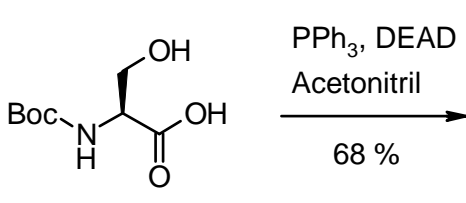

3<smiles>CC(C)(C)OC(=O)NC1COC1=O</smiles>

4

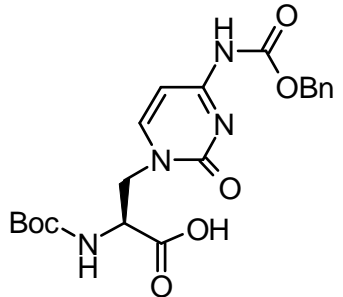

7 


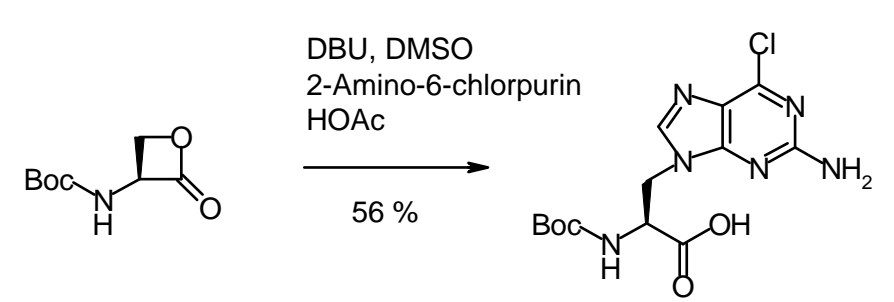

4
1. $\mathrm{TFA} / \mathrm{H}_{2} \mathrm{O}$

2. $\mathrm{H}_{2} \mathrm{O} / \mathrm{NaOH} /$ Dioxan $\mathrm{Boc}_{2} \mathrm{O}$<smiles>CC(C)=NC(=O)NC(CN1CCCC1)C(=O)O</smiles>

6

Abb. 3.11: Synthese der Alanyl-Nukleoaminosäuren

Als Ausgangsverbindung zur Synthese der Homoalanyl-Nukleoaminosäuren diente N-Boc-L-Asparaginsäurebenzylester 9 bzw. Boc-D-Asparaginsäurebenzylester ent9. ${ }^{[109,110]}$ Nach J. M. Bland ${ }^{[111]}$ wurden deren Seitenketten mit $\mathrm{BH}_{3} \cdot$ THF zum Alkohol 10/ent-10 reduziert und über eine Appel-Reaktion ${ }^{[112,113]}$ zum N-Boc-L- $y$-Brom-homoalanylbenzylester 11 bzw. N-Boc-D- $y$-Brom-homoalanylbenzylester ent-11 bromiert (Abb. 3.12). ${ }^{[15]}$<smiles>O=C(O)C[C@H](NC(=O)OCc1ccccc1)C(=O)OCc1ccccc1</smiles>

9<smiles>CCCCCCCCOC(=O)C(CCO)NC(=O)OC(C)(C)C</smiles>

10

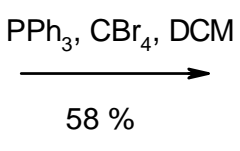<smiles>CC(C)(C)OC(=O)NC(CCBr)C(=O)OCc1ccccc1</smiles>

11

Abb. 3.12: Darstellung des $N$-Boc- $\gamma$-brom-homoalanylbenzylesters 11

Nukleophile Substitution des Bromids mit Benzyloxycarbonyl-geschütztem Cytosin $\left(\mathrm{C}_{z}\right)$ 5 und 2-Amino-6-chlorpurin wurde in Anwesenheit von $\mathrm{K}_{2} \mathrm{CO}_{3}$ bei Raumtemperatur durchgeführt. 2-Amino-6-chlorpurin-Derivat 12 wurde im nächsten Schritt mittels TFA $/ \mathrm{H}_{2} \mathrm{O}$ hydrolisiert, wobei gleichzeitig die Boc-Schutzgruppe entfernt wurde. Der darauf folgende Schritt wurde hydrogenolytisch mit $\mathrm{PdO} \cdot \mathrm{H}_{2} \mathrm{O}$ durchgeführt. Schließlich wurde mit Boc-Anhydrid zum Boc-L-HalG-OH 13 bzw. Boc-D-HalG-OH ent-13 geschützt (Abb. 3.13). 


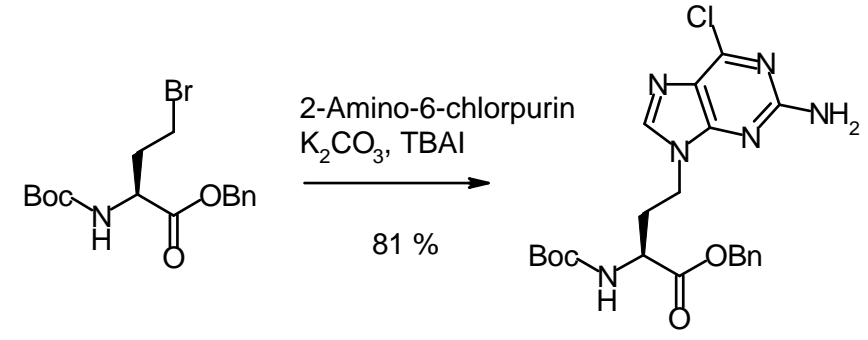

11

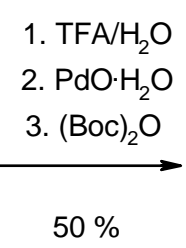<smiles>CC(C)(C)OC(=O)NC(CCn1cnc2c(=O)[nH]c(N)nc21)C(=O)O</smiles>

13

Abb. 3.13: Schematische Synthese von $N$-tert-Butoxycarbonyl- $y$-(9-guaninyl)-homoalanin 13

Die Schützung des Cytosins sowie das Nichtschützen des Guanins wurden bei der Synthese der Alanyl-Nukleoaminosäuren erläutert. Da der Erhalt der Benzyloxycarbonyl-Schutzgruppe der Cytosinbase erwünscht war, konnte hier keine hydrogenolytische Spaltung der Benzylgruppe erfolgen. Es wurde daher eine basische Verseifung mit $\mathrm{NaOH} / \mathrm{Dioxan} / \mathrm{H}_{2} \mathrm{O}$ durchgeführt (Abb. 3.14).<smiles>C[C@@H](C(=O)OCc1ccccc1)C(C)(C)C</smiles>

11
14<smiles>CC(C)(C)OC(=O)NC(CCn1ccc(NC(=O)OCc2ccccc2)nc1=O)C(=O)O</smiles>

15

Abb. 3.14: Darstellung von $N$-tert-Butoxycarbonyl- $\gamma$-(N-4-benzyloxycarbonyl-1-cytosinyl)-homoalanylbenzylester 15 


\subsection{Der Stilben-Linker}

Die Synthese des Stilben-Linkers 2 wurde ausgehend von Dimethyl-trans-stilben4,4'-dicarboxylat 16 (Abb. 3.15) gestartet. Nach dem ersten Reaktionsschritt wurde das Verseifungsprodukt 4,4'-trans-Stilbendicarboxylat 17 erhalten. Nachfolgende Chlorierung mittels Thionylchlorid und DMF führte quantitativ zum Säurechlorid und wurde ohne weitere Aufarbeitung weiter umgesetzt. Im nächsten Reaktionsschritt wurde das aktivierte Säurechlorid-Derivat 18 mit N-Boc-Ethylendiamin und Glycinmethylester versetzt (Abb. 3.15). Abhängig von der Reihenfolge der Zugabe kam es zu Produkt-Gemischen. Wurde das N-Boc-Ethylendiamin zuerst zur Reaktionsmischung gegeben, konnte als Nebenprodukt ein Stilben-Derivat 19 identifiziert werden, das an beiden para-Enden die Boc-geschützte Diaminoethyleneinheit aufwies. Im umgekehrten Fall, d.h. bei Zugabe von Glycinmethylester als erstes Reagenz, wurde neben dem gewünschten ein weiteres Produkt 20 erhalten, das an beiden para-Enden einen Diaminmethylester aufwies. Trotz zusätzlicher Methyleneinheit im 4,4'-trans-Stilben-(tert-butoxycarbonyl)-aminoethylcarbamoyl 19 könnte diese Verbindung als Linker fungieren, da der Abstand von $15.89 \AA$ für die imitierte Basenpaarung auf jeden Fall eingehalten wird (siehe Abb. 3.10). Nach erfolgter Trennung der Stilbenderivate würde eine Verseifung zum gewünschten trans-Stilben4-(carbonsäure-methylcarbamoyl)-4'-(tert-butoxycarbonyl)-aminoethylcarbamoyl 2 erfolgen. Die Synthese erwies sich als schwierig, da es zu starken Löslichkeitsproblemen kam. Die Reaktionen wurden alle in Suspensionen durchgeführt, was die Ausbeute beträchtlich beeinträchtigte. Außerdem konnte keine Trennung der einzelnen Derivate erreicht werden. 
<smiles>COC(=O)c1ccc(/C=C/c2ccc(C(=O)OC)cc2)cc1</smiles>

16

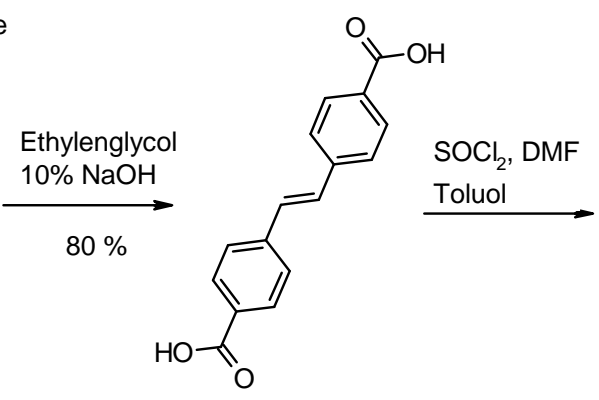

17<smiles>O=C(Cl)c1ccc(/C=C/c2ccc(C(=O)Cl)cc2)cc1</smiles>

18
1. N-Boc-Ethylendiamin, $\mathrm{NEt}_{3}, \mathrm{MeOH}$

2. Glycinmethylester, $\mathrm{NEt}_{3}, \mathrm{MeOH}$, THF
1. Glycinmethylester, $\mathrm{NEt}_{3}, \mathrm{MeOH}$

2. N-Boc-Ethylendiamin, $\mathrm{NEt}_{3}, \mathrm{MeOH}$, THF<smiles>COC(=O)CNC(=O)c1ccc(/C=C/c2ccc(C(=O)NCCNC(=O)OC(C)(C)C)cc2)cc1</smiles>

19<smiles>COC(=O)CNC(=O)c1ccc(/C=C/c2ccc(C(=O)NCC(=O)NCC(=O)c3ccc(/C=C/c4ccc(C(=O)NCCNC(=O)OC(C)(C)C)cc4)cc3)cc2)cc1</smiles>

20

$2^{\prime}$

Abb. 3.15: Synthese der Stilben-Linker trans-Stilben-4-(methylcarbonsäure-methylcarbamoyl)-4'-(tertbutoxycarbonyl)-aminoethylcarbamoyl) 2'， 4,4'-trans-Stilben-(tert-butoxycarbonyl)-aminoethylcarbamoyl 19 und 4,4'-trans-Stilben-(methylcarbonsäure-methylcarbamoyl)-aminoethylcarbamoyl 20 


\subsection{Synthese von PNA-Doppelsträngen mit verbrückendem Hegas-Linker}

Alternierend konfigurierte gemischte PNA-Sequenzen aus Alanyl- und HomoalanylNukleoaminosäuren wurden an fester Phase synthetisiert. Die Darstellung der Oligomere erfolgte manuell gemäß Peptid Festphasensynthese von Merrifield nach BocStrategie. ${ }^{[114,115]}$ Diese Strategie wurde gewählt, da Boc-geschützte Nukleoaminosäuren eine bessere Löslichkeit als Fmoc-geschützte aufweisen. Als feste Phase diente das mit Boc-L-Lys(2-Cl-Z)-OH belegte kommerziell erhältliche MBHA-PS-Harz (4-Methylbenzylhydrylamin-Polystyrol-Harz) mit $1 \%$ Divinylbenzol-Quervernetzung des Polystyrols (Abb. 3.16).

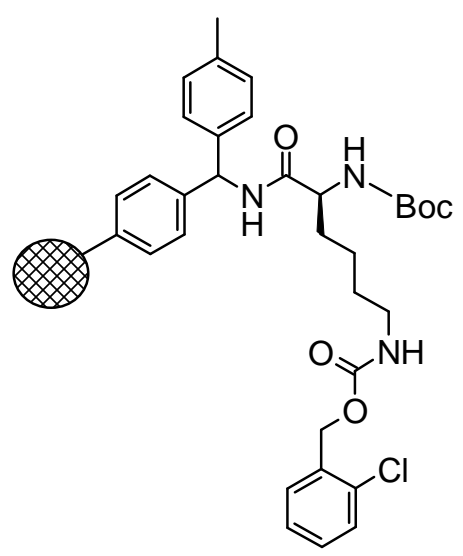

Abb. 3.16: MBHA-PS-Harz belegt mit Boc-L-Lys(2-Cl-Z)-OH

Das endständige Lysinamid diente hier der Erhöhung der Oligomer-Löslichkeit. ${ }^{[98}$ Zur Aktivierung der Nukleoaminosäuren wurden HATU ( $N$-(7-Aza-1H-benzotriazol-1-yl)1,1,3,3-tetramethyluroniumhexafluorophosphat) 21 und HOAt (7-Aza-1-hydroxybenzotriazol) 22 gewählt (Abb. 3.17). Als Aktivierungsreagenz bietet HATU die Vorteile einer hohen Kupplungsgeschwindigkeit, sehr guter Ausbeute und geringer Racemisierung bei sterisch anspruchsvollen Synthesen. ${ }^{[116,117,118]}$ 
<smiles>On1nnc2cccnc21</smiles>

21<smiles>CN(C)C(n1n[n+]([O-])c2ncccc21)=[N+](C)C</smiles>

22

Abb. 3.17: Aktivierungsreagenzien; links: HOAt (7-Aza-1-hydroxybenzotriazol) 21; rechts: HATU (O(7-Azabenzotriazol-1-yl)-1,1,3,3-tetramethyluroniumhexafluorphosphat) 22

Vor Beginn der Synthese (Abb. 3.18) musste das Harz mindestens zwei Stunden in DCM/NMP quellen. Im ersten Schritt wurde jeweils die temporäre N-terminale BocSchutzgruppe durch Zugabe von TFA/m-Kresol (95:5) entfernt. $m$-Kresol diente als scavenger und fing das tert-Butylkation ab. Nach der Entschützung wurde mit DCM/NMP gewaschen und mit Pyridin gespült. Das Spülen mit Pyridin ist zum einen wichtig, um die Säurereste der Entschützung zu neutralisieren, die bei der Kupplung stören. Zum anderen werden die Basenpaare entstapelt, um deren Aggregationen zu verhindern.

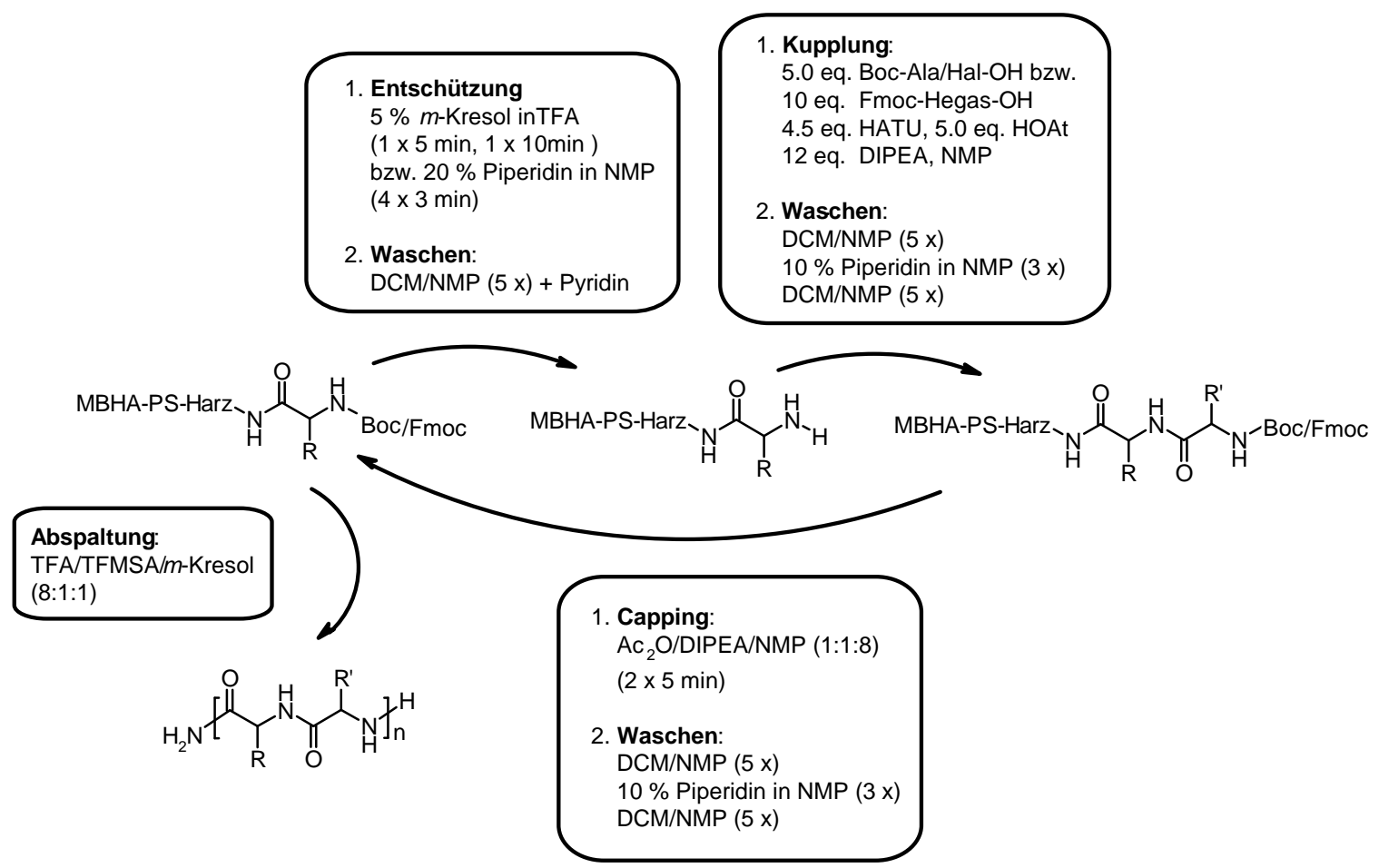

Abb. 3.18: Syntheseprotokoll für die Festphasensynthese der Alanyl- bzw. Homoalanyl-PNAs sowie Einführung des Linkers; R, R' = Nukleoaminosäurerest 
Im nächsten Schritt wurden die Kupplungsreagenzien HATU 22 und HOAt 21 (Abb. 3.18) sowie die einzuführende Boc-geschützte Aminosäure im fünffachen Überschuss trocken zu dem Harz gegeben. Nach Lösen in NMP wurde nach drei Minuten die Base DIPEA zugegeben. Die Alanyl- und Homoalanyl-Nukleoaminosäuren mit der Nukleobase Guanin wurden zwei Stunden der Kupplungsreaktion unterzogen, die der Nukleobase Cytosin eine Stunde. Die Bildung des Aktivesters mit HATU 22 und HOAt 21 konnte anhand einer Farbveränderung der Lösung zu gelb beobachtet werden. Bei Zugabe des Aktivierungsreagenzes HATU 22 musste darauf geachtet werden, dass es nicht im Überschuss eingesetzt wurde, damit die Uroniumgruppe die Aminofunktion nicht deaktivierte. Nach der Kupplung wurde mit DCM/NMP, 10 \%iger Piperidin-Lösung in NMP und DCM/NMP gewaschen, um weitere Verunreinigungen vom Harz zu spülen. Der letzte Schritt des Synthesezyklusses ist der Capping-Schritt. Um die Bildung nicht erwünschter Peptide vorzubeugen, wurden die freien Aminogruppen mit einer Lösung von $\mathrm{Ac}_{2} \mathrm{O} / \mathrm{DIPEA} / \mathrm{NMP}$ $(1: 1: 8)$ acetyliert. Der Synthesezyklus (Abb. 3.18) wurde bis zur gewünschten Kettenlänge wiederholt.

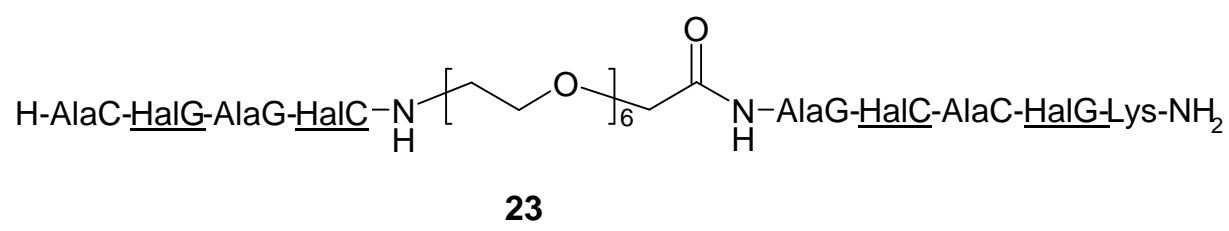

Abb. 3.19: H-AlaC- $\underline{\mathrm{HalG}}-\mathrm{AlaG}-\underline{\mathrm{HalC}}-[20-A m i n o-3,6,9,12,15,18$-hexaoxaeicosansäre)]-AlaG-HalC-AlaC

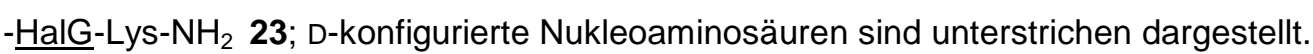

Im Falle des zu synthetisierenden Tetramer-Doppelstranges H-AlaC-HalG-AlaGHalC-Linker-AlaG-HalC-AlaC-HalG-Lys- $\mathrm{NH}_{2} 23$ (Abb. 3.19) wurde bis zur Nukleoaminosäure AlaG gekuppelt, im Fall des Hexamer-Oligomers H-AlaC-HalC-AlaGHalC-AlaG- $\underline{\text { HalG}}-$ Linker-AlaC-HalC-AlaG- $\underline{\text { HalC}}-\mathrm{AlaG}-\underline{H a l G}-\mathrm{Lys}-\mathrm{NH}_{2} 24$ (Abb. 3.20) bis zur Nukleoaminosäure AlaC. 


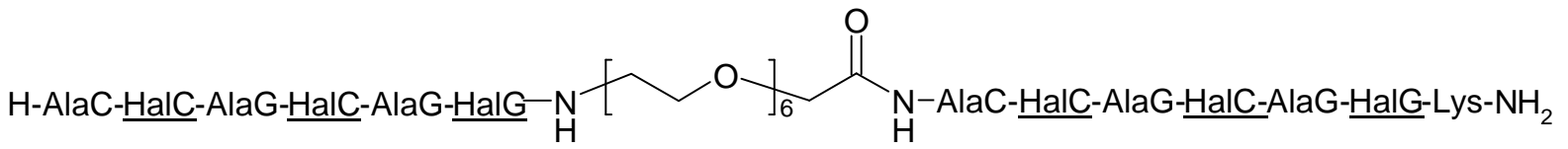
24

Abb. 3.20: $\quad$ H-AlaC- $\underline{\text { HalC}}-A l a G-\underline{H a l C}-A l a G-\underline{H a l G}-[20-A m i n o-3,6,9,12,15,18$-hexaoxaeicosansäure)]AlaC- $\underline{\text { HalC}}-\mathrm{AlaG}-\underline{\mathrm{HalC}}-\mathrm{AlaG}-\underline{\mathrm{HalG}}-\mathrm{Lys}-\mathrm{NH}_{2}$ 24; D-konfigurierte Nukleoaminosäuren sind unterstrichen dargestellt.

Der einzuführende Linker Fmoc-Hexaethylenglycolaminosäure 1 (Abb. 3.7 ${ }^{[119]}$, nachfolgend als Fmoc-Hegas-OH abgekürzt, wurde im zehnfachen Überschuss in das System eingeführt (Abb. 3.4, Schritte 1 bis 3). HATU 22 und HOAt 21 wurden hier ebenfalls zur Bildung des Aktivesters verwendet. Nach zwei Stunden Kupplung wurde gewaschen und die Fmoc-Schutzgruppe mit 20 \%iger Piperidin-Lösung in NMP abgespalten. Weitere Schritte wurden durchgeführt (Abb. 3.18). Nachdem alle erforderlichen Nukleoaminosäuren gekuppelt waren, wurde das fertige Peptid mit einer Mischung aus TFMSA/m-Kresol/TFA (1:1:8) vom Harz abgespalten. Die Oligomere wurden mit eisgekühltem tert-Butylmethylether ausgefällt, mittels HPLC-Chromatographie gereinigt und durch Elektrospray lonisation-Massenspektrometrie (ESIMS) charakterisiert. Bei der Reinigung per HPLC zeigte sich kein scharfes Elutionsprofil. Die Produktpeaks waren stark verbreitet.

\subsection{Spektroskopische Untersuchungen}

Mittels temperaturabhängiger UV-Spektroskopie wurden die Paarungskomplexe linkerverbrückter Alanyl/Homoalanyl-PNA Stränge untersucht. Die UV-Messungen geben Auskunft über die Stabilität der zu untersuchenden Komplexe und wurden im Bereich von 250 bis $280 \mathrm{~nm}$ durchgeführt. Dieser Wellenlängenbereich ist typisch für die elektronischen Übergänge der Pyrimidin- und Purinbasen, wobei das Absorptionsmaximum etwa bei $260 \mathrm{~nm}$ liegt. Das Rückgrat absorbiert in dieser Region nicht. Mit Hilfe der molaren Extinktionskoeffizieten $\varepsilon_{\text {mol }}$ kann über das LambertBeer'sche Gesetz $\left(\Delta \mathrm{E}=\varepsilon_{\mathrm{mol}} \cdot c \cdot d\right)$ die Konzentration $(c)$ der Oligopeptide ermittelt werden. Während der temperaturabhängigen Messung kommt es mit steigender Temperatur zum Schmelzen des Paarungskomplexes, was aufgrund der Entstapelung der Basenpaare mit einem Anstieg der Absorption einhergeht. Die nor- 
mierte Absorptionszunahme $\mathrm{H} \%$ wird gegen die Temperatur $\mathrm{T}$ aufgetragen. Der sigmoide Verlauf, die Schmelztemperatur $\mathrm{T}_{\mathrm{m}}$, d.h. 50 \% der maximalen Absorptionszunahme, und die Höhe der Hyperchromizität der resultierenden Schmelzkurve werden als $\mathrm{Maß}$ für die Paarungsstabilität und den Aggregationsgrad herangezogen. Vorteil dieser Spektroskopie ist die einfache und schnelle Handhabung sowie die Verwendung von nur geringen Substanzmengen. Temperaturabhängige UVMessungen wurden in dieser Arbeit in folgenden Lösungen gemessen: $10 \mathrm{~mm}$ Tris.HCl-Puffer $\mathrm{pH}$ 7, $10 \mathrm{~mm}$ Phosphat $\left(\mathrm{NaH}_{2} \mathrm{PO}_{4} / \mathrm{Na}_{2} \mathrm{HPO}_{4}\right)-\mathrm{Puffer} \mathrm{pH} 7$ und $\mathrm{MeOH}$. Die besten Ergebnisse wurden in Phosphat-Puffer erhalten. Die UV-Messung von H-AlaC- $\underline{\mathrm{HalG}}-\mathrm{AlaG}-\underline{\mathrm{HalC}}-[\mathrm{Hegas}]-\mathrm{AlaG}-\underline{\mathrm{HalC}}-\mathrm{AlaC}-\underline{\mathrm{HalG}}-\mathrm{Lys}-\mathrm{NH}_{2} 23$ ergab eine Schmelztemperatur von $\mathrm{T}_{\mathrm{m}}=1^{\circ} \mathrm{C}$ (Anhang, Abb. 8.1), wohingegen das Hexamer $\mathrm{H}$ AlaC- $\underline{\text { HalC}}-A l a G-\underline{H a l C}-A l a G-\underline{H a l G}-[H e g a s]-A l a C-\underline{H a l C}-A l a G-\underline{H a l C}-A l a G-\underline{H a l G}-L y s-$

$\mathrm{NH}_{2} 24$ eine Schmelztemperatur von $\mathrm{T}_{m}=25^{\circ} \mathrm{C}$ aufwies (Abb. 3.21). Die niedrige Stabilität des Tetramers rührt daher, dass Tetramere instabiler als Hexamere sind, da sie weniger Wasserstoffbrücken ausbilden können und aufgrund der geringeren Nukleobasenanzahl der Stapelungsbeitrag reduziert ist. ${ }^{[1]}$

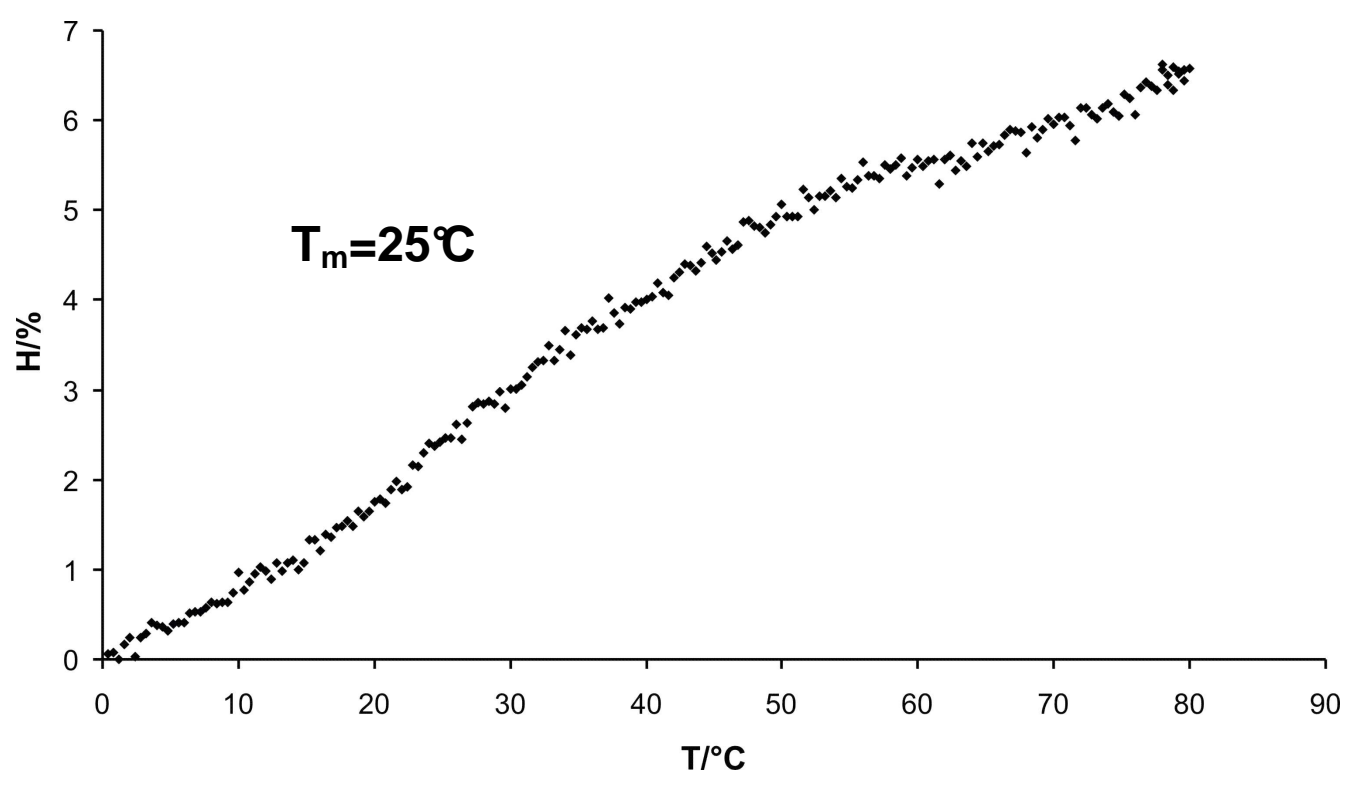

Abb. 3.21: UV-Spektrum von H-AlaC- $\underline{\mathrm{HalC}}-\mathrm{AlaG}-\underline{\mathrm{HalC}}-\mathrm{AlaG}-\underline{\mathrm{HalG}}-[\mathrm{Hegas}]-\mathrm{AlaC}-\underline{\mathrm{HalC}}-\mathrm{AlaG}-\underline{\mathrm{HalC}}-$ AlaG-HalG-Lys- $\mathrm{NH}_{2} 24 ; \mathrm{c}=12 \mu \mathrm{M}, 10 \mathrm{~mm}$ Phosphatpuffer $\left(\mathrm{NaH}_{2} \mathrm{PO}_{4} / \mathrm{Na}_{2} \mathrm{HPO}_{4}\right) \mathrm{pH} 7 ; \lambda=260 \mathrm{~nm}$ 
Messungen der Hexamere ohne kovalente Verknüpfung, d.h. Selbstpaarungen von $\mathrm{H}$-AlaG- $\underline{\mathrm{HalG}}-\mathrm{AlaC}-\underline{\mathrm{HalG}}-\mathrm{AlaC}-\underline{\mathrm{HalC}}-\mathrm{Lsy}-\mathrm{NH}_{2}$ 25, zeigen eine wesentlich höhere Schmelztemperatur von $52^{\circ} \mathrm{C} .{ }^{[120,121]}$

Auch das Tetramer H-AlaC- $\underline{\mathrm{HalG}}-\mathrm{AlaG}-\underline{\mathrm{HalC}}-[\mathrm{Hegas}]-\mathrm{AlaG}-\underline{\mathrm{HalC}}-\mathrm{AlaC}-\underline{\mathrm{HalG}}-\mathrm{Lys}-\mathrm{NH}_{2}$ 23 zeigt eine niedrigere Stabilität im Vergleich zur Selbstpaarung eines Alanyl-Oligomers ohne kovalente Verknüpfung. H-AlaG-AlaC-AlaG-AlaC-Lys- $\mathrm{NH}_{2}(\mathrm{c}=12 \mu \mathrm{M}) 26$ weist eine Schmelztemperatur von $T_{m}=12^{\circ} \mathrm{C}$ auf. ${ }^{[13 a]}$ Die Schmelztemperatur von $\mathrm{H}$ AlaC- $\underline{\text { HalG}}-A l a G-\underline{H a l C}-[H e g a s]-A l a G-\underline{H a l C}-A l a C-\underline{H a l G}-L y s-N_{2} \quad 23 \quad\left(T_{m}=18{ }^{\circ} \mathrm{C}\right)$ ist zwar höher, aber bei dem Vergleichspeptid H-AlaG-AlaC-AlaG-AlaC-Lys- $\mathrm{NH}_{2} 26$ erfolgt die Paarung im reverse Watson-Crick Modus (siehe Kap. 2.1). Im Allgemeinen weist die Paarung reiner Alanyl-PNA eine höhere Stabilität auf, als die der Homoalanyl/Alanyl-PNA, da die Nukleobasen aufgrund der Seitenkettenlänge (Methylen statt Ethylen) geringere konformationelle Freiheit aufweisen (siehe Tab. 3.1 und Abb. 3.2).

Bei beiden Oligomeren mit Linkern (Tetramer 23 wie Hexamer 24) wurden nach UVspektroskopischen Messungen geringere Stabilitäten bestimmt als erwartet. Der PNA-Doppelstrang wird somit durch den Glycol-Linker nicht stabilisiert, da dieser offensichtlich geometrisch einen ungünstigen Einfluß induziert. 


\section{Helikale $\alpha$-Peptide mit Nukleobasen als Erkennungs- einheit in der Seitenkette}

Ein weiteres Arbeitsgebiet stellt die Untersuchung von Wechselwirkungen proteinogener Aminosäuren mit Homoalanyl-Nukleobasen sowie von Nukleobasenpaarungen dar. Die Stabilität von $\alpha$-Helices gehört zu einer der wichtigsten Voraussetzungen für definierte Strukturen in Proteinen. ${ }^{[2,54]}$ Diese Stabilität ist wesentlich für die Ausbildung von coiled coil-Strukturen (siehe Kap. 2.3.3). ${ }^{[67,68]}$ Bisherige Arbeiten von H. Mihara (siehe Kap. 2.3.6) beschäftigten sich mit dem Einbau von Nukleoaminosäuren in $\alpha$-Helices. Hierbei wurden die Nukleobasen in Position $g$ und e des helical wheels (Kap. 2.3.2) eingebaut. ${ }^{[77,78]}$

In dieser Arbeit sollte überprüft werden, ob der Einbau von Nukleoaminosäuren in Position a und $d$ durch komplementäre Basenpaar-Wechselwirkungen zur Erkennung von $\alpha$-Helices führt. Die Nukleoaminosäuren wurden als Erkennungseinheit in $\alpha$ Peptidhelices inkorporiert und sollten der intermolekularen Erkennung zwischen den Peptidsträngen dienen. Die proteinogenen Aminosäuren und Nukleoaminosäuren wurden so gewählt, dass sich eine $\alpha$-Helix-Struktur aufbauen konnte.

Es wurden ausschließlich die Nukleobasen Guanin und Cytosin verwendet, da diese im Watson-Crick Modus drei Wasserstoffbrückenbindungen bilden und somit zu stabileren Komplexe führen als ihre Adenin/Thymin-Analoga (siehe Kap. 2.1). Die Lkonfigurierten Nukleoaminosäuren $\gamma$-(9-Guaninyl)-homoalanin (HalG) 13 und $\gamma$-(1Cytosinyl)-homoalanin (HalC) 15 wurden in Position a und $d$ der 21 mer-Sequenz AcA-HalC-AK-HalC-AKA-HalG-KA-HalC-AEA-HalG-AK-HalG-AK-NH 27 und der 15mer-Sequenzen Ac-KA-HalG-KA-HalC-AEA-HalG-AK-HalC-AK-NH 28 und AcKA-HalC-KA-HalC-AEA-HalG-AK-HalG-AK-NH 22 eingebaut (Abb. 4.1, 4.2, 4.3; Theorie siehe Kap. 2.3.2). 


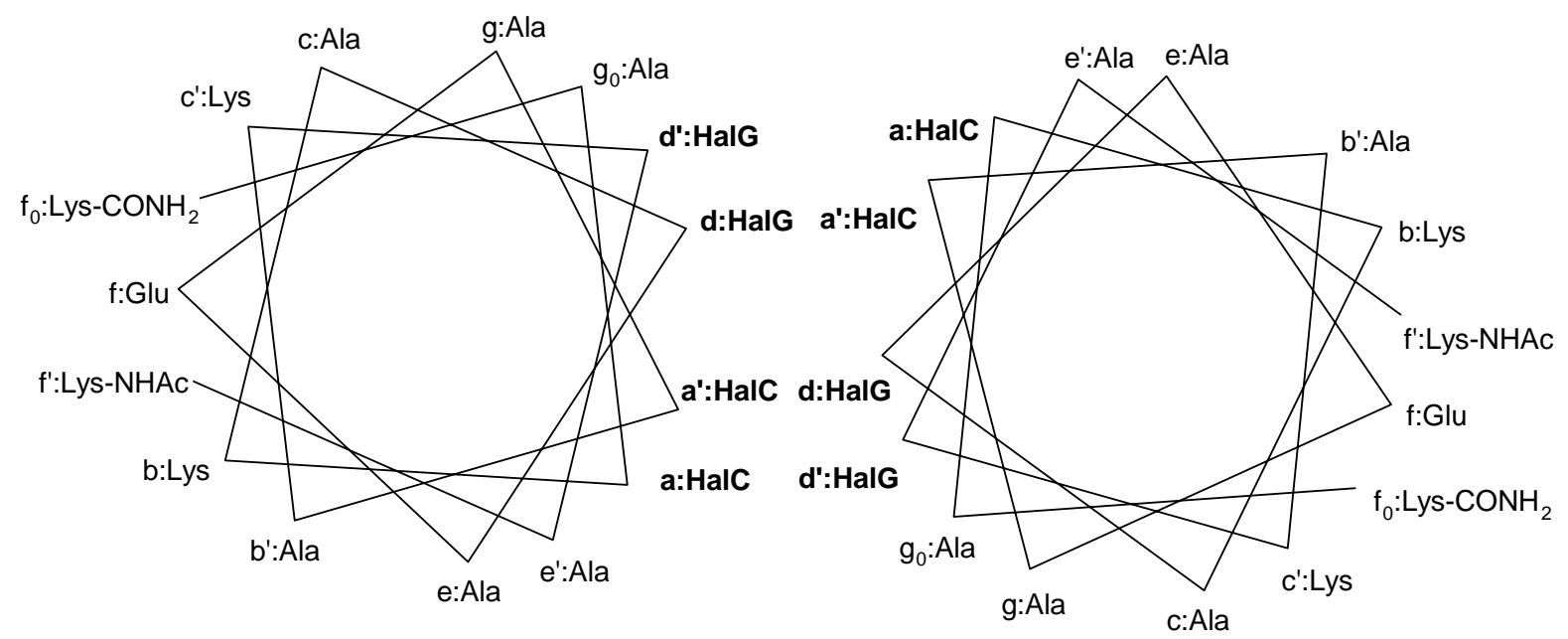

Abb. 4.1: Helical wheel-Darstellung der 15mer-Sequenz Ac-KA-HalG-KA-HalC-AEA-HalG-KA-HalCAK-NH ${ }_{2}$ 28; a,a' = HalC; b,b' = Lys,Ala; c,c' = Ala,Lys; d,d' = HalG; e,e' = Ala; $f_{0}, f^{\prime}, f^{\prime}=$ Lys,Glu,Lys; $\mathrm{g}_{0}, \mathrm{~g}=\mathrm{Ala} ; \mathrm{Ac}=$ Acetylgruppe

In den Positionen $a$ und $d$ befinden sich vorwiegend apolare Aminosäuren, wie Leucin, die hydrophobe Wechselwirkungen hervorrufen. Durch die hier eingesetzten Nukleoaminosäuren werden die Helix-Helix-Wechselwirkungen verstärkt. Werden geladene Aminosäuren in den interhelikalen Positionen $e$ und $g$ eingebaut, können inter- oder intrahelikale elektrostatische Wechselwirkungen hervorgerufen werden. Um diese zu verhindern, wurden in den hier synthetisierten Peptiden an den Positionen $e$ und $g$ ausschließlich Alanine verwendet. An die Position $b$ und $c$ wurden ebenfalls Alanine inkorporiert. In den Positionen $b, c$ und $f$ wurden Lysine verwendet, während für Position f'Glutaminsäure gewählt wurde. 

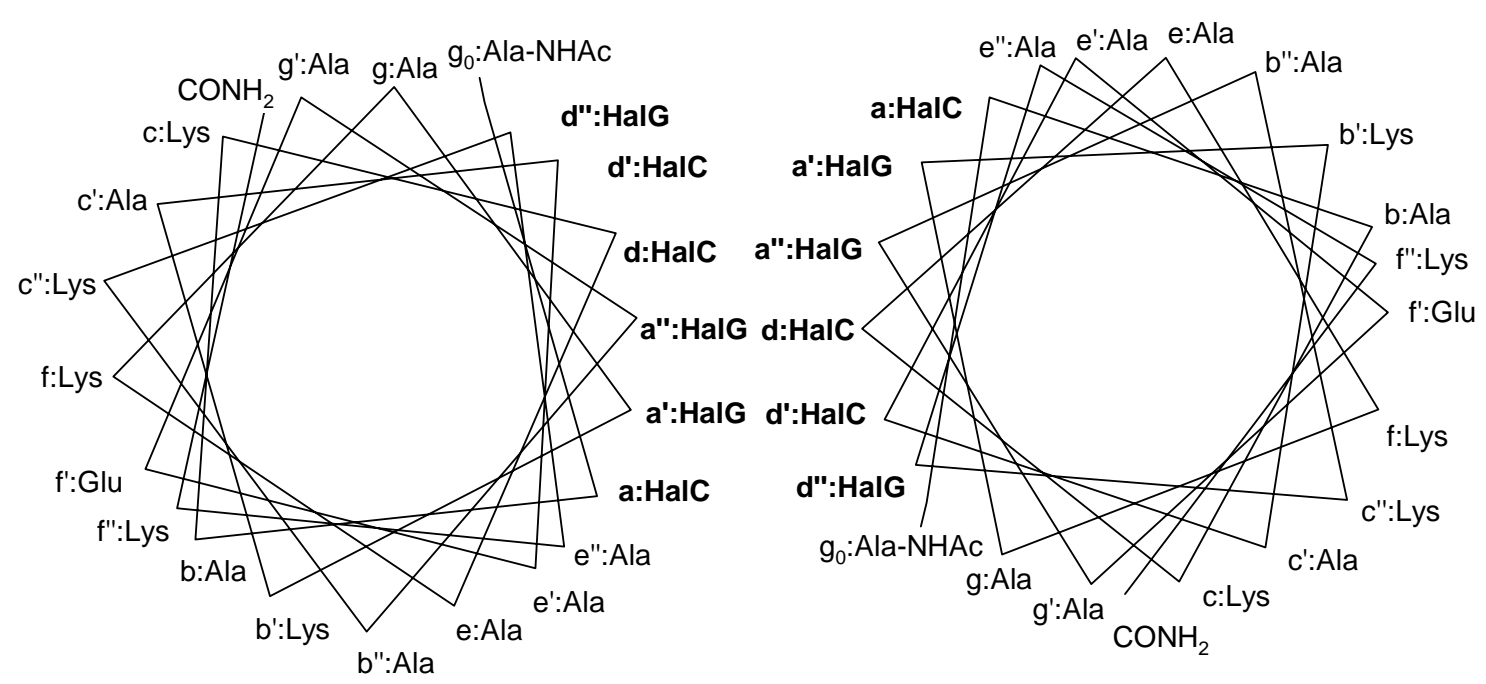

Abb. 4.2: Helical wheel-Darstellung der 21mer-Sequenz Ac-A-HalC-AK-HalC-AKA-HalG-KA-HalCAEA-HalG-AK-HalG-AK-NH 2 27; a,a',a" = HalC,HalG,HalG, b,b',b" = Ala,Lys,Ala; c,c',c" = Lys,Ala, Lys; d,d',d"' = HalC,HalC,HalG; e,e',e" =Ala; f,f',f" = Lys,Glu,Lys; go,g,g' = Ala; Ac = Acetylgruppe

Die Verwendung von Lysin diente einerseits zur Verbesserung der Löslichkeit und andererseits, um eine gewisse Stabilität durch das Ausbilden einer Lysin-Glutaminsäure-Lysin-Salzbrücke hervorzurufen. Die saure Aminosäure Glutaminsäure (Position $f$ ) hat im Vergleich zur Asparaginsäure den Vorteil, dass sie ein stärkerer Helixbildner ist.

Die Peptidsynthese wurde an fester Phase an einem Amid-Harz durchgeführt und am Ende der Synthese wurde das Oligomer acetylisiert, so dass nach Abspaltung der C-Terminus als Amid und der N-Terminus acyliert vorlag. Auf diese Weise konnten Helix-Dipol-Wechselwirkungen reduziert werden und eine ausschließliche Erkennung über die Nukleobasenpaarung untersucht werden. Es wurden 15mer- und 21 mer-Sequenzen dargestellt, wobei die größere Bedeutung dem 21mer-Peptid zukommt, da nach dem helical wheel erst die 18. Aminosäure mit der ersten ekliptisch übereinander zu liegen kommt (Kap. 2.3.2). 


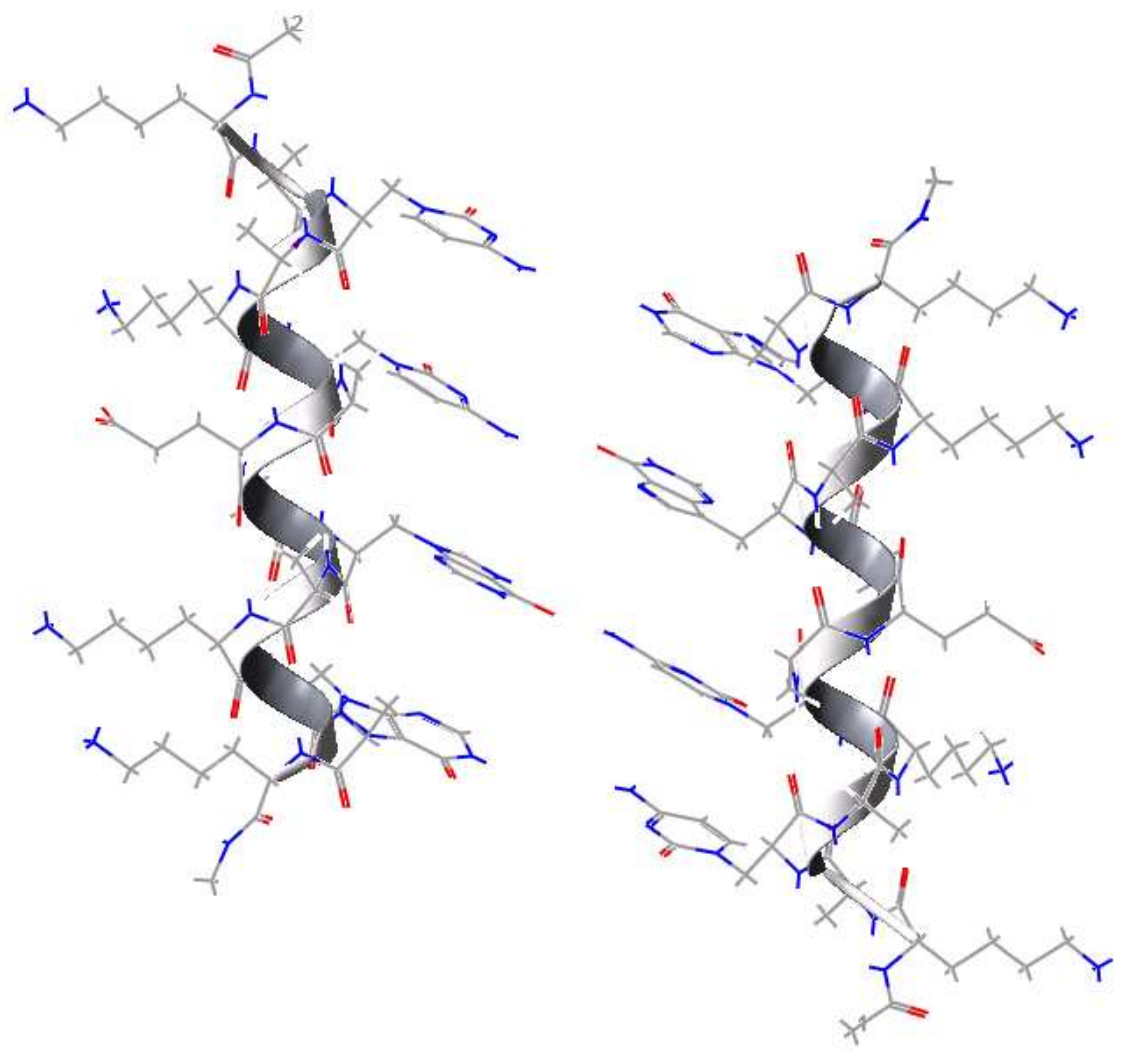

Abb. 4.3: Modell des 15mer-Oligomers Ac-KA-HalC-KA-HalC-AEA-HalG-AK-HalG-AK-NH 29 $\left(\right.$ MacroModel $^{\circledR}$ )

Für die Peptidsynthesen der Oligomere mit Homoalanyl-Nukleoaminosäuren sowie die der Testpeptide wurden vier unterschiedliche Methoden angewandt:

1. manuelle Boc-Peptidfestphasen-Strategie,

2. manuelle Fmoc-Peptidfestphasen-Strategie,

3. automatisierte Fmoc-Peptidfestphasen-Strategie

4. manuelle Boc-Thioligations-Strategie.

In Vorversuchen wurden zunächst Testpeptide mit ausschließlich natürlichen Aminosäuren hergestellt. Statt $\gamma$-(9-Guaninyl)-homoalanin (HalG) 13 wurde Tryptophan und anstelle von $\gamma$-(1-Cytosinyl)-homoalanin (HalC) 15 Tyrosin verwendet, da diese den Nukleoaminosäuren strukturell am ähnlichsten sind. 


\subsection{Synthese $\alpha$-helikaler Peptide nach Boc-Festphasen-Strategie}

Das Prinzip der Boc-Festphasensynthese wurde im Wesentlichen in Kap. 3.3 erläutert. Doch im Unterschied zum vorherigen Kapitel sollen nicht nur Kupplungen unnatürlicher Aminosäuren behandelt werden. Natürliche Aminosäuren haben den Vorteil, dass sie sich besser lösen und dass die hier verwendeten Aminosäuren leichter aktivierbar sind, weshalb andere Kupplungsreagenzien verwendet werden konnten. Als Kupplungsreagenzien wurden für die Aminosäuren HBTU $(N-(1 H$-Benzotriazol-1yl)-1,1,3,3-tetramethyluronium-hexafluorophosphat) 30 und HOBt (1-Hydroxybenzotriazol) 31 eingesetzt (Abb. 4.4). Die Homoalanyl-Nukleoaminosäuren wurden mit HATU und HOAt aktiviert. Als feste Phase wurde das ebenfalls in Kap. 3.3 erwähnte MBHA-PS-Harz, belegt mit Boc-L-Lys(2-Cl-Z)-OH, verwendet.<smiles>On1nnc2ccccc21</smiles>

31<smiles>CN(C)C(n1n[n+]([O-])c2ccccc21)=[N+](C)C</smiles>

30

Abb. 4.4: Aktivierungsreagenzien; links: HOBt (1-Hydroxybenzotriazol) 31 ; rechts: HBTU $(\mathrm{N}-(1 \mathrm{H}-$ Benzotriazol-1-yl)-1,1,3,3-tetramethyluronium-hexafluorophosphat) 30

In ersten Versuchen wurden die Aminosäuren sowie Nukleoaminosäuren in der Peptidfestphasen Synthese wie folgt behandelt: ${ }^{[122]}$

Entschützung: $\quad 5 \% \mathrm{~m}$-Kresol in TFA $(1 \times 5 \mathrm{~min}, 1 \times 10 \mathrm{~min})$

Waschen: $\operatorname{DCM}(5 \mathrm{x}), i-\mathrm{PrOH}(5 \mathrm{x}), \mathrm{DCM} / \mathrm{DMF}(5 \mathrm{x})$

Neutralisation: $\quad 80 \%$ Triethylamin in DCM $(2 \times 5$ min $)$

Waschen: DCM (3 x), i-PrOH (3 x), DCM/DMF (3 x), DMF (1 x)

Voraktivierung: $\quad$ Aminosäure(AS)/Nukleoaminosäure (5.0 eq.) + DMF + HBTU (4.5 eq.) + HOBt (5.0 eq.) + DIPEA (12 eq.)

Kupplung: 35 min-1.5 h (Doppelkupplung bei Trp ,Tyr und 1. AS)

Waschen: $\operatorname{DMF}(3 \mathrm{x}), i-\operatorname{PrOH}(3 \mathrm{x}), \operatorname{DCM}(3 \mathrm{x}), \mathrm{DCM} / \mathrm{DMF}(3 \mathrm{x})$

Capping: $\mathrm{Ac}_{2} \mathrm{O} / \mathrm{DIPEA} / \mathrm{DMF}(1: 1: 8)(2 \times 10 \mathrm{~min})$

Waschen: DCM (5 x), i-PrOH (5 x), DCM/DMF (5 x) 
Die Synthesen nach diesem Protokoll führten zu keinem Erfolg. Dagegen hat sich die Kupplungs-Methode der Nukleoaminosäuren, wie in Kap. 3.3 beschrieben (Abb. 4.5), bewährt. Wichtig war die Verwendung von NMP als Lösungsmittel sowie die Reaktionsdurchführung in einer kleinen Säule. Wurde nicht mit Pyridin gespült, gelang die Synthese weniger effektiv. Doppelkupplungen der ersten Aminosäure sowie die von Tryptophan und Tyrosin erwiesen sich als sinnvoll. Je nach Aminosäure wurde zwischen 35 Minuten und zwei Stunden gekuppelt.

Nach dieser Methode wurde zunächst das 15mer-Testpeptid AcKAWKAYAEAWAKYAK-NH 32 und anschließend die Nukleoaminosäuren-inkorporierten 15mer-Peptide Ac-KA-HalG-KA-HalC-AEA-HalG-AK-HalC-AK-NH 28 und AcKA-HalC-KA-HalC-AEA-HalG-AK-HalG-AK-NH 22 sowie das 21 mer-Peptid Ac-AHalC-AK-HalC-AKA-HalG-KA-HalC-AEA-HalG-AK-HalG-AK-NH 27 hergestellt. Die Schutzgruppen der Seitenketten wurden so gewählt, dass sie gleichzeitig mit der sauren Abspaltung vom Harz entfernt werden konnten. Für Lysin wurde die Seitenkette mit (2-Cl-Z), für Glutaminsäure mit $(\mathrm{OBn})$ und für Tyrosin mit (2-Br-Z)-Gruppe geschützt.

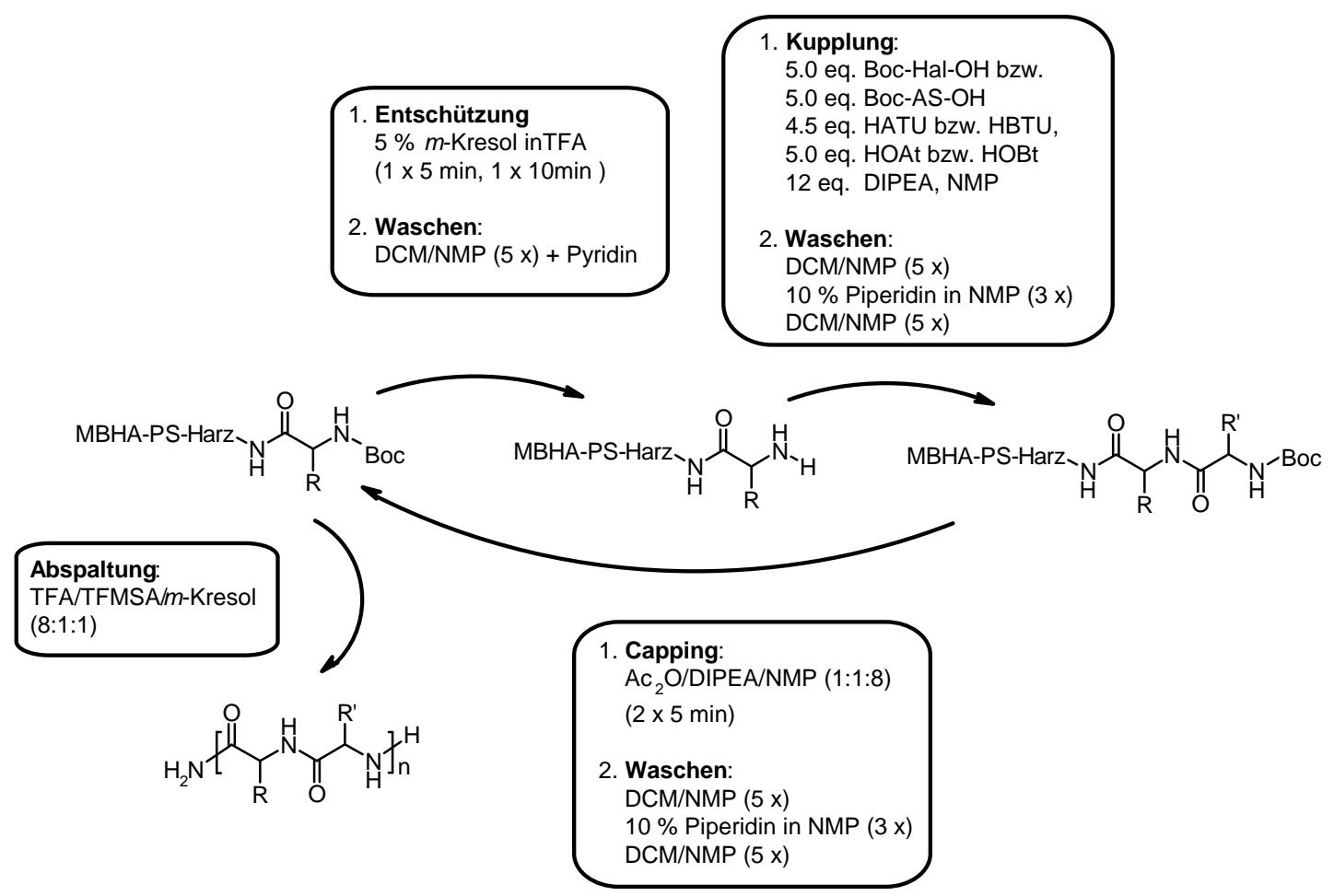

Abb. 4.5: Syntheseprotokoll für die Boc-Peptidfestphasen Synthese der gemischten Oligomere aus Homoalanyl-Nukleoaminosäuren und Aminosäuren; $A S$ = Aminosäure; R, R' = Aminosäurerest 


\subsection{Synthese $\alpha$-helikaler Peptide nach Fmoc-Festphasen-Strategie}

Da die Boc-Peptidfestphasen Synthese anfänglich Probleme bereitete, wurden die Boc-Nukleoaminosäuren zu Fmoc-Nukleoaminosäuren umgeschützt, da die FmocStrategie generell zu leichteren Kupplungen und höheren Kupplungsausbeuten führt. Außerdem erfolgte die HPLC-Aufreinigung der Peptide einfacher und die Testpeptide konnten ebenfalls automatisiert hergestellt werden. Dafür wurde die schlechtere Löslichkeit der Fmoc-Nukleoaminosäuren in Kauf genommen.

Nach der Fmoc-Methode wurden manuell das 15mer-Testpeptid AcKAWKAYAEAWAKYAK-NH ${ }_{2}$ 32, das modifizierte 15mer-Peptide Ac-KA-HalG-KAHalC-AEA-HalG-AK-HalC-AK-NH 28 sowie automatisiert das 21 mer-Testpeptid AcAYAKYAKAWKAYAEAWAKWAK- $\mathrm{NH}_{2} 33$ dargestellt.

Als feste Phase wurde für die manuelle sowie für die automatisierte Methode das Amidharz NovaSynTGR-Harz verwendet (Abb. 4.6). Als Seitenschutzgruppe wurde für Lysin (Boc), für Tryptophan (Boc) und für Glutaminsäure und Tyrosin (OtBu) verwendet, die mit der sauren Abspaltung vom Harz entfernt werden konnten. Die Synthese der Fmoc-geschützten Nukleoaminosäuren wird in Kap. 4.2.1 beschrieben.

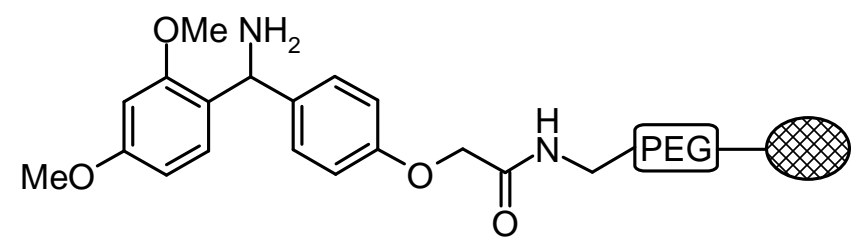

Abb. 4.6: Amidharz NovaSynTGR-Harz für die Fmoc-Peptidfestphasen Synthese

Nach zwei Stunden Quellen des Harzes in DCM/NMP wurden die Nukleoamino- bzw. Aminosäuren manuell nach dem Schema in Abb. 4.7 gekuppelt. Die Kupplungsreagenzien entsprachen bis auf einige Ausnahmen denender Boc-Strategie in Kap. 3.3. Die Doppelkupplung der ersten Aminosäure wurde mit DIC und HOBt $\mathbf{3 1}$ als Aktivierungsreagenzien für die erste Kupplung durchgeführt. Die zweite Kupplung erfolgte wie beschrieben mit HBTU $\mathbf{3 0}$ und HOBt 31. Für Tryptophan wurde eine Doppelkupplung durchgeführt. Die Entschützung verlief basisch mit $20 \%$ iger Piperidin-Lösung in NMP und die Kupplungszeiten variierten von 35 Minuten bis zu zwei Stunden. Die Kupplungszeiten der Fmoc-Nukleoaminosäuren waren analog zu 
denen der Boc-Nukleoaminosäuren (Kap. 3.3). Die Abspaltung vom Harz erfolgte mit einer Lösung von $\mathrm{H}_{2} \mathrm{O} / \mathrm{TIS} /$ Anisol/DTT/TFA (0.5:0.5:0.5:1:23).

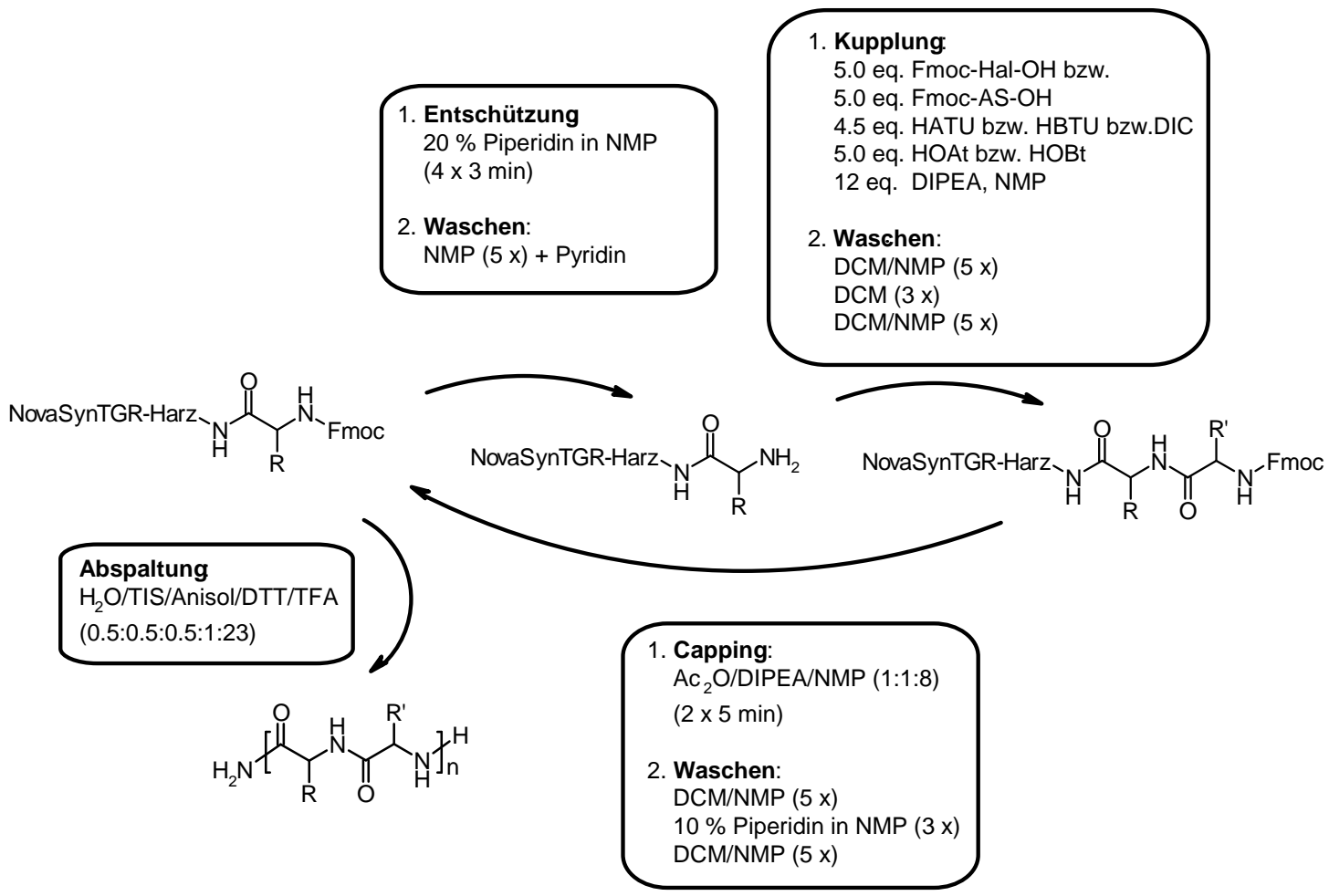

Abb. 4.7: Syntheseprotokoll für die manuelle Fmoc-Peptidfestphasen Synthese der gemischten Oligomere aus Homoalanyl-Nukleoaminosäuren und Aminosäuren; $A S=$ Aminosäure; R, R' = Aminosäurerest

\subsubsection{Synthese der Fmoc-Homoalanyl-Nukleoaminosäuren}

Die Verwendung der Fmoc-Schutzgruppe ermöglicht im Vergleich zur bisher etablierten Boc-Chemie ${ }^{[13 a, 16]}$ mildere und schnellere Entschützungs- und Kupplungsbedingungen. Die Synthese der Fmoc-geschützten Nukleoaminosäuren N-Fluorenylmethyloxycarbonyl- $y$-(9-guaninyl)-L-homoalanin $\quad$ (Fmoc-L-HalG-OH) 34 und $N$ Fluorenylmethyloxycarbonyl- $\gamma$-(4-benzyloxycarbonyl-1-cytosinyl)-L-homoalanin (Fmoc-L-HalC $\left.\mathrm{Z}_{\mathrm{Z}} \mathrm{OH}\right) 35$ erfolgte analog der Darstellung der entsprechenden Boc-geschützten Nukleoaminosäuren (Kap. 3.1). 12 wurde mit TFA/ $\mathrm{H}_{2} \mathrm{O}$ sauer hydrolisiert und nach Reduktion mittels $\mathrm{PdO} \cdot \mathrm{H}_{2} \mathrm{O}$ konnte L-HalG-OH 36 erhalten werden. 
<smiles>Nc1nc2c(ncn2CC[C@H](N)C(=O)O)c(=O)[nH]1</smiles>

36

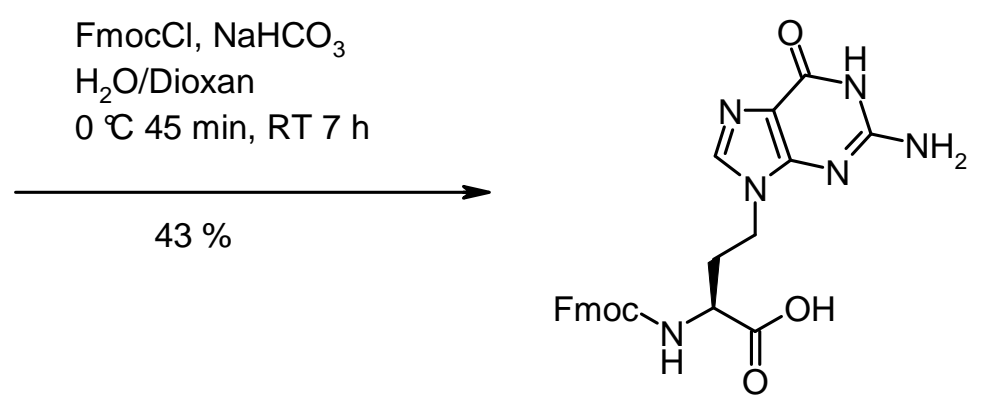

34<smiles>CC(C)(C)OC(=O)Nc1ccn(CCC(NC(=O)OC(C)(C)C)C(=O)O)c(=O)n1</smiles>

15

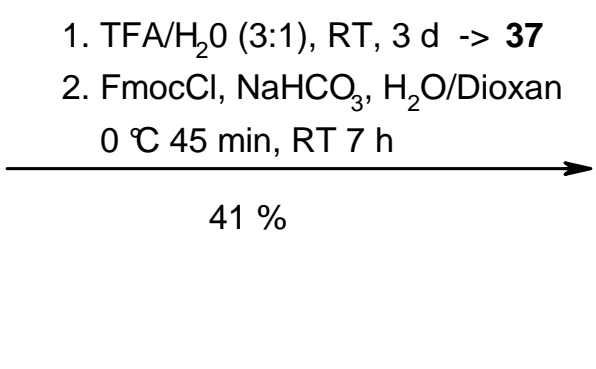

1. $\mathrm{TFA} / \mathrm{H}_{2} \mathrm{O}(3: 1), \mathrm{RT}, 3 \mathrm{~d}->\mathbf{3 7}$

FmocCl, $\mathrm{NaHCO}_{3}, \mathrm{H}_{2} \mathrm{O} /$ Dioxan

$41 \%$

35

Abb. 4.8: Darstellung von Fmoc-geschützen Homoalanyl-Nukleoaminosäuren; oben: $N$-Fluorenylmethyloxycarbonyl-y-(9-guaninyl)-L-homoalanin (Fmoc-L-HalG-OH) 34; unten: $\mathrm{N}$-Fluorenylmethyloxycarbonyl- $y$-(4-benzyloxycarbonyl-1-cytosinyl)-L-homoalanin (Fmoc-L-HalC $\left.\mathrm{Z}_{-} \mathrm{OH}\right) 35$

Unter Bedingungen nach Schotten-Baumann wurde L-HalG-OH 36 bzw. L-HalC $-\mathrm{OH}$ 37 mit Fluorenylmethyloxycarbonylchlorid $(\mathrm{FmocCl})$ und $\mathrm{NaHCO}_{3}$ als Base zu den Fmoc-geschützten Verbindungen 34 sowie 35 umgesetzt. ${ }^{[123]}$ Der Synthese von $\mathrm{N}$ Fluorenylmethyloxycarbonyl- $y$-(4-benzyloxycarbonyl-1-cytosinyl)-L-homoalanin (Fmoc-L-HalC $\left.\mathrm{Z}_{\mathrm{Z}} \mathrm{OH}\right) 35$ ging eine Entschützung von 15 mittels $\mathrm{TFA} / \mathrm{H}_{2} \mathrm{O}$ voraus (Abb. 4.8).

Es musste darauf geachtet werden, dass der $\mathrm{pH}$-Wert nicht unter $\mathrm{pH} 7$ sank, da durch Protonierung der freien Aminofunktion die Nukleophilie nicht mehr für die Reaktion mit dem Carbonylchlorid ausgereicht hätte. Der pH-Wert durfte auch nicht zu basisch sein, da es unter diesen Bedingungen zur Abspaltung der Fmoc-Schutzgruppe gekommen wäre.

Durch die Einführung der Fmoc-Schutzgruppe besteht unter den gewählten Bedingungen die Gefahr der Dipeptidbildung. Diese kann durch hohe Verdünnung und einem nur geringen Überschuss an $\mathrm{FmocCl}$ vermindert werden. 


\subsection{Synthese $\alpha$-helikaler Peptide mittels Boc-Thioester Ligation}

Eine andere Methode, die gewünschten Oligomere aufzubauen, stellt die native chemische Ligation dar. Diese basiert auf der Reaktion zwischen einem Thioester und einem Cystein in der Seitenkette eines Peptides zu einer Amidbindung. ${ }^{[124,125,126]}$ Der erste Schritt ist die chemoselektive trans-Thioveresterung eines ungeschützten $\mathrm{C}_{\alpha}$-Thioester-Peptides mit einem N-terminalen Cystein eines zweiten Peptides. Der gebildete Thioester unterliegt einem spontanen $\mathrm{S} \rightarrow \mathrm{N}$-Acyltransfer, der zur nativen chemischen Peptidbindung führt (Abb. 4.9). ${ }^{[127]}$

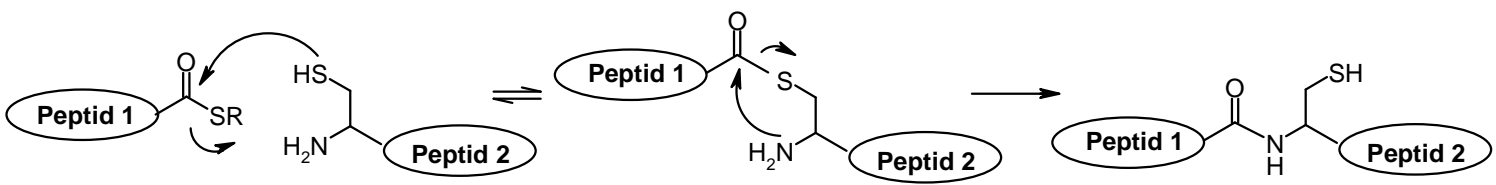

Abb. 4.9: Schematische Darstellung der nativen chemischen Ligation

Zusätzliche Cysteingruppen in den Peptiden können Disulfidbrücken bilden und zur Stabilisierung helikaler Peptide führen. Dafür sollten sich die Cysteingruppen in den Positionen $f$ und $f$ ' befinden (helical wheel in Abb. 4.10).

Das ursprüngliche 15mer-Peptid Ac-KA-HalG-KA-HalC-AEA-HalG-AK-HalC-AK-NH ${ }_{2}$ 28 bzw. das Testpeptid Ac-KAWKAYAEAWAKYAK-NH 32 wurden daher wie folgt modifiziert: Statt der Glutaminsäure wurde ein Cystein eingesetzt und zwischen dem Lysin und dem Alanin am N-Terminus zusätzlich ein Cystein eingebaut, so dass sich die nun 16mer-Zielsequenz ergab:

Ac-KCA-HalC-KA-HalG-ACA-HalC-AK-HalG-AK-NH 38 (Abb. 4.10) bzw.

Ac-KCAYKAWACAYAKWAK- $\mathrm{NH}_{2} 39$ 


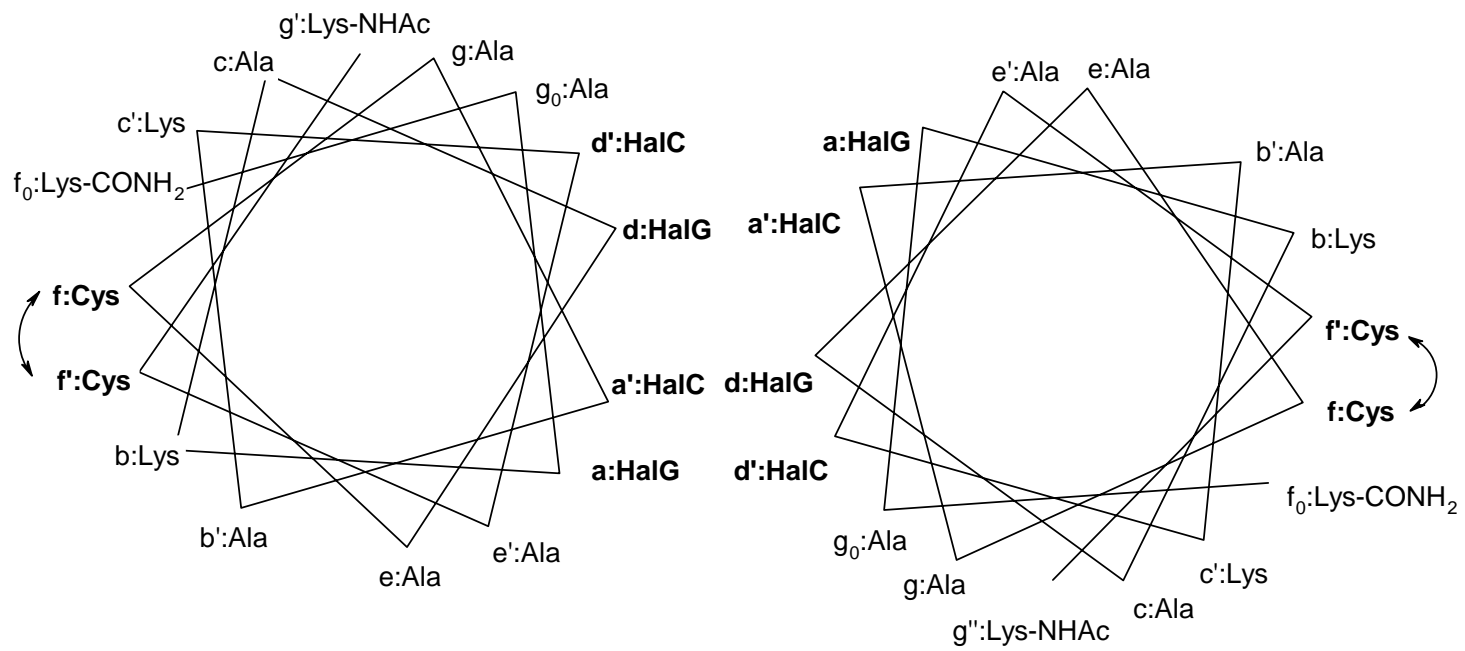

Abb. 4.10: Helical wheel-Darstellung der 16mer-Sequenz Ac-KCA-HalC-KA-HalG-ACA-HalC-KAHalG-AK-NH 38

Die Darstellung erfolgte nach folgendem Schema:

1. Herstellung des Boc-Ala-Thioester-MBHA-PS-Harz 40: Nach der Synthesevorschrift von J. P. Tam und Y.-A. Lu wurde zuerst 41 am MBHA-PS-Harz mit Mercaptopropionsäure hergestellt. ${ }^{[128]}$ Anschließend wurden Boc-Ala-OH 42 und Kupplungsreagenzien dazugegeben (Abb. 4.11).

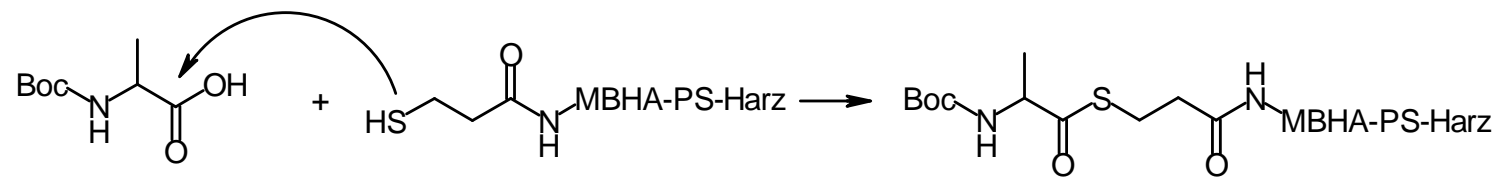

42

41

40

Abb. 4.11: Synthese des Thioesters 40

2. Via Peptidfestphasen Synthese wurde das Fragment Ac-KC(StBu)A-HalC-KAHalG-A-Thio- $\mathrm{NH}_{2}-\mathrm{MBHA}$-PS-Harz 43 synthetisiert und sauer vom Harz abgespalten. Die Cystein-Schutzgruppe ( $\mathrm{StBu}$ ) sollte nicht sauer abgespalten werden, so dass es zu keinen Konkurrenzreaktionen während der folgenden Ligation kommen konnte.

3. Gleichzeitig wurde das folgende zweite Peptid ebenfalls am MBHA-PS-Harz hergestellt und abgespalten: $\mathbf{H}_{2} \mathbf{N}-\mathrm{CA}-\mathrm{HalC}-\mathrm{AK}-\mathrm{HalG}-\mathrm{AK}_{-} \mathrm{NH}_{2} \mathbf{4 4}$. Das Cystein wurde 
mit $p$-Methoxybenzyl (pMeOBn) geschützt, das durch die saure Abspaltung entfernt werden konnte.

4. Die Ligation der beiden Peptide Ac-KC(StBu)A-HalC-KA-HalG-A-Thio-NH $\mathrm{NH}_{2} 43$ und H-CA-HalC-AK-HalG-AK-NH ${ }_{2} 44$ in Lösung ( $\mathrm{Na}_{2} \mathrm{HPO}_{4}$-Puffer) sollte zu AcKC(StBu)A-HalC-KA-HalG-ACA-HalC-AK-HalG-AK-NH ${ }_{2} 45$ führen (Abb. 4.12).

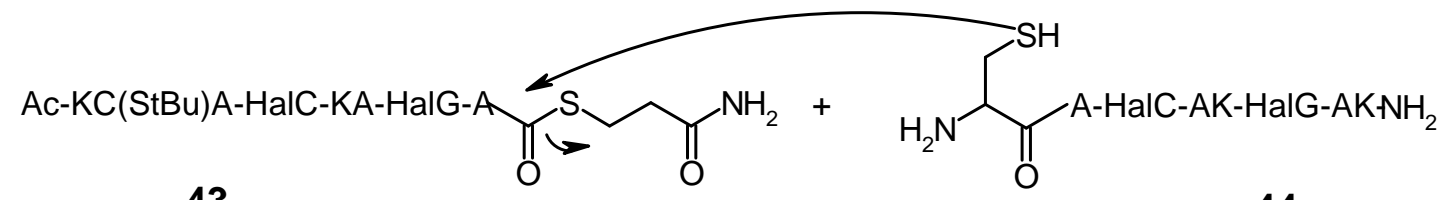

43

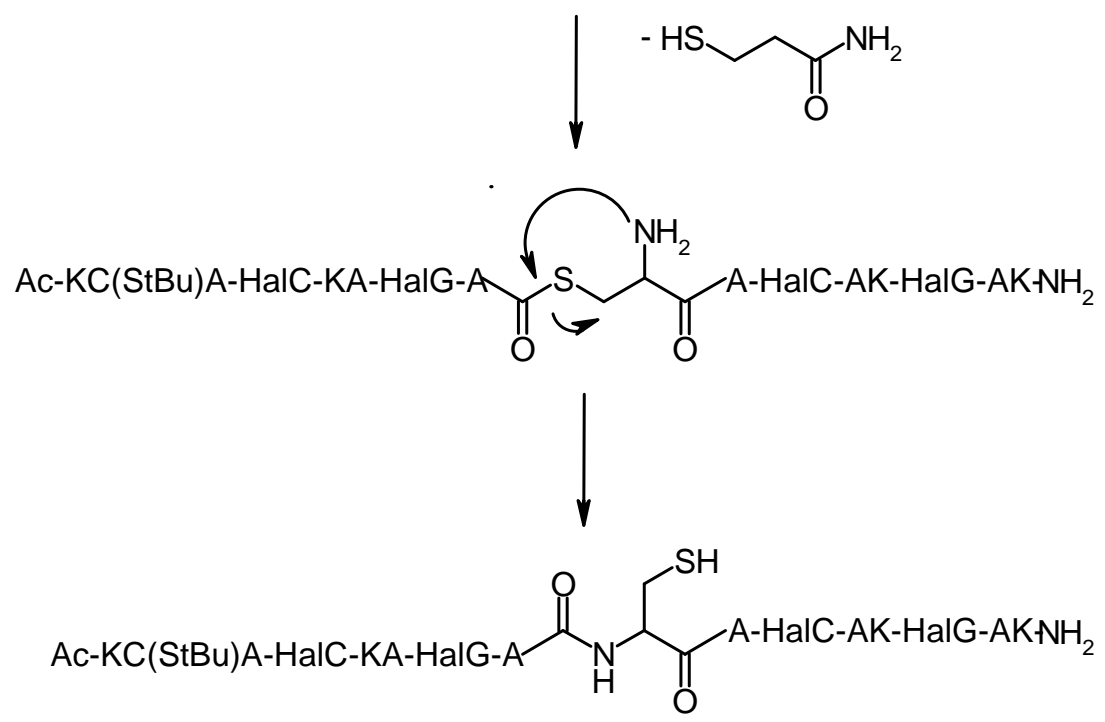

45

Abb. 4.12: Darstellung der trans-Thioveresterung und dem spontanen $S \rightarrow N-A c y l t r a n s f e r$ zum Ac$\mathrm{KC}(\mathrm{StBu}) \mathrm{A}$-HalC-KA-HalG-ACA-HalC-AK-HalG-AK-NH $\mathrm{H}_{2} 45$

Die einzelnen Fragmente konnten mit schlechten Ausbeuten hergestellt werden. Die Ligation verlief allerdings ohne Erfolg. Der Grund hierfür ist wahrscheinlich, dass die Fragmente sich nicht mehr an fester Phase befinden und somit die Ligation in Lösung erschwert ist. 


\subsection{Ergebnisse der spektroskopischen Untersuchungen}

Die Oligomere wurden in folgenden Lösungen UV- und CD-spektroskopisch untersucht:

$10 \mathrm{~mm}$ Tris. $\mathrm{HCl}-\mathrm{Puffer}, \mathrm{pH} 7$

$10 \mathrm{~mm}$ Tris $\cdot \mathrm{HCl}, 100 \mathrm{~mm} \mathrm{KCl}, 1 \mathrm{~mm} \mathrm{MgCl}$, $0.5 \mathrm{~mm}$ EDTA-Puffer, $\mathrm{pH} 7$

$10 \mathrm{~mm}$ Phosphat $\left(\mathrm{NaH}_{2} \mathrm{PO}_{4} / \mathrm{Na}_{2} \mathrm{HPO}_{4}\right)$-Puffer, $\mathrm{pH} 7$

Tris. $\mathrm{HCl}+30 \%$ TFE, $\mathrm{pH} 7$

TFE

$\mathrm{H}_{2} \mathrm{O}$

$\mathrm{MeOH}$

Es wurde ein Vergleich zwischen dem 15mer-Test-Oligomer AcKAWKAYAEAWAKYAK-NH ${ }_{2} 32$ und dem nukleobasen-modifizierten 15mer-Oligomer Ac-KA-HalG-KA-HalC-AEA-HalG-AK-HalC-AK-NH 28 aufgestellt. Nach UVspektroskopischen Messungen zeigte sich eine höhere Stabilität des Peptides mit den Nukleobasen. Die Hyperchromizität bei gleichen Konzentrationen und gleichem Lösungsmittel ist hier um mehr als das fünffache erhöht. Außerdem weist das Oligomer mit den Homoalanyl-Nukleoaminosäuren eine Schmelztemperatur von $T_{m}=36^{\circ} \mathrm{C}$ auf (Abb. 4.13), während sich beim Testpept id 32 keine Schmelztemperatur bestimmen lässt.

Dieses Ergebnis weist auf die Interaktion zweier Helices hin, die auf Basenpaarung basieren könnte. Durch den Einbau der Nukleobasen in den Seitenketten wird den Helices untereinander eine Aggregationsmöglichkeit gegeben, die eine strukturstabilisierende Wirkung hervorbringt. Die Tatsache, dass die Schmelzkurve des Testoligomers keinerlei sigmoiden Übergang aufweist, zeigt, dass die Stabilisierung auf Nukleobaseninteraktionen zurück zuführen ist. 


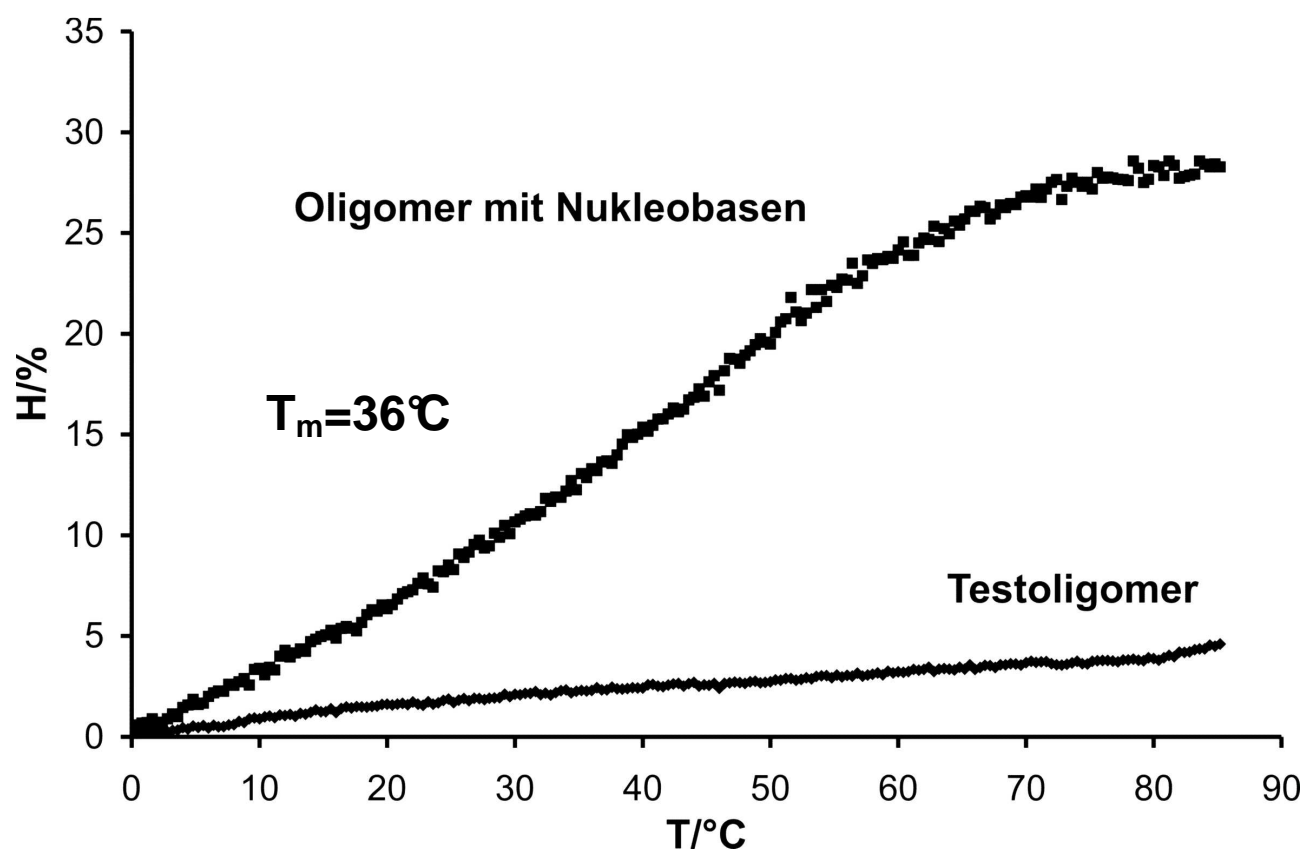

Abb. 4.13: UV-Spektrum des 15mer-Test-Oligomers Ac-KAWKAYAEAWAKYAK- $\mathrm{NH}_{2} 32 \mathrm{im}$ Vergleich zum 15mer-Oligomer Ac-KA-HalG-KA-HalC-AEA-HalG-AK-HalC-AK- $\mathrm{NH}_{2} \quad 28 ; \quad \mathrm{c}=10 \mu \mathrm{M} ; 10 \mathrm{mM}$ Tris $\cdot \mathrm{HCl}, 100 \mathrm{mM} \mathrm{KCl}, 1 \mathrm{mM} \mathrm{MgCl} 2,0.5 \mathrm{mM}$ EDTA, pH $7 ; \lambda=260 \mathrm{~nm}$

Die Spektren der 15mer-Oligomere Ac-KA-HalG-KA-HalC-AEA-HalG-AK-HalC-AK$\mathrm{NH}_{2} 28$ und Ac-KA-HalC-KA-HalC-AEA-HalG-AK-HalG-AK-NH 29 unterscheiden sich hinsichtlich der Schmelztemperatur unwesentlich. Das Oligomer 29 mit der Sequenzabfolge HalG-HalG-HalC-HalC ist $3^{\circ} \mathrm{C}$ stabile $r$, was wahrscheinlich darauf zurück zuführen ist, dass die benachbarten Guanine aufgrund der besseren Überlappung zusätzliche Stapelungswechselwirkungen hervorrufen (Abb. 4.14, 4.15). 


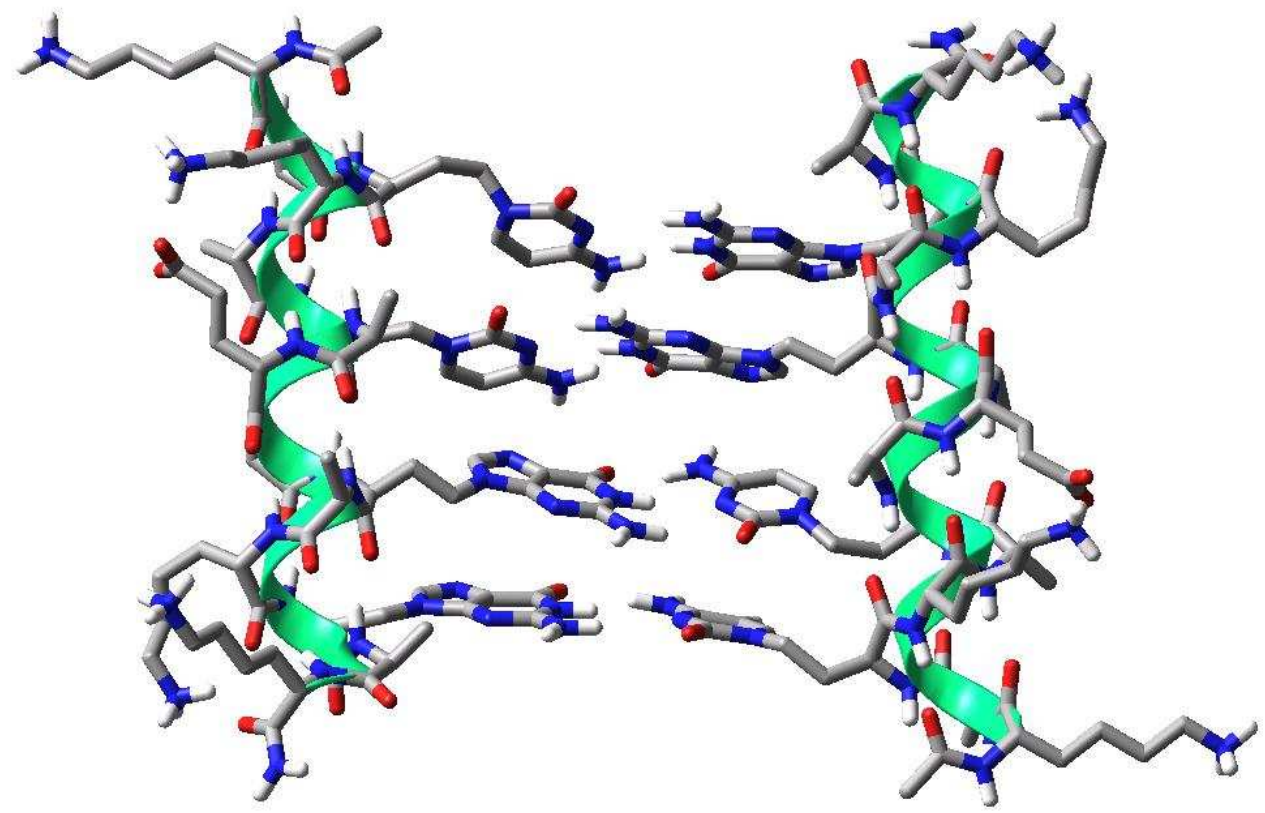

Abb. 4.14: Modell für Ac-KA-HalC-KA-HalC-AEA-HalG-AK-HalG-AK-NH 29 nach Energieminimierung $\left(\right.$ MacroMode ${ }^{\circledR}$, Amber $\left.^{*}, \mathrm{H}_{2} \mathrm{O}\right)$

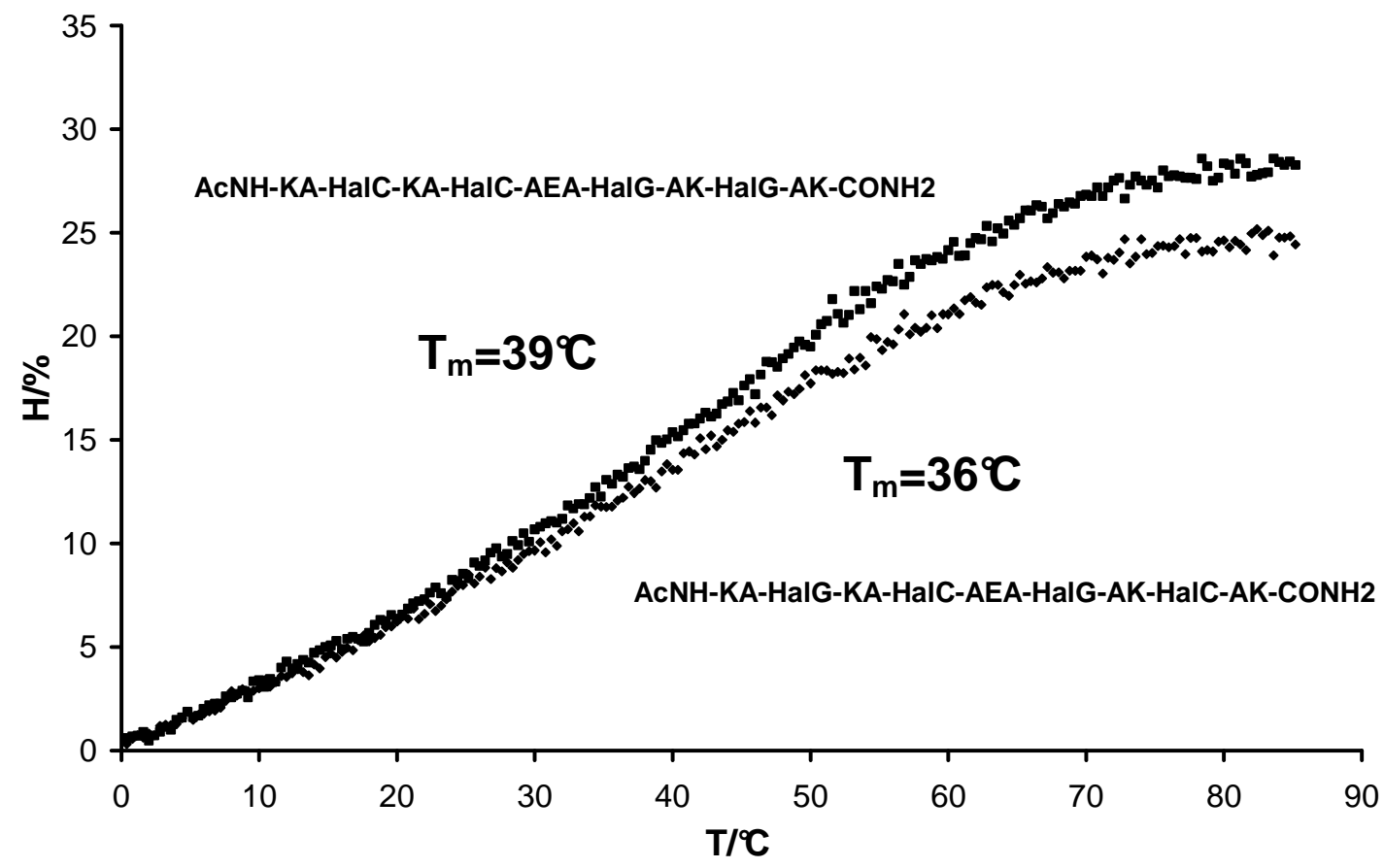

Abb. 4.15: UV-Spektrum des 15mer-Oligomers Ac-KA-HalC-KA-HalC-AEA-HalG-AK-HalG-AK-NH 29 im Vergleich zu dem 15mer-Oligomer Ac-KA-HalG-KA-HalC-AEA-HalG-AK-HalC-AK-NH ${ }_{2}$ 28; $\mathrm{C}=10 \mu \mathrm{m} ; 10 \mathrm{~mm}$ Tris $\cdot \mathrm{HCl}, 100 \mathrm{~mm} \mathrm{KCl}, 1 \mathrm{~mm} \mathrm{MgCl} 2,0.5 \mathrm{~mm}$ EDTA, pH 7; $\lambda=260 \mathrm{~nm}$,

Das 21 mer Oligomer Ac-A-HalC-AK-HalC-AKA-HalG-KA-HalC-AEA-HalG-AK-HalGAK-NH 27 zeigte im Vergleich zum 21 mer Testpeptid Ac-AYAKYAKAWKAYAEAW- 
AKWAK- $\mathrm{NH}_{2}$ 33, wie bei den 15mer-Oligomeren, einen sigmoiden Übergang und somit eine höhere Stabilität (Abb. 4.16).

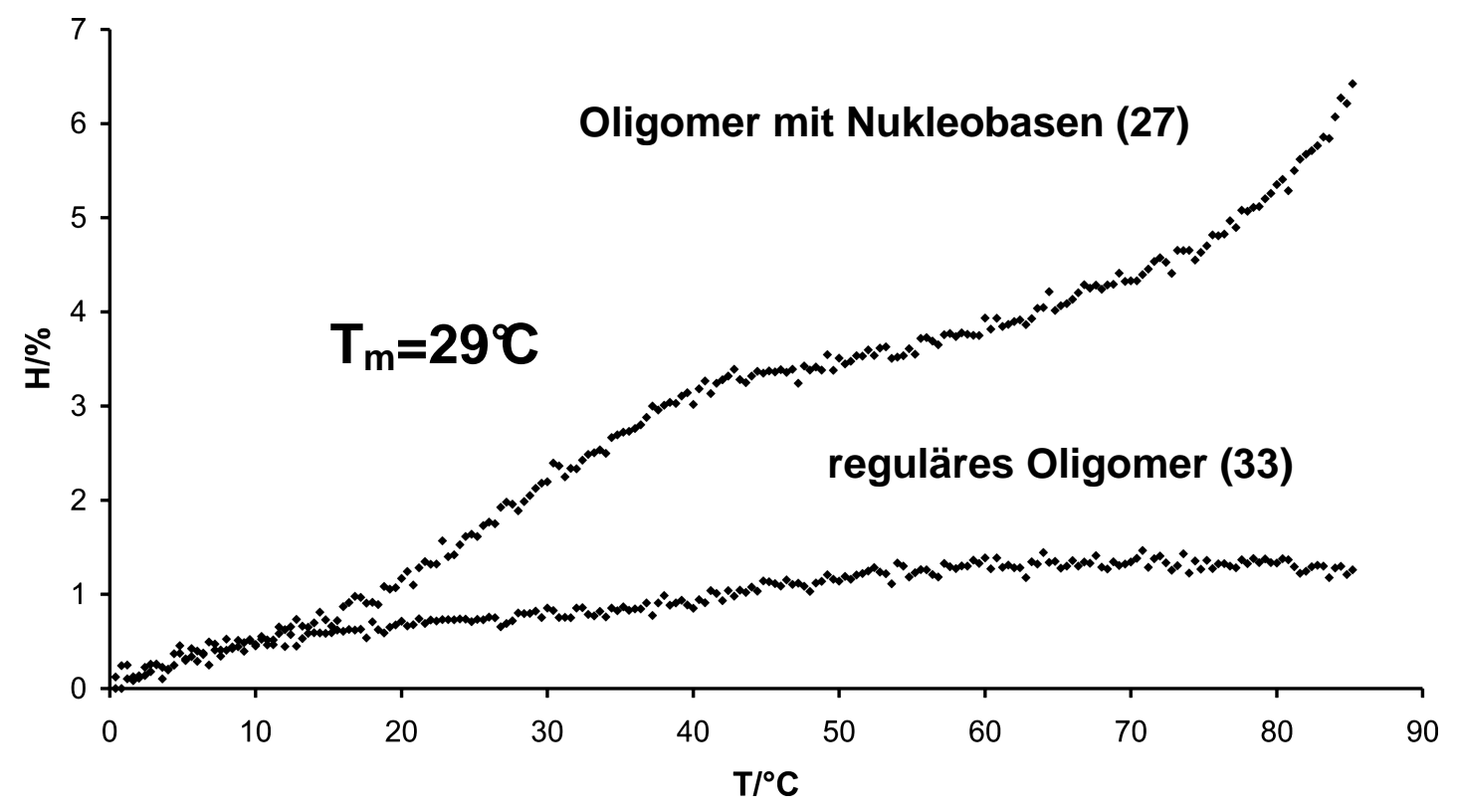

Abb. 4.16: UV-Spektrum des 21mer-Test-Oligomers Ac-AYAKYAKAWKAYAEAWAKWAK$\mathrm{NH}_{2} 33 \mathrm{im}$ Vergleich zu dem 21mer Oligomer Ac-A-HalC-AK-HalC-AKA-HalG-KA-HalC-AEAHalG-AK-HalG-AK-NH $\mathrm{N}_{2}$ 27; $\mathrm{c}=10 \mu \mathrm{M} ; 10 \mathrm{~mm}$ Tris. $\mathrm{HCl}, 100 \mathrm{mM} \mathrm{KCl}, 1 \mathrm{~mm} \mathrm{MgCl}, 0.5 \mathrm{~mm}$ EDTA, pH 7; $\lambda=260 \mathrm{~nm}$; der Anstieg der Absorption bei 27 oberhalb $70^{\circ} \mathrm{C}$ ist auf ein Abdampfen des Lösungsmittels zurück zuführen.

Die 15 mere 28 und 29 weisen mit $T_{m}=39^{\circ} \mathrm{C}$ bzw. $36^{\circ} \mathrm{C}$ eine höhere Schmelztemperatur auf als das 21 mer 27 mit $T_{m}=29 \mathrm{C}$. Diese Stabilitätsunterschiede sind wahrscheinlich auf verschiedene Sekundärstrukturen zurück zuführen.

CD-spektroskopische Untersuchungen des 21 mer-Oligomers Ac-A-HalC-AK-HalCAKA-HalG-KA-HalC-AEA-HalG-AK-HalG-AK-NH 27 (Abb. 4.17) und des 15merOligomers Ac-KA-HalC-KA-HalC-AEA-HalG-AK-HalG-AK-NH 29 (Abb. 4.18) zeigen zum einen die typischen $\alpha$-Helix Effekte, einen positiven Cotton-Effekt bei $191 \mathrm{~nm}$ und negative Cotton-Effekte bei $206 \mathrm{~nm}$ und $222 \mathrm{~nm}$, wobei stärkere Cotton-Effekte und damit höhere Helixanteile beim 15mer-Oligomer 29 zu erkennen sind. Zum anderen ist bei beiden Oligomeren eine schwache Temperaturabhängigkeit im Bereich der Nukleobasenabsorption im Wellenlängenbereich von $240-280 \mathrm{~nm}$ zu erkennen. Die Ausprägung des positiven Effektes verringert sich bei steigender Temperatur. 


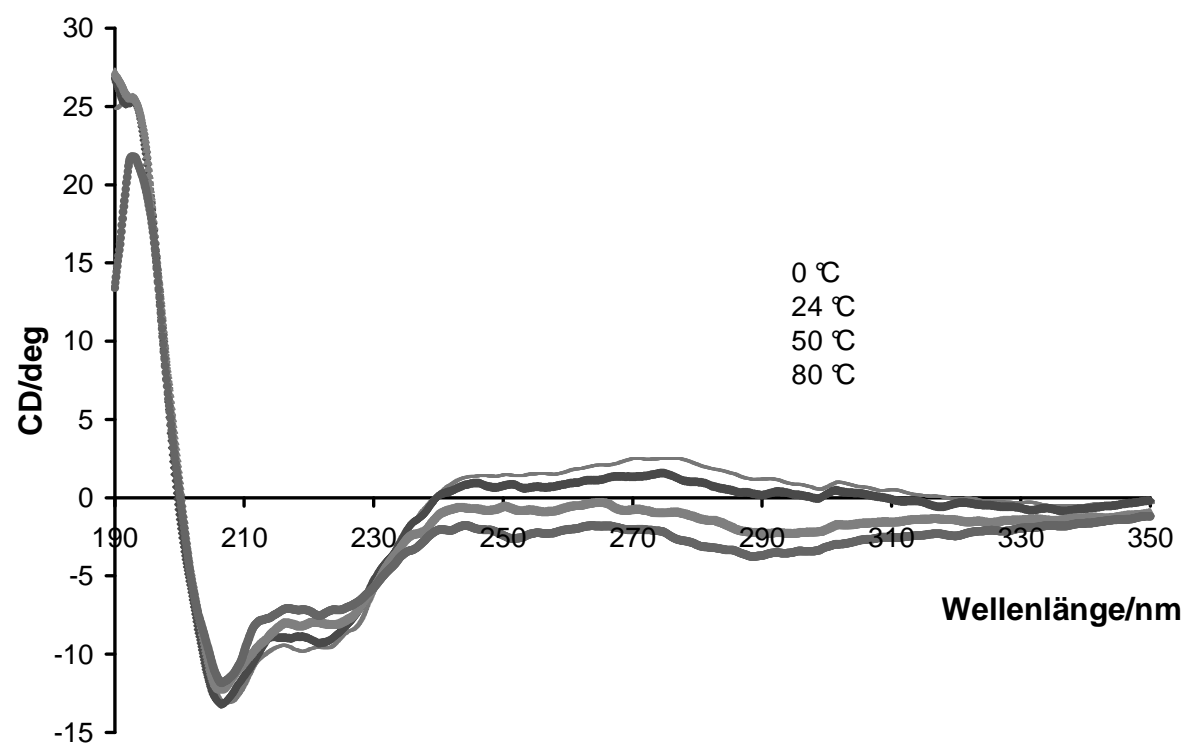

Abb. 4.17: CD-Spektrum des 21 mer-Oligomers Ac-A-HalC-AK-HalC-AKA-HalG-KA-HalC-AEA-HalGAK-HalG-AK- $\mathrm{NH}_{2} 27 ; \mathrm{C}=10 \mu \mathrm{M}$; TFE; bei 0, 24, 50 und $80{ }^{\circ} \mathrm{C}$

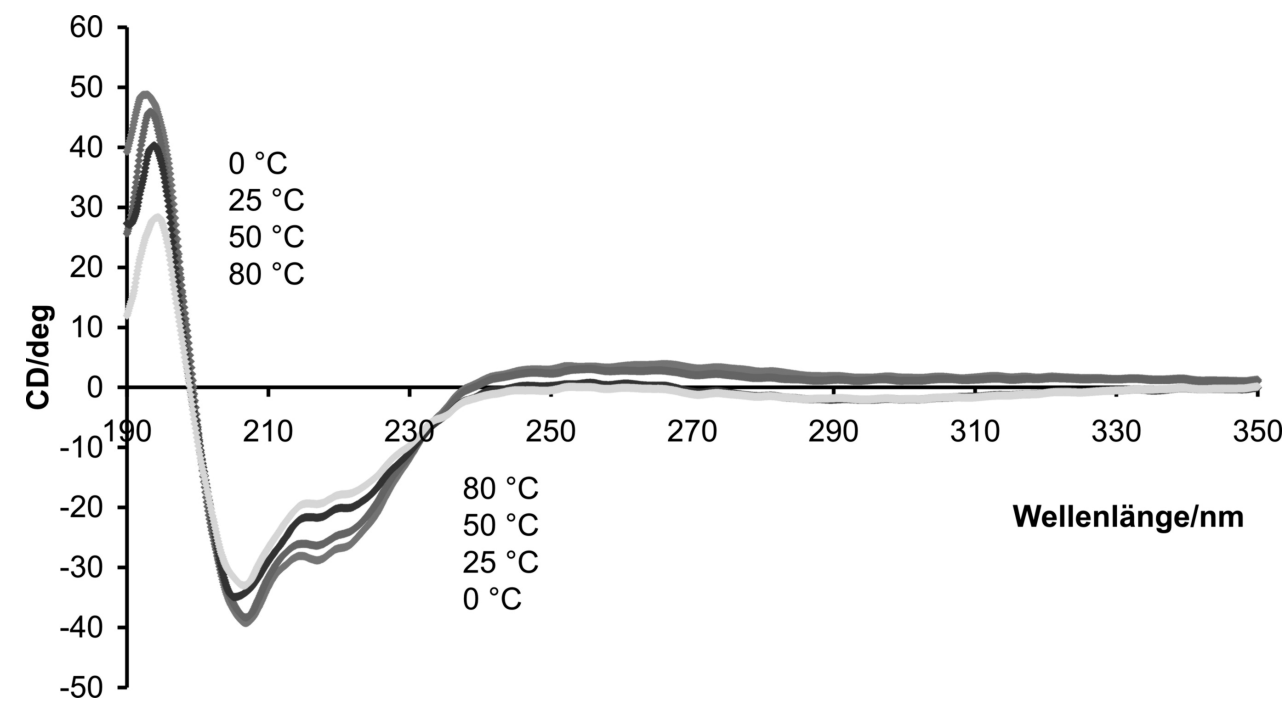

Abb. 4.18: CD-Spektrum des 15mer-Oligomers AC-KA-HalC-KA-HalC-AEA-HalG-AK-HalG-AK-NH 29; $\mathrm{C}=10 \mu \mathrm{M}$; TFE; bei $0,24,50$ und $80^{\circ} \mathrm{C}$

UV- und CD-spektroskopische Untersuchungen zeigen, dass das 15mer-Oligomer Ac-KA-HalC-KA-HalC-AEA-HalG-AK-HalG-AK-NH 29 im Vergleich zum 21merOligomer 27 höhere Stabilitäten und ausgeprägtere $\alpha$-Helixanteile aufweist. Ebenfalls konnte eine stärkere Stabilisierung der 15mer-Oligomere 28 und 29 und des 21 merOligomers $27 \mathrm{im}$ Vergleich zu den regulären Peptiden 32, 33 ohne Nukleobasen gezeigt werden. 


\section{Inkorporation von Nukleoaminosäuren in das lineare Mikropeptid-Gerüst MCoTI-29}

Dieser Teil der Arbeit befasst sich mit der Modifizierung des linearen Mikroproteins MCoTI-29 (Kap. 2.4). Unnatürliche Aminosäuren wurden in die reaktive Inhibitorschleife des Cystinknotens in Position P1 eingebaut, wobei die offenkettige Form verwendet wurde. ${ }^{[129]}$ Dieser Bereich der Schleife ist bekannt als potenter $\alpha$-Helixbildner. Es wurden chemisch synthetisierte Verbindungen eingebaut, die zu einer hohen biologischen Aktivität und Stabilität führten. Bei diesen Verbindungen handelte es sich um Alanyl-Nukleoaminosäuren (Kap 2.1, Kap. 3), die als Mimetika für Aminosäuren, wie Phenylalanin, Tryptophan und Arginin eingesetzt werden können (Abb. 5.1). ${ }^{[130]}$

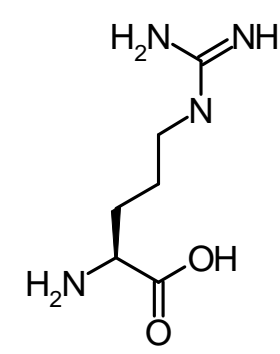

H-L-Arg-OH<smiles>Nc1nc2c(ncn2C[C@H](N)C(=O)O)c(=O)[nH]1</smiles>

H-D-AlaG-OH (ent-46)

Abb. 5.1: L-Arginin (links) und dessen isostere Nukleoaminosäure D-AlaG ent-46 (rechts), eingebaut in Position P1 des linearen Mikroproteins MCoTI-29 ${ }^{[130]}$

Heterozyklische Arginin-Mimetika wurden wegen der hohen Selektivität und der ausgeprägten Thrombin-Inhibierung als Aminosäuren für die Darstellung von trypsinähnlichen Serin-Protease Inhibitoren verwendet. ${ }^{[131,132]}$

Die Nukleobasen können Änderungen hinsichtlich der konformationellen Flexibilität, der Ladungsverteilung und des Protonierung-Verhaltens hervorrufen. Zudem sind sie in der Lage, Wasserstoffbrückenbindungen auszubilden. Diese Veränderungen können zu einer besseren Bioverfügbarkeit, höheren Bindungsaffinitäten und zu einer Erhöhung der Rezeptor-Selektivität führen. ${ }^{[133]}$

Als Nukleobasen wurden Purin-Gerüste als konformationell starre Arginin-Mimetika in die Synthese von zyklischen Pentapeptiden eingeführt, die auf der Struktur des zyklischen RGD(Arg-Gly-Asp)-Peptides basieren. ${ }^{[134]}$ 
Im Weiteren ist die Synthese der Nukleoaminosäuren Fmoc-D-AlaG-OH ent-46 und Fmoc-L-AlaG-OH 46 dargestellt sowie deren Inkorporation in das lineare Mikropeptid MCoTI-29.

\subsection{Synthese der Fmoc-Alanyl-Nukleoaminosäuren und deren Einbau in das lineare Mikropeptid}<smiles>Nc1nc2c(ncn2C[C@H](N)C(=O)O)c(=O)[nH]1</smiles>

47

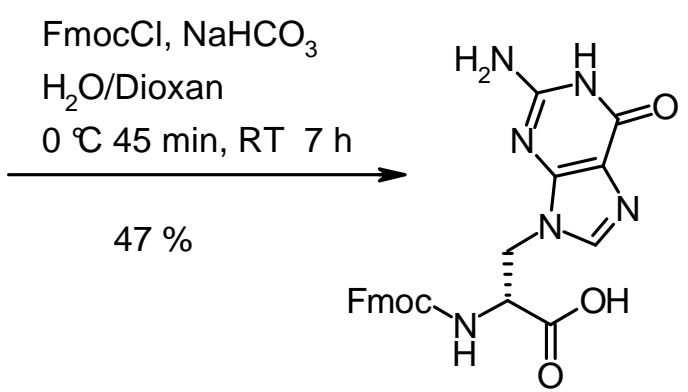

46

Abb. 5.2: Synthese der Fmoc-geschützten Nukleoaminosäuren Fmoc-D-AlaG-OH ent-46 und Fmoc-LAlaG-OH 46

Die Synthese der Fmoc-geschützten Nukleoaminosäuren verlief analog zu der der Boc-geschützen Nukleoaminosäuren (Kap. 3.1). ${ }^{[133]}$ Ausgehend von $\mathbf{4 7}$ wurde wie bei den Homoalanyl-Nukleoaminosäuren dargestellt (Kap.4.2.1) mit $\mathrm{FmocCl}$ und $\mathrm{NaHCO}_{3}$ die Fmoc-Schutzgruppe eingeführt und Fmoc-L-AlaG-OH 46 bzw. Fmoc-DAlaG-OH ent-46 erhalten (Abb. 5.2).

\section{P1}

\section{H-GVCP-AlaG-ILKKCRRDSDCPGACICRGNGYCG-NH ${ }_{2}$ (48)}

Abb. 5.3: Sequenz des linearen Mikropeptids 48

Das lineare Mikropeptid 48 (Abb. 5.3) wurde automatisiert sowie manuell nach der Fmoc-Strategie an fester Phase (Kap. 4.2) synthetisiert. Der Einbau der Nukleoaminosäure Fmoc-D-AlaG-OH ent-46 sowie der der Aminosäure Fmoc-L-lle-OH, direkt im Anschluss an die Nukleoaminosäure, wurden manuell durchgeführt. Ebenso erfolgte die Kupplung der Fmoc-L-Cys(Trt)-OH manuell. ${ }^{[129]}$ Als Seitenschutzgruppe 
wurde für Asparagin (Trt), für Lysin (Boc), für Asparaginsäure (OtBu), für Serin $(t \mathrm{Bu})$ und für Arginin (Pbf) verwendet, die nach saurer Abspaltung vom Harz ebenfalls entfernt wurden. Die Guaninbase der Alanyl-Nukleoaminosäure wurde nicht geschützt (Kap.3.1). Der Synthesezyklus entspricht dem in Kap.4.2 beschriebenen. ${ }^{[133]}$

\subsection{Ergebnisse und Diskussion der biologischen Aktivität}

Wegen der relativ geringen Löslichkeit und des erhöhten Aggreagtionspotentials der Fmoc-geschützten Alanyl-Nukleoaminosäuren wurde die Inkorporation dieses Bausteines manuell durchgeführt.

Es wurde zum einen gezeigt, dass es möglich ist, Nukleoaminosäuren in die P1-Position des linearen MCoTI-29 einzubauen. Zum anderen zeigten die Trypsin-Inhibitor Untersuchungen, jeweils mit den inkorporierten Nukleoaminosäuren, D-AlaG bzw. LAlaG, eine messbare Trypsin-Inhibitor Aktivität (Tab. 5.1). ${ }^{[129]}$

\begin{tabular}{|c|c|c|}
\hline $\begin{array}{l}\text { MCoTI-29 mit AlaG/AlaG in } \\
\text { der Inhibitorschleife }\end{array}$ & $\begin{array}{l}\text { Trypsin } \\
K_{\text {iapp, }}[\mathrm{nm}]\end{array}$ & $\begin{array}{l}\text { Tryptase } \\
K_{\text {iapp, }}[\mathrm{nm}]\end{array}$ \\
\hline -PAlaGILKK- (48) & 1000 & 4000 \\
\hline -PAlaGILKK- (ent-48) & 1000 & 10000 \\
\hline -P $\quad \mathrm{R} \quad$ ILKK- & 0.8 & 20 \\
\hline
\end{tabular}

Tab. 5.1: Analytik des linearen Mikroproteins MCoTI-29 mit D-AlaG (AlaG) und L-AlaG (AlaG) im Vergleich zu Arginin; Geschwindigkeitskonstante $K_{\text {iapp }}$ (inhibition apparently) wurde jeweils gegen Trypsin und human $\beta$-III Tryptase gemessen. ${ }^{84]}$

Beide Mikroproteine zeigen eine schwache Inhibierung der menschlichen Tryptase. Interessanterweise zeigt die D-AlaG-Nukleoaminosäure an der Position P1 eine leicht bessere Inhibierungskonstante.

Somit sind neben Arginin auch andere basische Aminosäure-Analoga in der P1-Position in der Lage an die enzymatisch aktiven Seiten zu binden. Die heterozyklischen Verbindungen als Thrombin-Inhibitoren sind interessant, weil im Vergleich zu der Guanidinoalkyl-Seitengruppe von Arginin die Basizität herabgesetzt ist und der heteroaromatische Ring starke Rigidität aufweist. ${ }^{[133,135]}$ Außerdem sind die Nukleoaminosäuren mit einer zusätzlichen Protonen-Donor-Akzeptor-Funktionalität ausge- 
stattet. Eine geringere Selektivität der eingebauten Nukleoaminosäuren wird im Vergleich zu den Arginin-Analoga gemessen, da wahrscheinlich die Nukleobasen aus sterischen Gründen benachteiligt sind. 


\section{Zusammenfassung und Ausblick}

Die Möglichkeit, Nukleoaminosäuren als Nukleotid- bzw. Aminosäure-Mimetika zu verwenden, macht ihren Einbau in verschiedenste natürliche und synthetische Protein- und Peptidstrukturen interessant. Wegen ausgebildeter Wasserstoffbrückenbindungen sowie hydrophober und elektrostatischer Kräfte kann diese Substitution zu vielversprechenden neuen Eigenschaften führen und Wechselwirkungen mit DNA und RNA ermöglichen.

Ausgehend von enantiomerenreinen Aminosäuren sowie Aminosäurederivaten wurden im Rahmen dieser Arbeit unterschiedliche Boc-geschützte Alanyl- und Homoalanyl-Nukleoaminosäuren sowie Fmoc-geschützte Alanyl- und Homoalanyl-Nukleoaminosäuren synthetisiert. Aufgrund der für die Nukleobasen-Paarung erforderlichen alternierend konfigurierten PNA-Stränge wurden die Nukleoaminosäuren in beiden enantiomeren Formen hergestellt. Die Darstellung der Peptidnukleinsäuren aus den Nukleoaminosäuren erfolgte mittels Peptidfestphasen Synthese nach der Boc- bzw. Fmoc-Strategie.

Zur Imitation der Watson-Crick Basenpaarung wurde eine kovalente Verknüpfung von antiparallelen PNA-Strängen über den Hexaethylenglycolaminosäure (Hegas)Linker 1 geschaffen. Dazu wurde einerseits die Stabilisierung auf Tetramer-Doppelstränge und andererseits die Wirkung auf Hexamer-Doppelstränge untersucht.

Der Aufbau der PNA-Stränge sowie die Einführung des Hegas-Linkers 1 erfolgten durch Festphasen Synthese. Mittels temperaturabhängiger UV-Spektroskopie wurden die Stabilitäten der Doppelstränge des Tetramers $\mathbf{2 3}$ und des Hexamers 24 ermittelt und mit den Stabilitäten der rein selbstpaarenden Oligomeren verglichen (Tab. 6.1). 


\begin{tabular}{|c|c|c|}
\hline PNA-Oligomere & $\mathrm{T}_{\mathrm{m}}$ & Paarungsmodus \\
\hline $\begin{array}{l}\text { H-AlaC- } \underline{\mathrm{HalC}}-\mathrm{AlaG}-\underline{\mathrm{HalC}}-\mathrm{AlaG}-\underline{\mathrm{HalG}}-[\mathrm{hegas}] \\
\text { AlaC- } \underline{\mathrm{HalC}}-\mathrm{AlaG}-\underline{\mathrm{HalC}}-\mathrm{AlaG}-\underline{\mathrm{HalG}}-\mathrm{Lys}-\mathrm{NH}_{2} 24\end{array}$ & $25^{\circ} \mathrm{C}$ & Watson-Crick \\
\hline $\begin{array}{l}\text { H-AlaC-HalG-AlaG-HalC-[hegas]- } \\
\text { AlaG- } \underline{H a l C}-\text { AlaC- } \underline{\text { HalG}}-\text { Lys- } \mathrm{NH}_{2} 23\end{array}$ & $18^{\circ} \mathrm{C}$ & Watson-Crick \\
\hline H-AlaG- $\underline{\text { HalG}}-\mathrm{AlaC}-\underline{\mathrm{HalG}}-\mathrm{AlaC}-\underline{\mathrm{HalC}}-\mathrm{Lys}-\mathrm{NH}_{2} 25$ & $52^{\circ} \mathrm{C}$ & Watson-Crick \\
\hline H-AlaG-AlaC-AlaG-AlaC-Lys- $\mathrm{NH}_{2} 26$ & $12^{\circ} \mathrm{C}$ & reverse Watson-Crick \\
\hline
\end{tabular}

Tab. 6.1: Schmelztemperaturen $\left(T_{m}\right)$ und Paarungsmodi der PNA-Oligomere mit und ohne Verknüpfungseinheit hegas 1

Das Hexamer weist eine höhere Paarungsstabilität auf als das Tetramer, was den Erwartungen entspricht, da mehr Basenpaarungen im Hexamer möglich sind (Tab. 6.1). Im Vergleich zu den selbstpaarenden Oligomeren 25 und 26 ohne kovalente Verknüpfung wurde eine unerwartete Destabilisierung des Systems beobachtet (Tab. 6.1), die eine Störung der idealen Paarungsgeometrie oder eine alternierende Erkennungsmöglichkeit nahe legt. Durch die Einführung eines starren Gerüstes als Verknüpfungseinheit sollten höhere Stabilitäten erhalten werden. Deshalb wurden in dieser Arbeit die Synthesen verschiedener Stilbenderivate durchgeführt. Dazu wurde, ausgehend von 4,4'-trans-Stilbendicarboxylat 16 über eine Säureaktivierung mit $\mathrm{SOCl}_{2}$ drei verschiedene Derivate dargestellt. Die Darstellung des orthogonalfunktionalisierten Stilbens 2 erwies sich als äußerst schwierig, da zwischen den Säurechlorid-Gruppen keinerlei Differenzierung gelang.

Ein weiterer Aspekt dieser Arbeit war der Einbau von Nukleoaminosäuren in $\alpha$-helikale Peptide. Hierbei wurden Nukleoaminosäuren in eine Peptid-Sequenz inkorporiert, so dass aufgrund der Organisation und Erkennung der Nukleobasen eine Selbstpaarung zweier $\alpha$-Helix-Stränge ermöglicht wurde. 


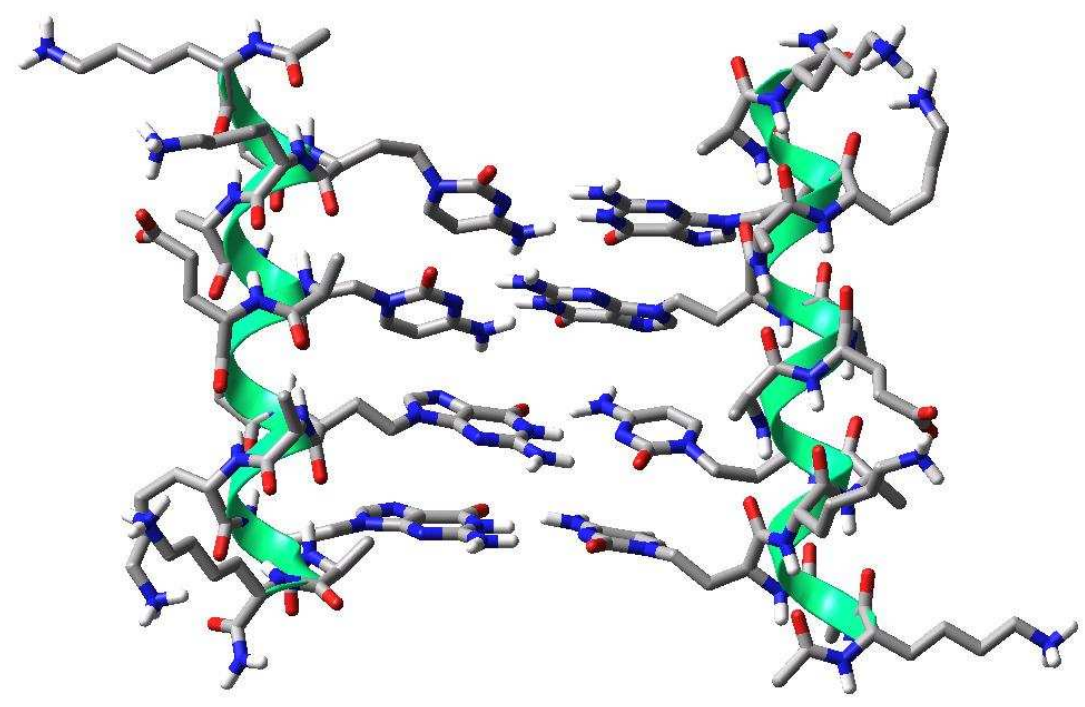

Abb. 6.1: Modell des 15mer-Oligomers Ac-KA-HalC-KA-HalC-AEA-HalG-AK-HalG-AK-NH 29 nach Energieminimierung $\left(\right.$ MacroMode $^{\circledR}$, Amber $\left.^{*}, \mathrm{H}_{2} \mathrm{O}\right)$

Die 21mer- und 15mer-Oligomere 27, 28 und 29 (Abb. 6.1) wurden hinsichtlich ihrer Paarungseigenschaften untersucht und mit nicht nukleobasen-modifizierten Peptiden verglichen. Die durch UV-Spektroskopie untersuchten Oligomere zeigten eine eindeutige Stabilisierung durch den Einbau von Nukleobasen, da reguläre Petide keinen sigmoiden Übergang aufwiesen (Tab. 6.2).

\begin{tabular}{|c|c|}
\hline Oligomere & $T_{m}$ \\
\hline Ac-KA-HalC-KA-HalC-AEA-HalG-AK-HalG-AK-NH 22 & $39^{\circ} \mathrm{C}$ \\
\hline Ac-KA-HalG-KA-HalC-AEA-HalG-AK-HalC-AK-NH 228 & $36^{\circ} \mathrm{C}$ \\
\hline Ac-KAWKAYAEAWAKYAK-NH ${ }_{2} 32$ & - \\
\hline Ac-A-HalC-AK-HalC-AKA-HalG-KA-HalC-AEA-HalG-AK-HalG-AK-NH 22 & $29^{\circ} \mathrm{C}$ \\
\hline Ac-AYAKYAKAWKAYAEAWAKWAK-NH ${ }_{2} \mathbf{3 3}$ & - \\
\hline
\end{tabular}

Tab. 6.2: Schmelztemperaturen $\left(T_{m}\right)$ der synthetisierten helikalen 15 mer- und 21 mer-Oligomere mit und ohne Nukleobasen-Inkorporation

Die Wechselwirkungen durch Nukleobasen-Erkennung des $\alpha$-helikalen Doppelstranges von Ac-KA-HalC-KA-HalC-AEA-HalG-AK-HalG-AK-NH 29 führten zu einer stärkeren Stabilisierung als die des Oligomers Ac-KA-HalG-KA-HalC-AEA-HalG-AKHalC-AK- $\mathrm{NH}_{2}$ 28. Obwohl das $21 \mathrm{mer}$ sechs Basenpaare aufweist, zeigt das $15 \mathrm{mer}$ mit vier Basenpaaren eine um ca. $10^{\circ} \mathrm{C}$ höhere Stabi lität. 
In weiteren Arbeiten soll die Stabilisierung anhand von kürzeren und längeren Sequenzen untersucht werden. Durch den Einbau des Basenpaares Adenin/Thymin können andere Paarungsmodi verwendet werden, um Unterscheidungen hinsichtlich der Stabilität des Paarungsverhaltens der Erkennungsregion genauer zu untersuchen.

Eine weitere Inkorporation der Nukleobasen wurde an dem linearen Mikropeptid MCoTI-29 48 durchgeführt. Der Austausch einer Arginineinheit gegen eine Nukleobase führte zu biologischer Aktivität und zeigte, dass bizyklische Heteroaromaten wegen der zusätzlichen Protonen-Donor-Akzeptor-Funktionalität eine interessante Alternative zur Modifikation natürlicher Peptide und Proteine darstellen.

Im Rahmen dieser Arbeit wurden die Eigenschaften Nukleobasen-funktionalisierter Peptide dargestellt. Es konnte gezeigt werden, welche Einflüsse aromatische Seitenketten mit der Möglichkeit der wasserstoffbrückenbildenden Basenpaarung auf die Struktur und Aggregation von Peptiden haben. 


\section{Summary and Outlook}

The knowledge about nucleoamino acids, nucleotides and amino acid mimetica gives the opportunity to implement them in various natural and synthetic protein and peptide structures. The substitution by these elements leads to new and promising properties which might allow interactions with DNA and RNA, since various forces like hydrogen bondings, hydrophobic, and electrostatic interactions are involved.

Different Boc-protected Alanyl- and Homoalanyl-nucleoamino acids and Fmocprotected Alanyl- and Homoalanyl-nucleoamino acids were synthesized from enantiomerically pure amino acids and amino acid derivatives. The nucleoamino acids were made in both enantiomeric forms due to the necessity of alternating configuration for nucleobase pairings. Oligomerization of the peptide nucleic acids (PNA) from the nucleoamino acids was done by Boc- and Fmoc-solid phase peptide synthesis.

Antiparallel PNA double strands were accomplished via covalent binding with hexaethylene glycol amino acid (hegas)-linker 1 for imitation of the Watson-Crick base pairing. Therefore double strand stabilities of tetramer $\mathbf{2 3}$ and hexamer 24 were investigated. Oligomerization and the incorporation of hegas-linker 1 were performed by solid phase peptide synthesis. Stabilities of the tetrameric and hexameric double strands of $\mathbf{2 3}$ and $\mathbf{2 4}$ were investigated by temperature-dependent UV spectroscopy and compared to selfpairing oligomers 25 and 26 (table 6.1).

\begin{tabular}{|c|c|c|}
\hline PNA-oligomers & $\mathrm{T}_{\mathrm{m}}$ & pairing mode \\
\hline 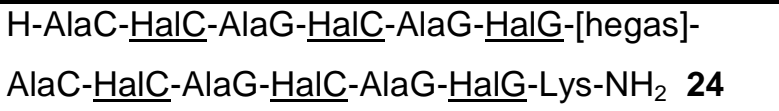 & $25^{\circ} \mathrm{C}$ & Watson-Crick \\
\hline 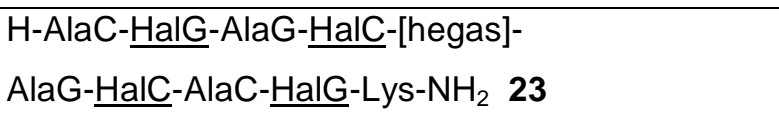 & $18^{\circ} \mathrm{C}$ & Watson-Crick \\
\hline H-AlaG- $\underline{\text { HalG}}-\mathrm{AlaC}-\underline{\mathrm{HalG}}-\mathrm{AlaC}-\underline{\mathrm{HalC}}-\mathrm{Lys}-\mathrm{NH}_{2} 25$ & $52^{\circ} \mathrm{C}$ & Watson-Crick \\
\hline H-AlaG-AlaC-AlaG-AlaC-Lys- $\mathrm{NH}_{2} 26$ & $12^{\circ} \mathrm{C}$ & reverse Watson-Crick \\
\hline
\end{tabular}

Table 6.1: Melting temperatures $\left(T_{m}\right)$ and pairing mode of the PNA-oligomers with and without hegaslinker 1 
According to the prospect the hexameric oligomer showed higher pairing stability than the tetrameric oligomer due to the fact the hexameric oligomer can form more base pairs (table 6.1). These linked systems showed less stability compared to the self pairing oligomers $\mathbf{2 5}$ and $\mathbf{2 6}$ that are not additionally stabilized by covalent binding (table 6.1). Reasons for that might be their pairing geometry or alternated recognition possibilities. Higher stabilities could be achieved with more rigid linkers. Therefore various stilben derivates were synthesized starting with 4,4'-transstilbendicarboxylate $\mathbf{1 6}$. Activation of 16 with $\mathrm{SOCl}_{2}$ leads to three different derivates. Differentiation between both acid chlorid groups turned out to be difficult so that orthogonal functionalized stilbene 2 could not be isolated.

Another part of this dissertation dealt with the incorporation of nucleoamino acids in $\alpha$-helical peptides. Organization and recognition of the nucleobases should lead to a selfpairig of two $\alpha$-helical strands.

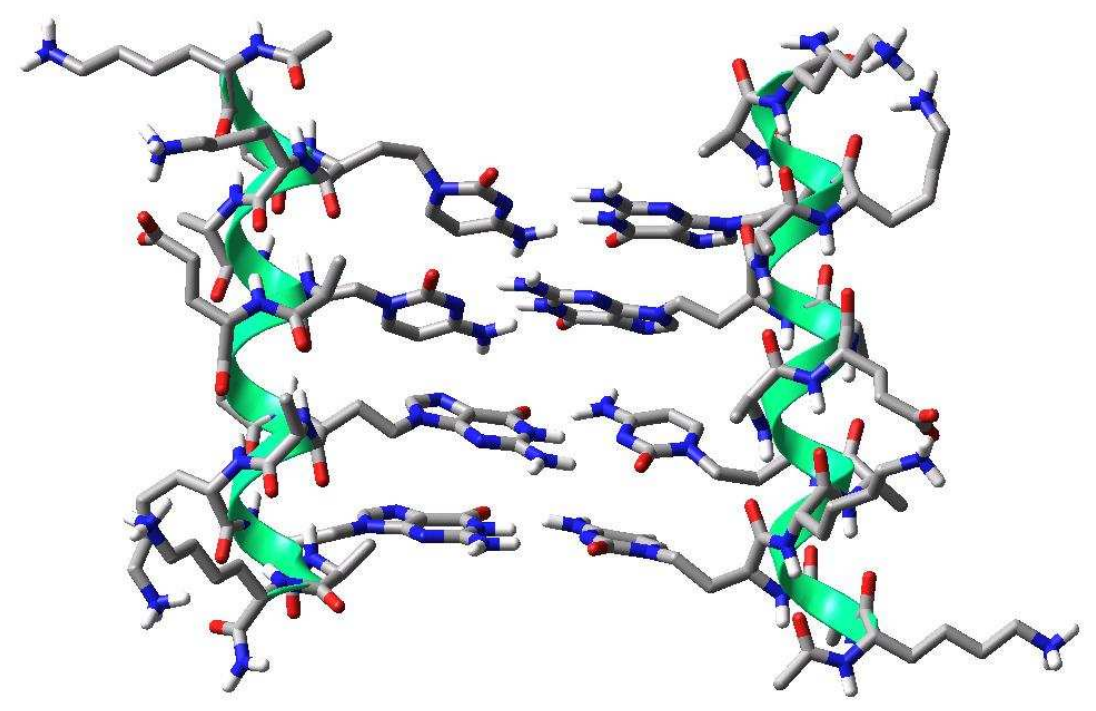

Figure 6.1: Model of the 15-residue system Ac-KA-HalC-KA-HalC-AEA-HalG-AK-HalG-AK-NH 29 after energy minimization $\left(\right.$ MacroMode $^{\circledR}$, Amber $^{*}, \mathrm{H}_{2} \mathrm{O}$ )

The 21-residue and 15-residue system 27, 28 and 29 (figure 6.1) were analyzed regarding their pairing properties and compared to the nucleobase-modified peptides 32 and 33. Stabilization of the oligomers was accomplished by nucleobase pairing since regular peptides did not show any sigmoidal transition (table 6.2). 


\begin{tabular}{|c|c|}
\hline oligomers & $\mathrm{T}_{\mathrm{m}}$ \\
\hline Ac-KA-HalC-KA-HalC-AEA-HalG-AK-HalG-AK-NH ${ }_{2} \mathbf{2 9}$ & $39{ }^{\circ} \mathrm{C}$ \\
\hline Ac-KA-HalG-KA-HalC-AEA-HalG-AK-HalC-AK-NH ${ }_{2} \mathbf{2 8}$ & $36{ }^{\circ} \mathbf{C}$ \\
\hline Ac-KAWKAYAEAWAKYAK-NH ${ }_{2} \mathbf{3 2}$ & - \\
\hline Ac-A-HalC-AK-HalC-AKA-HalG-KA-HalC-AEA-HalG-AK-HalG-AK-NH ${ }_{2} \mathbf{2 7}$ & $29^{\circ} \mathrm{C}$ \\
\hline Ac-AYAKYAKAWKAYAEAWAKWAK-NH ${ }_{2} \mathbf{3 3}$ & - \\
\hline
\end{tabular}

Table 6.2: Melting temperatures $\left(T_{m}\right)$ of the synthesized helical 15-residue and 21-residue systems with and without nucleobase-incorporation

Nucleobase-incorporation led to a higher stability for $\mathbf{2 9}$ than for oligomer $\mathbf{2 8}$. The 15-residue system gave $10^{\circ} \mathrm{C}$ higher stability even though the 21-residue system has two additional basepairs. In further studies the stability should be investigated by analyzing longer and shorter sequences. Using the basepair adenine/thymine instead of guanine/cytosine different stabilities regarding pairing behaviour of the recognition unit might be shown.

Another nucleobase-incorporation was performed into the linear micropeptide MCoTi29 48. Replacing the arginine unit by the nucleobase guanine gave remaining biological activity meaning that bicyclic heteroaromates with its additional protondonor-aceptor-functionalties might be an interesting alternative for native peptideand protein-modifications.

In conclusion, this thesis dealt with the properties of nucleobase-functionalized peptides. Influences of aromatic sidechains on the structure and aggreagation of peptides could be shown. 


\section{Experimenteller Teil}

\subsection{Allgemeine Arbeitstechniken}

\section{Dünnschichtchromatographie (DC)}

Es wurden Dünnschichtfertigplatten mit Aluminiumfolie als Trägermaterial der Firma Merck verwendet (Kieselgel 60 F254, Schichtdicke $0.25 \mathrm{~mm}$ ). Zum Nachweis der Substanzen diente Fluoreszenzlöschung bei $254 \mathrm{~nm}$ sowie die Tauchfärbung mit Ninhydrin-Lösung (500 mL Ethanol, 3.00 mL Essigsäure, $1.00 \mathrm{~g}$ Ninhydrin) unter anschließendem Erhitzen mit einem Heißluftgebläse.

\section{Flash-Säulenchromatographie (FC)}

Als Säulenmaterial wurde Kieselgel 60 der Firma Merck mit einer Korngröße von 40 $62 \mu \mathrm{m}$ verwendet. Die Säulen wurden nass mit 50 -100fachem Überschuss an Kieselgel befüllt und das Substanzgemisch entweder als konzentrierte Lösung (im Laufmittel) oder adsorbiert an Kieselgel aufgetragen. Die Länge und der Durchmesser der verwendeten Säulen sowie die Laufmittel sind jeweils angegeben.

\section{Reverse Phase Chromatographie (RP)}

Es wurde RP-Kieselgel der Firma YMC (ODS-A, AA06S50, $60 \AA$, S-50 $\mu \mathrm{m}, \mathrm{C}-18$ ) verwendet. Die Substanzen wurden in wenig Wasser suspendiert und auf die mit Wasser äquilibrierte Säulenpackung gegeben. Der Gehalt an Methanol wurde schrittweise erhöht.

\section{Hochleistungsflüssigkeitschromatographie (HPLC)}

Analytische und präparative HPLC wurden an Geräten der Firma Pharmacia (Äkta Basic, P900, UV 900) durchgeführt. Die Analytik wurde mittels YMC-Säulen (J'sphere ODS-H80, $250 \times 4.6 \mathrm{~mm}, 4 \mu \mathrm{m}, 80 \AA$, C-18, Fluss: $1 \mathrm{~mL} / \mathrm{min}$ und J'sphere ODS - AM, $250 \times 4.6 \mathrm{~mm}, 5 \mu \mathrm{m}, 120 \AA$, C-18, Fluss: $1 \mathrm{~mL} / \mathrm{min})$ durchgeführt. Zur Bestimmung der Enantiomerenreinheit wurde eine Sephasil Peptide Säule (250 x $4.6 \mathrm{~mm}, 5 \mu \mathrm{m}, 100 \AA$, C-18, Fluss: $1 \mathrm{~mL} / \mathrm{min})$ verwendet. Die präparative Trennung erfolgte mit einer YMC-Säule (J'sphere ODS-H80, $250 \times 20 \mathrm{~mm}, 4 \mu \mathrm{m}$, $80 \AA ̊$, C-18, Fluss: $10 \mathrm{~mL} / \mathrm{min})$. 
Die Gradienten der Laufmittel A $\left(\mathrm{H}_{2} \mathrm{O}, 0.1 \% \mathrm{TFA}\right)$ und B $\left(\mathrm{ACN} / \mathrm{H}_{2} \mathrm{O}\right.$ (8:2), $0.1 \%$ TFA) bzw. B' (Acetonitril/ $\mathrm{H}_{2} \mathrm{O}$ (9:1), $0.1 \%$ TFA) sind jeweils angegeben. Die UV-Detektion erfolgte bei den Wellenlängen 215 nm, 254 nm, $260 \mathrm{~nm}$ und $280 \mathrm{~nm}$.

\section{Circulardichroismus-Spektroskopie (CD)}

Die Messungen wurden an einem JASCO J-810A Spektropolarimeter, ausgerüstet mit einer JASCO PTC423S Temperiereinheit, durchgeführt. Der Probenraum wurde permanent mit Stickstoff (3-5 L/min) gespült. Die Temperatur wurde im Temperierblock direkt neben der Küvette gemessen. Alle Messungen wurden mit fünf Akkomodationen, $1.00 \mathrm{~nm}$ bandwidth, $1.00 \mathrm{~s}$ response und mit einem scan speed von $100 \mathrm{~nm} / \mathrm{min}$ durchgeführt. Messungen in Lösung wurden in Quarzglasküvetten $(I=1.00 \mathrm{~cm})$ vorgenommen.

\section{UV-Spektroskopie}

Die Schmelzkurven wurden mit einem JASCO V-550 Spektrometer, ausgerüstet mit einer programmierbaren JASCO ETC-505S/ETC-505T Peltier-Temperiereinheit, aufgenommen. Die Spektren wurden in einer Quarzglasküvette $(I=1.00 \mathrm{~cm})$ bei den Wellenlängen $250 \mathrm{~nm}, 255 \mathrm{~nm}, 260 \mathrm{~nm}$ und $280 \mathrm{~nm}$ aufgenommen. Der Probenraum wurde permanent mit Stickstoff ( $3-5 \mathrm{~L} / \mathrm{min}$ ) gespült. Die Temperaturen wurden im Temperierblock direkt neben der Küvette gemessen.

Es wurde folgendes Temperaturprogramm für die temperaturabhängigen UVMessungen verwendet:

$20^{\circ} \mathrm{C} \rightarrow 80^{\circ} \mathrm{C}(10 \mathrm{~min}) \rightarrow 80^{\circ} \mathrm{C}(3 \mathrm{~min}) \rightarrow-2^{\circ} \mathrm{C}(26 \mathrm{~min}) \rightarrow-2^{\circ} \mathrm{C}(180 \mathrm{~min})$

$\rightarrow 80{ }^{\circ} \mathrm{C}(180 \mathrm{~min}) \rightarrow-2^{\circ} \mathrm{C}(180 \mathrm{~min}) \rightarrow-2^{\circ} \mathrm{C}(180 \mathrm{~min}) \rightarrow 80^{\circ} \mathrm{C}(180 \mathrm{~min})$

$\rightarrow-2^{\circ} \mathrm{C}(180 \mathrm{~min}) \rightarrow 28^{\circ} \mathrm{C}(5 \mathrm{~min})$

Die Hyperchromizität $(H \%)$ ist definiert als

$$
H \%=\frac{\left(A_{T}-A_{0}\right) \cdot 100}{A_{0}}
$$

wobei $A_{T}$ die Absorption bei der Messtemperatur $T$ und $A_{0}$ der kleinste Absorptionswert eines Entpaarungsexperimentes ist. Die Konzentrationen (c) der Oligomer-Lösungen wurden über die Absorption $(A)$ der Nukleobasen durch das Lambert Beer'sche Gesetz bestimmt. 
Lambert Beer'sches Gesetz: $\quad c=\frac{A}{\varepsilon \cdot 1}$

Gemessen wurde in einer Quarzküvette $(I=1.00 \mathrm{~cm})$. Unter Annahme, dass die Extinktion der Nukleoaminosäuren durch die Heterobasen erfolgt, wurden die Extinktionskoeffizienten $\left(\varepsilon_{254} \mathrm{~nm}\right)$ der Peptidnukleinsäuren in erster Näherung durch Addition der Extinktionskoeffizienten der Nukleoaminosäuren berechnet. ${ }^{[136]}$

\section{Massenspektrometrie (MS)}

Die ESI-Massenspektren wurden an einem Gerät der Firma Finnigan (Typ LCQ oder TSQ 7000) aufgenommen. Die Aufnahme der EI-Massenspektren erfolgte an einem Instrument der Firma Varian (Typ MAT 731). Die Aufnahme der hochaufgelösten ESI-Massenspektren (HR-MS) erfolgte an einem APEX-Q IV 7T-Spektrometer der Firma Bruker.

\section{Infrarot-Spektroskopie (IR)}

Die Aufnahme der IR-Spektren erfolgte an einem Gerät der Firma Perkin Elmer Typ 1600 Series FT-IR unter Benutzung von KBr-Presslingen.

\section{Optische Drehung}

Die Drehwerte wurden mit einem Polarimeter 241 der Firma Perkin Elmer gemessen. Der spezifische Drehwert $[\alpha]_{D}^{20}$ ergibt sich aus $[\alpha]_{\mathrm{D}}^{20}=\frac{\alpha \cdot 100}{c \cdot l}$.

Hierbei stellt $\alpha$ den gemessenen Drehwert bei $20^{\circ} \mathrm{C}$ und der Wellenlä nge $589 \mathrm{~nm}, c$ die Konzentration (in g/100 mL) und / die Küvettenlänge (hier $1.00 \mathrm{dm}$ ) dar.

\section{Kernspinresonanzspektroskopie (NMR)}

Die NMR-Spektren wurden an Varian Unity 300 oder Varian INOVA 600 Spektrometern aufgenommen. Die Probentemperatur betrug im Fall von $\mathrm{CDCl}_{3} 27^{\circ} \mathrm{C}$ und für $\left[D_{6}\right] D M S O$, falls nicht anders angegeben, $35^{\circ} \mathrm{C}$. Die che mische Verschiebung der Signale ist in Einheiten der $\delta$-Skala registriert (TMS $=0 \mathrm{ppm})$. Als interner Standard dienten die Resonanzsignale der Restprotonen der verwendeten deuterierten Lösungsmittel; $\mathrm{CDCl}_{3}: 7.24 \mathrm{ppm}$ ( $\left.{ }^{1} \mathrm{H}-\mathrm{NMR}\right)$ und $77.0 \mathrm{ppm}\left({ }^{13} \mathrm{C}-\mathrm{NMR}\right)$, [D $\left.\mathrm{D}_{6}\right] \mathrm{DMSO}$ : $2.49 \mathrm{ppm}\left({ }^{1} \mathrm{H}-\mathrm{NMR}\right), 39.5 \mathrm{ppm}\left({ }^{13} \mathrm{C}-\mathrm{NMR}\right)$. Die Multiplizitäten der Signale 
werden durch die Abkürzungen $\mathrm{s}=$ Singulett, $\mathrm{d}=$ Dublett, $\mathrm{dd}=$ Dublett vom Dublett, $\mathrm{t}=$ Triplett, $\mathrm{q}=$ Quartett, $\mathrm{m}=$ Multiplett, $\mathrm{s} b r=$ breites Singulett charakterisiert. Die Kopplungskonstanten $J$ sind in Hertz $(\mathrm{Hz})$ angegeben. ${ }^{13} \mathrm{C}-\mathrm{NMR}$-Spektren wurden als ${ }^{1} \mathrm{H}$-Breitbandentkoppelte oder als ATP-Spektren aufgenommen. Die Signalzuordnung erfolgte mit Hilfe von $\left[{ }^{1} \mathrm{H},{ }^{1} \mathrm{H}\right]$-COSY- und HSQC-Experimenten.

\section{Automatisierte Festphasensynthese}

Die automatisierte Synthese einiger Peptide erfolgte an einem ABI 433A Syntheziser der Firma Applied Biosystems. Als Synthese-Protokoll wurde ein FastMoc 0.1 Modus verwendet. Die genaue Beschreibung des angewendeten Protokolls erfolgt in AAV4.

\section{Reagenzien}

Die verwendeten Harze wurden von der Firma Novabiochem bezogen. Die Peptidkupplungsreagenzien wurden von Applied Biosystems, IRIS Biotech und Novabiochem erhalten. Die Aminosäurederivate wurden von Novabiochem, Fluka, MultiSyntech und Bachem bezogen. Alle anderen Reagenzien stammen von Fluka, Sigma-Aldrich, Lancaster und Acros und entsprachen der Qualität zur Synthese.

\section{Lösungsmittel}

Alle technischen Lösungsmittel wurden vor Gebrauch destilliert. DMF abs., NMP abs. und THF abs. wurden von Fluka in der Qualität puriss. absolut bezogen. Pyridin und Dichlormethan wurden über $\mathrm{CaH}_{2}$ getrocknet und destilliert. Lösungsmittel für die HPLC wurden vor Verwendung durch Rühren im Vakuum entgast. Acetonitril (HPLCQualität) wurde von Acros Organics bezogen und Wasser wurde mittels einer Wasseraufbereitungsanlage Simplicity der Firma Milipore aufbereitet.

\section{Reaktionen}

Für luft- und feuchtigkeitsempfindliche Reaktionen diente Argon (99.996\%) als Inertgas. Die Glasgeräte wurden zuvor mittels Heißluftgebläse im Vakuum ausgeheizt und mit Argon gespült. 


\subsection{Allgemeine Arbeitsvorschriften (AAV)}

\section{AAV1: Bestimmung der Enantiomerenreinheit ${ }^{[104,105]}$}

$\mathrm{Zu}$ der jeweiligen Alanyl-Nukleoaminosäure (5.00 $\mu \mathrm{mol}, 1.00$ eq.) wurde TFA $(120 \mu \mathrm{L})$ gegeben und die Lösung für 10 min bei RT geschüttelt. Nachdem TFA im Hochvakuum entfernt wurde, wurde der Rückstand in Wasser (175 $\mu \mathrm{L}$ ) sowie $\mathrm{NaHCO}_{3}$-Puffer ( $\left.\mathrm{pH} 9, c=1.20 \mathrm{~mol} / \mathrm{L}, 175 \mu \mathrm{L}\right)$ aufgenommen und hierzu eine Lösung von $N$-Boc-L-Ala-OSu (8.68 mg, $30.0 \mu$ mol, 6.00 eq.) in THF (350 $\mu$ L) gegeben. Die Reaktionsmischung wurde für $5 \mathrm{~h}$ bei RT geschüttelt. Nachdem mit $10 \%$ iger TFA auf pH 2.5 angesäuert wurde, wurde der Feststoff filtriert, $5.00 \mu \mathrm{L}$ für HPLC-Analytik entnommen und die Diastereomere an einer RP-C-18 Säule getrennt. Die Integration der Absorptionsbanden bei 254 nm ergab das jeweilige Enantiomerenverhältnis.

\section{AAV2: Manuelle Synthese der PNA-Oligomere nach Boc-Festphasenstrategie}

Die gemischten PNA-Oligomere wurden über Boc-Festphasensynthese nach folgendem Synthesezyklus an N-Boc-L-Lys(2-Cl-Z)-MBHA-Harz (Belegungsdichte $n=0.590-0.660 \mathrm{mmol} / \mathrm{g}$ ) aufgebaut. Die Festphasensynthese fand in einer kleinen Säule statt, welche zur Reaktion langsam rotiert wurde.

\section{Quellen}

Das Harz wurde 2 h in DCM/NMP (1:1) gequollen.

\section{Entschützen}

Das harzgebundene Peptid wurde mit einer Lösung von $5 \% \mathrm{~m}$-Kresol in TFA ( $1 \times 5 \mathrm{~min}, 1 \times 10 \mathrm{~min}$, jeweils $2 \mathrm{~mL}$ ) bei RT umgesetzt. Anschließend wurde mit DCM/NMP $(1: 1,5 \times 2 \mathrm{~mL})$ gewaschen.

\section{Entstapeln}

Zum Neutralisieren wie auch zum Entstapeln wurde mit Pyridin $(5 \times 2 \mathrm{~mL})$ gewaschen. Nachfolgend wurde das Harz mittels Druckluft für 3 min trockengeblasen.

\section{Kupplung}

Boc-geschützte Nukleoaminosäure (5.00 eq.) wurde jeweils mit HATU (4.50 eq.) und HOAt (5.00 eq.) zu dem Harz gegeben und in NMP gelöst. Nach 5 min wurde DIPEA 84 
(12.0 eq.) zugegeben und die Reaktionsmischung für die jeweils angegebene Zeit rotiert. Boc-geschützte Aminosäure (5.00 eq.) wurde jeweils mit HBTU (4.50 eq.), HOBt (5.00 eq.) und DIPEA (12.0 eq.) in NMP gelöst zu dem Harz gegeben und die Reaktionsmischung für die jeweils angegebene Zeit rotiert. Die Kupplung von Boc$\operatorname{Trp}(\mathrm{Boc})-\mathrm{OH}$ und von Boc-Tyr(OtBu)-OH sowie die Kupplung der ersten Aminosäure wurde als Doppelkupplung $(2 \times 45 \mathrm{~min})$ durchgeführt.

\section{Waschen}

Die überschüssigen Kupplungsreagenzien wurden nach der Kupplung vom Harz gewaschen. Dazu wurde zunächst mit DCM/NMP $(1: 1,5 \times 2 \mathrm{~mL})$, danach mit Piperidin/NMP (1:9, $3 \times 2 \mathrm{~mL})$ und erneut mit DCM/NMP $(1: 1,5 \times 2 \mathrm{~mL})$ gespült.

\section{Capping}

Um die Bildung unerwünschter Peptidsequenzen zu vermeiden, wurden mögliche freie Aminofunktionen des harzgebundenen Peptides mit einer Lösung aus $\mathrm{Ac}_{2} \mathrm{O} / \mathrm{DIPEA} / \mathrm{NMP}(1: 1: 8,2 \times 5 \mathrm{~min}, 2 \mathrm{~mL})$ acetyliert. Anschließend wurde mit DCM/NMP $(1: 1,5 \times 2 \mathrm{~mL})$, Piperidin/NMP $(1: 9,3 \times 2 \mathrm{~mL})$ und DCM/NMP (1:1, $5 \times 2 \mathrm{~mL})$ gespült.

Die Schritte Entschützten bis Capping wurden unter Verwendung der jeweiligen Nukleoaminosäure bzw. Aminosäure bis zum Ende der gewünschten Sequenz wiederholt. Nach der letzten Kupplung wurde der Capping-Schritt ausgelassen. Stattdessen wurde das Harz mit DCM/NMP (1:1, $5 \times 2 \mathrm{~mL})$, DCM $(5 \times 2 \mathrm{~mL})$ und mit $\mathrm{MeOH}(5 \times 2 \mathrm{~mL})$ gewaschen. Nachdem das Harz im Vakuum über $\mathrm{KOH}$ für wenigstens vier Stunden getrocknet wurde, wurde das Harz der Abspaltlösung (TFMSA/m-Kresol/TFA (1:1:8, $2 \mathrm{~mL}))$ für $2 \mathrm{~h}$ bei $0{ }^{\circ} \mathrm{C}$ und dan ach für $2 \mathrm{~h}$ bei RT ausgesetzt. Das erhaltene Filtrat wurde evaporiert und der Rückstand mit kaltem $\mathrm{Et}_{2} \mathrm{O}$ bzw. tert-Butylmethylether prezipitiert. Der so erhaltene Feststoff wurde zentrifugiert und der Ether abpipettiert. Zur Reinigung wurde dieser Vorgang 2-3 mal wiederholt und der erhaltene Feststoff aus Wasser lyophilisiert. 


\section{AAV3: Manuelle Synthese der linearen Peptide nach Fmoc-Festphasenstrategie}

Die Peptide wurden mittels Festphasensynthese nach dem nachfolgenden Synthesezyklus an NovaSynTGR-Harz (Belegungsdichte $n=0.200 \mathrm{mmol} / \mathrm{g}$ ) aufgebaut. Die Festphasensynthese fand in einer Spritze mit eingelegter Fritte statt, welche zur Reaktion geschüttelt wurde.

\section{Quellen}

Das Harz wurde $2 \mathrm{~h}$ in DCM/NMP (1:1) gequollen.

\section{Entschützen}

Das harzgebundene Peptid wurde mit einer Lösung von $20 \%$ Piperidin in NMP $(4 \times 3 \mathrm{~min}, 2 \mathrm{~mL})$ geschüttelt. Anschließend wurde mit NMP gespült.

\section{Kupplung}

Die Fmoc-geschützte Nukleoaminosäure (5.00 eq.) wurde jeweils mit HATU (4.50 eq.) und HOAt (5.00 eq.) zu dem Harz gegeben und in NMP gelöst. Nach 5 min wurde DIPEA (10.0 eq.) zugegeben und die Reaktionsmischung für die jeweils angegebene Zeit geschüttelt.

Fmoc-geschützte Aminosäure (5.00 eq. bzw. 4.00 eq.) wurde jeweils mit HBTU (4.50 eq.) und HOBt (5.00 eq.) in NMP gelöst und DIPEA (10.0 eq.) zugegeben.

Die Kupplung der ersten Aminosäure wurde folgendermaßen als Doppelkupplung ( $2 \times 1 \mathrm{~h})$ durchgeführt: Die erste Kupplung erfolgte mit DIC (10.0 eq.) und $\mathrm{HOBt}$ (5.00 eq.) in NMP, die zweite mit HBTU (4.50 eq.), HOBt (5.00 eq.) und DIPEA (10.0 eq.) in NMP. Die Lösung der übrigen Aminosäuren wurde für die jeweils angegebene Zeit geschüttelt. Die Kupplung von Fmoc-Trp-OH und Fmoc-Pro-OH wurden als Doppelkupplung (2 × 45 min) durchgeführt.

\section{Waschen}

Die überschüssigen Kupplungsreagenzien wurden nach der Kupplung vom Harz gewaschen. Dazu wurde zunächst mit DCM/NMP (1:1, $5 \times 2 \mathrm{~mL})$, danach mit DCM $(3 \times 2 \mathrm{~mL})$ und erneut mit DCM/NMP $(1: 1,5 \times 2 \mathrm{~mL})$ gespült. 


\section{Capping}

Um die Bildung unerwünschter Peptidsequenzen zu vermeiden, wurden mögliche freie Aminofunktionen des harzgebundenen Peptides mit einer Lösung aus $\mathrm{Ac}_{2} \mathrm{O} / \mathrm{DIPEA} / \mathrm{NMP}(1: 1: 8,2 \times 5 \mathrm{~min}, 2 \mathrm{~mL})$ acetyliert. Anschließend wurde mit DCM/NMP (1:1, $5 \times 2 \mathrm{~mL})$, Piperidin/NMP (1:9, $3 \times 2 \mathrm{~mL})$ und DCM/NMP (1:1, $5 \times 2 \mathrm{~mL})$ gespült.

Die Schritte Entschützen bis Capping wurden unter Verwendung der jeweiligen Aminosäure bis zum Ende der gewünschten Sequenz wiederholt. Nach der letzten Kupplung wurde der Entschützungsschritt wiederholt und nach dem Waschen zusätzlich mit DCM $(5 \times 2 \mathrm{~mL})$ und mit $\mathrm{MeOH}(5 \times 2 \mathrm{~mL})$ gewaschen. Nachdem das Harz im Vakuum über $\mathrm{KOH}$ für $24 \mathrm{~h}$ getrocknet wurde, wurde das Harz mit der jeweiligen Abspaltlösung für $2 \mathrm{~h}$ versetzt. Die Standardlösung $\mathrm{H}_{2} \mathrm{O} / T I S / A n i s o l / D T T / T F A$ (0.5:0.5:0.5:1:23) wurde für alle Peptide eingesetzt. Das erhaltene Filtrat wurde evaporiert und der Rückstand mit kaltem $\mathrm{Et}_{2} \mathrm{O}$ bzw. tert-Butylmethylether prezipitiert. Die Mischung wurde zentrifugiert, der $\mathrm{Et}_{2} \mathrm{O}$ abpipettiert und dieser Vorgang 2-3 mal wiederholt. Der Feststoff wurde aus $\mathrm{H}_{2} \mathrm{O}$ /Dioxan (1:2) lyophilisiert.

\section{AAV4: Automatische Synthese der linearen Peptide nach Fmoc-}

\section{Festphasenstrategie}

Die automatische Festphasensynthese wurde an NovaSynTGR-Harz (Belegungsdichte $n=0.200 \mathrm{mmol} / \mathrm{g}$ ) durchgeführt. Das Volumen der Spülreagenzien betrug je nach aktueller Durchflussgeschwindigkeit 2-3 mL. Der sequenzielle Aufbau des Peptids erfolgte nach folgendem Schema:

1. Für die Entschützung der Fmoc-Schutzgruppe wurde das Harz zuerst mit $22 \%$ Piperidin in NMP (2 min, $1 \mathrm{~mL}$ ) versetzt. Nach Filtration wurde erneut $22 \%$ Piperidin in NMP (8 $\min , 1 \mathrm{~mL}$ ) zugegeben.

2. Zur Reinigung des Harzes wurde es mit NMP (4 $\mathrm{x})$ gespült und im Stickstoffstrom getrocknet. 
3. Für die Kupplung der Aminosäuren, wurden diese (10.0 eq.) in NMP (2 mL) gelöst und mit einer Lösung von HBTU/HOBt $(0.450 \mathrm{M}, 2.00 \mathrm{~mL}$, 9.00 eq.) in NMP präaktiviert (6 min). Nach dem Zusatz einer DIPEALösung (2.00 M, 2.00 mL, 20.0 eq.) in DMF wurde die Mischung zum Harz gegeben und geschüttelt (45 min).

4. Nach Spülen des Harzes mit NMP $(2 x)$ wurde mit einer Lösung aus $\mathrm{Ac}_{2} \mathrm{O} / \mathrm{DMF}(1: 9)$ gecappt.

Die Schritte 1-4 wurden bis zum Erreichen der gewünschten Oligomerlänge wiederholt. Nachdem Schritt 1 zum terminalen Entschützen durchgeführt wurde, wurde mit NMP $(4 \mathrm{x})$ und DCM $(2 \mathrm{x})$ gespült. Das Harz wurde für mindestens $3 \mathrm{~h}$ über $\mathrm{KOH}$ im Vakuum getrocknet. Die Abspaltung des Peptides vom Harz erfolgte entsprechend AAV3. 


\subsection{Synthetisierte Verbindungen}

\section{Boc-Alanyl-Nukleoaminosäuren}

(S)-N-tert-Butoxycarbonyl- $\beta$-(2-amino-6-chlor-9-purinyl)-alanin (8)

(R)-N-tert-Butoxycarbonyl- $\beta$-(2-amino-6-chlor-9-purinyl)-alanin (ent-8)

(S)- $\beta$-(9-Guaninyl)-alanin (47)

(R)- $\beta$-(9-Guaninyl)-alanin (ent-47)

(S)- $N$-tert-Butoxycarbonyl- $\beta$-(9-guaninyl)-alanin (Boc-L-AlaG-OH) (6)

(R)- $N$-tert-Butoxycarbonyl- $\beta$-(9-guaninyl)-alanin (Boc-D-AlaG-OH) (ent-6)

$N$-4-Benzyloxycarbonyl-1-cytosin (5)

(S)-N-tert-Butoxycarbonyl- $\beta$-(N-4-benzyloxycarbonyl-1-cytosinyl)-alanin (Boc-L-AlaC $\left.{ }_{Z}-\mathrm{OH}\right)(7)$

(R)-N-tert-Butoxycarbonyl- $\beta$-( $N$-4-benzyloxycarbonyl-1-cytosinyl)-alanin (Boc-D-AlaC $\mathrm{Z}-\mathrm{OH})($ ent-7)

\section{Boc-Homoalanyl-Nukleoaminosäuren}

(S)-N-tert-Butoxycarbonyl- $\gamma$-hydroxy-homoalanylbenzylester (10)

(R)-N-tert-Butoxycarbonyl- $\gamma$-hydroxy-homoalalanylbenzylester (ent-10)

(S)-N-tert-Butoxycarbonyl- $y$-brom-homoalanylbenzylester (11)

(R)-N-tert-Butoxycarbonyl- $y$-brom-homoalanylbenzylester (ent-11)

(S)-N-tert-Butoxycarbonyl- $\gamma$-(2-amino-6-chlor-9-purinyl)-homoalanylbenzylester (12)

(R)-N-tert-Butoxycarbonyl- $y$-(2-amino-6-chlor-9-purinyl)-homoalanylbenzylester (ent-12)

(S)-y-(9-Guaninyl)-homoalanylbenzylester (49)

(R)- $\gamma$-(9-Guaninyl)-homoalanylbenzylester (ent-49)

(S)- $\gamma$-(9-Guaninyl)-homoalanin (36)

(R)- $y$-(9-Guaninyl)-homoalanin (ent-36)

(S)-N-tert-Butoxycarbonyl- $\gamma$-(9-guaninyl)-homoalanin (Boc-L-HalG-OH) (13)

(R)-N-tert-Butoxycarbonyl- $\gamma$-(9-guaninyl)-homoalanin (Boc-D-HalG-OH) (ent-13)

(S)-N-tert-Butoxycarbonyl- $\gamma$-(N-4-benzyloxycarbonyl-1-cytosinyl)-homoalanylbenzylester (14)

(R)-N-tert-Butoxycarbonyl- $y$-(N-4-benzyloxycarbonyl-1-cytosinyl)-homoalanylbenzylester (ent-14) 
(S)-N-tert-Butoxycarbonyl- $\gamma$-(N-4-benzyloxycarbonyl-1-cytosinyl)-

homoalanylbenzylester (Boc-L-HalC $\left.\mathrm{Z}_{\mathrm{Z}} \mathrm{OH}\right)$ (15)

(R)-N-tert-Butoxycarbonyl- $\gamma$-(N-4-benzyloxycarbonyl-1-cytosinyl)-

homoalanylbenzylester (Boc-D-HalC $\left.\mathrm{H}_{-} \mathrm{OH}\right)$ (ent-15)

\section{Fmoc-Alanyl-Nukleoaminosäuren}

(S)- $N$-Fluorenylmethyloxycarbonyl- $\beta$-(9-guaninyl)-alanin

(Fmoc-L-AlaG-OH) (46)

(R)- $N$-Fluorenylmethyloxycarbonyl- $\beta$-(9-guaninyl)-alanin

(Fmoc-D-AlaG-OH) (ent-46)

\section{Fmoc-Homoalanyl-Nukleoaminosäuren}

(S)-N-Fluorenylmethyloxycarbonyl- $y$-(9-guaninyl)-homoalanin

(Fmoc-L-HalG-OH) (34)

(S)- $y$-(4-Benzyloxycarbonyl-1-cytosinyl)-homoalanin (37)

(S)-N-Fluorenylmethyloxycarbonyl- $y$-(4-benzyloxycarbonyl-1-cytosinyl)-homoalanin (Fmoc-L-HalC $\left.\mathrm{Z}_{\mathrm{Z}} \mathrm{OH}\right)(35)$

\section{Stilben-Linker}

4,4'-trans-Stilbendicarboxylat (17)

4,4'-trans-Stilbendicarbonsäuredichlorid (18)

trans-Stilben-4-(methylcarbonsäure-methylcarbamoyl)-4'-(tert-butoxycarbonyl)aminoethylcarbamoyl) (2') + 4,4'-trans-Stilben-(tert-butoxycarbonyl)-aminoethylcarbamoyl (19)

trans-Stilben-4-(methylcarbonsäure-methylcarbamoyl)-4'-(tert-butoxycarbonyl)aminoethylcarbamoyl) (2') + 4,4'-trans-Stilben-(methylcarbonsäure-methylcarbamoyl)-aminoethylcarbamoyl (20) 


\section{Synthese der gemischten Peptidnukleinsäuren}

H-Gly-Val-Cys-Pro-AlaG-Ile-Leu-Lys-Lys-Cys-Arg-Arg-Asp-Ser-Asp-Cys-Pro-Gly-AlaCys-Ile-Cys-Arg-Gly-Asn-Gly-Tyr-Cys-Gly- $\mathrm{NH}_{2}$ (47) nach Fmoc-Festphasenstrategie

H-Gly-Val-Cys-Pro-AlaG-Ile-Leu-Lys-Lys-Cys-Arg-Arg-Asp-Ser-Asp-Cys-Pro-Gly-AlaCys-Ile-Cys-Arg-Gly-Asn-Gly-Tyr-Cys-Gly-NH 2 (ent-47)

nach Fmoc-Festphasenstrategie

Ac-Lys-Ala-Tyr-Lys-Ala-Trp-Ala-Glu-Ala-Tyr-Ala-Lys-Trp-Ala-Lys- $\mathrm{NH}_{2}$ (32) nach Boc-Festphasenstrategie

Ac-Lys-Ala-Tyr-Lys-Ala-Trp-Ala-Glu-Ala-Tyr-Ala-Lys-Trp-Ala-Lys- $\mathrm{NH}_{2}$ (32) nach Fmoc-Festphasenstrategie

Ac-Lys-Ala-HalC-Lys-Ala-HalG-Ala-Glu-Ala-HalC-Ala-Lys-HalG-Ala-Lys- $\mathrm{NH}_{2}$ (28) nach Fmoc-Festphasenstrategie

Ac-Lys-Ala-HalC-Lys-Ala-HalC-Ala-Glu-Ala-HalG-Ala-Lys-HalG-Ala-Lys- $\mathrm{NH}_{2}$ (29) nach Boc-Festphasenstrategie

Ac-Lys-Ala-HalG-Lys-Ala-HalC-Ala-Glu-Ala-HalG-Ala-Lys-HalC-Ala-Lys- $\mathrm{NH}_{2}$ (28) nach Boc-Festphasenstrategie

Ac-Lys-Ala-Trp-Lys-Ala-Trp-Ala-Glu-Ala-Tyr-Ala-Lys-Trp-Ala-Lys-Ala-Tyr-Lys-AlaTyr-Ala- $\mathrm{NH}_{2}$ (33) nach Fmoc-Festphasenstrategie

Ac-Lys-Ala-HalG-Lys-Ala-HalG-Ala-Glu-Ala-HalC-Ala-Lys-HalG-Ala-Lys-Ala-HalCLys-Ala-HalC-Ala- $\mathrm{NH}_{2}$ (27) nach Boc-Festphasenstrategie 


\section{Synthese der gemischten Peptidnukleinsäuren mit Linker}

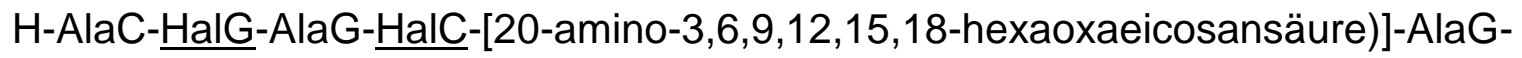
HalC-AlaC- $\underline{\text { HalG}}-$ Lys- $\mathrm{NH}_{2}$ (23)

H-AlaC- $\underline{\text { HalC}}-A l a G-\underline{H a l C}-A l a G-\underline{H a l G}-[20$-amino-3,6,9,12,15,18-hexaoxaeicosansäure)]-AlaC- $\underline{\mathrm{HalC}}-\mathrm{AlaG}-\underline{\mathrm{HalC}}-\mathrm{AlaG}-\underline{\mathrm{HalG}}-\mathrm{Lys}-\mathrm{NH}_{2}(\mathbf{2 4})$ 


\subsection{Synthese der Nukleoaminosäuren}

(S)-N-tert-Butoxycarbonyl- $\beta$-(2-amino-6-chlor-9-purinyl)-alanin (8) ${ }^{[17]}$<smiles>CC(C)(C)OC(=O)NC1COC1=O</smiles>

4<smiles>Nc1nc(Cl)c2nc[nH]c2n1</smiles>

48<smiles>CC(C)(C)OC(=O)N[C@@H](Cn1cnc2c(Cl)nc(N)nc21)C(=O)O</smiles>

8

$\mathrm{C}_{8} \mathrm{H}_{13} \mathrm{NO}_{4}[187.20] \quad \mathrm{C}_{5} \mathrm{H}_{4} \mathrm{CIN}_{5}[169.57]$ $\mathrm{C}_{13} \mathrm{H}_{17} \mathrm{CIN}_{6} \mathrm{O}_{4}[356.77]$

Unter Argon wurde zu einer Suspension von 2-Amino-6-chlorpurin (48, $1.76 \mathrm{~g}$, $10.4 \mathrm{mmol}$, 1.30 eq.) in DMSO $(5.00 \mathrm{~mL})$ innerhalb von $15 \mathrm{~min}$ DBU (1.36 mL, $1.39 \mathrm{~g}, 9.15 \mathrm{mmol}, 1.15$ eq.) zugetropft und anschließend $15 \mathrm{~min}$ bei RT gerührt. Innerhalb weiterer 15 min wurde eine Lösung von (S)-N-tert-ButoxycarbonylSerinlacton (4, $1.49 \mathrm{~g}, 7.96 \mathrm{mmol}, 1.00 \mathrm{eq}$.) in DMSO (5.00 mL) zugetropft. Nach $5 \mathrm{~h}$ Rühren bei RT wurde die Reaktion mittels Zugabe von HOAc $(0.501 \mathrm{~mL}, 8.76 \mathrm{mmol}$, 1.10 eq.) zum Abschluss gebracht. Das Lösungsmittel wurde im Hochvakuum entfernt und der Rückstand mittels FC an Kieselgel $(\mathrm{I}=12 \mathrm{~cm}, \varnothing=7 \mathrm{~cm}, \mathrm{EE} / \mathrm{MeOH}$ 8:2, Gradient $1 \%$ HOAc pro $1000 \mathrm{~mL}$ ) aufgereinigt. Es wurden $1.53 \mathrm{~g}(4.29 \mathrm{mmol}$, $54 \%$ ) der gewünschten Verbindung als weißer Feststoff isoliert.

DC $\left(\mathrm{CHCl}_{3} / \mathrm{MeOH} / \mathrm{H}_{2} \mathrm{O} / \mathrm{HOAc} 70: 30: 3: 0.3\right): \mathrm{R}_{\mathrm{f}}=0.25$.

${ }^{1} \mathrm{H}-\mathrm{NMR}\left(300 \mathrm{MHz},\left[\mathrm{D}_{6}\right] \mathrm{DMSO}\right): \delta=1.05$ (s, 1.5H, $t$-Bu-Rotamer), 1.25 (s, 7.5H, $t$ $\mathrm{Bu}$ ), 4.15 (dd, $J=14 \mathrm{~Hz}, J=10 \mathrm{~Hz}, 1 \mathrm{H}, \mathrm{H}-\beta)$, 4.24-4.27 (m, $1 \mathrm{H}, \mathrm{H}-\alpha), 4.46(\mathrm{~m}, 1 \mathrm{H}$; Hß), 6.90 (s br, 2H, NH$H_{2}$ ), 7.00 (d, J = $8 \mathrm{~Hz}, 1 \mathrm{H}, \mathrm{NHBoc}$ ), 7.92 (s, 1H, H-8) ppm.

${ }^{13} \mathrm{C}-\mathrm{NMR}\left(75 \mathrm{MHz},\left[\mathrm{D}_{6}\right] \mathrm{DMSO}\right): \delta=28.2\left(\mathrm{C}\left(\mathrm{CH}_{3}\right)_{3}\right), 44.2(\mathrm{C}-\beta), 53.2(\mathrm{C}-\alpha), 78.5$ $\left(\mathrm{C}\left(\mathrm{CH}_{3}\right)_{3}\right), 123.4$ (C-5), 143.6 (C-8), 149.3 (C-4), 154.4 (C-2), 155.3 (CONH), 159.9 (C4), $171.4(\mathrm{COOH}) \mathrm{ppm}$. 


\section{(R)-N-tert-Butoxycarbonyl- $\beta$-(2-amino-6-chlor-9-purinyl)-alanin (ent-8)}

Es wurde eine dem (S)-Enantiomer analoge Synthese durchgeführt. Die Charakterisierung über NMR-Spektroskopie ergab entsprechende Daten.

(S)- $\beta-(9-G u a n i n y l)-a l a n i n ~(47)^{[17]}$<smiles>CC(C)(C)OC(=O)NC(Cn1cnc2c(Cl)nc(N)nc21)C(=O)O</smiles>

8<smiles>Nc1nc2c(ncn2C[C@H](N)C(=O)O)c(=O)[nH]1</smiles>

47

$\mathrm{C}_{13} \mathrm{H}_{17} \mathrm{CIN}_{6} \mathrm{O}_{4}[356.77]$

Eine Lösung von (S)-N-tert-Butoxycarbonyl- $\beta$-(2-amino-6-chlor-9-purinyl)-alanin (8, $1.06 \mathrm{~g}, 2.97 \mathrm{mmol}, 1.00$ eq.) in TFA/ $\mathrm{H}_{2} \mathrm{O}(3: 1,12.2 \mathrm{~mL})$ wurde für $4 \mathrm{~d}$ bei RT gerührt. Die Reaktionsmischung wurde evaporiert und unter Zugabe von $1 \mathrm{~N} \mathrm{HCl}$ bis zur Trockene eingedampft.

DC (i-PrOH $/ \mathrm{H}_{2} \mathrm{O} / \mathrm{HOAc} / \mathrm{NaCl}$ 5:2:1: ges. $): \mathrm{R}_{\mathrm{f}}=0.17$.

${ }^{1} \mathrm{H}-\mathrm{NMR}\left(300 \mathrm{MHz},\left[\mathrm{D}_{6}\right] \mathrm{DMSO}\right): \delta=4.49-4.53(\mathrm{~m}, 2 \mathrm{H}, \mathrm{H}-\alpha, \mathrm{H}-\beta), 4.62-4.64(\mathrm{~m}, 1 \mathrm{H}$, $\mathrm{H}-\beta$ ), 7.45 (s br, 2H, NH$H_{2}$ Purin), 8.89 (s, 1H, H-8), 9.01 (s br, 2H, NH $H_{2}, 11.89$ (s, $1 \mathrm{H}$, NHPurin) ppm.

${ }^{13}$ C-NMR (75 MHz, [D $]$ DMSO): $\delta=44.2(\mathrm{C}-\beta), 51.1(\mathrm{C}-\alpha), 108.9$ (C-5), 138.0 (C-8), 150.5 (C-4), 153.9 (C-2), 155.9 (C-6), $168.0(\mathrm{COOH}) \mathrm{ppm}$. 


\section{(R)- $\beta$-(9-Guaninyl)-alanin (ent-47)}

Es wurde eine dem Enantiomer analoge Synthese durchgeführt. Die Charakterisierung über NMR-Spektroskopie ergab entsprechende Daten.

(S)-N-tert-Butoxycarbonyl- $\beta$-(9-guaninyl)-alanin (Boc-L-AlaG-OH) (6) ${ }^{[17]}$<smiles>Nc1nc2c(ncn2C[C@H](N)C(=O)O)c(=O)[nH]1</smiles>

47<smiles>CC(C)(C)OC(=O)NC(Cn1cnc2c(=O)[nH]c(N)nc21)C(=O)O</smiles>

6

$\mathrm{C}_{8} \mathrm{H}_{10} \mathrm{~N}_{6} \mathrm{O}_{3}[238.21]$

$\mathrm{C}_{13} \mathrm{H}_{18} \mathrm{~N}_{6} \mathrm{O}_{5}$ [338.33]

Das Rohprodukt (S)- $\beta$-(9-Guaninyl)-alanin (47, $70.7 \mathrm{~g}, 2.97 \mathrm{mmol}, 1.00 \mathrm{eq}$.) wurde in Dioxan/ $\mathrm{H}_{2} \mathrm{O} / 1 \mathrm{~N} \mathrm{NaOH}(2: 1: 1,20.0 \mathrm{~mL})$ aufgenommen, auf $0{ }^{\circ} \mathrm{C}$ gekühl t und mit $\mathrm{N}$ Di-tert-butyldicarboxylat $(0.710 \mathrm{~g}, 3.27 \mathrm{mmol}, 1.10 \mathrm{eq}$.) versetzt. Nach $45 \mathrm{~min}$ wurde die Reaktionsmischung auf RT erwärmt. Der pH-Wert wurde mittels $1 \mathrm{~N} \mathrm{NaOH}$ auf $\mathrm{pH}$ 9.0-9.5 eingestellt und die Mischung unter Kontrolle des $\mathrm{pH}$-Wertes für $70 \mathrm{~h}$ bei RT weitergerührt. Daraufhin wurde die Lösung unter Zugabe von $1 \mathrm{~N} \mathrm{HCl}$ auf pH 6.5 angesäuert und bis zur Trockene eingeengt. Das Rohprodukt wurde mittels FC an RP-Kieselgel $\left(\mathrm{I}=10 \mathrm{~cm}, \varnothing=2 \mathrm{~cm}, \mathrm{H}_{2} \mathrm{O}\right.$, Gradient $10 \% \mathrm{MeOH}$ pro $\left.500 \mathrm{~mL}\right)$ gereinigt. Es wurden $0.512 \mathrm{~g}(1.49 \mathrm{mmol}, 50 \%)$ der gewünschten Verbindung als weißer Feststoff isoliert.

DC (i-PrOH/ $\mathrm{H}_{2} \mathrm{O} / \mathrm{HOAc} / \mathrm{NaCl}$ 5:2:1: ges. $): \mathrm{R}_{\mathrm{f}}=0.60$.

${ }^{1} \mathrm{H}$-NMR $\left(300 \mathrm{MHz},\left[\mathrm{D}_{6}\right] \mathrm{DMSO}\right): \delta=0.97(\mathrm{~s}, 1.5 \mathrm{H}, t$-Bu-Rotamer), $1.24(\mathrm{~s}, 7.5 \mathrm{H}, t$ $\mathrm{Bu})$, 4.07-4.18 (m, $2 \mathrm{H}, \mathrm{H}-\alpha, \mathrm{H}-\beta), 4.50(\mathrm{~d}, J=10 \mathrm{~Hz}, 1 \mathrm{H}, \mathrm{H}-\beta), 6.49\left(\mathrm{~s} \mathrm{br}, 2 \mathrm{H}, \mathrm{NH} \mathrm{H}_{2}\right.$ ), $6.68(\mathrm{~d}, J=7 \mathrm{~Hz}, 1 \mathrm{H}, \mathrm{NHBoc}), 7.88$ (s, $1 \mathrm{H}, \mathrm{H}-8), 8.51$ (s, $1 \mathrm{H}, \mathrm{H}-6) \mathrm{ppm}$.

${ }^{13} \mathrm{C}$-NMR $\left(75 \mathrm{MHz},\left[\mathrm{D}_{6}\right] \mathrm{DMSO}\right): \delta=28.2\left(\mathrm{C}\left(\mathrm{CH}_{3}\right)_{3}\right), 44.3(\mathrm{C}-\beta), 54.3(\mathrm{C}-\alpha), 78.1$ $\left(\mathrm{C}\left(\mathrm{CH}_{3}\right)_{3}\right), 127.0$ (C-5), 143.3 (C-6), 148.5 (C-8), $153.4(\mathrm{C}-4), 155.2(\mathrm{CONH}), 160.6$ (C-2), $172.2(\mathrm{COOH}) \mathrm{ppm}$. 
Zur Bestimmung des Enantiomerenüberschusses wurde 6 nach AAV1 mit N-Boc-LAla-OSu umgesetzt: >96\% ee. HPLC: (Gradient: $5-18 \%$ B' in 30 min, like Diastereomer) $t_{r}=17.4 \mathrm{~min}$.

\section{(R)-N-tert-Butoxycarbonyl- $\beta$-(9-guaninyl)-alanin (Boc-D-AlaG-OH) (ent-6)}

Es wurde eine dem Enantiomer analoge Synthese durchgeführt. Die Charakterisierung über NMR-Spektroskopie ergab entsprechende Daten. Zur Bestimmung des Enantiomerenüberschusses wurde ent-6 nach AAV1 mit N-Boc-L-Ala-OSu umgesetzt: > $97 \%$ ee. HPLC: (Gradient: 5 - $18 \%$ B' in 30 min, unlike Diastereomer) $t_{r}=18.8$ min.

\section{N-4-Benzyloxycarbonyl-1-cytosin $(5)^{[17,137]}$}<smiles>Nc1cc[nH]c(=O)n1</smiles>

49

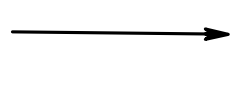

$\mathrm{C}_{4} \mathrm{H}_{5} \mathrm{~N}_{3} \mathrm{O}[111.10]$<smiles>O=C(Nc1cc[nH]c(=O)n1)OCc1ccccc1</smiles>

5

$\mathrm{C}_{12} \mathrm{H}_{11} \mathrm{~N}_{3} \mathrm{O}_{3}$ [245.24]

Zu einer Lösung von Cytosin (49, 15.0 g, 135 mmol, 1.00 eq.) in trockenem Pyridin (240 mL) wurde bei $0^{\circ} \mathrm{C}$ DMAP (3.30 g, $27.0 \mathrm{mmol}$, 0.200 eq.) zugegeben. Nach langsamen Zutropfen von Chlorameisensäurebenzylester $(84.0 \mathrm{~mL}, 297 \mathrm{mmol}$, 50 \%ige Lösung Toluol, 2.20 eq.) wurde auf RT aufgetaut und für 72 h gerührt. Die Lösung wurde mit Eiswasser $(150 \mathrm{~mL})$ hydrolisiert, der Niederschlag abfiltriert und mit $\mathrm{Et}_{2} \mathrm{O}(5 \times 80 \mathrm{~mL})$ gewaschen. Es wurden $22.2 \mathrm{~g}(90.5 \mathrm{mmol}, 67 \%)$ der gewünschten Verbindung als weißer Feststoff erhalten.

${ }^{1} \mathrm{H}-\mathrm{NMR}\left(300 \mathrm{MHz},\left[\mathrm{D}_{6}\right] \mathrm{DMSO}\right): \delta=5.10$ (s, 2H, CH $\left.\mathrm{H}_{2} \mathrm{Ph}\right), 6.95$ (d, J=7 Hz, $\left.1 \mathrm{H}, \mathrm{H}-5\right)$, 7.27-7.38 (m, 5H, Ph), 7.52 (d, J=7 Hz, 1H, H-6), 7.81 (s br, 2H, NH) ppm. 
(S)-N-tert-Butoxycarbonyl- $\beta$-( $N$-4-benzyloxycarbonyl-1-cytosinyl)-alanin (Boc-L$\left.\mathrm{AlaC}_{\mathrm{Z}}-\mathrm{OH}\right)(7)^{[17,137]}$<smiles>O=C(Nc1cc[nH]c(=O)n1)OCc1ccccc1</smiles>

4

$\mathrm{C}_{8} \mathrm{H}_{13} \mathrm{NO}_{4}[187.20]$
5

$\mathrm{C}_{12} \mathrm{H}_{11} \mathrm{~N}_{3} \mathrm{O}_{3}[245.24]$<smiles>CC(C)(C)OC(=O)N[C@@H](Cn1ccc(NC(=O)OCc2ccccc2)nc1=O)C(=O)O</smiles>

7

Zu einer Suspension von N-4-Benzyloxycarbonyl-1-cytosin (5, $6.00 \mathrm{~g}, 24.5 \mathrm{mmol}$, 2.00 eq.) in DMSO (12.0 mL) wurde DBU (2.70 mL, $2.79 \mathrm{~g}, 18.4 \mathrm{mmol}, 1.50$ eq.) gegeben. Innerhalb von 15 min wurde eine Lösung von (S)-N-tert-Butoxycarbonylserinlacton (4, $2.29 \mathrm{~g}, 12.2 \mathrm{mmol}, 1.00 \mathrm{eq}$.) in DMSO (5.00 mL) zugetropft und weitere $3 \mathrm{~h}$ bei RT gerührt. Die Reaktion wurde durch Zugabe von HOAc (1.10 mL, $18.3 \mathrm{mmol}$, 1.50 eq.) beendet. Das Produkt wurde mittels FC an Kieselgel $(I=10 \mathrm{~cm}, \varnothing=6 \mathrm{~cm}$, EE/MeOH 9:1, Gradient $1 \%$ HOAc auf $500 \mathrm{~mL}$ ) gereinigt. Nachfolgend wurde das Produkt aus Nitromethan umkristallisiert. Es wurden $2.59 \mathrm{~g}$ (5.99 mmol, 49 \%) der gewünschten Substanz als weißer Feststoff erhalten.

DC $\left(\mathrm{EE} / \mathrm{MeOH} / \mathrm{H}_{2} \mathrm{O} / \mathrm{HOAc} / \mathrm{NaCl}\right.$ 10:1:1:0.5: ges. $): \mathrm{R}_{\mathrm{f}}=0.32$.

${ }^{1} \mathrm{H}-\mathrm{NMR}\left(300 \mathrm{MHz},\left[\mathrm{D}_{6}\right] \mathrm{DMSO}\right): \delta=1.26(\mathrm{~s}, 9 \mathrm{H}, t-\mathrm{Bu}), 3.39(\mathrm{~m}, 1 \mathrm{H}, \mathrm{H}-\beta), 4.01-4.13$ $(\mathrm{m}, 1 \mathrm{H}, \mathrm{H}-\alpha), 4.45$ (dd, J=12.7 Hz, J=3.5 Hz, $1 \mathrm{H}, \mathrm{H}-\beta), 5.17$ (s, 2H, CH $\mathrm{H}_{2} \mathrm{Ph}$ ), 6.21 (s, 1H, NHBoc), $6.86(\mathrm{~d}, J=7.2 \mathrm{~Hz}, 1 \mathrm{H}, \mathrm{H}-5), 7.34-7.41(\mathrm{~m}, 5 \mathrm{H}, \mathrm{Ph}), 7.86$ (d, $J=7.2 \mathrm{~Hz}, 1 \mathrm{H}, \mathrm{H}-6), 10.58$ (s br, $1 \mathrm{H}, \mathrm{COOH}$ ) ppm.

${ }^{13} \mathrm{C}-\mathrm{NMR}\left(75 \mathrm{MHz},\left[\mathrm{D}_{6}\right] \mathrm{DMSO}\right): \delta=28.0\left(\mathrm{C}\left(\mathrm{CH}_{3}\right)_{3}\right), 52.5(\mathrm{C}-\beta), 53.2(\mathrm{C}-\alpha), 66.2$ $\left(\mathrm{CH}_{2} \mathrm{Ph}\right), 77.6\left(\mathrm{C}\left(\mathrm{CH}_{3}\right)_{3}\right), 93.2(\mathrm{C}-5), 127.7(m-\mathrm{Ph}), 127.9(p-\mathrm{Ph}), 128.3(o-\mathrm{Ph}), 135.9$ (C-4), 150.1 (C-6), 153.2 (C-2), 162.4 (COOBn), $171.2(\mathrm{COOH}) \mathrm{ppm}$.

Zur Bestimmung des Enantiomerenüberschusses wurde 7 nach AAV1 mit N-Boc-LAla-OSu umgesetzt: > $96 \%$ ee. HPLC: (Gradient: $10-50 \%$ B' in 30 min, like Diastereomer) $\mathrm{t}_{\mathrm{r}}=26.0 \mathrm{~min}$. 
(R)-N-tert-Butoxycarbonyl- $\beta$-( $N$-4-benzyloxycarbonyl-1-cytosinyl)-alanin (Boc-D$\left.\mathrm{AlaC}_{\mathrm{Z}}-\mathrm{OH}\right)($ ent-7)

Es wurde eine dem (S)-Enantiomer analoge Synthese durchgeführt. Die Charakterisierung über NMR-Spektroskopie ergab entsprechende Daten. Zur Bestimmung des Enantiomerenüberschusses wurde ent-7 nach AAV1 mit N-Boc-LAla-OSu umgesetzt: >96\% ee. HPLC: (Gradient: $10-50 \%$ B' in 30 min, unlike Diastereomer) $\mathrm{t}_{\mathrm{r}}=26.7 \mathrm{~min}$.

(S)-N-tert-Butoxycarbonyl- $\gamma$-hydroxy-homoalanylbenzylester $(10)^{[111]}$<smiles>CC(C)(C)OC(=O)NC(CC(=O)O)C(=O)Oc1ccccc1</smiles>

9

$\mathrm{C}_{16} \mathrm{H}_{21} \mathrm{NO}_{6}$ [323.34]

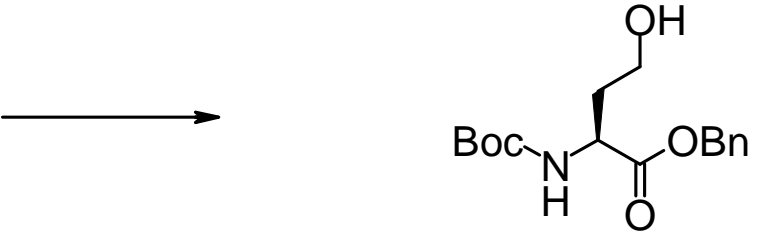

10

$\mathrm{C}_{16} \mathrm{H}_{23} \mathrm{NO}_{5}[309.36]$

Bei $0{ }^{\circ} \mathrm{C}$ wurde zu einer $\mathrm{BH}_{3} \cdot$ THF-Lösung $(31.0 \mathrm{~mL}, 31.0 \mathrm{mmol}$, 2.00 eq.) unter Argon eine Lösung von (S)-Benzyl- $N$-(tert-butoxycarbonyl)-asparaginsäure $(9,5.00 \mathrm{~g}$, $15.5 \mathrm{mmol}, 1.00$ eq.) in trockenem THF $(20.0 \mathrm{~mL})$ langsam zugetropft und die Reaktionsmischung $6 \mathrm{~h}$ bei $0{ }^{\circ} \mathrm{C}$ gerührt. Anschließend wurde die Lösung $24 \mathrm{~h}$ bei $4{ }^{\complement} \mathrm{C}$ im Kühlschrank gelagert, bevor die Reaktion du rch Zugabe von HOAc (10\%) in Methanol $(20.0 \mathrm{~mL})$ beendet wurde. Das Lösungsmittel wurde im Hochvakuum entfernt und der Rückstand unter Eiskühlung in EE aufgenommen. Die Lösung wurde mit jeweils eisgekühlter $\mathrm{NaHCO}_{3}$-Lösung $(3 \times 35.0 \mathrm{~mL})$, halbges. $\mathrm{K}_{2} \mathrm{CO}_{3}$-Lösung $(3 \times 35.0 \mathrm{~mL})$ und ges. NaCl-Lösung $(2 \times 35.0 \mathrm{~mL})$ gewaschen sowie die wässrige Phase mit EE $(35.0 \mathrm{ml})$ rückextrahiert. Die vereinigten organischen Phasen wurden über $\mathrm{MgSO}_{4}$ getrocknet, das Lösungsmittel entfernt und der Rückstand mittels $\mathrm{FC}$ an Kieselgel ( $I=25 \mathrm{~cm}, \varnothing=5 \mathrm{~cm}$, Hexan/EE 3:2) aufgereinigt. Es wurden $2.98 \mathrm{~g}$ $(9.63 \mathrm{mmol}, 62 \%)$ der gewünschten Verbindung als weißer Feststoffl isoliert.

DC (Hexan/EE 3:2): $R_{f}=0.47$. 
${ }^{1} \mathrm{H}-\mathrm{NMR}\left(300 \mathrm{MHz}, \mathrm{CDCl}_{3}\right): \delta=1.42(\mathrm{~s}, 9 \mathrm{H}, t$-Bu), 1.52-1.68 (m, $1 \mathrm{H}, \mathrm{H}-\beta), 2.09-2.21$ $(\mathrm{m}, 1 \mathrm{H}, \mathrm{H}-\beta), 3.58-3.73(\mathrm{~m}, 2 \mathrm{H}, \mathrm{H}-\gamma), 4.51(\mathrm{~m}, 1 \mathrm{H}, \mathrm{H}-\alpha), 5.18\left(\mathrm{~s}, 2 \mathrm{H}, \mathrm{CH}_{2} \mathrm{Ph}\right), 5.39(\mathrm{~d}$, $J=7.8 \mathrm{~Hz}, 1 \mathrm{H}, \mathrm{N} H \mathrm{Boc}), 7.33$ (s, 5H, Ph) ppm.

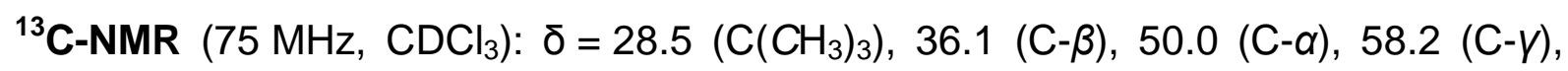
$67.3\left(\mathrm{CH}_{2} \mathrm{Ph}\right), 80.5\left(\mathrm{C}\left(\mathrm{CH}_{3}\right)_{3}\right), 128.0$, $(m-\mathrm{Ph}), 128.5(p-\mathrm{Ph}), 128.6(o-\mathrm{Ph}), 135.2(i-$ $\mathrm{Ph}), 155.5(\mathrm{CONH}), 172.4(\mathrm{COOBn}) \mathrm{ppm}$.

$\operatorname{ESI-MS~}(\mathrm{m} / \mathrm{z}): 332.2[\mathrm{M}+\mathrm{Na}]^{+}$.

\section{(R)-N-tert-Butoxycarbonyl- $\gamma$-hydroxy-homoalanylbenzylester (ent-10)}

Es wurde eine dem (S)-Enantiomer analoge Synthese durchgeführt. Die Charakterisierung über NMR-Spektroskopie ergab entsprechende Daten.

(S)-N-tert-Butoxycarbonyl- $\gamma$-brom-homoalanylbenzylester (11) ${ }^{[113]}$<smiles>O=C(N[C@@H](CCO)C(=O)OCc1ccccc1)Oc1ccccc1</smiles>

10

$\mathrm{C}_{16} \mathrm{H}_{23} \mathrm{NO}_{5}$ [309.36]<smiles>CC(C)(C)OC(=O)N[C@@H](CCBr)C(=O)OCc1ccccc1</smiles>

11

$\mathrm{C}_{16} \mathrm{H}_{22} \mathrm{BrNO}_{4}$ [372.25]

(S)-N-tert-Butoxycarbonyl- $y$-hydroxy-homoalanylbenzylester $(10,1.40 \mathrm{~g}, 4.53 \mathrm{mmol}$, 1.00 eq.) wurde unter Argon in trockenem DCM $(30.0 \mathrm{~mL})$ gelöst und auf $-5{ }^{\circ} \mathrm{C}$ gekühlt. Unter Lichtausschluß wurde $\mathrm{CBr}_{4}$ ( $300 \mathrm{~g}, 9.06 \mathrm{mmol}, 2.00$ eq.) zugegeben. $\mathrm{PPh}_{3}$ (2.38 g, $9.06 \mathrm{mmol}, 2.00$ eq.) wurde in trockenem DCM $(15.0 \mathrm{~mL})$ gelöst, auf $-5{ }^{\circ} \mathrm{C}$ gekühlt, zur Reaktionsmischung gegeben und bei RT $2 \mathrm{~h}$ gerührt. Nach Entfernung des Lösungsmittels wurde der Rückstand mittels $F C$ an Kieselgel $(I=25 \mathrm{~cm}$, $\varnothing=5 \mathrm{~cm}$, Hexan/EE 5:1, Gradient $1 \%$ HOAc pro $500 \mathrm{~mL}$ ) aufgereinigt. Es wurden $979 \mathrm{mg}$ (2.63 mmol, $58 \%$ ) der gewünschten Verbindung als farbloses Öl isoliert, das bei $4^{\circ} \mathrm{C}$ auskristallisierte.

DC $\left(\right.$ Hexan/EE 5:1): $R_{f}=0.68$. 
${ }^{1} \mathrm{H}-\mathrm{NMR}\left(300 \mathrm{MHz}, \mathrm{CDCl}_{3}\right): \delta=1.42(\mathrm{~s}, 9 \mathrm{H}, t-\mathrm{Bu}), 2.13-2.23(\mathrm{~m}, 1 \mathrm{H}, \mathrm{H}-\beta), 2.33-2.48$ $(\mathrm{m}, 1 \mathrm{H}, \mathrm{H}-\beta), 3.38(\mathrm{t}, J=6.6 \mathrm{~Hz}, 2 \mathrm{H}, \mathrm{H}-\gamma), 4.45(\mathrm{~m}, 1 \mathrm{H}, \mathrm{H}-\alpha), 5.07-5.17(\mathrm{~m}, 3 \mathrm{H}$, $\left.\mathrm{NHBoc}, \mathrm{CH}_{2} \mathrm{Ph}\right), 7.34(\mathrm{~m}, 5 \mathrm{H}, \mathrm{Ph}) \mathrm{ppm}$.

${ }^{13}$ C-NMR $\left(75 \mathrm{MHz}, \mathrm{CDCl}_{3}\right): \delta=28.3\left(\left(\mathrm{C}\left(\mathrm{CH}_{3}\right)_{3}\right), \mathrm{C}-\gamma\right), 35.8(\mathrm{C}-\beta), 52.6(\mathrm{C}-\alpha), 67.4$ $\left(\mathrm{CH}_{2} \mathrm{Ph}\right), 80.3\left(\mathrm{C}\left(\mathrm{CH}_{3}\right)_{3}\right), 128.3(m-\mathrm{Ph}), 128.6(p-\mathrm{Ph}, o-\mathrm{Ph}), 135.2(i-\mathrm{Ph}), 155.3$ (CONH), 171.6 (COOBn) ppm.

ESI-MS $(m / z): 396.1[\mathrm{M}+\mathrm{Na}]^{+}, 766.7[2 \mathrm{M}+\mathrm{Na}]^{+}$.

(R)-N-tert-Butoxycarbonyl- $\boldsymbol{y}$-brom-homoalanylbenzylester (ent-11)

Es wurde eine dem (S)-Enantiomer analoge Synthese durchgeführt. Die Charakterisierung über NMR-Spektroskopie ergab entsprechende Daten.

(S)-N-tert-Butoxycarbonyl-y-(2-amino-6-chlor-9-purinyl)-homoalanylbenzylester $(12)^{[17]}$<smiles>CC(C)(C)OC(=O)N[C@@H](CCBr)C(=O)OCc1ccccc1</smiles>

11<smiles>Nc1nc(Cl)c2nc[nH]c2n1</smiles>

48<smiles>CC(C)(C)OC(=O)NC(CCn1cnc2c(Cl)nc(N)nc21)C(=O)OCc1ccccc1</smiles>

12

$\mathrm{C}_{16} \mathrm{H}_{22} \mathrm{BrNO}_{4}$ [372.25]

$\mathrm{C}_{5} \mathrm{H}_{4} \mathrm{CIN}_{5}[169.57]$

$\mathrm{C}_{17} \mathrm{H}_{19} \mathrm{CIN}_{6} \mathrm{O}_{2}[374.83]$

(S)-N-tert-Butoxycarbonyl- $y$-brom-homoalanylbenzylester (11, $357 \mathrm{mg}, 959 \mu \mathrm{mol}$, 1.00 eq.), 2-Amino-6-chlorpurin (48, $0.244 \mathrm{~g}, 1.44 \mathrm{mmol}, 1.50$ eq.), $\mathrm{K}_{2} \mathrm{CO}_{3}$ (0.199 g, $1.44 \mathrm{mmol}, 1.50$ eq.) und TBAI (35.0 mg, $96.0 \mu \mathrm{mol}, 0.100$ eq.) wurden bei RT $93 \mathrm{~h}$ in DMF (50.0 mL) gerührt. Die Reaktion wurde durch Zugabe von HOAc $(80.0 \mu \mathrm{L}$, $144 \mu \mathrm{mol}, 1.50$ eq.) beendet und das Lösungsmittel mittels Codestillation mit Toluol im Hochvakuum entfernt. Der Rückstand wurde mittels $F C$ an Kieselgel $(\mathrm{I}=25 \mathrm{~cm}$, $\varnothing=5 \mathrm{~cm}$, Hexan/EE 1:3) aufgereinigt. Es wurden $291 \mathrm{mg}(777 \mu \mathrm{mol}, 81 \%)$ der gewünschten Verbindung als weißer Feststoff isoliert. 
DC $\left(\right.$ Hexan/EE 1:3): $R_{f}=0.52$.

${ }^{1} \mathrm{H}-\mathrm{NMR}\left(300 \mathrm{MHz}, \mathrm{CDCl}_{3}\right): \delta=1.42(\mathrm{~s}, 9 \mathrm{H}, t-\mathrm{Bu}), 2.15-2.24(\mathrm{~m}, 1 \mathrm{H}, \mathrm{H}-\beta), 2.32-2.46$ (t, J = 8.4 Hz, 2H, H- $v$ ), $4.38(\mathrm{~m}, 1 \mathrm{H}, \mathrm{H}-\alpha), 5.07$ (s, 2H, CH 5.53 (d, J=7.2 Hz, 1H, NHBoc), 7.22-7.35 (m, 5H, Ph), 7.75 (s, 1H, H-8) ppm.

ESI-MS $(m / z): 483.1[\mathrm{M}+\mathrm{Na}]^{+}$.

(R)-N-tert-Butoxycarbonyl- $y$-(2-amino-6-chlor-9-purinyl)-homoalanylbenzylester (ent-12)

Es wurde eine dem (S)-Enantiomer analoge Synthese durchgeführt. Die Charakterisierung über NMR-Spektroskopie ergab entsprechende Daten.

(S)-Y-(9-Guaninyl)-homoalanylbenzylester $(49)^{[17,137]}$<smiles>Nc1nc(Cl)c2ncn(CCC(NC(=O)OCc3ccccc3)C(=O)OCc3ccccc3)c2n1</smiles>

12

$\mathrm{C}_{17} \mathrm{H}_{19} \mathrm{CIN}_{6} \mathrm{O}_{2}[374.83]$<smiles>Nc1nc2c(ncn2CC[C@H](N)C(=O)OCc2ccccc2)c(=O)[nH]1</smiles>

49

$\mathrm{C}_{16} \mathrm{H}_{18} \mathrm{~N}_{6} \mathrm{O}_{3}[342.36]$

Bei RT wurde eine Lösung von (S)-N-tert-Butoxycarbonyl-y-(2-amino-6-chlor-9purinyl)-homoalanylbenzylester (12, $382 \mathrm{mg}, 1.02 \mathrm{mmol}, 1.00$ eq.) in $\mathrm{TFA} / \mathrm{H}_{2} \mathrm{O}$ (3:1, $12.0 \mathrm{~mL}$ ) für $4 \mathrm{~d}$ zur Reaktion gebracht. Das Lösungsmittel wurde entfernt und das Produkt nach Aufschlämmen in $\mathrm{Et}_{2} \mathrm{O}(3 \mathrm{x})$ und anschließendem Evaporieren im Hochvakuum getrocknet.

DC $\left(i-\mathrm{PrOH} / \mathrm{H}_{2} \mathrm{O} / \mathrm{HOAc} / \mathrm{NaCl}\right.$ 5:2:1: ges. $): \mathrm{R}_{\mathrm{f}}=0.58$. 
${ }^{1} \mathrm{H}-\mathrm{NMR}\left(300 \mathrm{MHz},\left[\mathrm{D}_{6}\right] \mathrm{DMSO}\right): \delta=2.25-2.45(\mathrm{~m}, 2 \mathrm{H}, \mathrm{H}-\beta), 4.21(\mathrm{t}, J=7.0 \mathrm{~Hz}, 2 \mathrm{H}$, $\mathrm{H}-\gamma$ ), 5.15 (q, J=12 Hz, 2H, CH$H_{2} \mathrm{Ph}$ ), 6.87 (s br, 2H; NH $), 7.37$ (s, 5H; Ph), 8.32 (s, $1 \mathrm{H} ; \mathrm{H}-8$ ), 8.67 (s br, 2H; $\mathrm{NH}_{2}$ Purin) ppm.

ESI-MS $(\mathrm{m} / \mathrm{z}): 343.2[\mathrm{M}+\mathrm{H}]^{+}, 365.3[\mathrm{M}+\mathrm{Na}]^{+}, 685.1[2 \mathrm{M}+\mathrm{H}]^{+}, 707.2[2 \mathrm{M}+\mathrm{Na}]^{+}$.

\section{(R)-Y-(9-Guaninyl)-homoalanylbenzylester (ent-49)}

Es wurde eine dem (S)-Enantiomer analoge Synthese durchgeführt. Die Charakterisierung über NMR-Spektroskopie ergab entsprechende Daten.

(S)-Y-(9-Guaninyl)-homoalanin (36) $)^{[17,137]}$<smiles>Nc1nc2c(ncn2CCC(N)C(=O)O)c(=O)[nH]1</smiles>

49<smiles>Nc1nc2c(ncn2CC[C@@H](N)C(=O)O)c(=O)[nH]1</smiles>

36

$\mathrm{C}_{16} \mathrm{H}_{18} \mathrm{~N}_{6} \mathrm{O}_{3}$ [342.36]

$\mathrm{C}_{9} \mathrm{H}_{12} \mathrm{~N}_{6} \mathrm{O}_{3}$ [252.23]

Zu einer Lösung von (S)-N-tert-Butoxycarbonyl- $y$-(9-guaninyl)-homoalanylbenzylester (49, $726 \mathrm{mg}, 2.12 \mathrm{mmol}, 1.00$ eq.) in $\mathrm{MeOH} / \mathrm{HOAc}(19: 1,60.0 \mathrm{~mL})$ wurde unter Argon PdO $\cdot \mathrm{H}_{2} \mathrm{O}$ (328 mg, $2.33 \mathrm{mmol}, 1.10$ eq.) gegeben. Nach Spülen mit Wasserstoff wurde unter Wasserstoffatmosphäre mittels Ultraschall aktiviert und bei RT $2 \mathrm{~h}$ gerührt. Nach Spülen der Reaktionsmischung mit Argon wurde über Celite filtriert und mit warmen $\mathrm{MeOH}(3 \times 40 \mathrm{~mL}$ ) gewaschen. Nach Entfernen des Lösungsmittels mit Tolulol als Azeotrop wurden $482 \mathrm{mg}$ (1.91 mmol, $91 \%$ ) der gewünschten Verbindung als weißer Feststoff erhalten.

DC $\left(i-\mathrm{PrOH} / \mathrm{H}_{2} \mathrm{O} / \mathrm{HOAc} / \mathrm{NaCl}\right.$ 5:2:1: ges. $): \mathrm{R}_{\mathrm{f}}=0.16$. 
${ }^{1} \mathrm{H}-\mathrm{NMR}\left(300 \mathrm{MHz},\left[\mathrm{D}_{6}\right] \mathrm{DMSO}\right): \delta=2.15-2.40(\mathrm{~m}, 2 \mathrm{H}, \mathrm{H}-\beta), 3.77(\mathrm{t}, J=7.0 \mathrm{~Hz}, 1 \mathrm{H}$;

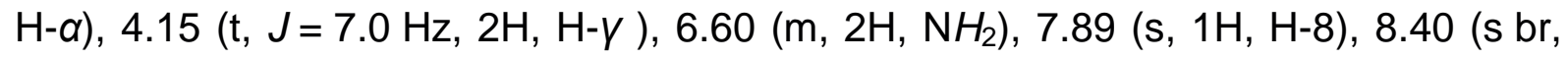
$2 \mathrm{H}, \mathrm{N} \mathrm{H}_{2}$ Purin) ppm.

ESI-MS $(m / z): 253.1[\mathrm{M}+\mathrm{H}]^{+}$.

(R)-Y-(9-Guaninyl)-homoalanin (ent-36)

Es wurde eine dem (S)-Enantiomer analoge Synthese durchgeführt. Die Charakterisierung über NMR-Spektroskopie ergab entsprechende Daten.

(S)-N-tert-Butoxycarbonyl- $y$-(9-guaninyl)-homoalanin (Boc-L-HalG-OH) (13) ${ }^{[17,137]}$<smiles>Nc1nc2c(ncn2CC[C@H](N)C(=O)O)c(=O)[nH]1</smiles>

36<smiles>Nc1nc2c(ncn2CCC(NC(=O)Oc2ccccc2)C(=O)O)c(=O)[nH]1</smiles>

13

$\mathrm{C}_{9} \mathrm{H}_{12} \mathrm{~N}_{6} \mathrm{O}_{3}$ [252.23]

$\mathrm{C}_{14} \mathrm{H}_{20} \mathrm{~N}_{6} \mathrm{O}_{5}$ [352.35]

Das Rohprodukt (S)-V-(9-Guaninyl)-homoalaninbenzylester (36, 146 mg, $579 \mu \mathrm{mol}$, 1.00 eq.) wurde in $\mathrm{H}_{2} \mathrm{O} / 1 \mathrm{~N} \mathrm{NaOH} /$ Dioxan $(1: 1: 2,4 \mathrm{~mL})$ aufgenommen, auf $0^{\circ} \mathrm{C}$ gekühlt und mit $N$-Di-tert-butyldicarboxylat (183 mg, $840 \mu \mathrm{mol}, 1.45$ eq.) versetzt. Es wurde 45 min bei $0^{\circ} \mathrm{C}$ und $24 \mathrm{~h}$ bei RT gerührt, wobe i mittels $1 \mathrm{~N} \mathrm{NaOH}$ der pH-Wert auf 9.0-9.5 nachreguliert wurde. Nach Abkühlung auf $0^{\circ} \mathrm{C}$ wurde die Reaktionslösung nochmals mit $N$-Di-tert-Butyldicarboxylat $(63.0 \mathrm{mg}, 290 \mu \mathrm{mol}$, 0.500 eq.) versetzt, $1 \mathrm{~h}$ bei $0^{\circ} \mathrm{C}$ und $24 \mathrm{~h}$ bei RT gerührt. Die Reaktion wurde beendet, indem mit $1 \mathrm{~N} \mathrm{HCl}$ auf $\mathrm{pH} 6.5$ angesäuert wurde und das Lösungsmittel entfernt wurde. Das Rohprodukt wurde mittels FC an RP-Kieselgel $(I=10 \mathrm{~cm}$, $\varnothing=2 \mathrm{~cm}, \mathrm{H}_{2} \mathrm{O}$, Gradient $10 \% \mathrm{MeOH}$ pro $500 \mathrm{~mL}$ ) gereinigt. Es wurden $102 \mathrm{mg}$ $(0.290 \mathrm{mmol}, 50 \%)$ der gewünschten Verbindung als weißer Feststoff isoliert. 
DC (i-PrOH/ $\mathrm{H}_{2} \mathrm{O} / \mathrm{HOAc} / \mathrm{NaCl}$ 5:2:1: ges. $): \mathrm{R}_{\mathrm{f}}=0.50$.

${ }^{1} \mathrm{H}-\mathrm{NMR}\left(300 \mathrm{MHz},\left[\mathrm{D}_{6}\right] \mathrm{DMSO}\right): \delta=1.40(\mathrm{~s}, 9 \mathrm{H}, t-\mathrm{Bu}), 1.95(\mathrm{~m}, 1 \mathrm{H}, \mathrm{H}-\beta), 2.22(\mathrm{~m}$, $1 \mathrm{H}, \mathrm{H}-\beta), 3.80$ (m, 1H, H- $\alpha$ ), 4.00 (t, J=7.2 Hz, 2H, H- $\beta$ ), 6.40 (s br, 2H, NH $H_{2}$ Purin), 7.18 (d, J = 9.0 Hz, 1H, NHBoc), 7.58 (s, 1H, Ph), 10.53 (s br, 1H, NHPurin), 11.60 (s br, $1 \mathrm{H}, \mathrm{COOH}$ ) ppm.

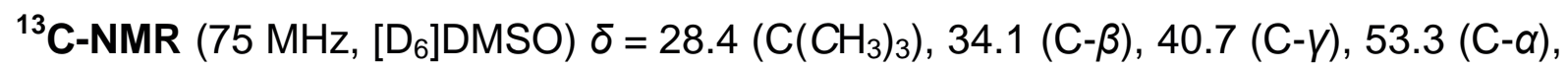
$77.8\left(\mathrm{C}\left(\mathrm{CH}_{3}\right)_{3}\right), 116.7(\mathrm{C}-5), 137.4(\mathrm{C}-8), 151.3$ (C-6), $154.4(\mathrm{C}-2), 155.5(\mathrm{CONH})$, $157.6(\mathrm{C}-4), 174.3(\mathrm{COOH}) \mathrm{ppm}$.

ESI-MS $(m / z): 397.1[\mathrm{M}+2 \mathrm{Na}]^{+}, 351.1[\mathrm{M}-\mathrm{H}]^{-}$.

Zur Bestimmung des Enantiomerenüberschusses wurde 13 nach AAV1 mit N-Boc-DPhe-OSu umgesetzt: > $96 \%$ ee. HPLC: (Gradient: $10-15 \%$ B' in 30 min, like Diastereomer) $\mathrm{t}_{\mathrm{r}}=25.5 \mathrm{~min}$.

(R)-N-tert-Butoxycarbonyl- $\boldsymbol{Y}$-(9-guaninyl)-homoalanin (Boc-D-HalG-OH) (ent-13)

Es wurde eine dem (S)-Enantiomer analoge Synthese durchgeführt. Die Charakterisierung über NMR-Spektroskopie ergab entsprechende Daten.

Zur Bestimmung des Enantiomerenüberschusses wurde ent-13 nach AAV1 mit $N$ Boc-D-Phe-OSu umgesetzt: > $96 \%$ ee. HPLC: (Gradient: $10-15 \%$ B' in 30 min, unlike Diastereomer) $t_{r}=28.0 \mathrm{~min}$. 
(S)-N-tert-Butoxycarbonyl- $\boldsymbol{Y}$-(N-4-benzyloxycarbonyl-1-cytosinyl)-homoalanylbenzylester $(14)^{[17,137]}$<smiles>CC(C)(C)OC(=O)N[C@@H](CCBr)C(=O)OCc1ccccc1</smiles>

11<smiles>O=C(Nc1cc[nH]c(=O)n1)OCc1ccccc1</smiles>

5

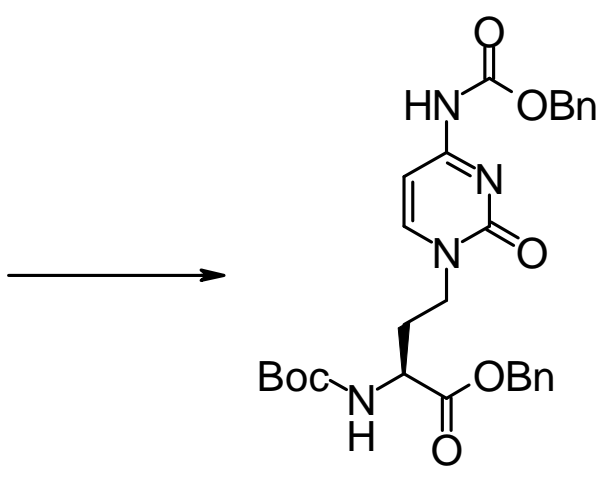

14

$\mathrm{C}_{16} \mathrm{H}_{22} \mathrm{BrNO}_{4}[372.25]$

$\mathrm{C}_{12} \mathrm{H}_{11} \mathrm{~N}_{3} \mathrm{O}_{3}$ [245.24]

$\mathrm{C}_{28} \mathrm{H}_{32} \mathrm{~N}_{4} \mathrm{O}_{7}$ [536.59]

Zu einer Lösung von (S)-N-tert-Butoxycarbonyl- $y$-brom-homoalanylbenzylester (11, $454 \mathrm{mg}, 1.20 \mathrm{mmol}, 1.00$ eq.) in absolutem DMF (35 mL) wurden $\mathrm{K}_{2} \mathrm{CO}_{3}$ (252 mg, $1.80 \mathrm{mmol}, 1.50$ eq.) und $\mathrm{N}$-4-Benzyloxycarbonyl-1-cytosin (5, $449 \mathrm{mg}, 1.80 \mathrm{mmol}$, 1.50 eq.) gegeben und die Reaktionsmischung für $87 \mathrm{~h}$ bei RT unter Argon gerührt. Nach Beendigung der Reaktion durch Zugabe von HOAc $(212 \mu \mathrm{L}, 1.80 \mathrm{mmol}$ 1.50 eq.) wurde das Lösungsmittel evaporiert und der Rückstand mittels FC an Kieselgel $(\mathrm{I}=25 \mathrm{~cm}, \varnothing=5 \mathrm{~cm}$, Hexan/EE 1:3) aufgereinigt. Es wurden $393 \mathrm{mg}$ (732 $\mu \mathrm{mol}, 61 \%$ ) der gewünschten Verbindung als weißer Feststoff erhalten.

DC (Hexan/EE 1:3): $R_{f}=0.32$.

${ }^{1} \mathrm{H}-\mathrm{NMR}\left(300 \mathrm{MHz},\left[\mathrm{D}_{6}\right] \mathrm{DMSO}\right): \delta=1.34(\mathrm{~s}, 9 \mathrm{H}, t-\mathrm{Bu}), 2.18-2.32(\mathrm{~m}, 2 \mathrm{H}, \mathrm{H}-\beta), 3.75-$ $4.10(\mathrm{~m}, 2 \mathrm{H}, \mathrm{H}-\gamma), 4.28(\mathrm{~s}, 1 \mathrm{H}, \mathrm{H}-\alpha), 5.05\left(\mathrm{~s}, 2 \mathrm{H},\left(\mathrm{C}_{\alpha} \mathrm{CO}_{2}\right) \mathrm{CH}_{2} \mathrm{Ph}\right), 5.17(\mathrm{~s}, 2 \mathrm{H}$, $\left.\left(\mathrm{NHCO}_{2}\right) \mathrm{CH}_{2} \mathrm{Ph}\right), 5.57$ (d, $\left.1 \mathrm{H}, \mathrm{H}-5\right), 7.24-7.30$ (m, 10H, Ph), 7.59 (d, J=7.2 Hz, 1H, H-6) ppm.

${ }^{13}$ C-NMR $\left(75 \mathrm{MHz}, \quad \mathrm{CDCl}_{3}\right): \quad \delta=33.6 \quad(\mathrm{C}-\beta), \quad 37.2(\mathrm{C}-\alpha), \quad 53.4 \quad\left(\mathrm{CH}_{2} \mathrm{Ph}\right), \quad 53.9$ ((NHCO) $\left.\mathrm{CH}_{2} \mathrm{Bn}\right), 66.2\left(\mathrm{C}\left(\mathrm{CH}_{3}\right)_{3}\right), 80.7(\mathrm{C}-5), 114.2(\mathrm{Ph}), 135.2(\mathrm{C}-6), 138.2$ ( $\left.\mathrm{C}_{\alpha} \mathrm{COBn}\right), 148.3$ (C-4), 157.4 ((NH)COOBn), 163.9 (CONH) ppm.

ESI-MS (m/z): $559.2[\mathrm{M}+\mathrm{Na}]^{+}$. 
(R)-N-tert-Butoxycarbonyl- $\boldsymbol{Y}$-(N-4-benzyloxycarbonyl-1-cytosinyl)-homoalanylbenzylester (ent-14)

Es wurde eine dem (S)-Enantiomer analoge Synthese durchgeführt. Die Charakterisierung über NMR-Spektroskopie ergab entsprechende Daten.

(S)-N-tert-Butoxycarbonyl- $\gamma$-( $N$-4-benzyloxycarbonyl-1-cytosinyl)-homoalanin (Boc-L-HalC Z-OH) $_{(15)^{[17,137]}}$<smiles>CC(C)(C)OC(=O)N[C@@H](CCn1ccc(NC(=O)OCc2ccccc2)nc1=O)C(=O)OCc1ccccc1</smiles>

14<smiles>CC(C)(C)OC(=O)N[C@H](CCn1ccc(NC(=O)OCc2ccccc2)nc1=O)C(=O)O</smiles>

15

$\mathrm{C}_{28} \mathrm{H}_{32} \mathrm{~N}_{4} \mathrm{O}_{7}$ [536.59]

(S)-N-tert-Butoxycarbonyl- $\gamma$-(N-4-benzyloxycarbonyl-1-cytosinyl)-homoalanylbenzylester (14, $328 \mathrm{mg}, 610 \mu \mathrm{mol}$, 1.00 eq.) wurde mit $\mathrm{H}_{2} \mathrm{O} / 1 \mathrm{~N} \mathrm{NaOH} /$ Dioxan (1:1:2, $50.0 \mathrm{~mL}$ ) aufgenommen und bei RT $1 \mathrm{~d}$ gerührt. Die Reaktion wurde beendet, indem mit $1 \mathrm{~N} \mathrm{HCl}$ auf $\mathrm{pH} 6$ angesäuert wurde und das Lösungsmittel mit Toluol als Azeotrop coevaporiert wurde. Nach Reinigung mittels FC an Kieselgel $(\mathrm{I}=20 \mathrm{~cm}$, $\varnothing=5 \mathrm{~cm}$, Hexan/EE 1:3) und an RP-Kieselgel $\left(\mathrm{I}=10 \mathrm{~cm}, \varnothing=2 \mathrm{~cm}, \mathrm{H}_{2} \mathrm{O}\right.$, Gradient $10 \% \mathrm{MeOH}$ pro $500 \mathrm{~mL})$ wurden $158 \mathrm{mg}(354 \mu \mathrm{mol}, 58 \%)$ der gewünschten Verbindung als weißer Feststoff erhalten.

DC $\left(\mathrm{EE} / \mathrm{MeOH} / \mathrm{H}_{2} \mathrm{O} / \mathrm{HOAc} 10: 1: 1: 0.5\right): \mathrm{R}_{\mathrm{f}}=0.43 ;(\mathrm{MeOH}): R_{\mathrm{f}}=0.73$.

${ }^{1} \mathrm{H}-\mathrm{NMR}\left(300 \mathrm{MHz},\left[\mathrm{D}_{6}\right] \mathrm{DMSO}\right): \delta=1.36(\mathrm{~s}, 9 \mathrm{H}, t-\mathrm{Bu}), 1.72-2.00(\mathrm{~m}, 2 \mathrm{H}, \mathrm{H}-\beta), 3.45-$ $3.56(\mathrm{~m}, 1 \mathrm{H}, \mathrm{H}-\alpha), 3.79$ (t, 2H, H- $/$ ), 5.17 (s, 2H, CH (d, 1H, H-5), 7.26-7.43 (m, 5H, Ph), 8.07 (d, J=7.2 Hz, 1H, H-6), 10.62 (s br, $1 \mathrm{H}$, $\mathrm{NH}$ ) ppm. 
${ }^{13} \mathrm{C}-N M R\left(75 \mathrm{MHz},\left[\mathrm{D}_{6}\right] \mathrm{DMSO}\right): \delta=28.3\left(\mathrm{C}\left(\mathrm{CH}_{3}\right)_{3}\right), 32.4(\mathrm{C}-\beta), 47.6(\mathrm{C}-\gamma), 53.2(\mathrm{C}-$ $\alpha), 66.5\left(\mathrm{CH}_{2} \mathrm{Ph}\right), 77.6\left(\mathrm{C}\left(\mathrm{CH}_{3}\right)_{3}\right), 93.8(\mathrm{C}-5), 128.0(m-\mathrm{Ph}), 128.3(p-\mathrm{Ph}), 128.6(0-$ $\mathrm{Ph}), 135$ (i-Ph), 136.2 (COOBn), 150.3 (C-6), 153.4 (C-4), 155.0 (C-2), 162.7 (CONHBoc), $173.3(\mathrm{COOH}) \mathrm{ppm}$.

ESI-MS $(m / z): 469.1[\mathrm{M}+\mathrm{Na}]^{+}$.

Zur Bestimmung des Enantiomerenüberschusses wurde 15 nach AAV1 mit N-Boc-DPhe-OSu umgesetzt: > $99 \%$ ee. HPLC: (Gradient: $30 \%$ B' in 30 min, like Diastereomer) $t_{r}=28.4 \mathrm{~min}$.

\section{(R)-N-tert-Butoxycarbonyl- $\boldsymbol{Y}$-( $N$-4-benzyloxycarbonyl-1-cytosinyl)-homoalanin} (Boc-D-HalC $\left.\mathrm{z}_{\mathrm{O}} \mathrm{OH}\right)$ (ent-15)

Es wurde eine dem (S)-Enantiomer analoge Synthese durchgeführt. Die Charakterisierung über NMR-Spektroskopie ergab entsprechende Daten. Zur Bestimmung des Enantiomerenüberschusses wurde ent-15 nach AAV1 mit N-Boc-DPhe-OSu umgesetzt: > $99 \%$ ee. HPLC: (Gradient: $30 \%$ B' in 30 min, unlike Diastereomer) $t_{r}=29.5 \mathrm{~min}$.

(S)- $N$-Fluorenylmethyloxycarbonyl- $\beta$-(9-guaninyl)-L-alanin (Fmoc-L-AlaG-OH) $(46)^{[138]}$<smiles>Nc1nc2c(ncn2C[C@H](N)C(=O)O)c(=O)[nH]1</smiles>

47

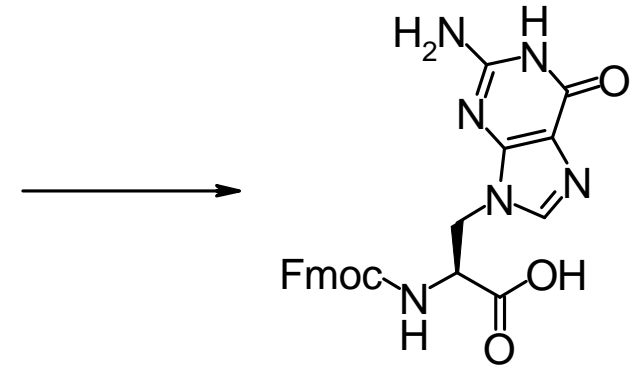

46

$\mathrm{C}_{8} \mathrm{H}_{10} \mathrm{~N}_{6} \mathrm{O}_{3}[238.21]$ $\mathrm{C}_{23} \mathrm{H}_{20} \mathrm{~N}_{6} \mathrm{O}_{4}[460.45]$

Das Rohprodukt (S)- $\beta$-(9-Guaninyl)-alanin (47, $1.04 \mathrm{~g}, 4.37 \mathrm{mmol}, 1.00$ eq.) wurde in ein Gemisch aus $\mathrm{H}_{2} \mathrm{O}$ /Dioxan $(2.5: 1,35.0 \mathrm{~mL})$ suspendiert und die Suspension mit 
ges. $\mathrm{NaHCO}_{3}$-Lösung auf $\mathrm{pH}$ 8.5-9.0 eingestellt. Die Suspension wurde auf $0^{\circ} \mathrm{C}$ gekühlt und unter Rühren 9-Fluorenylmethyloxycarbonylchlorid $(1.47 \mathrm{~g}, 5.68 \mathrm{mmol}$, 1.30 eq.) in Dioxan (20.0 mL) innerhalb von 10 min zugetropft. Der pH-Wert wurde auf $\mathrm{pH}$ 8.5-9.0 nachreguliert. Nach 45 min wurde die Kühlung entfernt und das Reaktionsgemisch weitere $7 \mathrm{~h}$ bei RT gerührt. Nach Entfernen des Dioxans wurde die wässrige Lösung mit $\mathrm{Et}_{2} \mathrm{O}(2 \times 4 \mathrm{~mL})$ gewaschen und anschließend lyophilisiert. Das Rohprodukt wurde mittels FC an Kieselgel $(I=20 \mathrm{~cm}, \varnothing=5 \mathrm{~cm}, \mathrm{EE} / \mathrm{MeOH} 8: 2$, Gradient $0.5 \%$ HOAc pro $500 \mathrm{~mL}$ ) gereinigt. Nach Codestillation mit Toluol wurden mittels FC an RP-Kieselgel $\left(\mathrm{I}=10 \mathrm{~cm}, \varnothing=2 \mathrm{~cm}, \mathrm{H}_{2} \mathrm{O}\right.$, Gradient $10 \% \mathrm{MeOH}$ pro $500 \mathrm{~mL}) 643 \mathrm{mg}$ (2.05 mmol, $47 \%)$ der gewünschten Verbindung als weißer Feststoff erhalten.

DC $\left(i-\mathrm{PrOH} / \mathrm{H}_{2} \mathrm{O} / \mathrm{HOAc} / \mathrm{NaCl}\right.$ 5:2:1: ges. $): \mathrm{R}_{\mathrm{f}}=0.61$.

${ }^{1} \mathrm{H}-\mathrm{NMR}$ (250 MHz, [D $\mathrm{D}_{6}$ DMSO): $\delta=4.01-4.15$ (m, 3H, H- $\alpha, \mathrm{H}-\beta, \mathrm{CHFmoc}$ ), 4.25-4.46 (m, 3H, H- $\beta, \mathrm{CH}_{2} \mathrm{Fmoc}$ ), 6.60 (s br, 3H, NHFmoc, NH $\mathrm{H}_{2}$, 7.29-7.39 (m, 4H, H-3 ${ }_{\mathrm{Fmoc}}, \mathrm{H}-$ $\left.4_{\text {Fmoc }}\right), 7.53(\mathrm{~s}, 1 \mathrm{H}, \mathrm{H}-8), 7.58-7.65\left(\mathrm{~m}, 2 \mathrm{H}, \mathrm{H}-2_{\text {Fmoc }}\right), 7.87\left(\mathrm{~m}, 2 \mathrm{H}, \mathrm{H}-5_{\text {Fmoc }}\right), 10.75$ (s, $1 \mathrm{H}$, NHPurin) ppm.

${ }^{13}$ C-NMR (100 MHz, [D 6 DMSO): $\delta=43.6$ (C- $\left.\beta\right), 46.7$ (CHFmoc), 54.3 (C- $\left.\alpha\right), 65.9$ $\left(\mathrm{CH}_{2} \mathrm{Fmoc}\right), 116.6$ (C-5), 120.1, 120.2 (C-5 Fmoc $), 125.3,125.4$ (C-2 Fmoc $\left._{\text {Fmo }}\right), 127.2,127.3$ (C-3 Fmoc ), 127.4, 127.7 (C-4 Fmoc $_{\text {) }} 137.9$ (C-8), 143.9, 144.0 (C-1 Fmoc $\left._{\text {foc }}\right), 151.4$ (C-4), 153.8 (C-2), 155.9 (CONH), $157.0(\mathrm{C}-6), 171.5(\mathrm{COOH}) \mathrm{ppm}$.

ESI-MS $(m / z): 483.3[\mathrm{M}+\mathrm{Na}]^{+}, 943.2[2 \mathrm{M}+\mathrm{Na}]^{+}$.

(R)- $N$-Fluorenylmethyloxycarbonyl- $\beta$-(9-guaninyl)-D-alanin

(Fmoc-D-AlaG-OH) (ent-46)

Es wurde eine dem (S)-Enantiomer analoge Synthese durchgeführt. Die Charakterisierung über NMR-Spektroskopie ergab entsprechende Daten. 


\section{(S)-N-Fluorenylmethyloxycarbonyl- $y$-(9-guaninyl)-homoalanin}

\section{(Fmoc-L-HalG-OH) (34)}<smiles>Nc1nc2c(ncn2CC[C@H](N)C(=O)O)c(=O)[nH]1</smiles>

36

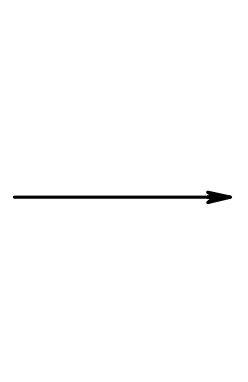

$\mathrm{C}_{9} \mathrm{H}_{12} \mathrm{~N}_{6} \mathrm{O}_{3}$ [252.23]<smiles>Nc1nc2c(ncn2CCC(NC(F)F)C(=O)O)c(=O)[nH]1</smiles>

34

$\mathrm{C}_{24} \mathrm{H}_{22} \mathrm{~N}_{6} \mathrm{O}_{5}$ [474.45]

Das Rohprodukt (S)- $\gamma$-(9-Guaninyl)-alanin (36, $227 \mathrm{mg}, 900 \mu \mathrm{mol}, 1.00$ eq.) wurde in ein Gemisch aus $\mathrm{H}_{2} \mathrm{O}$ /Dioxan $(2.5: 1,9.00 \mathrm{~mL})$ suspendiert und die Suspension mit ges. $\mathrm{NaHCO}_{3}$-Lösung auf $\mathrm{pH}$ 8.5-9.0 eingestellt. Die Suspension wurde auf $0 \mathrm{C}$ gekühlt und unter Rühren 9-Fluorenylmethyloxycarbonylchlorid (303 mg, $1.17 \mathrm{mmol}$, 1.30 eq.) in Dioxan $(5.00 \mathrm{~mL})$ innerhalb von 10 min zugetropft. Der pH-Wert wurde auf pH 8.5-9.0 nachreguliert. Nach 45 min wurde die Kühlung entfernt und das Reaktionsgemisch weitere $7 \mathrm{~h}$ bei RT gerührt. Nach Entfernung des Dioxans wurde die wässrige Lösung mit $\mathrm{Et}_{2} \mathrm{O}(2 \times 2 \mathrm{~mL})$ gewaschen und anschließend lyophilisiert. Das Rohprodukt wurde mittels FC an Kieselgel $(\mathrm{I}=25 \mathrm{~cm}, \varnothing=5 \mathrm{~cm}$, EE/MeOH 8:2, Gradient $0.5 \%$ HOAc pro $500 \mathrm{ml}$ ) gereinigt. Nach Codestillation mit Toluol wurden mittels FC an RP-Kieselgel $\left(\mathrm{I}=20 \mathrm{~cm}, \varnothing=4 \mathrm{~cm}, \mathrm{H}_{2} \mathrm{O}\right.$, Gradient $10 \% \mathrm{MeOH}$ pro $500 \mathrm{~mL}) 183 \mathrm{mg}(385 \mu \mathrm{mol}, 43 \%)$ der gewünschten Verbindung als weißer Feststoff erhalten.

DC (EE/MeOH/ $\mathrm{H}_{2} \mathrm{O} / \mathrm{HOAc} / \mathrm{NaCl}$ 10:1:1:0.5: ges. $): \mathrm{R}_{\mathrm{f}}=0.56$.

$[\alpha]_{\mathrm{D}}^{20}:+10.0(c=1.0, \mathrm{DMSO})$.

UV (Methanol): $\lambda_{\max }=261.0 \mathrm{~nm}$.

IR (Film): $v=3399,3125,1682,1630,1603,1409,1359,1250,1079,741 \mathrm{~cm}^{-1}$.

${ }^{1} \mathrm{H}-\mathrm{NMR}\left(300 \mathrm{MHz},\left[\mathrm{D}_{6}\right] \mathrm{DMSO}\right): \delta=2.00(\mathrm{~m}, 1 \mathrm{H}, \mathrm{H}-\beta), 2.23(\mathrm{~m}, 1 \mathrm{H}, \mathrm{H}-\beta), 3.78(\mathrm{~m}$, $1 \mathrm{H}, \mathrm{H}-\alpha), 3.98(\mathrm{t}, J=3.5 \mathrm{~Hz}, 2 \mathrm{H}, \mathrm{H}-\gamma), 4.25$ (m, 1H, CHFmoc), $4.34(\mathrm{~m}, 2 \mathrm{H}$, $\mathrm{CH}_{2} \mathrm{Fmoc}$ ), 6.42 (s, 2H, NH $\mathrm{H}_{2}$, 7.28-7.42 (m, 4H, H-3 Fmoc, $\left.\mathrm{H}-4_{\mathrm{Fmoc}}\right), 7.58$ (s, 1H, H-8),

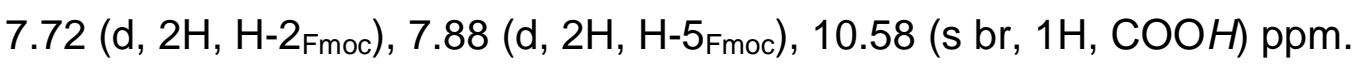


${ }^{13}$ C-NMR (75 MHz, [D 6 DMSO): $\delta=46.7$ (C- $\beta$ ), 65.4 (C- $\alpha$ ), 82.2 (CHFmoc), 109.5 (CV), $119.9\left(\mathrm{CH}_{2} \mathrm{Fmoc}\right), 121.5,128.8$ (C-3 Fmoc $\left._{1} C-4_{\mathrm{Fmoc}}, C-5_{\mathrm{Fmoc}}, C-2_{\mathrm{Fmoc}}\right), 139.3(C-8)$, $140.6\left(C-1_{\mathrm{Fmoc}}\right), 143.8\left(C-6_{\mathrm{Fmoc}}\right), 151.1(C-3), 153.5(C-4), 155.7(C O N H), 156.8(C-$ 6), $161.6(\mathrm{COOH}) \mathrm{ppm}$.

ESI-MS $(m / z): 497.3[\mathrm{M}+\mathrm{Na}]^{+}$.

(S)-Y-(4-benzyloxycarbonyl-1-cytosinyl)-homoalanin (37)<smiles>CC(C)(C)OC(=O)N[C@@H](CCn1ccc(NC(=O)OCc2ccccc2)nc1=O)C(=O)O</smiles>

15

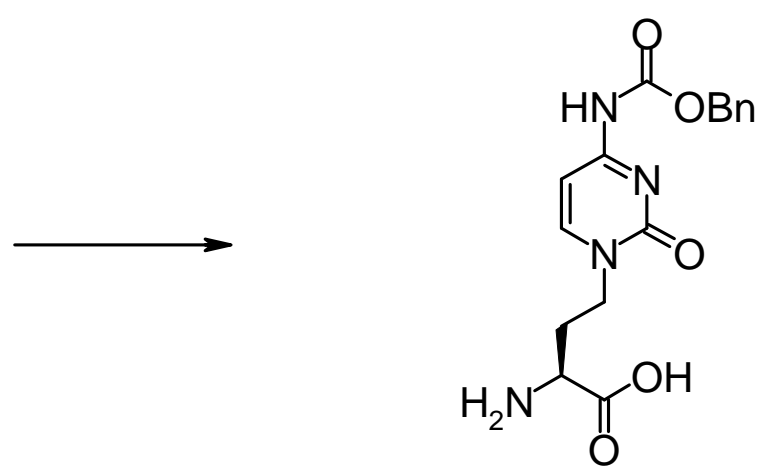

37

$\mathrm{C}_{21} \mathrm{H}_{26} \mathrm{~N}_{4} \mathrm{O}_{7}[446.46]$

$\mathrm{C}_{16} \mathrm{H}_{18} \mathrm{~N}_{4} \mathrm{O}_{5}$ [346.34]

Bei RT wurde eine Lösung von (S)- $N$-tert-Butoxycarbonyl- $\gamma$-( $N$-4-benzyloxycarbonyl1-cytosinyl)-homoalanin (15, $300 \mathrm{mg}, 559 \mu \mathrm{mol}, 1.00$ eq.) in TFA/ $\mathrm{H}_{2} \mathrm{O}(3: 1,8.00 \mathrm{~mL})$ für $4 \mathrm{~d}$ zur Reaktion gebracht. Das Lösungsmittel wurde entfernt und das Produkt nach Aufschlämmen in $\mathrm{Et}_{2} \mathrm{O}(3 \mathrm{x})$ und anschließendem Evaporieren im Hochvakuum getrocknet.

DC (i-PrOH/Wasser/HOAc/NaCl 5:2:1: ges. $): \mathrm{R}_{\mathrm{f}}=0.48$. 
(S)-N-Fluorenylmethyloxycarbonyl- $\gamma$-(4-benzyloxycarbonyl-1-cytosinyl) homoalanin (Fmoc-L-HalC $\mathrm{Z}_{\mathrm{Z}} \mathrm{OH}$ ) (35)<smiles>N[C@@H](CCn1ccc(NC(=O)OCc2ccccc2)nc1=O)C(=O)O</smiles>

37<smiles>O=C(Nc1ccn(CC[C@H](NC(=O)OCc2ccccc2)C(=O)O)c(=O)n1)OCc1ccccc1</smiles>

35

(S)- $\gamma$-(4-Benzyloxycarbonyl-1-cytosinyl)-homoalanin $\quad(37, \quad 251 \mathrm{mg}, \quad 725 \mu \mathrm{mol}$, 1.00 eq.) wurde in einem Gemisch aus $\mathrm{H}_{2} \mathrm{O}$ /Dioxan (2.5:1, $6.00 \mathrm{~mL}$ ) suspendiert und mit ges. $\mathrm{NaHCO}_{3}$-Lösung auf $\mathrm{pH}$ 8.5-9.0 eingestellt. Die Suspension wurde auf $0^{\circ} \mathrm{C}$ gekühlt und unter Rühren 9-Fluorenylmethyloxycarbonylchlorid (244 mg, $943 \mu \mathrm{mol}$, 1.30 eq.) in Dioxan (3.00 mL) innerhalb von 10 min zugetropft. Der pH-Wert wurde auf $\mathrm{pH}$ 8.5-9.0 nachreguliert. Nach 45 min wurde die Kühlung entfernt und das Reaktionsgemisch weitere $7 \mathrm{~h}$ bei RT gerührt. Nach Entfernung des Dioxans wurde die wässrige Lösung mit $\mathrm{Et}_{2} \mathrm{O}(2 \times 1 \mathrm{~mL})$ gewaschen und anschließend lyophilisiert. Das Rohprodukt wurde mittels FC an Kieselgel $(I=15 \mathrm{~cm}, \varnothing=3 \mathrm{~cm}$, EE/MeOH 8:2, Gradient $0.5 \%$ HOAc pro $500 \mathrm{ml}$ ) gereinigt. Nach Codestillation mit Toluol wurden mittels FC an RP-Kieselgel $\left(\mathrm{I}=15 \mathrm{~cm}, \varnothing=3 \mathrm{~cm}, \mathrm{H}_{2} \mathrm{O}\right.$, Gradient $10 \% \mathrm{MeOH}$ pro $500 \mathrm{~mL}) 170 \mathrm{mg}(299 \mu \mathrm{mol}, 41 \%)$ der gewünschten Verbindung als weißer Feststoff erhalten.

DC $\left(i-\mathrm{PrOH} / \mathrm{H}_{2} \mathrm{O} / \mathrm{HOAc} / \mathrm{NaCl}\right.$ 5:2:1: ges. $): \mathrm{R}_{\mathrm{f}}=0.68$.

$[\alpha]_{\mathrm{D}}^{20}:+3.4(c=1.0, \mathrm{DMSO})$.

UV (Methanol): $\lambda_{\max }=264.5 \mathrm{~nm}$.

IR (Film): v = 3275, 3093, 3038, 2941, 1648, 1626, 1501, 1448, 1025, 756, $740 \mathrm{~cm}^{-1}$.

${ }^{1} \mathrm{H}-\mathrm{NMR}\left(300 \mathrm{MHz},\left[\mathrm{D}_{6}\right] \mathrm{DMSO}\right): \delta=1.85-2.17(\mathrm{~m}, 2 \mathrm{H}, \mathrm{H}-\beta), 3.80(\mathrm{~m}, 2 \mathrm{H}, \mathrm{H}-\gamma), 4.02$ (m, 2H, H- $\alpha$ ), 4.26 (m, 1H, CHFmoc), 4.48 (m, 2H, CH $\mathrm{Fmoc}_{2}, 5.98$ (d, J=4.7 Hz, 
$\left.2 \mathrm{H}, \mathrm{CH}_{2} \mathrm{Bn}\right), 6.98(\mathrm{~m}, 3 \mathrm{H}, \mathrm{NHFmoc}, \mathrm{H}-6, \mathrm{H}-5), 7.20-4.48\left(\mathrm{~m}, 9 \mathrm{H}, \mathrm{Ph}, \mathrm{H}-3_{\mathrm{Fmoc}}, \mathrm{H}-\right.$ $4_{\text {Fmoc }}$ ), 7.50 (m, 4H, H-2 $\left.{ }_{F m o c}, H-5_{F m o c}\right), 8.05$ (d, J = 5.2 Hz, 1H, NHCOOBn) ppm.

${ }^{13} \mathrm{C}$-NMR (75 MHz, [D $\left.\left.\mathrm{D}_{6}\right] \mathrm{DMSO}\right): \delta=31.2(\mathrm{C}-\beta), 46.2$ (CHFmoc), 50.1 (C- $\alpha$ ), 46.6, 63.7 (C- $\gamma$ ), $66.3\left(\mathrm{CH}_{2} \mathrm{Fmoc}\right), 94.0$ (C-6), 120.1 (C-5), 125.1-128.8 (Ph, Fmoc) ppm. ESI-MS $(\mathrm{m} / \mathrm{z}): 569.9[\mathrm{M}+\mathrm{H}]^{+}, 481.1[\mathrm{M}+\mathrm{Na}]^{+}$. 


\subsection{Synthese des Stilben-Linkers}

\section{4,4'-trans-Stilbendicarboxylat (17)}<smiles>COC(=O)c1ccc(/C=C/c2ccc(C(=O)OC)cc2)cc1</smiles>

16

$\mathrm{C}_{18} \mathrm{H}_{16} \mathrm{O}_{4}[296.33]$<smiles>O=C(O)c1ccc(/C=C/c2ccc(C(=O)O)cc2)cc1</smiles>

17

$\mathrm{C}_{16} \mathrm{H}_{12} \mathrm{O}_{4}[268.27]$

Eine Suspension von Dimethyl-trans-stilben-4,4'-dicarboxylat (16, $100 \mathrm{mg}, 338 \mu \mathrm{mol}$, 1.00 eq.) in einer Lösung aus Ethylenglycol $(1.67 \mathrm{~mL}), \mathrm{H}_{2} \mathrm{O}(0.420 \mathrm{~mL})$ und $\mathrm{NaOH}$ (210 mg, $5.25 \mathrm{mmol}, 15.0$ eq.) wurde $5 \mathrm{~h}$ unter Rückfluss erhitzt. Die Mischung wurde mit $\mathrm{H}_{2} \mathrm{O}(17.0 \mathrm{~mL})$ versetzt und mit Aktivkohle (83.0 g) $15 \mathrm{~min}$ bis zum Sieden erhitzt. Nach Abfiltrieren der Aktivkohle wurde die freie Säure mit konz. $\mathrm{HCl}$ ausgefällt. Der gallertartige Niederschlag wurde erhitzt, abfiltriert und mit $\mathrm{H}_{2} \mathrm{O}, \mathrm{EtOH}$ und $\mathrm{MeOH}$ gewaschen. Nach Trocknen im Hochvakuum wurden $72.2 \mathrm{mg}(270 \mu \mathrm{mol}$, $80 \%)$ der gewünschten Verbindung als weißer Feststoff erhalten.

DC $\left(\mathrm{CHCl}_{3} / \mathrm{MeOH} / \mathrm{H}_{2} \mathrm{O} / \mathrm{HOAC} 70: 30: 3: 0.3\right): \mathrm{R}_{\mathrm{f}}=0.51$.

${ }^{1} \mathrm{H}-\mathrm{NMR}\left(300 \mathrm{MHz},\left[\mathrm{D}_{6}\right] \mathrm{DMSO}\right): \delta=7.45(\mathrm{~s}, 2 \mathrm{H}, \mathrm{Ph}-\mathrm{HC}=\mathrm{CH}-\mathrm{Ph}), 7.73-7.98(\mathrm{~m}, 8 \mathrm{H}$, $\mathrm{Ph}), 12.85$ (s br, 2H, $\mathrm{COOH}$ ) ppm.

${ }^{13} \mathrm{C}$-NMR $\left(75 \mathrm{MHz},\left[\mathrm{D}_{6}\right] \mathrm{DMSO}\right): \delta=126.7(\mathrm{~m}-\mathrm{Ph}), 129.7(o-\mathrm{Ph}), 129.8(\mathrm{Ph}-\mathrm{HC}=\mathrm{CH}-$ $\mathrm{Ph}), 129.9$ (i-Ph) $140.9(p-\mathrm{Ph}), 166.9(\mathrm{COOH}) \mathrm{ppm}$.

$\operatorname{ESI-MS~}(\mathrm{m} / \mathrm{z}): 269.8[\mathrm{M}+\mathrm{H}]^{+}$. 


\section{4,4'-trans-Stilbendicarbonsäuredichlorid (18) ${ }^{[139]}$}<smiles>O=C(O)c1ccc(/C=C/c2ccc(C(=O)O)cc2)cc1</smiles>

17

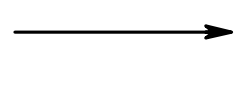

$\mathrm{C}_{16} \mathrm{H}_{12} \mathrm{O}_{4}[268.27]$<smiles>O=C(Cl)c1ccc(/C=C/c2ccc(C(=O)Cl)cc2)cc1</smiles>

18

$\mathrm{C}_{16} \mathrm{H}_{10} \mathrm{Cl}_{2} \mathrm{O}_{2}[305.16]$

Eine Suspension von 4,4'-trans-Stilbendicarboxylat (17, $210 \mathrm{mg}, 784 \mu \mathrm{mol}, 1.00$ eq.) in Toluol (4.00 mL), DMF (9.00 $\mu \mathrm{L}, 117 \mu \mathrm{mol}, 0.150$ eq.) und Thionylchlorid (127 $\mu \mathrm{L}$, 1.74 mol, 2.20 eq.) wurde $20 \mathrm{~h}$ unter Rückfluss erhitzt. Nach Entfernung des Lösungsmittels wurde im Hochvakuum getrocknet und die gewünschte Verbindung 18 in quantitativer Ausbeute erhalten.

DC $(\mathrm{MeOH}): \mathrm{R}_{\mathrm{f}}=0.46$.

${ }^{1} \mathrm{H}-\mathrm{NMR}\left(300 \mathrm{MHz},\left[\mathrm{D}_{6}\right] \mathrm{DMSO}\right): \delta=7.42(\mathrm{~m}, 2 \mathrm{H}, \mathrm{Ph}-\mathrm{HC}=\mathrm{CH}-\mathrm{Ph}), 7.65-7.95(\mathrm{~m}, 8 \mathrm{H}$, Ph) ppm.

${ }^{13} \mathrm{C}-\mathrm{NMR}\left(75 \mathrm{MHz},\left[\mathrm{D}_{6}\right] \mathrm{DMSO}\right): \delta=126.7(\mathrm{~m}-\mathrm{Ph}), 128.0(\mathrm{o}-\mathrm{Ph}), 128.9(\mathrm{Ph}-\mathrm{HC}=\mathrm{CH}-$ $\mathrm{Ph}), 129.7$ (i-Ph) 142.3 (p-Ph) ppm.

ESI-MS (m/z): $506.3[\mathrm{M}+\mathrm{H}]^{+}$. 
trans-Stilben-4-(methylcarbonsäure-methylcarbamoyl)-4'-(tert-butoxycarbonyl)aminoethylcarbamoyl) (2') +

4,4'-trans-Stilben-(tert-butoxycarbonyl)-aminoethylcarbamoyl (19)

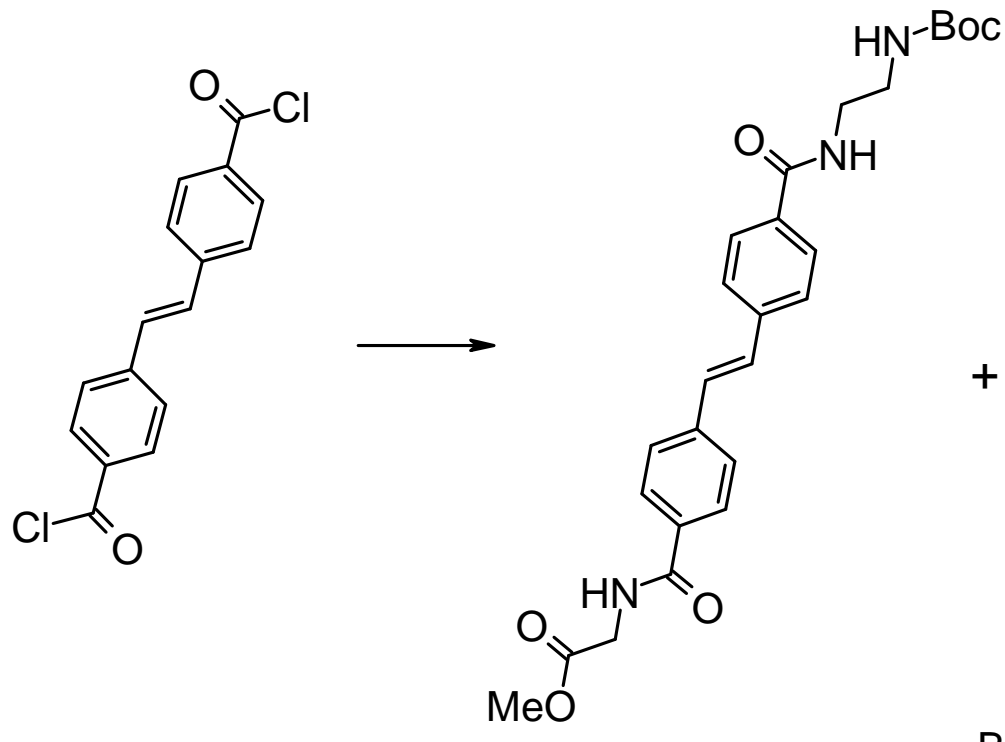

18

$\mathrm{C}_{16} \mathrm{H}_{10} \mathrm{Cl}_{2} \mathrm{O}_{2}[305.16]$

'

$\mathrm{C}_{26} \mathrm{H}_{31} \mathrm{~N}_{3} \mathrm{O}_{6}$ [481.55]

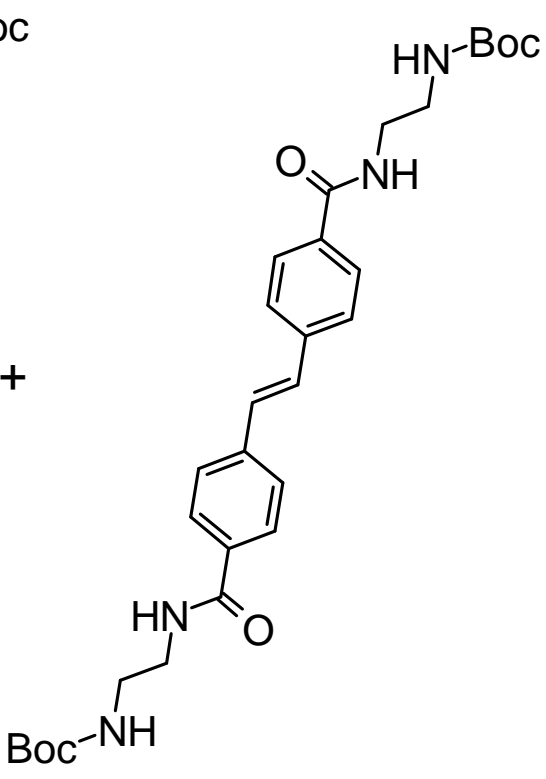

19

4,4'-trans-Stilbendicarbonsäuredichlorid (18, $300 \mathrm{mg}, 983 \mu \mathrm{mol}, 1.00$ eq.) wurde in THF $(5.00 \mathrm{ml})$ bei $0^{\circ} \mathrm{C}$ langsam zu einer kräftig ger ührten Lösung aus $N$-BocEthylendiamin (93.3 $\mu \mathrm{L}, 590 \mu \mathrm{mol}, 0.600$ eq.) und $\mathrm{NEt}_{3}$ (408 $\mu \mathrm{l}, 2.95 \mathrm{mmol}, 3.00$ eq.) in $\mathrm{MeOH}$ (3.00 mL) getropft. Nach 30 min wurde eine Lösung aus Glycinmethylester (124 mg, $983 \mu \mathrm{mol}, 1.00$ eq.) und $\mathrm{NEt}_{3}$ (408 $\mu \mathrm{l}, 2.95 \mathrm{mmol}, 3.00$ eq.) in $\mathrm{MeOH}$ $\left(3.00 \mathrm{~mL}\right.$ ) bei $0^{\circ} \mathrm{C}$ zu gegeben. Nach 30 min Rühren b ei $0^{\circ} \mathrm{C}$ wurde auf RT erwärmt und weitere $5 \mathrm{~h}$ gerührt. Das Lösungsmittel wurde auf die Hälfte reduziert und in $\mathrm{H}_{2} \mathrm{O}$ $(10.0 \mathrm{~mL})$ gegeben. Nach Abfiltrieren, Waschen mit $\mathrm{MeOH}$ und Trocknen im Hochvakuum wurden die Verbindungen 2' und 19 im Verhältnis 1:5 erhalten.

DC (EE/Pentan 1:3): $R_{f}=0.35$.

${ }^{1} \mathrm{H}-\mathrm{NMR}\left(\mathbf{2}^{\prime}\right)\left(300 \mathrm{MHz},\left[\mathrm{D}_{6}\right] \mathrm{DMSO}, 100\right.$ ' $): \delta=1.35$ (s, 9H, $\left.t-\mathrm{Bu}\right), 3.18\left(\mathrm{~m}, 2 \mathrm{H}, \mathrm{CH}_{2^{-}}\right.$ $\mathrm{CH}_{2}$-NHBoc), $3.37\left(\mathrm{~m}, 2 \mathrm{H}, \mathrm{CONH}-\mathrm{CH}_{2}-\mathrm{CH}_{2}\right), 3.68\left(\mathrm{~s}, 3 \mathrm{H}, \mathrm{OCH}_{3}\right), 3.92(\mathrm{~m}, 1 \mathrm{H}, \mathrm{NH}-$ $\mathrm{CH}-\mathrm{CO}), 4.08(\mathrm{~m}, 1 \mathrm{H}, \mathrm{NH}-\mathrm{CH}-\mathrm{CO}), 5.85$ (s, 1H, PhCO-NH-( $\left.\left.\mathrm{CH}_{2}\right)_{2}\right), 6.50$ (s br, $\mathrm{NHBoc}), 7.46(\mathrm{~m}, 2 \mathrm{H}, \mathrm{Ph}-\mathrm{HC}=\mathrm{CH}-\mathrm{Ph}), 7.75-8.05(\mathrm{~m}, 8 \mathrm{H}, \mathrm{Ph}), 8.62\left(\mathrm{~m}, 1 \mathrm{H}, \mathrm{COCH}_{2^{-}}\right.$ $\mathrm{NH}$-COPh) ppm. 
${ }^{1} \mathrm{H}-\mathrm{NMR}(19)\left(300 \mathrm{MHz},\left[\mathrm{D}_{6}\right] \mathrm{DMSO}, 100 \mathrm{C}\right): \delta=1.40(\mathrm{~s}, 18 \mathrm{H}, t-\mathrm{Bu}), 3.81-3.96(\mathrm{~m}$, $\left.8 \mathrm{H}, \mathrm{CH}_{2}\right), 5.62(\mathrm{~s}, 2 \mathrm{H}, \mathrm{NHBoc}), 7.54(\mathrm{~m}, 2 \mathrm{H}, \mathrm{Ph}-\mathrm{HC}=\mathrm{CH}-\mathrm{Ph}), 7.75-8.05(\mathrm{~m}, 8 \mathrm{H}, \mathrm{Ph})$ ppm.

$\operatorname{ESI-MS~}(\mathrm{m} / \mathrm{z}): 504.1\left[\mathrm{M}\left(\mathbf{2}^{\prime}\right)+\mathrm{Na}\right]^{+}, 575.2[\mathrm{M}(\mathbf{1 9})+\mathrm{Na}]^{+}$.

trans-Stilben-4-(methylcarbonsäure-methylcarbamoyl)-4'-(tert-butoxycarbonyl)aminoethylcarbamoyl) (2') +

4,4'-trans-Stilben-(methylcarbonsäure-methylcarbamoyl)-aminoethylcarbamoyl (20)

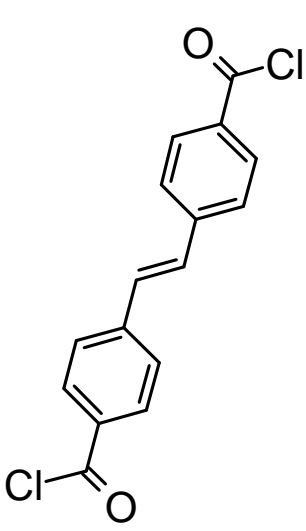

18

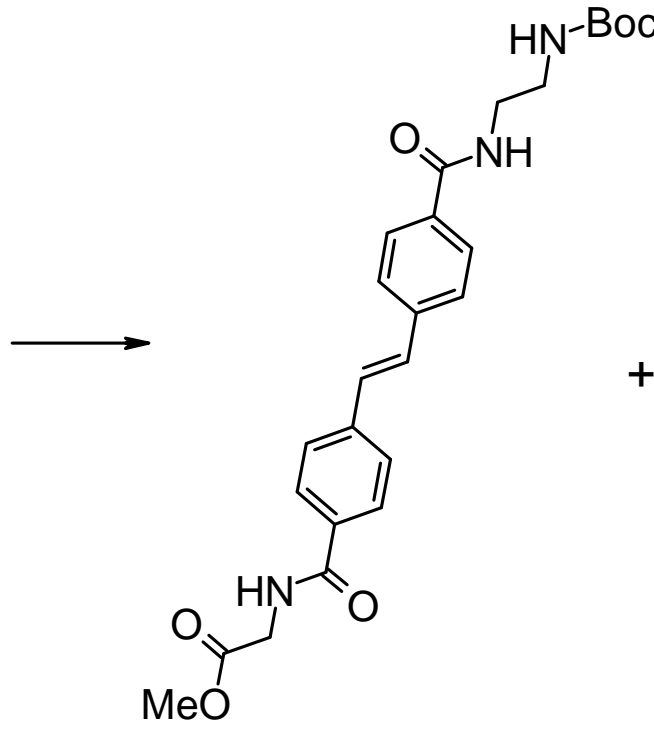

2'

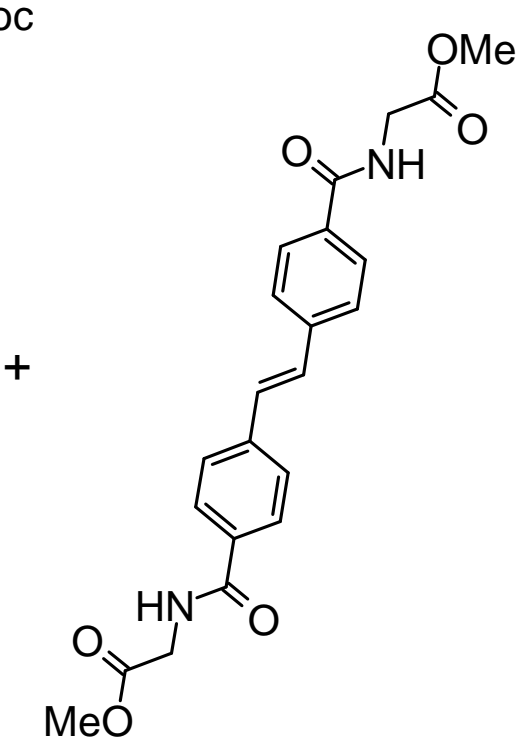

20

$\mathrm{C}_{16} \mathrm{H}_{10} \mathrm{Cl}_{2} \mathrm{O}_{2}[305.16]$

$\mathrm{C}_{26} \mathrm{H}_{31} \mathrm{~N}_{3} \mathrm{O}_{6}$ [481.55]

$\mathrm{C}_{22} \mathrm{H}_{22} \mathrm{~N}_{2} \mathrm{O}_{6}$ [410.43]

4,4'-trans-Stilbendicarbonsäuredichlorid (18, $230 \mathrm{mg}, 754 \mu \mathrm{mol}, 1.00$ eq.) wurde in THF (3.00 mL) bei $0^{\circ} \mathrm{C}$ langsam zu einer kräftig rüh renden Lösung aus Glycinmethylester (57.0 mg, $452 \mu \mathrm{mol}, 0.600$ eq.) und $\mathrm{NEt}_{3}$ (312 $\mu \mathrm{L}, 2.26$ mmol, 3.00 eq.) in $\mathrm{MeOH}(2.00 \mathrm{ml})$ getropft. Nach $30 \mathrm{~min}$ wurde eine Lösung aus $N$-BocEthylendiamin (119.2 $\mu$, $754 \mu \mathrm{mol}, 1.00$ eq.) und $\mathrm{NEt}_{3}(312 \mu \mathrm{L}, 2.26 \mathrm{mmol}, 3.00$ eq.) in $\mathrm{MeOH}\left(3.00 \mathrm{~mL}\right.$ ) bei $0^{\circ} \mathrm{C}$ zu gegeben. Nach 30 min Rühren bei $0^{\circ} \mathrm{C}$ wurde auf $\mathrm{RT}$ erwärmt und weitere $5 \mathrm{~h}$ gerührt, Das Lösungsmittel wurde auf die Hälfte reduziert und in $\mathrm{H}_{2} \mathrm{O}$ (8.00 mL) gegeben. Nach Abfiltrieren, Waschen mit $\mathrm{MeOH}$ und Trocknen im Hochvakuum wurden die Verbindungen 2' und 20 im Verhältnis 1:7 erhalten.

DC (EE/Pentan 1:3): $R_{f}=0.29$. 
${ }^{1} \mathrm{H}-\mathrm{NMR}\left(\mathbf{2}^{\prime}\right)\left(300 \mathrm{MHz},\left[\mathrm{D}_{6}\right] \mathrm{DMSO}, 100\right.$ ' $): \delta=1.42(\mathrm{~s}, 9 \mathrm{H}, t-\mathrm{Bu}), 3.22\left(\mathrm{~m}, 2 \mathrm{H}, \mathrm{CH}_{2}{ }^{-}\right.$ $\mathrm{CH}_{2}$-NHBoc), $3.44\left(\mathrm{~m}, 2 \mathrm{H}, \mathrm{CONH}-\mathrm{CH}_{2}-\mathrm{CH}_{2}\right), 3.86\left(\mathrm{~s}, 3 \mathrm{H}, \mathrm{OCH}_{3}\right), 4.14(\mathrm{~m}, 1 \mathrm{H}, \mathrm{NH}-$ $\mathrm{CH}-\mathrm{CO}$ ), 5.92 (s, 1H, PhCO-NH-( $\left.\left.\mathrm{CH}_{2}\right)_{2}\right), 6.60$ (s br, NHBoc), 7.49 (m, 2H, Ph$H \mathrm{C}=\mathrm{CH}-\mathrm{Ph}), 7.70-8.11(\mathrm{~m}, 8 \mathrm{H}, \mathrm{Ph}) \mathrm{ppm}$.

${ }^{1} \mathrm{H}-\mathrm{NMR}(20)\left(300 \mathrm{MHz},\left[\mathrm{D}_{6}\right] \mathrm{DMSO}, 100^{\circ} \mathrm{C}\right): \delta=3.00\left(\mathrm{~m}, 4 \mathrm{H}, \mathrm{CH}_{2}\right), 3.88(\mathrm{~s}, 6 \mathrm{H}$, $\left.\mathrm{OCH}_{3}\right), 7.42(\mathrm{~m}, 2 \mathrm{H}, \mathrm{Ph}-\mathrm{HC}=\mathrm{CH}-\mathrm{Ph}), 7.75-8.00(\mathrm{~m}, 8 \mathrm{H}, \mathrm{Ph}) \mathrm{ppm}$.

ESI-MS $(m / z): 412.5[\mathrm{M}(20)+\mathrm{H}]^{+}, 575.6\left[\mathrm{M}\left(\mathbf{2}^{\prime}\right)+\mathrm{Na}\right]^{+}$. 


\subsection{Synthese der gemischten Peptidnukleinsäuren}

\section{H-GVCP-AlaG-ILKKCRRDSDCPGACICRGNGYCG-NH 2 (47)}

\section{H-Gly-Val-Cys-Pro-AlaG-Ile-Leu-Lys-Lys-Cys-Arg-Arg-Asp-Ser-Asp-Cys-Pro-} Gly-Ala-Cys-Ile-Cys-Arg-Gly-Asn-Gly-Tyr-Cys-Gly- $\mathrm{NH}_{2}(47)$

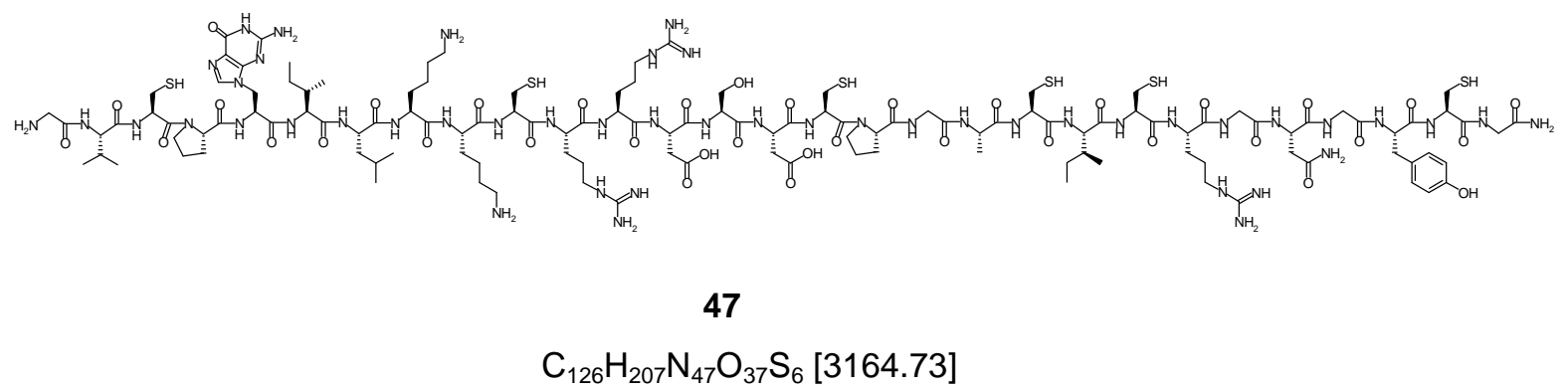

Das Peptid 47 wurde an NovoSynTGR-Harz $(81.5 \mathrm{mg}, 16.3 \mu \mathrm{mol}, 1.00$ eq., $200 \mu \mathrm{mol} / \mathrm{g}$ ) nach AAV3 und AAV4 aufgebaut. Die Kupplungszeit für Fmoc-LAsn(Trt)-OH (34.9 mg, $65.2 \mu \mathrm{mol}, 4.00$ eq.), Fmoc-L-lle-OH (23.0 mg, $65.2 \mu \mathrm{mol}$, 4.00 eq.), Fmoc-L-Lys(Boc)-OH (30.5 mg, $65.2 \mu \mathrm{mol}, 4.00$ eq.), Fmoc-L-Leu-OH (23.0 mg, $65.2 \mu \mathrm{mol}, 4.00$ eq.), Fmoc-L-Val-OH (22.1 mg, $65.2 \mu \mathrm{mol}, 4.00$ eq.) und Fmoc-L-Ala-OH (20.3 mg, $65.2 \mu \mathrm{mol}, 4.00$ eq.) betrug $30 \mathrm{~min}$, die von Fmoc-L$\operatorname{Tyr}(t \mathrm{Bu})-\mathrm{OH} \quad(30.0 \mathrm{mg}, \quad 65.2 \mu \mathrm{mol}, \quad 4.00$ eq. $)$ und Fmoc-L-Pro-OH $(23.0 \mathrm{mg}$, $65.2 \mu \mathrm{mol}, 4.00$ eq.) $40 \mathrm{~min}$, die von Fmoc-L-Asp(OtBu)-OH $(26.8 \mathrm{mg}, 65.2 \mu \mathrm{mol}$, 4.00 eq.) und Fmoc-L-Ser(tBu)-OH (25.0 mg, $65.2 \mu \mathrm{mol}, 4.00$ eq.) $50 \mathrm{~min}$, die für Fmoc-L-Gly-OH (19.4 mg, $65.2 \mu \mathrm{mol}, 4.00$ eq.), Fmoc-L-Arg(Pbf)-OH $\quad(42.3 \mathrm{mg}$, $65.2 \mu \mathrm{mol}, 4.00$ eq.) und Fmoc-L-Cys(Trt)-OH (95.5 mg, $163 \mu \mathrm{mol}, 10.0$ eq.) $1 \mathrm{~h}$ und die von Fmoc-L-AlaG-OH (46, 22.0 mg, $65.2 \mu \mathrm{mol}, 4.00$ eq.) $3 \mathrm{~h}$.

Als Kupplungsreagenzien wurden für die Nukleoaminosäure Fmoc-L-AlaG-OH (46) HATU (24.7 mg, $65.2 \mu \mathrm{mol}, 4.00$ eq.), HOAt (9.91 mg, $73.4 \mu \mathrm{mol}, 4.50$ eq.) sowie DIPEA (22.1 $\mu \mathrm{L}, 163 \mu \mathrm{mol}, 10.0$ eq.) verwendet. Für die restlichen Aminosäuren wurde HBTU (24.7 mg, $65.2 \mu \mathrm{mol}, 4.00$ eq.), HOBt (9.91 mg, $73.4 \mu \mathrm{mol}, 4.50$ eq.) sowie DIPEA (22.1 $\mu \mathrm{L}, 163 \mu \mathrm{mol}, 10.0$ eq.) verwendet. Für die Aminosäure Fmoc-LCys(Trt)-OH wurde DIC (25.2 $\mu \mathrm{L}, 163 \mu \mathrm{mol}, 10.0$ eq.) und HOBt $(9.91 \mathrm{mg}, 73.4 \mu \mathrm{mol}$, 4.50 eq.) verwendet. Die Kupplungen wurden in NMP (600 $\mu \mathrm{L})$ durchgeführt. Nach der Abspaltung wurde das Peptid aus Wasser lyophilisiert und mittels HPLC gereinigt. Es wurden $26.0 \mathrm{mg}(8.22 \mu \mathrm{mol}, 50 \%)$ des reinen Peptides erhalten. 
HPLC (Gradient: 5 - $60 \%$ B in $30 \mathrm{~min}$ ): $\mathrm{t}_{\mathrm{R}}=12.6 \mathrm{~min}$.

ESI-MS $(m / z): 1583.3[\mathrm{M}+\mathrm{H}]^{2+}$.

HR-MS $\mathrm{C}_{126} \mathrm{H}_{207} \mathrm{~N}_{47} \mathrm{O}_{37} \mathrm{~S}_{6}[\mathrm{M}+4 \mathrm{H}]^{4+}$ berechnet 791.60941, gefunden 791.60887.

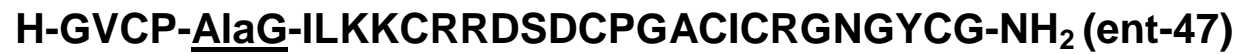

\section{H-Gly-Val-Cys-Pro-AlaG-Ile-Leu-Lys-Lys-Cys-Arg-Arg-Asp-Ser-Asp-Cys-Pro- Gly-Ala-Cys-Ile-Cys-Arg-Gly-Asn-Gly-Tyr-Cys-Gly- $\mathrm{NH}_{2}$ (ent-47)}

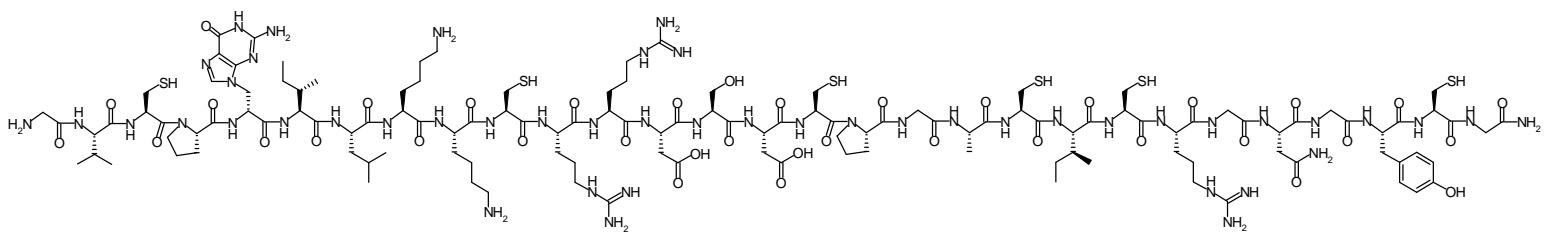

47

$\mathrm{C}_{126} \mathrm{H}_{207} \mathrm{~N}_{47} \mathrm{O}_{37} \mathrm{~S}_{6}$ [3164.73]

Das Peptid 47 wurde an NovoSynTGR-Harz $(81.5 \mathrm{mg}, 163 \mu \mathrm{mol}, 1.00$ eq., $200 \mu \mathrm{mol} / \mathrm{g}$ ) nach AAV3 und AAV4 aufgebaut. Die Kupplungszeit für Fmoc-LAsn(Trt)-OH (34.9 mg, $65.2 \mu \mathrm{mol}, 4.00$ eq.), Fmoc-L-lle-OH (23.0 mg, $65.2 \mu \mathrm{mol}$, 4.00 eq.), Fmoc-L-Lys(Boc)-OH (30.5 mg, $65.2 \mu \mathrm{mol}, 4.00$ eq.), Fmoc-L-Leu-OH (23.0 mg, $65.2 \mu \mathrm{mol}, 4.00$ eq.), Fmoc-L-Val-OH (22.1 mg, $65.2 \mu \mathrm{mol}, 4.00$ eq.) und Fmoc-L-Ala-OH (20.3 mg, $65.2 \mu \mathrm{mol}, 4.00$ eq.) betrug $30 \mathrm{~min}$, die von Fmoc-L$\operatorname{Tyr}(t \mathrm{Bu})-\mathrm{OH} \quad(30.0 \mathrm{mg}, \quad 65.2 \mu \mathrm{mol}, \quad 4.00$ eq. $)$ und Fmoc-L-Pro-OH $(23.0 \mathrm{mg}$, $65.2 \mu \mathrm{mol}, 4.00$ eq.) $40 \mathrm{~min}$, die von Fmoc-L-Asp(OtBu)-OH $(26.8 \mathrm{mg}, 65.2 \mu \mathrm{mol}$, 4.00 eq.) und Fmoc-L-Ser(tBu) $(25.0 \mathrm{mg}, 65.2 \mu \mathrm{mol}, 4.00$ eq.) $50 \mathrm{~min}$, die für Fmoc-LGly-OH (19.4 mg, $65.2 \mu \mathrm{mol}, 4.00$ eq.), Fmoc-L-Arg(Pbf)-OH (42.3 mg, $65.2 \mu \mathrm{mol}$, 4.00 eq.) und Fmoc-L-Cys(Trt)-OH (95.5 mg, $163 \mu \mathrm{mol}, 10.0$ eq.) $1 \mathrm{~h}$, die von FmocD-AlaG-OH (ent-46, $22.0 \mathrm{mg}, 65.2 \mu \mathrm{mol}, 4.00$ eq.) $3 \mathrm{~h}$.

Als Kupplungsreagenzien wurden für die Peptidnukleinsäure Fmoc-D-AlaG-OH (ent46) HATU (24.7 mg, $65.2 \mu \mathrm{mol}, 4.00$ eq.), HOAt (9.91 mg, $73.4 \mu \mathrm{mol}, 4.50$ eq.) sowie DIPEA (22.1 $\mu \mathrm{L}, 163 \mu \mathrm{mol}, 10.0$ eq.) verwendet. Für die restlichen Aminosäuren wurde HBTU (24.7 mg, $65.2 \mu \mathrm{mol}, 4.00$ eq.), HOBt (9.91 mg, $73.4 \mu \mathrm{mol}, 4.50$ eq.) sowie DIPEA (22.1 $\mu \mathrm{L}, 163 \mu \mathrm{mol}, 10.0$ eq.) verwendet. Für die Aminosäure Fmoc-LCys(Trt)-OH wurde DIC (25.2 $\mu \mathrm{L}, 163 \mu \mathrm{mol}, 10.0$ eq.) und HOBt $(9.91 \mathrm{mg}, 73.4 \mu \mathrm{mol}$, 
4.50 eq.) verwendet. Die Kupplungen wurden in NMP (600 $\mu \mathrm{L})$ durchgeführt. Nach der Abspaltung wurde das Peptid aus Wasser lyophilisiert und mittels HPLC gereinigt. Es wurden 32.2 mg (10.2 $\mu \mathrm{mol}, 62 \%)$ des reinen Peptides erhalten.

HPLC (Gradient: 5 - $60 \%$ B in $30 \mathrm{~min}$ ) $t_{R}=13.6$ min.

ESI-MS $(m / z): 791.8[\mathrm{M}+4 \mathrm{H}]^{4+}, 1054.9[\mathrm{M}+3 \mathrm{H}]^{3+}, 1582.5[\mathrm{M}+2 \mathrm{H}]^{2+}$.

HR-MS $\mathrm{C}_{126} \mathrm{H}_{207} \mathrm{~N}_{47} \mathrm{O}_{37} \mathrm{~S}_{6}[\mathrm{M}+4 \mathrm{H}]^{4+}$ berechnet 791.60941, gefunden 791.60056.

\section{AC-KAYKAWAEAYAKWAK-NH 2 (32)}

Ac-Lys-Ala-Tyr-Lys-Ala-Trp-Ala-Glu-Ala-Tyr-Ala-Lys-Trp-Ala-Lys- $\mathrm{NH}_{2}$ (32)

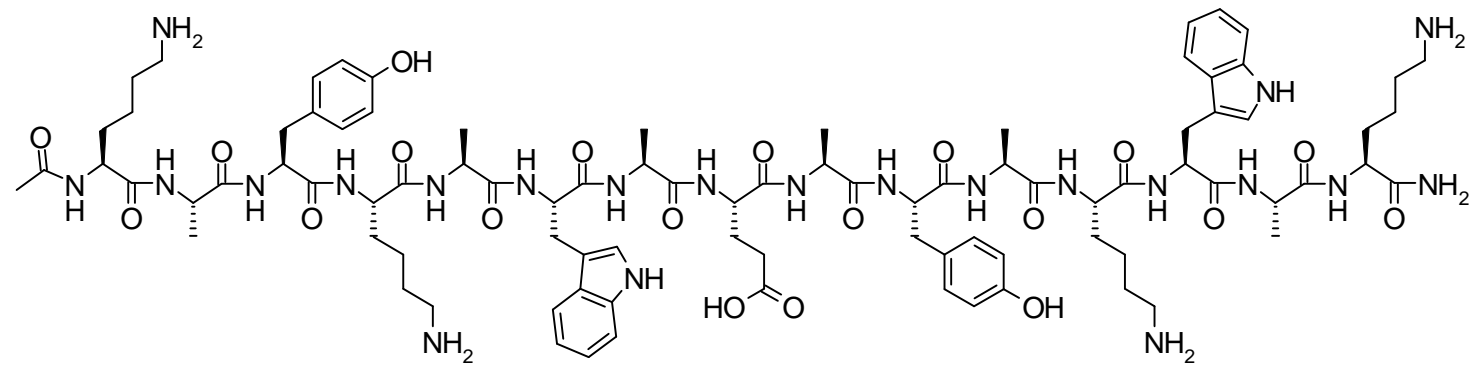

32

$$
\mathrm{C}_{89} \mathrm{H}_{128} \mathrm{~N}_{22} \mathrm{O}_{20}[1826.15]
$$

Das Peptid 32 wurde an Boc-L-Lys(2-Cl-Z)-MBHA-Harz (100 mg, $43.0 \mu \mathrm{mol}$, 1.00 eq., $430 \mu \mathrm{mol} / \mathrm{g})$ nach AAV2 aufgebaut. Die Kupplungszeit für Boc-L-Ala-OH (40.7 mg, $215 \mu \mathrm{mol}, 5.00$ eq.) sowie für Boc-L-Tyr(2-Br-Z)-OH (106.3 mg, $215 \mu \mathrm{mol}$, 5.00 eq.) betrug $45 \mathrm{~min}$ und für Boc-L-Trp-OH (71.5 mg, $215 \mu \mathrm{mol}, 5.00$ eq.) 2 x 45 min. Die Kupplungszeit für Boc-L-Glu(OBn)-OH (50.6 mg, $215 \mu \mathrm{mol}, 5.00$ eq.) sowie für Boc-L-Lys(2-Cl-Z)-OH (89.2 mg, $215 \mu \mathrm{mol}, 5.00$ eq.) betrug jeweils $35 \mathrm{~min}$. Als Kupplungsreagenzien wurden HBTU (73.4 mg, $194 \mu \mathrm{mol}, 4.50$ eq.) und HOBt (29.0 mg, $215 \mu \mathrm{mol}, 5.00$ eq.) sowie DIPEA (87.6 $\mu \mathrm{L}, 516 \mu \mathrm{mol}, 12.0$ eq.) verwendet. Die Kupplungen wurden in NMP $(600 \mu \mathrm{L})$ durchgeführt. Nach der Abspaltung wurde das Peptid aus Wasser lyophilisiert und mittels HPLC gereinigt. Es wurden $2.01 \mathrm{mg}$ (1.10 $\mu \mathrm{mol}, 3 \%)$ des reinen Peptides erhalten.

HPLC (Gradient: 5 - $60 \%$ B in $30 \mathrm{~min}$ ): $\mathrm{t}_{\mathrm{R}}=21.6 \mathrm{~min}$. 
ESI-MS $(\mathrm{m} / \mathrm{z}): 1849.9[\mathrm{M}+\mathrm{Na}]^{+}, 935.8[\mathrm{M}+2 \mathrm{Na}]^{2+}$

\section{AC-KAYKAWAEAYAKWAK- $\mathrm{NH}_{2}$ (32)}

Ac-Lys-Ala-Tyr-Lys-Ala-Trp-Ala-Glu-Ala-Tyr-Ala-Lys-Trp-Ala-Lys- $\mathrm{NH}_{2}$ (32)

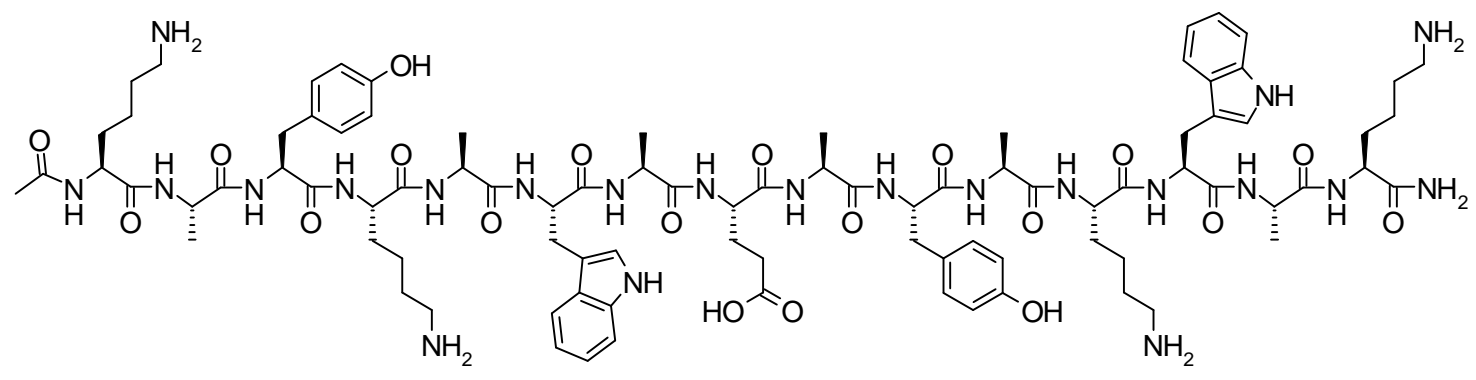

32

$\mathrm{C}_{89} \mathrm{H}_{128} \mathrm{~N}_{22} \mathrm{O}_{20}[1826.15]$

Das Peptid 32 wurde an NovoSynTGR-Harz (50 mg, $12.5 \mu \mathrm{mol}, 1.00$ eq., $250 \mu \mathrm{mol} / \mathrm{g}$ ) nach AAV3 aufgebaut. Die Kupplungzeit für Fmoc-L-Ala-OH (19.5 mg, $62.5 \mu \mathrm{mol}, 5.00$ eq.) und Fmoc-L-Glu(OtBu)-OH (26.6 mg, $62.5 \mu \mathrm{mol}, 5.00$ eq.) betrug $40 \mathrm{~min}$ und die von Fmoc-L-Lys(Boc)-OH (29.3 mg, $62.5 \mu \mathrm{mol}, 5.00$ eq.) $35 \mathrm{~min}$ Die Kupplungszeit für Fmoc-L-Trp(Boc)-OH (32.9 mg, $62.5 \mu \mathrm{mol}, 5.00$ eq.) sowie für Fmoc-L-Tyr(OtBu)-OH (28.7 mg, $62.5 \mu \mathrm{mol}, 5.00$ eq.) betrug jeweils $2 \times 30 \mathrm{~min}$ Als Kupplungsreagenzien wurden HBTU (21.4 mg, $56.3 \mu \mathrm{mol}, 4.50$ eq.), HOBt (8.44 mg, $62.5 \mu \mathrm{mol}$, 5.00 eq.) sowie DIPEA (21.2 $\mu \mathrm{L}, 150 \mu \mathrm{mol}, 12.0$ eq.) verwendet. Die Kupplungen wurden in NMP $(600 \mu \mathrm{L})$ durchgeführt. Nach der Abspaltung wurde das Peptid aus Wasser lyophilisiert und mittels HPLC gereinigt. Es wurden $13.1 \mathrm{mg}(7.17 \mu \mathrm{mol}, 57 \%)$ des reinen Peptides erhalten.

HPLC (Gradient: $5-60 \% \mathrm{~B}$ in $30 \mathrm{~min}$ ): $\mathrm{t}_{\mathrm{R}}=23.6 \mathrm{~min}$.

$\operatorname{ESI-MS~}(\mathrm{m} / \mathrm{z}): 1828.0[\mathrm{M}+\mathrm{H}]^{+}$. 
Ac-Lys-Ala-HalC-Lys-Ala-HalG-Ala-Glu-Ala-HalC-Ala-Lys-HalG-Ala-Lys- $\mathrm{NH}_{2}$ (28)

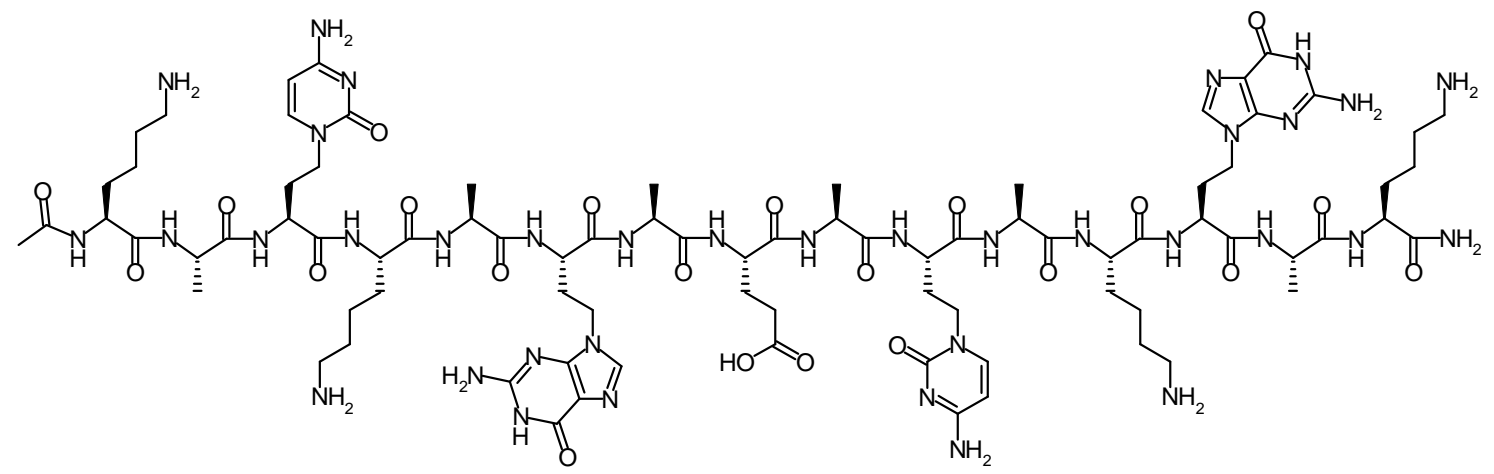

28

$\mathrm{C}_{83} \mathrm{H}_{130} \mathrm{~N}_{36} \mathrm{O}_{22}$ [1984.19]

Das Peptid 28 wurde an NovoSynTGR-Harz (50 mg, $12.5 \mu \mathrm{mol}, 1.00$ eq., $25.0 \mu \mathrm{mol} / \mathrm{g}$ ) nach AAV3 aufgebaut. Die Kupplungzeit für Fmoc-L-Ala-OH (19.5 mg, $62.5 \mu \mathrm{mol}$, 5.00 eq.) und Fmoc-L-Glu(OtBu)-OH (26.6 mg, $62.5 \mu \mathrm{mol}, 5.00$ eq.) betrug $40 \mathrm{~min}$ und die von Fmoc-L-Lys(Boc)-OH (29.3 mg, $62.5 \mu \mathrm{mol}, 5.00$ eq.) 35 min. Die Kupplungszeit von Fmoc-L-HalC $\mathrm{F}_{2} \mathrm{OH}$ (34.8 mg, $62.5 \mu \mathrm{mol}$, 5.00 eq.) betrug $1 \mathrm{~h}$ und die von Fmoc-L-HalG-OH (29.7 mg, $62.5 \mu \mathrm{mol}, 5.00$ eq.) $2 \mathrm{~h}$. Als Kupplungsreagenzien wurden für die Peptidnukleinsäuren Fmoc-L-HalG-OH und Fmoc-L-HalC ${ }_{z}-\mathrm{OH}$ HATU (21.4 mg, $56.3 \mu \mathrm{mol}, 4.50$ eq.), HOAt (8.44 mg, $62.5 \mu \mathrm{mol}$, 5.00 eq.) sowie DIPEA $(21.2 \mu \mathrm{L}, 150 \mu \mathrm{mol}, 12.0$ eq. $)$ verwendet. Für die Aminosäuren wurden HBTU (21.3 mg, $56.3 \mu \mathrm{mol}, 4.50$ eq.), HOBt $(8.34 \mathrm{mg}$, $62.5 \mu \mathrm{mol}$, 5.00 eq.) sowie DIPEA (21.2 $\mu \mathrm{L}, 150 \mu \mathrm{mol}, 12.0$ eq.) verwendet. Die Kupplungen wurden in NMP $(600 \mu \mathrm{L})$ durchgeführt. Nach der Abspaltung wurde das Peptid aus Wasser lyophilisiert und mittels HPLC gereinigt. Es wurden $7.55 \mathrm{mg}$ (3.81 $\mu \mathrm{mol}, 31 \%)$ des reinen Peptides erhalten.

HPLC (Gradient: 5 - $40 \%$ B in $30 \mathrm{~min}$ ): $\mathrm{t}_{\mathrm{R}}=10.5 \mathrm{~min}$.

ESI-MS $(\mathrm{m} / \mathrm{z}): 1012[\mathrm{M}+\mathrm{K}+\mathrm{H}]^{2+}, 675.9[\mathrm{M}+\mathrm{K}+2 \mathrm{H}]^{3+}$. 
Ac-KA-HaIC-KA-HaIC-AEA-HaIG-AK-HaIG-AK- $\mathrm{NH}_{2}$ (29)

Ac-Lys-Ala-HaIC-Lys-Ala-HaIC-Ala-Glu-Ala-HalG-Ala-Lys-HalG-Ala-Lys- $\mathrm{NH}_{2}$ (29)

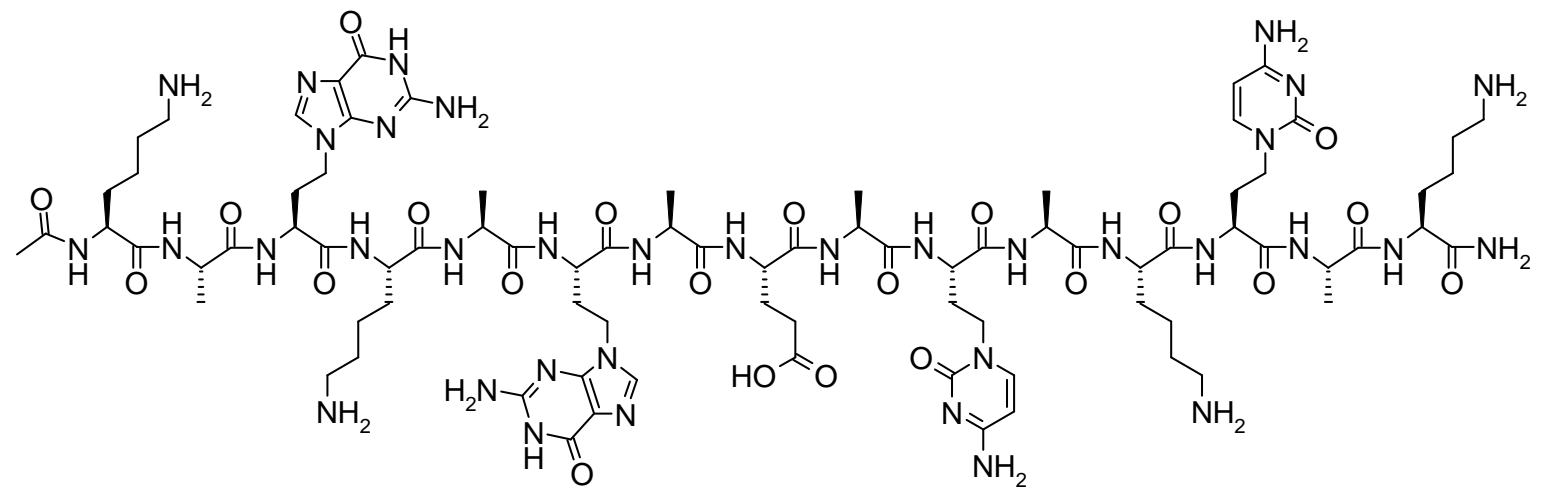

29

$\mathrm{C}_{83} \mathrm{H}_{130} \mathrm{~N}_{36} \mathrm{O}_{22}$ [1984.19]

Das Peptid 29 wurde an Boc-L-Lys(2-Cl-Z)-MBHA-Harz (50.0 mg, $21.5 \mu \mathrm{mol}$, 1.00 eq., $43.0 \mu \mathrm{mol} / \mathrm{g})$ nach AAV2 aufgebaut. Die Kupplungszeit für Boc-L-Ala-OH (20.4 mg, $108 \mu \mathrm{mol}, 5.00$ eq.) betrug $45 \mathrm{~min}$ und für Boc-L-Glu(OBn)-OH (36.3 mg, $108 \mu \mathrm{mol}, 5.00$ eq.) sowie für Boc-L-Lys(2-Cl-Z)-OH (44.6 mg, $108 \mu \mathrm{mol}, 5.00$ eq.) jeweils $35 \mathrm{~min}$. Die Kupplungszeit von Boc-L-HalC $\mathrm{Z}_{2} \mathrm{OH}$ (48.0 mg, $108 \mu \mathrm{mol}, 5.00$ eq.) betrug $1 \mathrm{~h}$ und die von Boc-L-HalG-OH (37.9 mg, $108 \mu \mathrm{mol}, 5.00$ eq.) $2 \mathrm{~h}$. Als Kupplungsreagenzien wurden für die Peptidnukleinsäuren Fmoc-L-HalG-OH und Fmoc-L-HalC $z_{z} \mathrm{OH}$ HATU (36.8 mg, $96.8 \mu \mathrm{mol}, 4.50$ eq.), HOAt (14.6 mg, $108 \mu \mathrm{mol}$, 5.00 eq.) sowie DIPEA $(43.8 \mu \mathrm{L}, 285 \mu \mathrm{mol}, 12.0$ eq. $)$ verwendet. Für die Aminosäuren wurden HBTU (36.7 mg, $96.8 \mu \mathrm{mol}, 4.50$ eq.) und HOBt (14.5 mg, $0.108 \mathrm{mmol}, 5.00$ eq.) sowie DIPEA (43.8 $\mu \mathrm{L}, 285 \mu \mathrm{mol}, 12.0$ eq.) verwendet. Die Kupplungen wurden in NMP $(500 \mu \mathrm{L})$ durchgeführt. Nach der Abspaltung wurde das Peptid aus Wasser lyophilisiert und mittels HPLC gereinigt. Es wurden $1.61 \mathrm{mg}$ (811 nmol, 4 \%) des reinen Peptides erhalten.

HPLC (Gradient: 5 - $40 \%$ B in $30 \mathrm{~min}$ ) $t_{R}=19.2 \mathrm{~min}$.

ESI-MS $(m / z): 662.4[\mathrm{M}+3 \mathrm{H}]^{3+}, 992.7[\mathrm{M}+2 \mathrm{H}]^{2+}$.

HR-MS $\mathrm{C}_{83} \mathrm{H}_{130} \mathrm{~N}_{36} \mathrm{O}_{22}[\mathrm{M}+4 \mathrm{H}]^{4+}$ berechnet 496.76129, gefunden 496.76117. 
Ac-Lys-Ala-HalG-Lys-Ala-HaIC-Ala-Glu-Ala-HaIG-Ala-Lys-HaIC-Ala-Lys- $\mathrm{NH}_{2}$ (28)

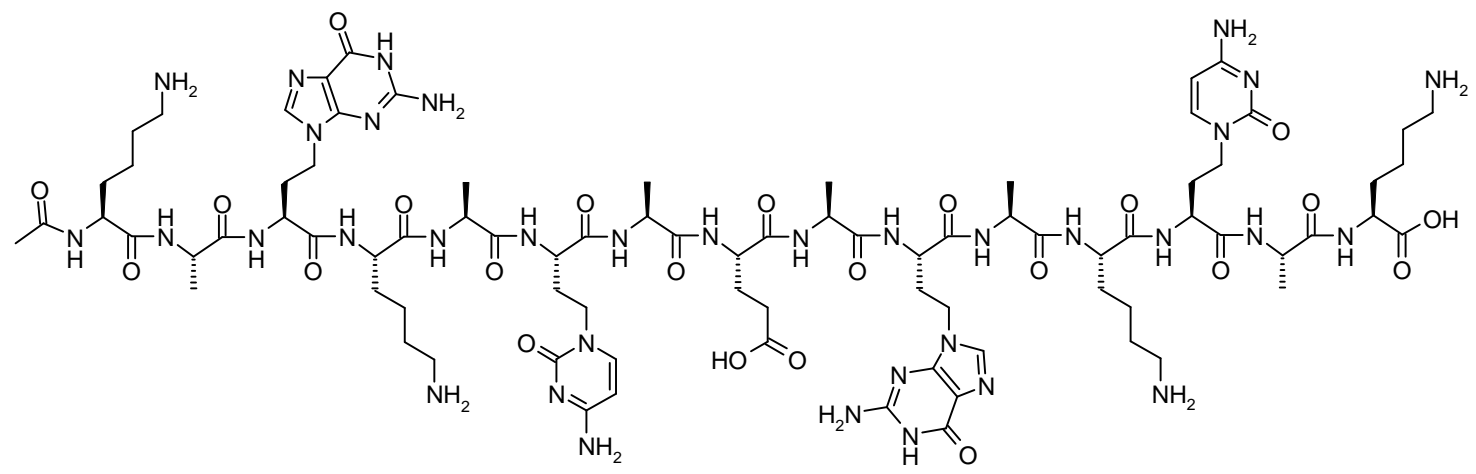

$$
\frac{28}{\mathrm{C}_{83} \mathrm{H}_{130} \mathrm{~N}_{36} \mathrm{O}_{22}[1984.19]}
$$

Das Peptid 28 wurde an Boc-L-Lys(2-Cl-Z)-MBHA-Harz (50 mg, $21.5 \mu \mathrm{mol}, 1.00$ eq., $430 \mu \mathrm{mol} / \mathrm{g})$ nach AAV2 aufgebaut. Die Kupplungszeit für Boc-L-Ala-OH (20.4 mg, $108 \mu \mathrm{mol}, 5.00$ eq.) betrug $45 \mathrm{~min}$ und für Boc-L-Glu(OBn)-OH (36.3 mg, $108 \mu \mathrm{mol}$, 5.00 eq.) sowie für Boc-L-Lys(2-Cl-Z)-OH (44.6 mg, $108 \mu \mathrm{mol}, 5.00$ eq.) jeweils 35 min. Die Kupplungszeit von Boc-L-HalC ${ }_{z}-\mathrm{OH}$ (48.0 mg, $108 \mu \mathrm{mol}, 5.00$ eq.) betrug $1 \mathrm{~h}$ und die von Boc-L-HalG-OH (37.9 mg, $108 \mu \mathrm{mol}, 5.00$ eq.) $2 \mathrm{~h}$. Als Kupplungsreagenzien wurden für die Peptidnukleinsäuren Boc-L-HalG-OH und BocL-HalC ${ }_{Z}-\mathrm{OH}$ HATU (36.8 mg, $96.8 \mu \mathrm{mol}, 4.50$ eq.), HOAt $(14.6 \mathrm{mg}, 108 \mu \mathrm{mol}$, 5.00 eq.) sowie DIPEA $(43.8 \mu \mathrm{L}, 285 \mu \mathrm{mol}, 12.0$ eq. $)$ verwendet. Für die Aminosäuren wurden HBTU (36.7 mg, $96.8 \mu \mathrm{mol}, 4.50$ eq.) und HOBt (14.5 mg, $108 \mu \mathrm{mol}$, 5.00 eq.) sowie DIPEA (43.8 $\mu \mathrm{L}, 285 \mu \mathrm{mol}, 12.0$ eq.) verwendet. Die Kupplungen wurden in NMP $(500 \mu \mathrm{L})$ durchgeführt. Nach der Abspaltung wurde das Peptid aus Wasser lyophilisiert und mittels HPLC gereinigt. Es wurden $2.61 \mathrm{mg}$ (1.32 $\mu \mathrm{mol}, 6 \%$ ) des reinen Peptides erhalten.

HPLC (Gradient: 5 - $40 \% \mathrm{~B}$ in $30 \mathrm{~min}$ ): $\mathrm{t}_{\mathrm{R}}=11.8 \mathrm{~min}$.

ESI-MS $(\mathrm{m} / \mathrm{z}): 1012[\mathrm{M}+\mathrm{K}+\mathrm{H}]^{2+}, 675.9[\mathrm{M}+\mathrm{K}+2 \mathrm{H}]^{3+}$. 


\section{Ac-AYAKYAKAWKAYAEAWAKWAK- $\mathrm{NH}_{2}$ (33)}

Ac-Ala-Tyr-Ala-Lys-Tyr-Ala-Lys-Ala-Trp-Lys-Ala-Tyr-Ala-Glu-Ala-Trp-Ala-LysTrp-Ala-Lys- $\mathrm{NH}_{2}$ (33)

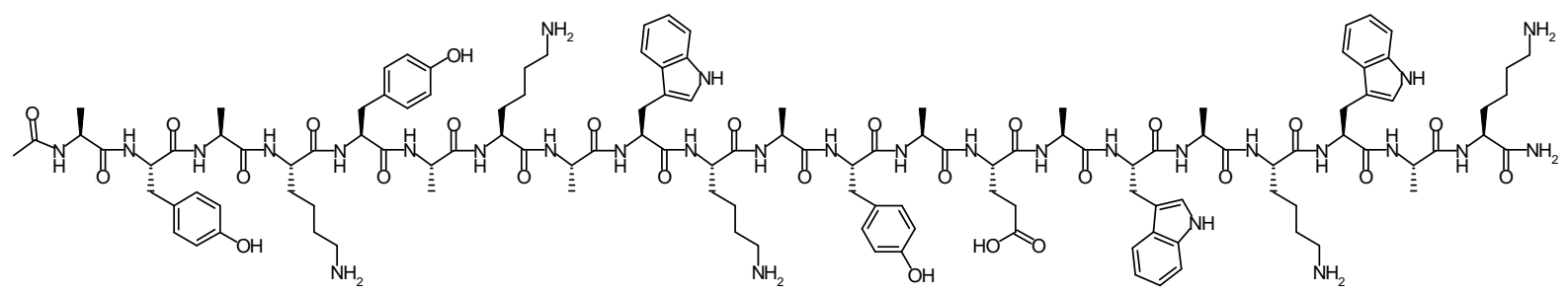

33

$$
\mathrm{C}_{124} \mathrm{H}_{174} \mathrm{~N}_{30} \mathrm{O}_{27} \text { [2516.95] }
$$

Das Peptid 33 wurde nach AAV4 automatisiert an NovaSynTGA-Harz (400 mg, $100 \mu \mathrm{mol}, 1.00$ eq., $250 \mu \mathrm{mol} / \mathrm{g}$ ) aufgebaut. Die verwendeten Aminosäuren waren Fmoc-L-Ala-OH (19.5 mg, $500 \mu \mathrm{mol}, 5.00$ eq.), Fmoc-L-Lys(Boc)-OH (234 mg, $500 \mu \mathrm{mol}, 5.00$ eq.), Fmoc-L-Trp-OH (263 mg, $500 \mu \mathrm{mol}, 5.00$ eq.), Fmoc-L-Glu(OtBu)$\mathrm{OH}$ (213 mg, $500 \mu \mathrm{mol}, 5.00$ eq.) und Fmoc-L-Tyr(OtBu)-OH (230 mg, $500 \mu \mathrm{mol}$, 5.00 eq.). Nach Abspaltung vom Harz und Reinigung mittels HPLC-Chromatographie wurden $83.3 \mathrm{mg}(33.1 \mu \mathrm{mol}, 33 \%)$ des gewünschten Peptides erhalten.

HPLC (Gradient: 30 - $80 \%$ B in $30 \mathrm{~min}$ ): $\mathrm{t}_{\mathrm{R}}=10.6 \mathrm{~min}$.

ESI-MS $(\mathrm{m} / \mathrm{z}): 1258.8[\mathrm{M}+2 \mathrm{H}]^{2+}, 839.8[\mathrm{M}+3 \mathrm{H}]^{3+}$.

HR-MS $\mathrm{C}_{124} \mathrm{H}_{174} \mathrm{~N}_{30} \mathrm{O}_{27}[\mathrm{M}+4 \mathrm{H}]^{2+}$ berechnet 630.29384, gefunden 630.27641. 


\section{Ac-Ala-HalC-Ala-Lys-HalC-Ala-Lys-Ala-HalG-Lys-Ala-HalC-Ala-Glu-Ala-HalG-} Ala-Lys-HalG-Ala-Lys- $\mathrm{NH}_{2}$ (33)

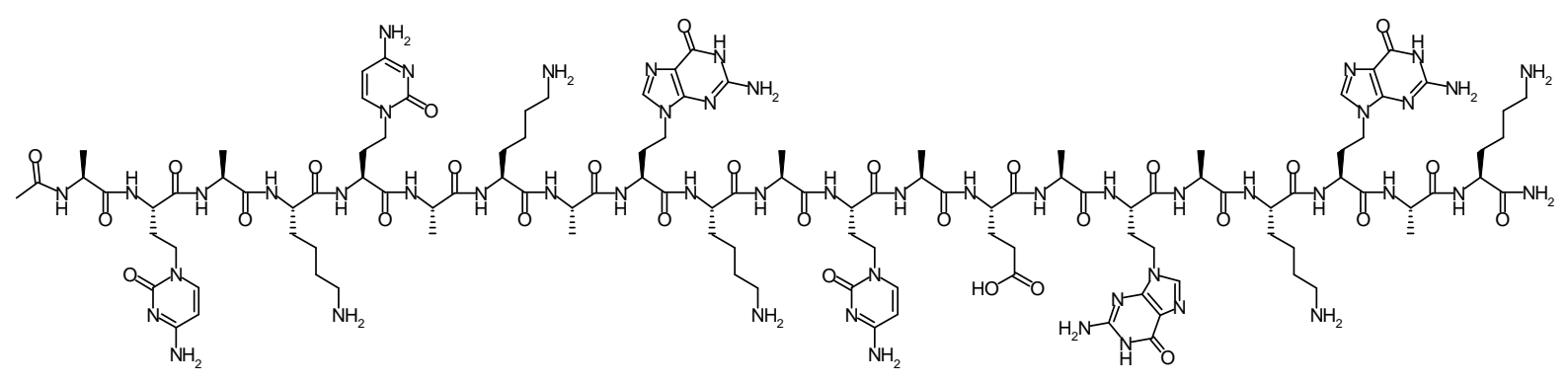

Das Peptid 33 wurde an Boc-L-Lys(2-Cl-Z)-MBHA-Harz (50 mg, $21.5 \mu \mathrm{mol}, 1.00$ eq., $430 \mu \mathrm{mol} / \mathrm{g})$ nach AAV2 aufgebaut. Die Kupplungszeit für Boc-L-Ala-OH (20.4 mg, $108 \mu \mathrm{mol}, 5.00$ eq.) betrug $45 \mathrm{~min}$ und für Boc-L-Glu(OBn)-OH (36.3 mg, $108 \mu \mathrm{mol}$, 5.00 eq.) sowie für Boc-L-Lys(2-Cl-Z)-OH (44.6 mg, $108 \mu \mathrm{mol}, 5.00$ eq.) jeweils 35 min. Die Kupplungszeit von Boc-L-HalC $-\mathrm{OH}$ (48.0 mg, $108 \mu \mathrm{mol}, 5.00$ eq.) betrug $1 \mathrm{~h}$ und die von Boc-L-HalG-OH (37.9 mg, $108 \mu \mathrm{mol}, 5.00$ eq.) $2 \mathrm{~h}$. Als Kupplungsreagenzien wurden für die Peptidnukleinsäuren Boc-L-HalG-OH und BocL-HalC $z_{-} \mathrm{OH}$ HATU $(36.8 \mathrm{mg}, 96.8 \mu \mathrm{mol}, 4.50$ eq.), HOAt $(14.6 \mathrm{mg}, 108 \mu \mathrm{mol}$, 5.00 eq.) sowie DIPEA $(43.8 \mu \mathrm{L}, 28.5 \mu \mathrm{mol}, 12.0$ eq. $)$ verwendet. Für die Aminosäuren wurden HBTU (36.7 mg, $96.8 \mu \mathrm{mol}, 4.50$ eq.) und HOBt (14.5 mg, $108 \mu \mathrm{mol}$, 5.00 eq.) sowie DIPEA (43.8 $\mu$, $285 \mu \mathrm{mol}, 12.0$ eq.) verwendet. Die Kupplungen wurden in NMP $(500 \mu \mathrm{L})$ durchgeführt. Nach der Abspaltung wurde das Peptid aus Wasser lyophilisiert und mittels HPLC gereinigt. Es wurden $3.61 \mathrm{mg}$ (1.31 $\mu \mathrm{mol}, 6 \%$ ) des reinen Peptides erhalten.

HPLC (Gradient: 5 - $55 \%$ B in $30 \mathrm{~min}$ ): $\mathrm{t}_{\mathrm{R}}=15.5 \mathrm{~min}$.

ESI-MS $(\mathrm{m} / \mathrm{z}): 1377.5[\mathrm{M}+2 \mathrm{H}]^{2+}, 918.8[\mathrm{M}+3 \mathrm{H}]^{3+}, 689.4[\mathrm{M}+4 \mathrm{H}]^{4+}$.

HR-MS $\mathrm{C}_{115} \mathrm{H}_{177} \mathrm{~N}_{51} \mathrm{O}_{30}[\mathrm{M}+\mathrm{H}]^{+}$berechnet 2752.38924, gefunden 2752.38926. 


\subsection{Synthese der gemischten Peptidnukleinsäuren mit Linker}

H-AlaC-HaIG-AlaG-HalC-[20-amino-3,6,9,12,15,18-hexaoxaeicosansäure)]-AlaGHalC-AlaC-HalG-Lys- $\mathrm{NH}_{2}$ (23)

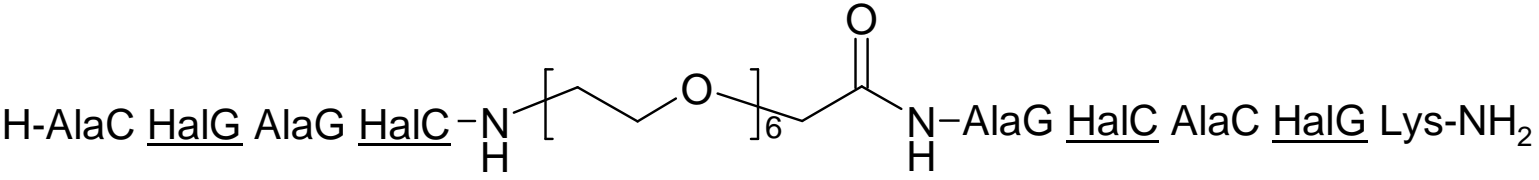

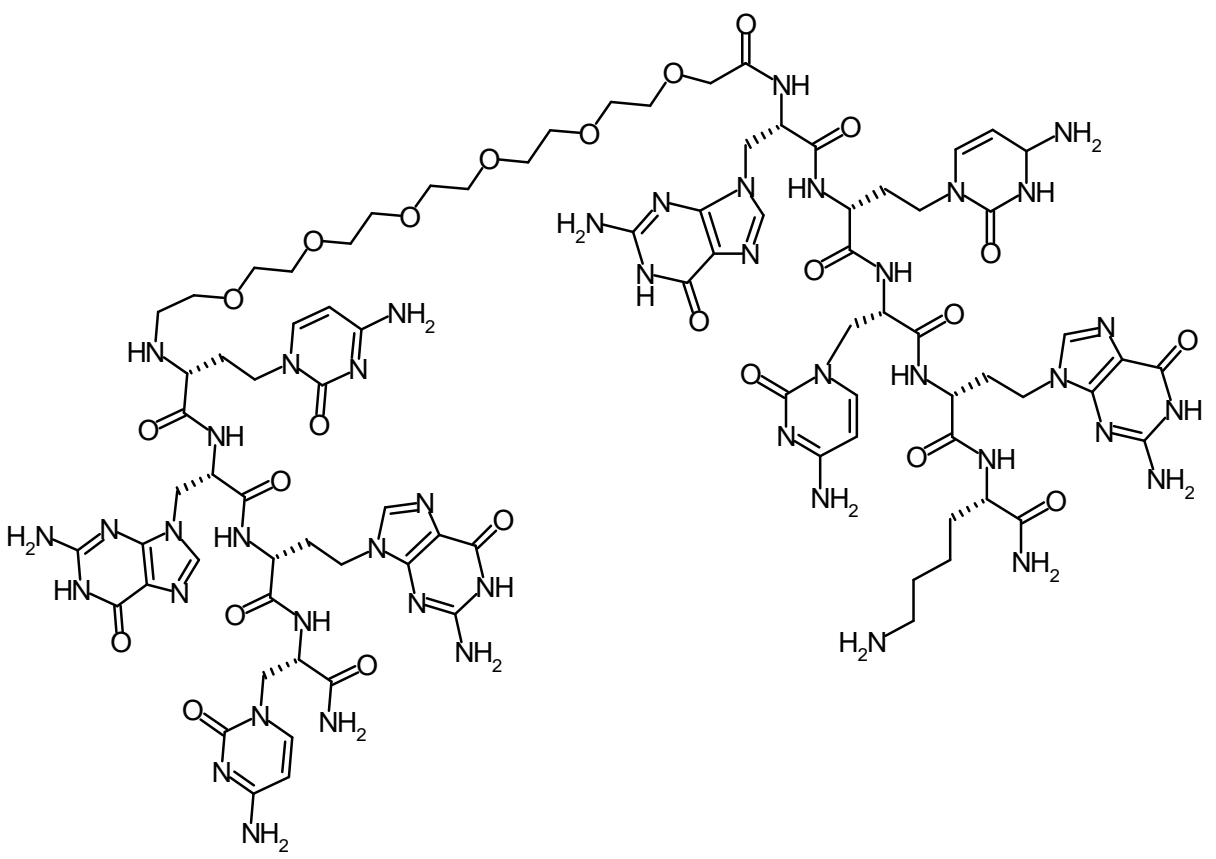

23

$\mathrm{C}_{84} \mathrm{H}_{116} \mathrm{~N}_{44} \mathrm{O}_{24}[2126.14]$

Das Peptid 23 wurde an Boc-L-Lys(2-Cl-Z)-MBHA-Harz (50 mg, $21.5 \mu \mathrm{mol}, 1.00$ eq., $430 \mu \mathrm{mol} / \mathrm{g})$ nach AAV2 aufgebaut. Die Kupplungszeit von Boc-D-HalC $\mathrm{C}_{-} \mathrm{OH}$ (48.0 mg, $108 \mu \mathrm{mol}, 5.00$ eq.) und Boc-L-AlaC $\mathrm{Z}-\mathrm{OH}$ (46.5 mg, $108 \mu \mathrm{mol}, 5.00$ eq.) betrug jeweils $1 \mathrm{~h}$ und die von Boc-D-HalG-OH (37.9 mg, $108 \mu \mathrm{mol}, 5.00$ eq.), Boc-LAlaG-OH (36.2 mg, $108 \mu \mathrm{mol}, 5.00$ eq.) und die von 20-(N-Fluorenylmethyloxycarbonyl)-amino-3,6,9,12,15,18-hexaoxaeicosansäure) (1, $121 \mathrm{mg}, 215 \mu \mathrm{mol}$, 10.0 eq.) $2 \mathrm{~h}$. Als Kupplungsreagenzien wurden HATU $(36.8 \mathrm{mg}, 96.8 \mu \mathrm{mol}$, 4.50 eq.), HOAt (14.6 mg, $108 \mu \mathrm{mol}, 5.00$ eq.) sowie DIPEA (43.8 $\mu \mathrm{L}, 285 \mu \mathrm{mol}$, 12.0 eq.) verwendet. Die Kupplungen wurden in NMP (500 $\mu \mathrm{L})$ durchgeführt. Nach der Kupplung des Glycollinkers 1 erfolgte die Entschützung der Fmoc-Gruppe mittels $20 \%$ Piperidin in NMP ( $4 \times 3$ min, 2 mL). Nach der Abspaltung wurde das Peptid aus 
Wasser lyophilisiert und mittels HPLC gereinigt. Es wurden $2.24 \mathrm{mg}$ (1.05 $\mu \mathrm{mol}, 5 \%)$ des reinen Peptides erhalten.

HPLC (Gradient: 5 - $45 \%$ B in $30 \mathrm{~min}$ ): $\mathrm{t}_{\mathrm{R}}=21.6 \mathrm{~min}$.

ESI-MS $(\mathrm{m} / \mathrm{z}): 1086.5[\mathrm{M}+\mathrm{Na}]^{+}$.

HR-MS $\mathrm{C}_{84} \mathrm{H}_{116} \mathrm{~N}_{44} \mathrm{O}_{120}[\mathrm{M}+\mathrm{K}]^{+}$berechnet 2165.148914, gefunden 2165.15834.

H-AlaC-HalC-AlaG- $\underline{\text { HalC}}-A l a G-\underline{H a I G}-[20-a m i n o-3,6,9,12,15,18-h e x a o x a e i c o s a n-$

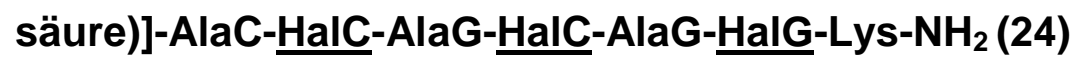

H-AlaC $\underline{\text { HalC }}$ AlaG $\underline{\text { HalC }}$ AlaG $\underline{\text { HalG }}-N_{\mathrm{H}}^{N}$

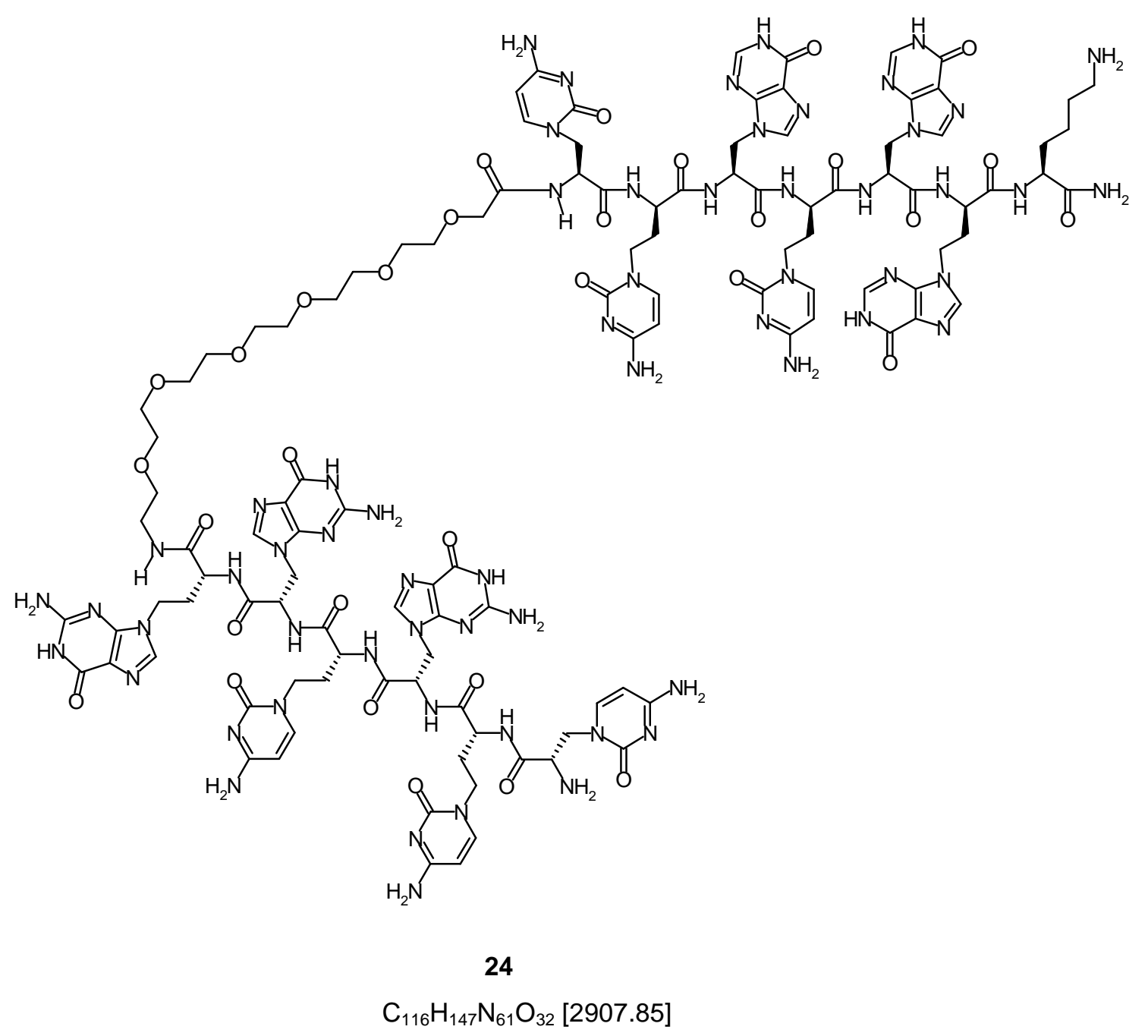

Das Peptid 24 wurde an Boc-L-Lys(2-Cl-Z)-MBHA-Harz (50 mg, $215 \mu \mathrm{mol}, 1.00$ eq., $430 \mu \mathrm{mol} / \mathrm{g}$ ) nach AAV2 aufgebaut. Die Kupplungszeit von Boc-D-HalC $-\mathrm{OH}$ 
(48.0 mg, $108 \mu \mathrm{mol}, 5.00$ eq.) und Boc-L-AlaC $\mathrm{Z}_{2}-\mathrm{OH}$ (46.5 mg, $108 \mu \mathrm{mol}, 5.00$ eq.) betrug jeweils $1 \mathrm{~h}$ und die von Boc-D-HalG-OH ( $37.9 \mathrm{mg}, 108 \mu \mathrm{mol}, 5.00$ eq.), Boc-LAlaG-OH (36.2 mg, $108 \mu \mathrm{mol}, 5.00 \mathrm{eq}$.) und von 20-(N-Fluorenylmethyloxycarbonyl)amino-3,6,9,12,15,18-hexaoxaeicosansäure) (1, $66.9 \mathrm{mg}, 215 \mu \mathrm{mol}, 10.0$ eq.) $2 \mathrm{~h}$. Als Kupplungsreagenzien wurden HATU ( $36.8 \mathrm{mg}, 96.8 \mu \mathrm{mol}, 4.50$ eq.), HOAt (14.6 mg, $108 \mu \mathrm{mol}, 5.00$ eq.) sowie DIPEA (43.8 $\mu \mathrm{L}, 285 \mu \mathrm{mol}, 12.0$ eq.) verwendet. Die Kupplungen wurden in NMP $(500 \mu \mathrm{L})$ durchgeführt. Nach der Kupplung des Glycollinkers 1 erfolgte die Entschützung der Fmoc-Gruppe mittels $20 \%$ Piperidin in NMP $(4 \times 3 \mathrm{~min}, 2 \mathrm{~mL})$. Nach der Abspaltung wurde das Peptid aus Wasser lyophilisiert und mittels HPLC gereinigt. Es wurden $2.15 \mathrm{mg}(740 \mathrm{nmol}, 3 \%)$ des reinen Peptides erhalten.

HPLC (Gradient: 5 - $100 \%$ B in $30 \mathrm{~min}$ ): $\mathrm{t}_{\mathrm{R}}=9.45 \mathrm{~min}$.

ESI-MS $(\mathrm{m} / \mathrm{z}): 2930.22[\mathrm{M}+\mathrm{Na}]^{+}, 1485.65\left[\mathrm{M}+2 \mathrm{Na}+\mathrm{H}_{2} \mathrm{O}\right]^{2+}$.

HR-MS $\mathrm{C}_{116} \mathrm{H}_{147} \mathrm{~N}_{61} \mathrm{O}_{32}[\mathrm{M}+\mathrm{H}]^{+}$berechnet 2907.82685, gefunden 2907.43258 . 


\section{Anhang}

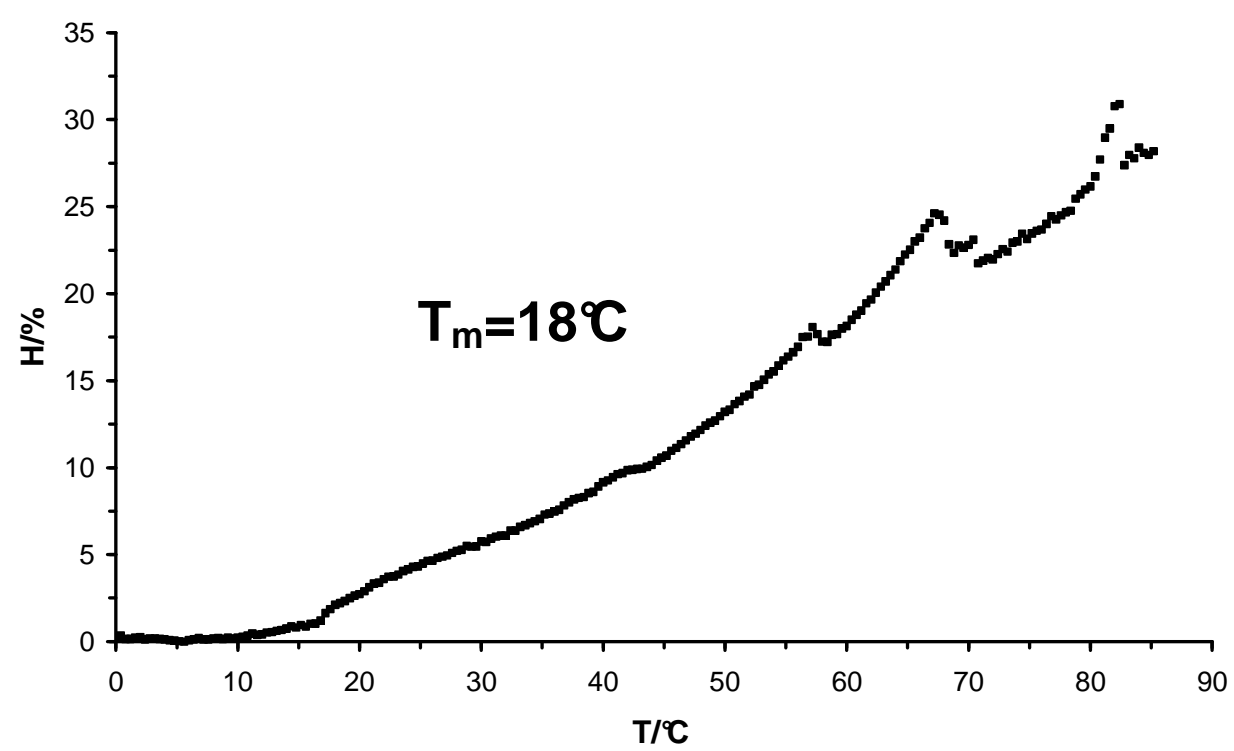

Abb. 8.1: UV-Spektrum des Oligomers H-AlaC-HalG-AlaG- $\underline{H a l C}-[20$-amino-3,6,9,12,15,18hexaoxaeicosansäre)]-AlaG- $\underline{\text { HalC}}-\mathrm{AlaC}-\underline{\mathrm{HalG}}-\mathrm{Lys}-\mathrm{NH}_{2}$ 23; $\mathrm{c}=12 \mu \mathrm{M}, 10 \mathrm{mM}$ Phosphatpuffer $\mathrm{pH} 7 ; \lambda=260 \mathrm{~nm}$; D-konfigurierte Nukleoaminosäuren sind unterstrichen dargestellt.

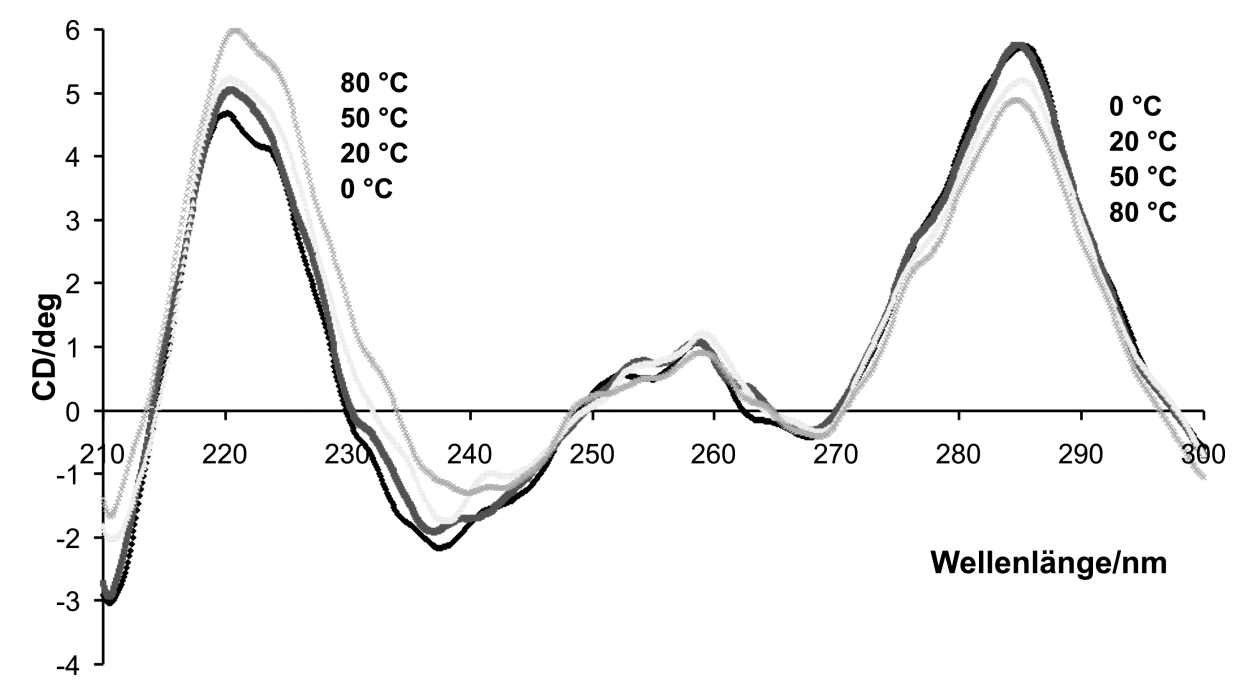

Abb. 8.2: CD-Spektrum des Oligomers H-AlaC-HalG-AlaG- $\underline{\mathrm{HalC}}-[20$-amino-3,6,9,12,15,18hexaoxaeicosansäre)]-AlaG- $\underline{\mathrm{HalC}}-\mathrm{AlaC}-\underline{\mathrm{HalG}}-\mathrm{Lys}-\mathrm{NH}_{2}$ 23; c = $12 \mu \mathrm{M}, 10 \mathrm{mM}$ Phosphatpuffer $\mathrm{pH} 7 ; \lambda=260 \mathrm{~nm}$; D-konfigurierte Nukleoaminosäuren sind unterstrichen dargestellt. 


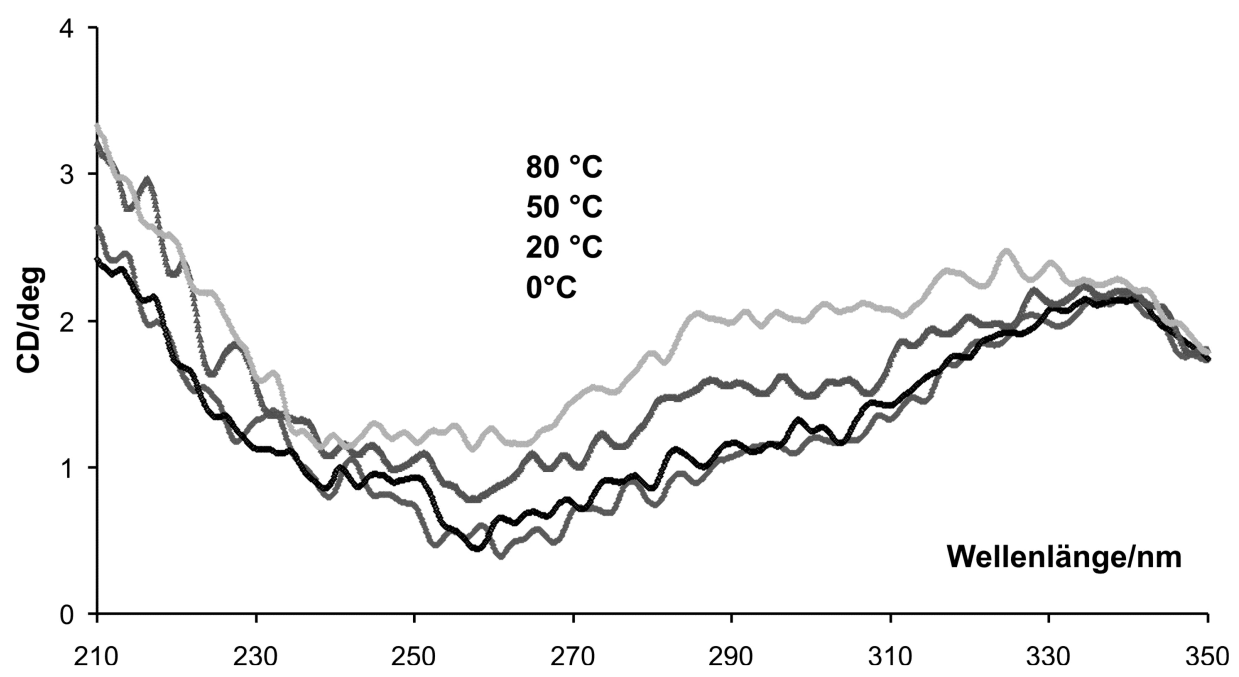

Abb. 8.3: CD-Spektrum des H-AlaC-HalC-AlaG-HalC-AlaG-HalG-[20-amino-3,6,9,12,15,18hexaoxaeicosansäure)]-AlaC- $\underline{\mathrm{HalC}}-\mathrm{AlaG}-\underline{\mathrm{HalC}}-\mathrm{AlaG}-\underline{\mathrm{HalG}}-\mathrm{Lys}-\mathrm{NH}_{2} \quad 24 ; \mathrm{c}=12 \mu \mathrm{M}, 10 \mathrm{mM}$ Phosphatpuffer $\mathrm{pH} 7 ; \lambda=260 \mathrm{~nm}$; D-konfigurierte Nukleoaminosäuren sind unterstrichen dargestellt. 


\section{Abkürzungsverzeichnis}

$\AA$

A

AAV

Abb.

ACN

HOAC

Ala

AlaC

AlaG

AS

Boc

br

$\mathrm{Bn}$

$\mathrm{C}_{z}$

$c$

C

CD

COSY

$\delta$

d

DBU

DC

DCM

dd

DEAD

DIC

DIPEA

DMAP

DMF

DMSO

$\left[\mathrm{D}_{6}\right] \mathrm{DMSO}$

DMT
Angström

Adenin

Allgemeine Arbeitsvorschrift

Abbildung

Acetonitril

Essigsäure

Alanin

Cytosinylalanin

Guaninylalanin

Aminosäure

tert-Butoxycarbonyl

breit

benzyl

N-4-Benzoxycarbonylcytosin

Konzentration

Cytosin

Circular Dichroismus

Correlated Spectroscopy

chemische Verschiebung

Dublett

1,8-Diazabicyclo[5,4,0]undec-7-en

Dünnschicht Chromatographie

Dichlormethan

Dublett vom Dublett

Diethylazodicarboxylat

$\mathrm{N}, \mathrm{N}$-Diisopropylcarbodiimid

$N, N$-Diisopropylethylamin

4-(Dimethylamino)-pyridin

Dimethylformamid

Dimethylsulfoxid

Hexadeuterodimethylsulfoxid

Dimethoxytrityl 


$\begin{array}{ll}\text { DNA } & \text { Desoxyribonukleinsäure } \\ \text { DTT } & \text { 1,4-Dithioerythrit } \\ \varepsilon & \text { Extinktionskoeffizient } \\ \text { EDC } & \text { 1-(3-Methylaminopropyl)-3-ethylcarbodiimid } \\ \text { EE } & \text { Essigsäureethylester } \\ \text { ee } & \text { enantiomeric excess } \\ \text { EI } & \text { Elektronenstoß lonisation } \\ \text { ent } & \text { Enantiomer }\end{array}$

ESI Elektrospray lonisation

eq. Äquivalent

FC Flashchromatographie

Fmoc 9-Fluorenylmethyloxycarbonyl

G Guanin

$\mathrm{H} \%$ prozentuale Hyperchromizität

HalC Cytosinylhomoalanin

HalG Guaninylhomoalanin

HATU Hydroxypyridiniumtriazolyltetramethyluroniumhexafluorophospha ( $\mathrm{N}-\mathrm{-7}$ Aza-1 $H$-benzotriazol-1-yl)-1,1,3,3-tetramethyluroniumhexafluorophosphat)

HBTU Hydroxybenzotriazolyltetramethyluroniumhexafluorophosphat $(\mathrm{N}-(1 \mathrm{H}-$ Benzotriazol-1-yl)-1,1,3,3-tetramethyluronium-hexafluorophosphat)

HSQC Heteronuclear Single Quantum Coherence

HOAt 7-Aza-1-hydroxybenzotriazol

HOBt 1-Hydroxybenzotriazol

HPLC Hochleistungsflüssigkeitschromatographie

$\mathrm{Hz} \quad$ Hertz

HR High Resolution

I Intensität

IR Infrarot

i-PrOH iso-Propanol

konz. konzentriert

$J \quad$ skalare Kopplungskonstante

k Geschwindigkeitskonstante (inhibition apparently)

$\lambda_{\max } \quad$ Absorptionsmaximum 


\begin{tabular}{ll} 
M & molar \\
$m$ & meta \\
$\mathrm{m}$ & Multiplett \\
$\mathrm{m} / z$ & Verhältnis Masse zu Ladung \\
$\mathrm{M}$ & Molmasse \\
McoTi-II & Momordica Cochinensis Trypsin Inhibitor-II \\
MBHA & 4-Methylbenzyhydrylamin \\
Me & Methyl \\
MeOH & Methanol \\
MHz & Megahertz \\
MS & Massenspektrometrie \\
$\tilde{V}$ & Wellenzahl \\
N & normal \\
$n$ & Beladungsdichte \\
NMP & N-Methylpyrrolidin-2-on \\
NMR & Nuclear Magnetic Resonance \\
o & ortho \\
OAc & Acetat \\
OSu & N-Hydroxysuccinimidester einer Carbonsäure \\
$p$ & para \\
pH & negativer dekadischer Logarithmus \\
Ph & Phenyl \\
PNA & Peptidnukleinsäure \\
ppm & parts per million \\
PS & Polystyrol \\
q & Quartett \\
R & Rest \\
RP & Reverse Phase \\
RT & Raumtemperatur \\
RNA & Ribonukleinsäure \\
$\mathrm{s}$ & Singulett \\
SPPS & Solid Phase Peptide Synthesis \\
t & Triplett \\
T & Tesla \\
& \\
\hline &
\end{tabular}




$\begin{array}{ll}\text { T } & \text { Thymin } \\ \text { T } & \text { Temperatur } \\ \text { TBAI } & \text { Tetrabutylammoniumiodid } \\ \text { tert } & \text { tertiär } \\ \text { TFA } & \text { Trifluoressigsäure } \\ \text { TFMSA } & \text { Trifluormethansulfonsäure } \\ \text { THF } & \text { Tetrahydrofuran } \\ \mathrm{T}_{\mathrm{m}} & \text { Schmelztemperatur } \\ \mathrm{t}_{\mathrm{r}} & \text { Retentionszeit } \\ \text { Tris } & \text { Tris(hydroxymethyl)-aminomethan } \\ \mathrm{UV} & \text { Ultraviolett } \\ \text { VIS } & \text { visible } \\ \text { WC } & \text { Watson-Crick } \\ \mathrm{Z} & \text { Benzoyloxycarbonyl }\end{array}$




\section{Literaturverzeichnis}

[1] P. A. Levene, J. Biol. Chem. 1920, 483-495.

[2] D. Voet, J. G. Voet, C. W. Pratt, Lehrbuch der Biochemie, Wiley-VCH, Weinheim 2002.

[3] F. J. Schmidt, S. Hecht (Ed.), Bioorganic Chemistry: Nucleic Acids, Oxford University Press, New York, 1996, 375.

[4] L. Stryer, Biochemie, Spektrum Akademischer Verlag, Berlin, 1996.

[5] W. Saenger, Principles of Nucleic Acid Structure, Springer Verlag, New York, 1984.

[6] C. M. Blackburn, M. J. Gait, Nucleic Acids in Chemistry and Biology, Oxford University Press, Oxford, 1996.

[7] A. Eschenmoser, M. Dobler, Helv. Chim. Acta 1992, 75, 218.

[8] D. R. Duckett, A. I. H. Murchie, R. M. Clegg, G. S. Bassi, M.-J. E. Giraud-Panis, D. M. J. David, Biophys. Chem. 1997, 68, 53.

[9] R. E. Holmlin, P. J. Dandliker, J. K. Barton, Angew. Chem. 1997, 109, 2830-2848.

[10] H. J. C. Berendsen, Science 1998, 282, 642-643.

[11] C. M. Dobson, M. Karplus, Curr. Opin. Struct. Biol. 1999, 9, 92-101.

[12] U. Diederichsen, T. K. Lindhorst, B. Westermann, L. A. Wessjohann, Bioorganic Chemistry Highlights and New Aspects, Wiley-VCH, Weinheim, 1999, 255-256.

[13] a) U. Diederichsen, Angew. Chem. 1996, 108, 458; b) U. Diederichsen, Bioorg. \& Med. Chem. Lett. 1997, 13, 1743; c) U. Diederichsen, H. W. Schmitt, Tetrahedron Lett. 1995, 36, 475; d) U. Diederichsen, H. W. Schmitt, Angew. Chem. Int. Ed. Engl. 1998, 37, 302.

[14] a) U. Diederichsen, H.W. Schmitt, Tetrahedron Lett. 1996, 37, 475-478; b) U. Diederichsen, Angew. Chem. Int. Ed. Engl. 1997, 36, 1886; c) U. Diederichsen, D. Weicherding, Synlett 1999, S1, 917-920; d) U. Diederichsen, D. Weicherding, E. Vockelmann, Chimia 1998, 9, 467.

[15] a) U. Diederichsen, H.W. Schmitt, Eur. J. Org. Chem 1996, 827; b) U. Diederichsen, Bioorg. Med. Chem. Lett. 1998, 8, 165; c) U. Diederichsen, Angew. Chem. 1997, 109, 2411; d) U. Diederichsen, H. W. Schmitt, Angew. Chem. 1998, 110, 312. e) U. Diederichsen, C. M. Biro, Bioorg. Med. Chem. Lett. 2000, 10, 1417. 
[16] U. Diederichsen, Lineare Nukleinsäure-Analoga mit peptidischem Rückgrat, Habilitationsschrift, TU München 1999.

[17] D. P. Weicherding, Synthese von Alanyl- und Homoalanyl-Peptidnucleinsäuren Untersuchung der Homologie, der Wechselwirkungen mit Aminosäuren und des photoinduzierten Elektronentransfers, Dissertation, TU München 2000.

[18] E. Vockelmann, Synthese und Untersuchung der Dimerisierung von Alanyl-/Norvalyl-Peptidnucleinsäuren und Peptiden, Dissertation, TU München 2000.

[19] P. H. Harbury, T. Zhang, P. S. Kim, T. Alber, Science 1993, 262, 1401.

[20] C. Micklatcher, J. Chmielewski, Curr. Opin. Chem. Biol. 1999, 3, 724.

[21] N. E. Zhou, C. M. Kay, R. S. Hodges, J. Mol. Biol. 1994, 237, 500.

[22] S. Matsumura, T. Takahashi, A. Ueno, H. Mihara, Chem. Eur. J. 2003, 9, 48294837.

[23] D. L. Zoetewey, B. P. Tripet, T. G. Kutateladze, M. J. Overduin, J. M. Wood, R. S. Hodges, J. Mol. Biol. 2003, 334(5), 1063-1076.

[24] Reste 468-497 des Proteins ProP; blau = R488; rot = D475, D478

[25] M. Schiffer, A. B. Edmundson, Biophys. J., 1967, 7, 121-135.

[26] L. Stryer, Biochemie, 4.Ed, Spektrum Verlag, Heidelberg, Berlin, New York, 1991.

[27] D. H. Apella, J. J. Barchi Jr., S. R. Durell, S. H. Gellman, J. Am. Chem. Soc. 1999, 121, 2309-2310.

[28] P. E. Nielsen, M. Egholm, R. H. Berg, O. Buchardt, Science 1991, 254, 1497.

[29] B. Hyrup, P. Nielsen, Bioorg. Med. Chem. 1996, 4, 5.

[30] M. R. Ghadrari, K. Kobayashi, J. R. Granja, R. K. Chadha, Angew. Chem. 1995, 107,76 .

[31] P. Wittung, P. E. Nielsen, O. Buchardt, M. Egholm, B. Nordén, Nature 1994, 368, 561.

[32] A. Mattes, O. Seitz, Angew. Chem. 2001, 113, 3277.

[33] A. Lenzi, G. Reginato, M. Taddei, Tetrahedron Lett. 1995, 36, 1717.

[34] M. Chattoraj, B. King, G. Bublitz, S. Boxer, Proc. Natl. Acad. Sci. 1996, 93, 8362.

[35] G. Quinkert, E. Egert, C. Griesinger, Aspekte der organischen Chemie, Verlag Helvetica Chimica Acta, Basel, 1995.

[36] M. M. Shemyakin, Y. A. Ovchinnikov, V. T. Ivanov, Angew. Chem. 1969, 81, 523-529.

[37] B. Devadas, N. Leonard, J. Am. Chem. Soc. 1986, 108, 5012. 
[38] M. Durand, K. Chevrie, M. Chassignol, N. T. Thuong, J. C. Maurizot, Nucleic Acids Res. 1990, 18, 6353-6359.

[39] M. Salunke, T. Wu, R. L. Letsinger, J. Am. Chem. Soc. 1992, 114, 8768-8772.

[40] A. E. Ferentz, G. L.Verdine, J. Am Chem. Soc 1991, 113, 4000-4002.

[41] H. Li, Y. Qiu, E. Moyroud, Y. Kishi, Angew. Chem. 2001, 113, 1519.

[42] X. Qiao, Y. Kishi, Angew. Chem. 1999, 111, 977.

[43] F. Nagatsugi, N. Tokuda, M. Maeda, S. Sasaki, Bioorg. Med. Chem. Lett. 2001, 11, 2577-2579.

[44] J. C Tabone, M. R. Stamm, H. B. Gamper, R. B. Meyer, Biochemistry 1994, 33, 375-383.

[45] T. R. Webb, M. D. Matteucci, J. Am. Chem. Soc. 1986, 108, 2764-2765.

[46] M. Cowart, S. Benkovic, Biochemistry 1991, 30, 788.

[47] R. L. Letsinger, T. Wu, J. Am. Chem. Soc. 1994, 116, 811-812.

[48] R. L. Letsinger, T. Wu, J. Am. Chem. Soc. 1995, 117, 7323-7328.

[49] R. Argauer, M. Shapiro, J. Econ. Entomol. 1997, 90, 416-420.

[50] L. Pauling, R. B. Corey, J. Am. Chem. Soc 1950, 72, 5349.

[51] L. Pauling, R. B. Corey, H. R. Branson, PNAS 1951, 37, 235-240.

[52] L. Pauling, R. B. Corey, PNAS 1951, 37, 282-285.

[53] L. Pauling, R. B. Corey, PNAS 1951, 37, 272-281.

[54] L. Pauling, R. B. Corey, PNAS 1951, 37, 235-2410.

[55] L. Pauling, R. B. Corey, PNAS 1951, 37, 241-250.

[56] L. Pauling, R. B. Corey, PNAS 1951, 37, 251-256.

[57] a) L. Pauling, R. B. Corey, PNAS 1951, 37, 256-261; b) L. Pauling, R. B. Corey, PNAS 1951, 37, 261-271.

[58] J. C. Kendrew, G. Bodo, H. M. Dintzis, R. G. Parrish, H. Wyckoff, D. C. Phillips, Nature 1958, 181, 662.

[59] S. Richardson, Advances in Protein Chemistry 1981, 14, 167-339.

[60] J. Kendrew, R. Dickerson, B. Strandberg, R. Hart, D. Davies, D. Phillips, V. Shore, Nature 1960, 185, 422.

[61] M. Perutz, M. Rossman, A. Cullis, H. Muirhead, G. Will, A. North, Nature 1960, 85, 416-422.

[62] H. Berman, J. Westbrook, Z. Feng, G. Gilliland, T. Bhat, H. Weissig, I. Shindyalov, P. Bourne, Nucl. Acids Res. 2000, 28, 235-42. 
[63] IUPAC-IUB Commission on Biochemical Nomenclature, Biochemistry 1970, 9, 3471-3479.

[64] G. N. Ramachandran, V. Sasisekharan, Adv. Protein Chem.1968, 23, 283-438.

[65] Standard-Bindungslängen: $\mathrm{C}_{\alpha}-\mathrm{CO}: 1.52 \AA$; C=O:1.23 $\AA$; CO-N:1.33 $\AA$;

$\mathrm{N}-\mathrm{C}_{\alpha}: 1.45 \AA$.

[66] M. Schiffer, A. B. Edmundson, Biophys. J. 1967, 7, 121-135.

[67] H. A. Kramers, G. H. Wannier, Phys. Rev. 1941, 60, 252-262.

[68] C. Cohen, D. A. D. Parry, Trends in Biochem. Sci. 1986, 11, 245-248.

[69] F. H. C. Crick, Acta Cristallogr. 1953, 6, 689-697.

[70] O. D. Monera, C. M. Kay, R. S. Hodges, Biochemistry 1994, 33, 3862-3871.

[71] P. Y. Chou, G. D. Fasmann, Biochemistry 1974, 13, 211-222.

[72] P. Y. Chou, G. D. Fasmann, Biochemistry 1974, 13, 222-245.

[73] P. Y. Chou, G. D. Fasman, Ann. Rev. Biochem. 1978, 47, 251-276.

[74] T. Jordan, I. Muker Jr., Y. Wang, T. G. Spiro, J. Mol. Struct. 1996, 379, 51-64.

[75] J. D. Rieker, J. C. Hu, Methods Enzymol. 2000, 328, 282-296.

[76] W. H. Landschultz, P. F. Johnson, S. L. McKnight, Science 1988, 240, 17591764.

[77] S. Matsumara, A. Ueno, H. Mihara, Chem. Commun. 2000, 1615-1616.

[78] T. Takahashi, K. Hamasaki, I. Kumagai, A. Ueno, H. Mihara, Chem. Commun. 2000, 349.

[79] D. Craik, N. L. Daly, C. Waine, Toxicon 2001, 39, 43.

[80] N. W. Isaacs, Curr. Opin. Struct. Biol. 1995, 5, 391.

[81] P. K. Pallaghy, K. J. Nielsen, D. J. Craik, R. S. Norton, Protein Science 1994, 3, 1833.

[82] M. E. Felizmenio-Quimio, N. L. Daly, D. J. Craik , J. Biol Chem. 2001, 276, 22875-22882.

[83] J. F. Hernandez, J. Gagnon, L. Chiche, T. M. Nguyen, J. P. Andrieu, A. Heitz, T. Trinh Hong, T. T. Pham, D. Le Nguyen, Biochemistry 2000, 39, 5722-5730.

[84] O. Avrutina, Cystine-Knot Microproteins: Total Synthesis, Modifications and Application to Drug Design, Dissertation, Göttingen 2006.

[85] J. P. Tam, Y-A Lu, J.-L. Yang, K.-W. Chiu, J. Biol. Chem 1999, 96, 8913.

[86] D. J. Craik, N. L. Daly, T. Bond, C. Waine, J. Mol. Biol. 1999, 294, 1327-1336.

[87] L. Gran, Acta Pharmacol. Toxicol. 1973, 33, 400-408. 
[88] K. M. Witherup, M. J. Bogusky, P. S. Anderson, H. Ramjit, R. W. Ransom, T. Wood, M. Sardana, J. Nat. Prod. 1994, 57, 1619-1625.

[89] N. L. Daly, S. Love, P. F. Alewood, D. J. Craik, Biochemistry 1999, 38, 1060610614.

[90] J. P. Tam, Y. A. Lu, J. L. Yang, K. W. Chiu, Proc. Natl. Acad. Sci. U. S. A. 1999, 96, 8913-8918.

[91] K. R. Gustafson, R. C. Sowder II, L. E. Henderson, I. C. Parsons, Y. Kashman, J. H. Cardellina II, J. B. McMahon, R. W. Buckheit Jr, L. K. Pannell, M. R. Boyd, J. Am. Chem. Soc. 1994, 116, 9337-9338.

[92] J. P. Tam, Y. A. Lu, Tetrahedron Lett. 1997, 38, 5599-5602.

[93] J. P. Tam, Y. A. Lu, Q. Yu, J. Am. Chem. Soc. 1999, 121, 4316-4324.

[94] M. L. J. Korsinczky, H. J. Schirra, K. J. Rosengren, J. West, B. A. Condie, L. Otvos, M. Anderson, D. J. Craik, J. Med. Biol. 2001, 311, 579-591.

[95] C. J. Noren, S. J. Anthony-Cahill, M. C.Griffith, P. G. Schultz, Science 1989, 244, 182.

[96] P. E. Dawson, T. W. Muir, J. Clark-Lewis, S: B. H. Kent, Science 1989, 266, 182. [97] S. B. Kent, Annu. Rev. Biochem. 1988, 57, 957.

[98] M. Egholm, O. Buchardt, L. Christensen, C. Behrens, S. M. Freier, D. A. Driver, R. H. Berg, S. K. Kim, B. Norden, P. E. Nielsen, Nature 1993, 365, 566-568.

[99] Bindungslängen: C-C:1.54, C-N:1.47, (=)N-C(=):1.47, N=C:1.25, C-NH $\mathrm{NH}_{2}: 1.34, \mathrm{~N}-$ $\mathrm{H}: 1.21, \mathrm{C}=\mathrm{O}: 1.22, \mathrm{C}_{\text {arom }}=\mathrm{C}_{\text {arom }}: 1.39, \mathrm{C}=\mathrm{C}: 1.33 \AA$.

[100] C. F. Guerra, F. M. Bickelhaupt, J. G. Smijders, E. J. Baerends, Chemistry-A European Journal 1999, 5, 3581-3594.

[101] V. Khavimon, L. Shataeva, A, Chernova, Neuroendocrinology Lett. 2005, 26, 237-241.

[102] G. Thumshirn, U. Hersel, S. L. Goodman, H. Kessler, Chem. Eur. J. 2003, 9, 2717-2725.

[103] D. Boumrah, M. M. Campbell, S. Fenner, R. G. Kinsman, Tetrahedron 1997, 53, 6977-6992.

[104] P. Lohse, B. Oberhauser, B. Oberhauser-Hofbauer, G. Baschang, A. Eschenmoser, Croatica Chim. Acta 1996, 69, 535-562.

[105] P. Lohse, Synthese und Eigenschaften von oligomeren Nucleodipeptamidinium-Salzen, Dissertation ETH 9937, Zürich 1992.

[106] L. D. Arnold, R. G. May, J. C. Vederas, J. Am. Chem. Soc. 1985, 107, 7105. 
[107] L. D. Arnold, R. G. May, J. C. Vederas J. Am. Chem. Soc. 1988, 110, 2237.

[108] I. Collins, J. Chem. Soc., Perkin Trans. / 1998, 1869.

[109] A. Lenzi, G. Reginato, M. Taddei, Tetrahedron Lett. 1995, 36, 1713-1716.

[110] P. Ciapetti, F. Soccolini, M. Taddei, Tetrahedron 1997, 53, 1167-1176.

[111] J. M. Bland, Synthetic Communications 1995, 25, 467-477.

[112] R. Appel, Angew. Chem. 1975, 24, 863.

[113] G. M. Salituro, C. A, Townsend, J. Am. Chem. Soc. 1990, 112, 760-770.

[114] R. B. Merrifield, J. Am. Chem. Soc. 1963, 85, 2149-2154.

[115] R. B. Merrifield, Angew. Chem. 1985, 97, 801-812.

[116] L. A. Carpino, A. El-Faham, C. A. Minor, F. Albericio, J. Chem. Soc. Chem. Comm. 1994, 201-203.

[117] L. A. Carpino, A. El-Faham, F. Albericio, Tetrahedron Lett. 1994, 35, 22792282.

[118] L. A. Carpino, J. Am. Chem. Soc. 1993, 115, 4397-4398.

[119] Freundlicherweise von E. Liebler zur Verfügung gestellt.

[120] U. Diederichsen, D. Weicherding, N. Diezemann, Org. Biomol. Chem. 2005, 3, 1058-1066.

[121] A. Küsel, J. Zhang, M. Alvarino Gil, C. A. Stückl, W. Meyer-Klaucke, F. Meyer, U. Diederichsen, Eur. J. Inorg. Chem., 2005, 4317-4324.

[122] M. Mergler, J.P. Durieux, The Bachem Practise of SPPS, Bachem AG, Bubendorf, Schweiz, 2000.

[123] L. A. Carpino, G. Y. Han, J. Org. Chem. 1972, 37, 3404-3409.

[124] P. E. Dawson, T. W. Muir, I. Clark-Lewis, S. B. Kent, Science 1994, 266, 776779.

[125] P. E. Dawson, S. B. Kent, Annu. Rev. Biochem. 2000, 69, 923-960.

[126] T. Wieland, E. Bokelmann, L. Bauer, H. U. Lang, H. Lau, Annallen Chemie 1953, 583, 129-149.

[127] R. David, M. P. O. Richter, A. G. Beck-Sickinger, Eur. J. Biochem. 2004, 271, 663-677.

[128] J. P. Tam, Y.-A. Lu, C. F. Liu,J. Shao, L. Zhang, C. Rao, In Peptides: Chemistry, Structure and Biology-Proceedings of the 14th American Peptide Symposium 1995.

[129] O. Avrutina, H.-U. Schmoldt, H. Kolmar, U. Diederichsen, Eur. J. Org. Chem. 2004, 4931. 
[130] O. Avrutina, H.-U. Schmoldt, D. Gabrijelcic-Geiger, D. Le Nguyen, C. P. Sommerhoff, U. Diederichsen, H. Kolmar, Biol. Chem. 2005, 386, 1301-1306.

[131] L. Peterlin-Mašič, D. Kikelj, Tetrahedron 2001, 57, 7073.

[132] L. Peterlin-Mašič, A. Kranjc, P. Marinko, G. Mlinšek, T. Šolmajer, M. Stegnar, D Kikelj, Bioorg. Med. Chem. 2003, 13, 3171.

[133] K. Lorenz, U. Diederichsen, Lett. Pept. Sci. 2003, 10, 111-117.

[134] R. Haubner, D. Finsinger, H. Kessler, Angew. Chem. 1997, 109, 1440-1456.

[135] P. Marinko, J. Kastelic, A. Krbavčič, D. Kikelj, Tetrahedron Lett. 2001, 42, 8911.

[136] Extinktionskoeffizienten der Nukleoaminosäuren: AlaC $\varepsilon_{250 \mathrm{~nm}}=13800 \mathrm{dm}^{3} /$ $(\mathrm{mol} \cdot \mathrm{cm})$, AlaG $\varepsilon_{259 \mathrm{~nm}}=11700 \mathrm{dm}^{3} /\left(\mathrm{mol} \cdot \mathrm{cm}\right.$, HalG $\varepsilon_{259 \mathrm{~nm}}=12500 \mathrm{dm} /(\mathrm{mol} \cdot \mathrm{cm})$, HalC $\varepsilon_{266 \mathrm{~nm}}=15000 \mathrm{dm}^{3} /(\mathrm{mol} \cdot \mathrm{cm}$ ) (aus D. Weicherding, Synthese von Alanyl- und Homoalanyl-Peptidnukleinsäuren Untersuchungen der Homologie, der Wechselwirkungen mit Aminosäuren und des photoinduzierten Elektronentransfers Dissertation, TU München 2000).

[137] S. A. Thomson, J. A. Josey, R. Cadilla, M. D. Gaul, C. F. Hassman, M. J. Luzzio, A. J. Pipe, K. L. Reed, D. J. Ricca, R. W. White, S. A. Noble, Tetrahedron 1995, 51, 6179-6194.

[138] K. B. Lorenz, Nucleoaminosäuren als Aminosäure-Isostere in potentiellen Pharmaka, Diplomarbeit, Würzburg 2000.

[139] R. L. Letzinger, T. Wu, J. Am. Chem.Soc. 1995, 117, 7327-7328. 


\section{LEBENSLAUF}

Name:

Geboren am:

Geboren in:

Staatsangehörigkeit:

Aug. 1984 - Juni 1988

Aug. 1988 - Mai 1997

Okt. 1997 - Feb. 2003

April 2000

Okt. 2001 - Feb. 2002

April 2002 - Feb. 2003

Feb. 2003

April 2002 - Feb. 2006

April 2002 - März 2003

April 2003 - Sept. 2003

April 2003 - Sept. 2005

Okt. 2005
Nadine Jede

24.06.1978

Neumünster

Deutsch

Besuch der Dr. Gerlich Schule, Trappenkamp

Besuch des Städtischen Gymnasiums, Bad Segeberg

abgeschlossen mit der Allgemeinen Hochschulreife

Aufnahme des Studiums der Chemie an der GeorgAugust-Universität zu Göttingen

Diplom-Chemiker-Vorprüfung

Fortgeschrittenes Praktikum der Organischen Chemie an der chemischen Fakultät der Universidad de La Coruña (Spanien) in der Arbeitsgruppe von Prof. Dr. C. J. González und Prof. Dr. J. R. Gonzáles

Diplomarbeit unter Leitung von Prof. Dr. U. Diederichsen zu dem Thema: Oligomerisierung von Guaninyl-Derivaten aufgrund der Organisation in Tetraden

Diplom-Chemiker Hauptprüfung

Dissertation bei Prof. Dr. U. Diederichsen am Institut für Organische und Biomolekulare Chemie der Georg-August Universität zu Göttingen, Synthese und Untersuchung von Nukleobasen-funktionalisierten Peptiden.

Assistentin im chemischen Praktikum für Mediziner und Zahnmediziner an der Universität Göttingen

Assistentin im organisch chemischen Praktikum für Biologen und Lehramtskandidaten an der Universität Göttingen

Assistentin im organisch chemischen Grundpraktikum Teil B für Chemiker an der Universität Göttingen Assistentin im organisch chemischen Grundpraktikum Teil A für Chemiker an der Universität Göttingen 